\title{
The significance of myocardial non-esterified fatty acid accumulation during ischemia and reperfusion
}

Citation for published version (APA):

van Bilsen, M. (1988). The significance of myocardial non-esterified fatty acid accumulation during ischemia and reperfusion. [Doctoral Thesis, Maastricht University]. Rijksuniversiteit Limburg. https://doi.org/10.26481/dis.19880325mb

Document status and date:

Published: 01/01/1988

DOI:

10.26481/dis.19880325mb

Document Version:

Publisher's PDF, also known as Version of record

\section{Please check the document version of this publication:}

- A submitted manuscript is the version of the article upon submission and before peer-review. There can be important differences between the submitted version and the official published version of record.

People interested in the research are advised to contact the author for the final version of the publication, or visit the DOI to the publisher's website.

- The final author version and the galley proof are versions of the publication after peer review.

- The final published version features the final layout of the paper including the volume, issue and page numbers.

Link to publication

\footnotetext{
General rights rights.

- You may freely distribute the URL identifying the publication in the public portal. please follow below link for the End User Agreement:

www.umlib.nl/taverne-license

Take down policy

If you believe that this document breaches copyright please contact us at:

repository@maastrichtuniversity.nl

providing details and we will investigate your claim.
}

Copyright and moral rights for the publications made accessible in the public portal are retained by the authors and/or other copyright owners and it is a condition of accessing publications that users recognise and abide by the legal requirements associated with these

- Users may download and print one copy of any publication from the public portal for the purpose of private study or research.

- You may not further distribute the material or use it for any profit-making activity or commercial gain

If the publication is distributed under the terms of Article $25 \mathrm{fa}$ of the Dutch Copyright Act, indicated by the "Taverne" license above, 
The significance of

myocardial non-esterified fatty acid accumulation

during ischemia and reperfusion 

The significance of

myocardial non-esterified fatty acid accumulation during ischemia and reperfusion

\section{Proefschrift}

ter verkrijging van de graad van doctor

aan de Rijksuniversiteit Limburg te Maastricht.

op gezag van de Rector Magnificus, Prof. Dr. F.IM. Bonke, volgens het besluit van het College van Dekanen. in het openbaar te verdedigen

op vrijdag 25 maart 1988 om 16.00 uur.

door

Marc van Bilsen

geboren te Delft in 1958. 
Promotar:

Prot. Dr. R. S. Reneman

Co-promotor:

Dr. G.J. van der Vusse

Beoordelingscommissie:

Prof. Dr. M.A. Allessie

Prof. Dr. W.C. Hülsmann

Prof. Dr. H.M. Piper

Prof. Dr. H.A.J. Struyker Boudier

Prof. Dr. R.F.A. Zwaial

Het verschijnen van dit proefschrift werd mede mogelijk gemaakt door steun van de Nederlandse Hartstichting.

Dit proefschrift kwam tot stand mede door een bijdrage van /C/.Farma. 
o mijkdom van het onvoltooide

De mogelijkheden der gedachte

de strikte duang der werke $i$ jkheid

T.H. Leopold, 1951)

Voor mitin ouders

Aan Diewwe, Josetien en Lisanne 


\section{CONTENTS}

CHAPTER 1 OUTLINE OF THE THESIS.

page

1.1 Statement of the probiem.

1.2 Aim of the study.

1.3 Experimental approach.

CHAPTER 2 INTRODUCTORY REMARKS.

2.1 The experimental model. 7

2.1.1 Ischemia and reperfusion: in-situ 7

2.1.2 Perfusion of isolated hearts. 8

2.2 Effects of ischemia and reperfusion on 10 the myocardium.

2.2.1 Myocardial metabolism during $\quad 10$

2.2.2 Myocardial metabolism during 13

2.3 Myocardial lipid metabolism. 14

2.3.1 Myocardial lipid metabolism under $\quad 15$

2.3.2 Myocardial 1ipid metabolism during 19

2.3.3 Metabolic and functional derange- 23

CHAPTER 3 EFFECTS OF PYRUVATE ON POST-ISCHEMIC MYOCARDIAL RECOVERY AT VARIOUS WORKLOADS.

3.1 Introduction 25

3.2 Methods 26

3.3 Results 32

3.4 Discussion 41

3.5 Summary 47

3.6 Appendix 49

CHAPTER 4 PURINE NUCLEOTIDE METABOLISM DURING ISCHEMIA AND REPERFUSION: ITS RELATION TO MYOCARDIAL DAMAGE.

4.1 Introduction 53

4.2 Methods 54

4.3 Results 57

4.4 Discussion 68

4.5 Summary 78 
CHAPTER 5 LIPID ALTERATIONS IN ISOLATED, WORKING RAT HEARTS DURING ISCHEMIA AND REPERFUSION: ITS RELATION TO MYOCARDIAL DAMAGE.

5.1 Introduction 79

5.2 Methods 80

5.3 Results 84

5.4 Discussion 98

5.5 Summary 110

CHAPTER 6 EFFECTS OF MEPACRINE AND NICOTINIC ACID ON NEFA ACCUMULATION AND MYOCARDIAL DAMAGE IN TRANSIENTLY ISCHEMIC HEARTS.

$\begin{array}{lll}6.1 & \text { Introduction } & 111 \\ 6.2 & \text { Methods } & 114 \\ 6.3 & \text { Results } & 116 \\ 6.4 & \text { Discussion } & 123 \\ 6.5 & \text { Summary } & 132\end{array}$

CHAPTER 7 THE EFFECTS OF PYRUVATE AND POCA, A CARNITINE ACYLTRANSFERASE I INHIBITOR, ON NEFA ACCUMULATION DURING ISCHEMIA AND REPERFUSION.

7.1 Introduction 133

7.2 Methods 135

7.3 Results 136

7.4 Discussion 148

7.5 Summary 155

CHAPTER 8 ISCHEMIA, REPERFUSION AND MYOCARDIAL DAMAGE: CONCLUDING REMARKS.

8.1 The nature of ischemia and reperfusion induced 157 lipid changes.

8.2 myocardial damage. 158

8.2.1 Enzyme release and post-ischemic 158

8.2.2 ATP, post-ischemic function and cell 160

8.2.3 Lipid changes and cell damage. 162

$\begin{array}{ll}\text { REFERENCES } & 167\end{array}$

$\begin{array}{lc}\text { SUMMARY } & 183\end{array}$

$\begin{array}{lr}\text { SAMENVATTING } & 187\end{array}$

$\begin{array}{ll}\text { CURR ICULUM VITAE } & 190\end{array}$

$\begin{array}{ll}\text { NAWOORD } & 191\end{array}$ 

CHAPTER 1

OUTLINE OF THE THESIS.

\subsection{Statement of the problem.}

About two decades ago it was reported that serum levels of free fatty acids (non-esterified fatty acids or NEFA's) are elevated during myocardial infarction in man (Kurien and 01iver, 1966). These investigators observed a relation between elevated free fatty acid levels and the incidence of severe arrhythmias in patients with acute myocardial infarction 101 iver et al., 1968). It was belfeved that the rise in free fatty acid levels was the result of catecholamine induced activation of triacylglycerol lipases in adipose tissue (01iver et al., 1968, Opie, 1975). However, it remained unclear whether the increased catecholamine levels per se, or the concomitant increased free fatty acid levels were responsible for the enhanced vulnerability of the heart as far as arrhythmias were concerned. It was proposed that increased serum levels of fatty acids would result in an enhanced flux of NEFA's into the myocytes and augment cardiac oxygen demand. In addition, the intracellular levels of NEFA"s and long-chain acyl Coenzyme-A (acyl-COA) would increase in the oxygen deprived tissue (Kurien and 01 iver, 1970; Opie, 1970a). It was not until 1977 that Weishaar and coworkers (1977) showed that intracellular levels of NEFA's rise during myocardial ischemia.

At present, altered myocardial lipid homeostasis is considered as a potentially important mediator of myocardial cell damage during ischemia. Due to impaired oxidation of fatty acids, extracted from the blood, accumulation of NEFA's, long-chain acylcarnitine and long-chain acyl-COA to noxious levels is anticipated (Liedtke et al., 1978; Shug et al., 1978; Whitmer et al., 1978). Besides, degradation of endogenous lipid pools, like triacylglycerols and phospholfipids may also be involved (Weglicki et al., 1973; Van der Vusse et a1., 1982; Chien et al., 1984). The degradation of endogenous triacylglycerols would lead to an additional rise in NEFA's and related compounds. Since phospholipids are important constituents of cellular membranes, the loss of 
these components might compromise the integrity of the membranes as biological barriers and as a suitable micro-environment for enzymatic reactions. Furthermore, lysophospholipids, partial degradation products of phospholipids, are likely adversely affecting myocardial function and metabolilsm. Indeed, addition of these lipids to cell-free systems, perfused organs or in-situ hearts has been shown to induce changes in enzyme activity and membrane permeability, and alterations in the electrophysiological and mechanical properties of the tifsue (reviewed by Katz and Messineo, 1981; Corr et a1., 1984; Moore, 1985).

Previous studies (Van der Vusse et al., 1982; Chien et a1., 1984; Prinzen et a1., 1984), using the regionally ischemic dog heart, indicated that the accumulation of NEFA's during ischemia is a relatively slow process and dependent on the duration and severity of the ischemic insult. It was proposed that the accumulated NEFA's most likely originate from membrane phospholipids, because the tissue content of non-esterified arachidonic acid, a fatty acid known to be almost exclusively present in phospholipids, markedly increased during ischemia. In addition, it was noted by Prinzen and colleagues (1984) that NEFA's started to accumulate at a time when the transition from reversible to irreversible damage is likely to take place, i.e. after 45 to 60 minutes of ischemia (Jennings et al., 1978; Schaper et al., 1979).

The mechanism underlying the assumed degradation of phospholipids is still obscure. Both an enhanced deacylation, due to the activation of phospholipases, and a reduced reacylation might be involved (Chien et al. 1984; Das et al., 1986). The latter process might be inhibited due to inactivation of the enzymes involved or the depletion of essential reactants, like ATP, during ischemia.

Several studies demonstrated that triacylglycerol homeostasis is also affected during ischemia, but the results obtailned are contradictory (Van der Vusse et a1, 1987a). A variety of investigators reported an increase in the myocardial content of triacylglycerols in the flow deprived tissue (Jesmok et al., 1978; Burton et a1., 1986) In contrast, others proposed that net hydrolysis of triacylglycerols is favored during ischemia (Opie et al., 1973; Vik-Mo et al., 1979), suggesting that endogenous triacylglycerols might serve as an additional source of NEFA's during ischemia.

Although salvage of the myocardium is only possible by timely restoration of blood supply, there is increasing evidence that reperfusion per se might be harmful for cardiac tissue (reviewed by Fox et al., 1985; Van der Vusse and 
Reneman, 1985b). The restoration of blood flow after an ischemic insult has been shown to be associated with the influx of massive amounts of calcium (Shen and Jennings, $1972 \mathrm{a}, \mathrm{b}$ ) and, hence, the activation of calcium-dependent phospholipases has to be anticipated (Takahashi and Kako, 1983; Das et al., 1986). Therefore, reperfusion might even exacerbate myocardial liplid changes. As yet, the effects of reperfusion on myocardial lipid homeostasis and its possible consequences for myocardial metabolism and function are poorly understood. Das and colleagues (1986) reported a substantial decline (about 20\%) in the myocardial content of phospholipids during reperfusion. other investigators (Schwaiger et al., 1985) demonstrated that the oxidation of fatty acids was hampered in the post-ischemic state.

\subsection{Aim of the study.}

Despite the rapidly growing number of studies conducted to investigate disturbances in lipid metabolism and its possible consequences for myocardial tissue damage, many aspects are still poorly understood.

At this moment, the origin of the NEFA's accumulated during ischemia is still obscure. Likewise, knowledge of the mechanism responsible for the accumulation of MEFA's is far from complete. As discussed above, accumulation of NEFA's due to the degradation of phospholipids is feasible, but a contribution of triacylglycerols can not be excluded. Insight into these problems is hampered by the large variation in NEFA values (table 1.1), reported in literature (Hunneman and Schweickhardt, 1982). Van der Vusse and coworkers (Van der Vusse and Reneman, 1984a; Van der Vusse et al., 1985a) provided conclusive evidence that high values of NEFA"s (especially of poly-unsaturated MEFA"s, like arachidonic acid) in normoxic as well as ischemic myocardial tissue could be attributed to methodological artefacts, such as hydrolysils of tissue derived phospholipids during the extraction and separation procedures. In addition, erroneously high NEFA levels have been reported by application of assay techniques lacking specificity.

Regarding the underlying mechanism, a relation between the tissue content of NEFA's and the depletion of ATP has been observed (Prinzen et a1., 1984; Gunn et al., 1985). However, it remains to be established whether this relation is causative. 
Table 1.1 content of MEFA in the left ventricle of the dag and rat heart durling fio rnoxle circumstances (nanomoles per gram wet weight).

\begin{tabular}{|c|c|c|c|}
\hline Species & Amount & Assay method & Reference \\
\hline \multirow[t]{7}{*}{ Dog } & 29 & Gas-11quid chronatography & Van der Wusse et al. \\
\hline & 56 & Gas-1 iquid chromatography & $\begin{array}{l}\text { Hunneman et a } 1 . \\
(1982)\end{array}$ \\
\hline & 175 & Gas-lliquid chromatography & $\begin{array}{l}\text { Weglicki et al. } \\
(1973)\end{array}$ \\
\hline & 1240 & Gas-lliquid chromatography & $\begin{array}{l}\text { Wei shaar et al. } \\
\text { (1977) }\end{array}$ \\
\hline & 3570 & Colorimetry & $\begin{array}{l}\text { Suzuki et al. } \\
(1981)\end{array}$ \\
\hline & 10800 & THtrimetry & $\begin{array}{l}\text { Haider et al. } \\
(1977)\end{array}$ \\
\hline & 11000 & Colorimetry & $\begin{array}{l}\text { Andrieu et ail. } \\
(1979)\end{array}$ \\
\hline \multirow[t]{7}{*}{ Rat } & 45 & $\begin{array}{l}\text { Colorimetry lafter thin- } \\
\text { Hayer chroma tography }\end{array}$ & $\begin{array}{l}\text { Garl and and Randle } \\
(1954)\end{array}$ \\
\hline & 52 & Gas-Tiquid chromatography & $\begin{array}{l}\text { Yan der vusse et al. } \\
\text { (1983) }\end{array}$ \\
\hline & 140 & Gas-1 fquid chromatography & $\begin{array}{c}\text { Kramer and Hulan } \\
(1978)\end{array}$ \\
\hline & 500 & Gas-1 iquid chromatography & $\begin{array}{l}015 \text { son and Hoeschen } \\
(1967)\end{array}$ \\
\hline & 795 & Gas-1 lquid chromatography & $\begin{array}{l}\text { Lochner et al. } \\
(1978)\end{array}$ \\
\hline & 7000 & Gas-1 lquid chromatography & $\begin{array}{l}\text { Houtsmuller et al. } \\
(1970)\end{array}$ \\
\hline & 12680 & Tftrimetry & $\begin{array}{l}\text { Shipp et al. } \\
(1964)\end{array}$ \\
\hline
\end{tabular}

It is also unknown whether reperfusion leads to additional changes in $11 \mathrm{p}$ id metabollsm and whether this is associated with additional tissue damage. Desplte the large body of evidence from in-vitro studies on the deleterious effects of elevated concentrations of NEFA's, 1ysophospholipids and other lipid intermediates, it still remains to be elucidated whether these observations can be extrapolated to the in-vivo situation. In view of the potentially important role of disturbances in myocardial lipid metabolism in the development of tissue damage during ischemia and reperfusion, evaluation of the effects of specific metabolic and pharmacological interventions is of interest. Not only because it could lead to new therapeutic measures to protect the jeopardized myacardium, but al so because important information could be 
obtained about the mechanism underlying the disturbances in lipid homeostasis and their consequences for myocardial damage.

Therefore, the objective of this study was to obtain better insight into:

- the time course of NEFA accumulation during ischemia and its relation to changes in the myocardial content of phospholipids and triacylglycerols.

- the relation between adenine nucleotide and carbohydrate metabolism and NEFA accumulation during ischemia.

- the nature of the lipid changes, if any, taking place during reperfusion.

- the possible role of the lipid changes during ischemia and reperfusion in the development of myocardial damage.

- the ability to modify myocardial lipid metabolism through metabolic and pharmacological interventions and its consequences for myocardial damage.

\subsection{Experimental approach.}

The isolated, assisted, working rat heart, perfused with a modified KrebsHenseleit bicarbonate buffer, was used as experimental model. After a period of normoxic perfusion, the hearts were subjected to periods of global ischemia of various durations. Thereafter, the hearts were reperfused for a constant period of time. Myocardial function was assessed from such parameters as heart rate, left ventricular pressure and cardiac output. The release of lactate dehydrogenase, a cytosolic enzyme, was used to assess the extent of irreversible cell damage. The effects of ischemia and reperfusion on myocardial lipid metabolism were assessed by measuring the tissue contents of phospholipids (including the lyso-forms of phosphatidylcholine and phosphatidylethanolamine), triacylglycerols and NEFA's. Besides, the tissue content of glycerol-3-phosphate and glycerol was measured to assess possible disturbances in triacylglycerol homeostasis. The former being an essential reactant in the synthesis of triacylglycerols and the latter being an end-product of triacylglycerol breakdown. High-energy phosphate metabolism was investigated, by measuring the tissue content of creatine phosphate, inorganic phosphate and 
adenlme nucleotides, in order to delineate a possible relationship between cardiac energy metabolism and 1 ipid homeostasis. The accumulation and release of products of purine nucleotide metabolism, i.e. nucleosides and oxypurines, were also determined. The tissue contents of glycogen and lactate, and in a number of experiments those of glucose and pyruwate, were measured to assess myocardial substrate demand under ischemic conditions.

Although this ex-vivo model has distinct advantages, it has also certain 1 imitations (discussed in section 2.1.). Therefore, it was first attempted to define the characteristics of this model in terms of functional and metabolic stability. To this end hearts were normoxically perfused for up to two hours and the effects of workload and substrate supply were investigated (chapter 3). Since ATP depletion has been considered to play a central role in the sequence of metabolic events, eventually leading to ischemic tissue damage (discussed in section 2.2), special attention was paid to the effects of ischemita and reperfusion on myocardial adenine nucleotide metabolism (chapter $4)$ and its possible relation to disturbances in lipid metabolism (chapter 5).

The nature of the lipid changes associated with ischemia and reperfusion, the possible mechanisms underlying these changes, and its consequences for the integrity of myocardial cells are subject of investigations in the chapters 5 through 7 . In chapter 5 the results are presented of a study on the effect of the duration of ischemia on myocardial lipid metabolism during ischemia and reperfusion. The effects of presumed blockers of phospholipase activity (mepacrine) and hormone sensitive triacylglycerol lipase activity (nicotinic acid) on the accumulation of NEFA's and myocardial damage were studied in chapter 6 . In chapter 7 experiments are presented in which an attempt was made to modify the oxidation of NEFA's by varying substrate supply and by adding an inhybitor of carnitine acyltransferase I (POCA). In the last chapter (chapter 8) the results obtained are summarized and placed in a broader perspective. 
INTRODUCTORY REMARKS.

\subsection{The experimental model.}

In the present study the isolated, assisted, working rat heart was used to investigate the importance of changes in lipid homeostasis in the development of myocardial damage during ischemia and reperfusion. The hearts were rendered globally ischemic and reperfused thereafter. The features, advantages and disadvantages of this model are outlined below.

\subsubsection{Ischemia and reperfusion: in-situ and ex-vivo.}

In ischemic heart disease part of the myocardium becomes underperfused either acutelly as a result of coronary spasm or thrombus formation, or gradually due to progressive atherosclerosis. In the clinical setting blood supply can be restored by thrombolysis, angioplasty or coronary-bypass grafting.

Due to incomplete occlusion of the coronary artery, supplying blood to the affected area, and/or collateral flow, some residual flow will of ten reach the ischemic area. As a result a gradient is often observed in the supply of blood from the central towards the lateral zones, and from the subendocardial to subepicardial layers of the affected area (Prinzen et al., 1987). Moreover, the flow-deprived tissue must withstand the mechanical forces exerted by the surrounding non-ischemic areas. This poses additional stress to the tissue adjacent to the dyskinetic or hypokinetic ischemic reglon. Thus, the severity of the ischemic insult is heterogeneous and rather unpredictable.

In the present study the effects of ischemia and reperfusion on myocardial metabolism and function were assessed with the use of isolated, working rat hearts, subjected to a period of global no-flow ischemla. Contrary to the regionally ischemic heart, the ischemic phase is characterized by (a) the absence of any residual flow, and (b) an almost immediate cessation of mechan- 
ical activity of the entire heart. As a consequence the ischemic insult imposed is highly reproduclble.

In the present experimental set-up restoration of perfusate supply was accomplished by reinstallation of retrograde perfusion of the heart. Following 5 minutes of retrograde perfusion the hearts were again allowed to eject.

\section{1 .2 Perfusion of isolated hearts.}

During the last decades the isolated perfused rat heart has been used extensively to study cardiac metabolism under both physiolagical leffects of work demand and substrates) and pathophysiological conditions (hypertrophy, diabetes, restricted oxygen supply).

Essentially two perfusion modes of this model are in use. First, the so-called Langendorff perfused heart, in which coronary perfusate is supplied by retrograde perfusion of the aorta (Langendorff, 1895). In this situation the load of the left ventricle can be varied by altering the perfusion pressure (Neelly et all., 1967; Opie et a1., 1971), while filling of the left ventricular lumen is only possible by Thebesian vein drainage. As a consequence external work of the left ventricle is negligible. Second, the left ventricular ejecting heart preparation lalso referred to as working heart preparation), as originally introduced by Neely and coworkers (1967). In this model perfusate enters the left ventricle via the left atrium and is ejected through the aorta. The heart is responsible for its own coronary supply. The workload can easily be varied by modifying the prelload (i.e. left atrial filling pressure) and/or afterload (aortic pressure). By means of a slight. modification of the perfusion system the model can be changed into an assisted, working heart preparation, i.e. the heart will become retrogradely perfused whenever the heart is unable to maintain its own coronary flow, for instance, in case of mechanical fallure or fibrillation. This model has been used throughout the present study.

In this ex-vivo model the function of the heart can easily be monitored by measuring hemodynamic parameters. Performance of the working heart can be evaluated in terms of contractility (left ventricular pressure, rate of pressure rise) as well as pump performance (cardiac output). As compared to in-vivo heart preparations cardiac function can be studied in a highly stan- 
dardized way. The workload and the supply of substrate(s) are controllable. During the course of the experiment interferences due to alterations in the levels of circulating hormones (e.g. insulin, catecholamines), sympathetic innervation, peripheral resistance and substrate supply are non-existent.

It is obvious that this ex-vivo model has also its limitations, most of which are related to the properties of the perfusion medium. Instead of whole blood a (modified) Krebs-Henseleit or Tyrode's buffer is often used as perfusion medium. Hence the oxygen carrying capacity is reduced. Even after saturation with a gas mixture of $\mathrm{O}_{2} / \mathrm{CO}_{2}$ (95/5, by volume) the amount of dissolved axygen is about 10\% of the axygen present in arterial blood. To compensate for the Jimited oxygen carrying capacity of the perfusate the coronary flow rate is very high. Whether coronary supply matches myocardial demand is still a matter of debate (Duvelleroy et al., 1976; Segel and Rendig. 1982; Opie, 1984). In addition, the absence of high-molecular weight substances in the perfusion medium, inducing colloid osmotic pressure, will result in a certain degree of tissue edema.

Traditionally glucose is the substrate supplied to ex-vivo perfused hearts. However, the heart preferentially uses fatty acids. Under physiological conditions up to $70 \%$ of the energy demands of the in-situ heart are met by the oxidation of fatty acids (reviewed by Neely et al., 1972b). Indeed, isolated hearts perfused with glucose as exogenous substrate have to rely on endogenous substrate stores, like triacylglycerols and glycogen, for their energy demands (Crass et a1., 1970; Takenaka and Takeo, 1976). Consumption of endogenous substrates is abolished by addition of insulin linconsistent results) or fatty acids. The present findings (chapter 3) demonstrate that addition of pyruvate is also adequate. Although not a common substrate, in this study pyruvate was preferred over fatty actds. The absence of exogenous fatty acids enabled us to study the involvement of endogenous lifpid pools on the accumulation of NEFA's.

Finally, it should be noted that, due to evaporation of extracellular fluid, in the absence of adequate perfusate supply (ischemia) the temperature of the air-exposed tissue might be lowered. Hence, a condition of moderate hypothermia might exist during the ischemic phase.

The features discussed above indicate that the model used differs in several aspects from the heart in-situ. However, the high degree of standardization of the experimental conditions and, hence, the reproducibility of the 
model, facilitates interpretation of the complex metabolic effects of ischemia and reperfusion.

\subsection{Effects of ischemia and reperfusion on the myocardium.}

Myocardial ischemia is defined as a state of underperfusion of the tilssue, resulting in inadequate supply of oxygen. Ischemic injury progresses as a function of the duration and severity of underperfusion and eventually leads to tilssue necrosis. Salvage of the jeopardized tissue is only possible if blood flow is restored.

\subsubsection{Myocardial metabolism during ischemia.}

Ischemia induces a rapid decline in mechanical function of the affected tissue. Since large amounts of energy are required for contraction and relaxation of the muscle, the abolishment of mechanical activity may be considered as an intrinsic way to spare energy during perfods of oxygen shortage. In the absence of oxygen, which is the ultimate electron acceptor of the respiratory chain, the concentrations of $N A D H$ and FADH will rise in the mitochondrial matrix and, hence, the oxidation of fatty acids and the activity of the citric acid cycle will be inhibited (Moore et al., 1980). Residual ATP formation takes place through anaerobic glycolysis (fig 2.1). Initialiy the rate of anaerobic glycolysis is stimulated. However, due to the accumulation of lactate, hydrogen ions and NADH in the cytosolic compartment and subsequent inhibition of regulatory enzymes of the glycolytic pathway, such as phosphofructokinase and glyceraldehyde-3-phosphate dehydrogenase, the rate of glycolysis will soon slow down (Kuebler and Spieckermann, 1970; Rovetto et al., 1973, 1975; Neely et a1., 1975). The rate of ATP synthesis is insufficient to meet the energy demands of the tissue and, hence, the myocardial content of ATP diminishes (Jennings et $11 ., 1978$; Jennings and Steenbergen, 1985). The decline in ATP is associated with a transient increase in the content of ADP and accumulation of AMP. Part of the AMP accumulated is dephosphorylated to adenosine, which, in turn, can be further degraded to inosine, (hypo)xanthine and uric acid. The reduced avallability of ATP will imhibit the activity of 


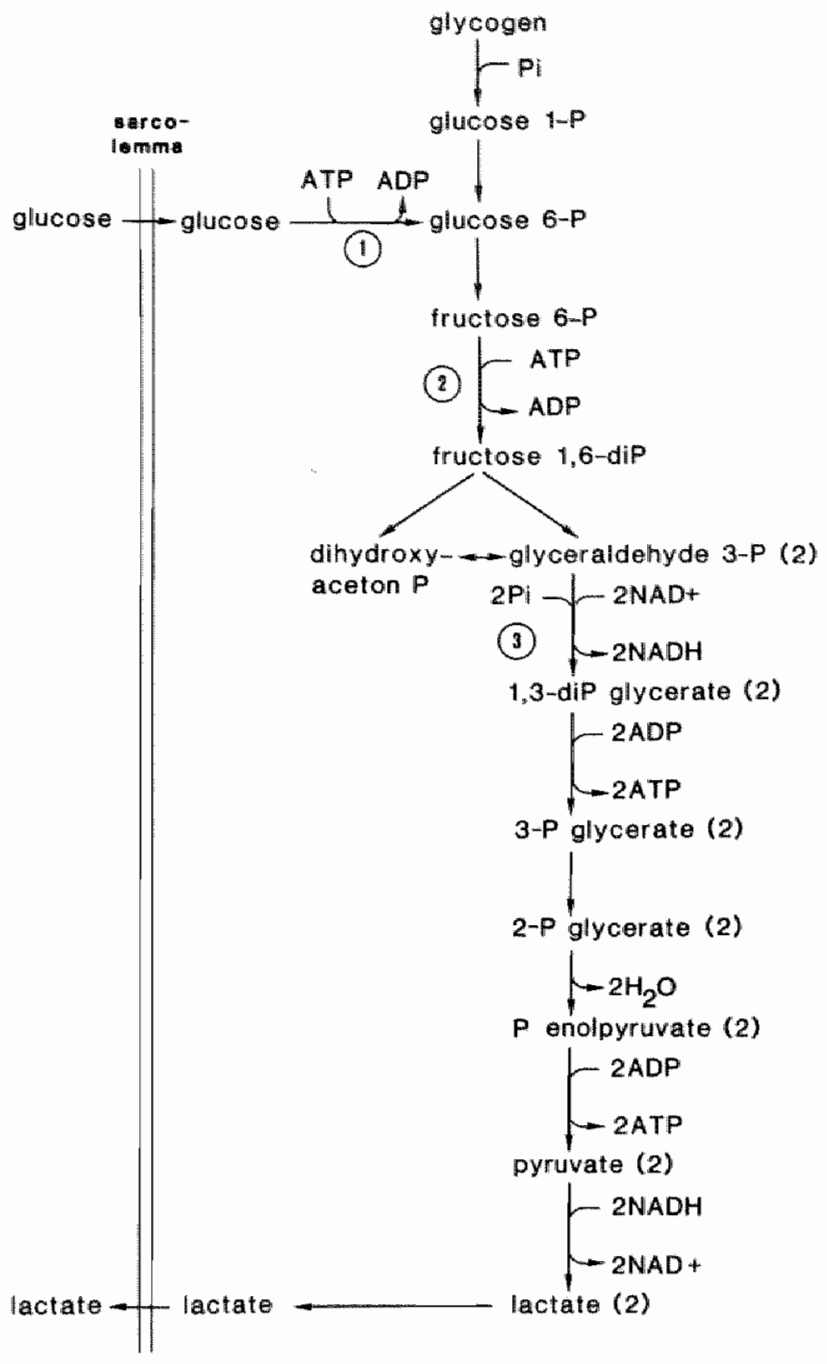

Fig 2.1 Metabolism of glucose and glycogen in axygen deprived myocardial tissue. The numbers refer to key enzymes, regulating the activity of the glycolytic pathway; (1) hexokinase, (2) phosphofructokinase, (3) gilyceraldehyde-3-phosphate dehydrogenase. 
ionic pumps and calcium homeostasis becomes disturbed (Nayler, 1981). After some time ultrastructural changes, such as mitochondrial swelling will become apparent (Schaper et a1., 1979; Apstein et al., 1983). Eventually contracture will develop (Hearse et al., 1977b; Jennings and Ganote, 1974), cellular membranes will lose their integrity and proteins will be released from the cells (Agress et al., 1955).

All vital cellular processes, like the synthesis of blomolecules and the maintenance of transmembrane ionic gradients, require input of chemical energy stored in the form of ATP. Mechanical work performed by the heart is also ATP dependent. It is therefore not surprising that loss of ATP during ischemia has always been considered a major determinant of irreversible cellular damage. This is once more 11 lustrated in a simplified scheme (fig 2.2). As a consequence, preservation of the ATP content during ischemia (via improvement of blood supply; reduction of cardiac work; enhancement of glucose oxidation relative to that of fatty acids; increasing the rate of anaerobic glycolysis) has always been considered of primary importance for salvage of the jeopar-

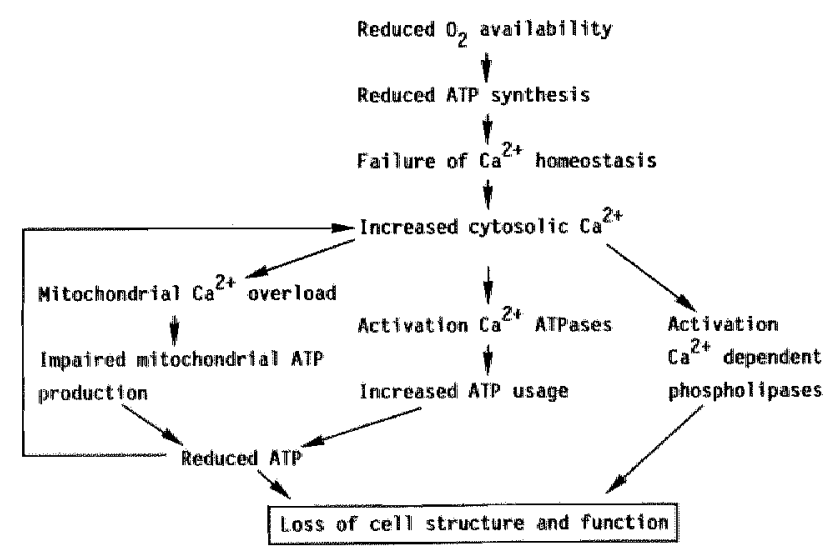

Fig 2.2 Schematic representation of the proposed sequence of events ultimately leading to ischemic cell damage (madified after Nayler, 1981). 
dized myocardium. Indeed such measures are beneficial to the heart as evidenced by the attenuation of ultrastructural damage and the reduction of infarct sizze (Maroko and Braunwald, 1976).

\subsubsection{Myocardial metabol ism during reperfusion.}

Restoration of flow to the jeopardized tissue seldom results in complete recovery of mechanical function. Myocardial function remains depressed for relatively long periods of time or may not recover at al1, depending on the severity and duration of the preceding period of ischemia (Lavallee et al., 1983). Restoration of flow is oftem associated with a sudden exacerbation of ultrastructural damage to the myocardium (Jennings and Reimer, 1983). It is believed that reperfusion only accelerates ultrastructural changes in cells, which were already irreversibly damaged during the preceding ischemic period (Jennings and Reimer, 1983; Kloner et a1., 1981). However, several studies indicate that reperfusion by itself might be detrimental to the heart and induces additional tissue damage (reviewed by Hearse, 1977a; Fox et a1., 1985; Van der Vusse and Reneman, 1985b; Buckberg, 1986). Research conducted to investigate this problem is complicated by the fact that it is difficult to establish, whether the phenomena observed during reperfusion are merely the outcome of events taking place during the preceding ischemic episode, or are, at least partly, a consequence of reperfusion per se. The fact that the extent of functional recovery and tissue damage following global and regional ischemia can be modulated by changing the conditions of reperfusion and the composition of the reperfusate (Buckberg, 1986), suggests that the extent of tissule damage is not solely determined by the preceding ischemila.

Various mechanisms have been proposed to explain the potentially harmful effects of reperfusion. Firstly, during ischemia the tissue osmolarity sharply increases due to the accumulation of low molecular wellght substances, like lactate and inorganic phosphate ITranum-Jensen et a1. 1981; Steenbergen et a]. 1985). As a consequence restoration of flow will lead to a massive influx of water, resulting in extracellular and intracellular edema. The edema might disturb ionic gradients, impair blood flow, and al ter post-1schemic compliance of the tissue (Apstein et al., 1977; Vogel et a1., 1986). Secondly, reperfusion leads not only to washout of accumulated products like lactate but also 
of nucleosides and purine bases. Hence, these products are withdrawn from metabolic salvage pathways directed to replenish the adenine nucleotide pool. As a consequence ATP can not rapldily be restored to control levels, not even when mitochondrial function is adequately preserved (DeBoer et a1., 1980; Jennings et a1., 1981; Swain et a1., 1982). Thirdly, reperfusion and, hence, the reintroduction of oxygen results in the formation of oxygen free radicals. (Jolly et a1., 1984). These reactive oxygen species (superoxide anion, hydroxyl radical), if not scavenged by the cellular defense mechanism, could initiate cross linking of proteins and induce lipid peroxidation. Both an enhanced production of these radicals during reperfusion (Mccord, 1985) and a reduced capacity to scavenge the radicals could be involved (Meerson et al., 1982). Fourthly, ischemia results in a diminished capacity of the cells to maintain ionic gradients. As a result of the steep concentration gradient of calcium from the extracellular space to the intracellular compartment, reperfusion will result in a massive influx of calcium (Shen and Jennings, 1972a, $1972 \mathrm{~b})$. High cytosolic levels of calcium not only interfere with the contractile process, but also with mitochondrial energy production (Peng et al." 1977). Besides, it will activate calcium dependent enzymes, among which proteases and phospholipases (Sheman et a1., 1980; Franson et a1., 1983). Finally, during reperfusion leukocytes will penetrate the jeopardized tissue and cause plugging of the microvasculaturo (Engler et al., 1983). In addition, reactive oxygen species are released from the activated leukocytes.

Although it is obvious that reperfusion is the only way to salvage the ischemic myocardium, these considerations clearly indicate that reperfusion has to be performed with care to avoid potentialiy harmful effects as much as possible.

\subsection{Myocardial lifpld metabolism.}

The metabolic changes associated with ischemia and reperfusion (ATP depletion, osmolar load, free radical formation, calcium (nflux) will directly or indirectly jeopardize the integrity of myacardial membranes. A large body of evidence indicates that membrane damage is the proximate cause of irreversible cell damage (Farber et al., 1981; Jennings et al., 1986). There is increasing evidence that changes in myocardial lipid metabolism affect the 
integrity of cellular membranes (reviewed by Farber et al. 1981; Katz and Messineo, 1981 ; Corr et al., 1984). The effects of ischemia and reperfusion on myocardial lipid metabolism and its relation to cell damage are reviewed in the following paragraphs.

\subsubsection{Myocardial 1 ipid metabolism under physiological conditions.}

Under physiological conditions 60 - $80 \%$ of the energy demands of the heart are met by the oxidation of fatty acids. The remaining $20-40 \%$ is derived from the oxidation of glucose, lactate and ketone bodies. Both fatty acids non-covalently bound to albumin and covalentlly linked to triacylglycerols are potential candidates for intracellular oxidation. Triacylglycerols are transported in the plasma together with phospholipids and cholesterol-esters in the form of chylamicrons and very low density lipoproteins (VLDL). Prior to extraction by the cardiac cells the fatty acids esterified to triacylglycerols have to be released by the action of lipoprotein lipase, which is localized at the luminal side of the endothelium. The mechanism responsible for the uptake of fatty acids by the myacardium is still obscure. The steep concentration gradient for NEFA's from plasma to sarcoplasm is likely to be the driving force (Van der Vusse et a1., 1982, 1983). The process appears to be energy independent (Spector, 1971) and might be carrier-mediated (Stremmel et al., 1985). Intracellular transport of fatty acids is most likely mediated by fatty acid binding proteins (FABP), known to be present in large amounts in the cytosol (Ockner et a1., 1972; Mishkin et al., 1972; for review see Glatz and Veerkamp, 1985 ).

After entering the cytosol NEFA"s have to be activated before they can be metabolized (fig 2.3). The term "activated" refers to the binding of NEFA's with Coenzyme-A ( $C O A)$ through thio-esterification, a reaction catallyzed by the enzyme acyl-COA synthetase localized at the surface of the outer mitachondrial membrane and sarcoplasmic reticulum (Aas, 1971; Groot et a1., 1976). The presence of acy1-COA synthetase activity in the microsomal fraction of the heart has been questioned by Nomann and coworkers (1983). The high-energy thio-ester bond of the acyl-COA molecule is much more reactive as compared to the free carboxyl group of the NEFA molecule. The so-formed acyl-CoA forms the common intermediate for most of the metabolic pathways involving fatty acids. 


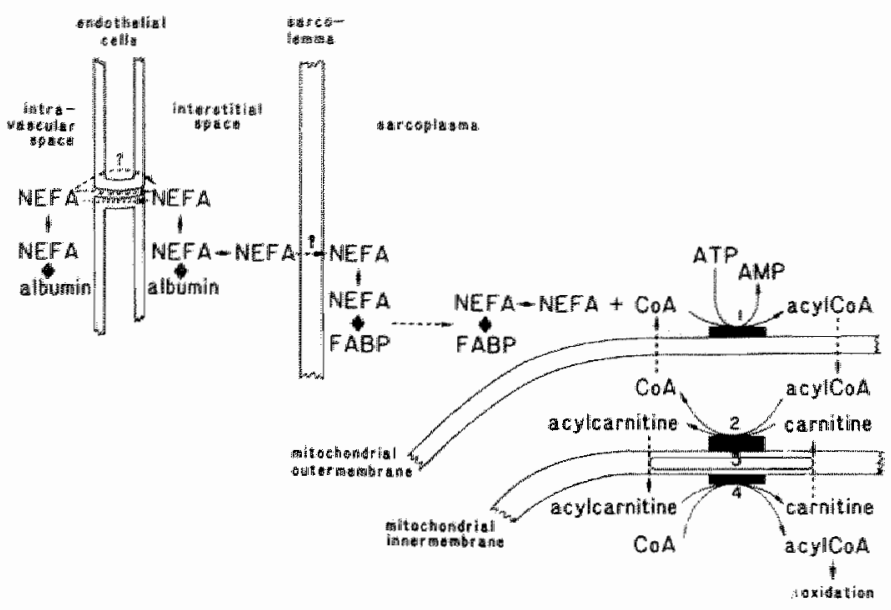

Fig 2.3 Uptake, transport, activation and oxidation of NEFA's in myocardial tissue. FABP refers to fatty acid binding protein. Mumbers refer to the enzymes invollved; (1) acyl-COA synthetase, (2) carnitine acyltransferase I, the activity of which was thought to reside on the outer side of the inner mitachondrital membrane; recently the site of lacalization has been questioned (see text), (3) carnitime acylcarnitine translocase, (4) carnitine acyltransferase II.

When used as a fuel the fatty acid moiety of acyl-COA needs to be transported into the mitochondrial matrix. Therefore, the fatty acid moiety is coupled to carnitine by the action of carnitine acyltransferase 1 , the activity of which was considered to reside at the outer surface of the inner mitochondrial membrane. However, recently Murthy and Pande (1987) provided evidence that the activity of this enzyme resides at the inner side of the outer mitochondrial membrane. Acylcarnitine is transported across the inner mitochondrial membrane via exchange against mitochondrial free carnitine 1:1 exchange ratio) by carnitine acylcarnitine translocase. Finally, the fatty acid molety of acylcarnitine is again coupled to COA by the action of carnitine acyltransferase II, localized at the matrix side of the inner mitochondrial membrane. Acyl-COA is then degraded through consecutive removal of acetyl moleties, a process referred to as $\beta$-oxidation. During each cycle one malecule of NAD and FAD is reduced. Additional reducing equiwalents are formed 


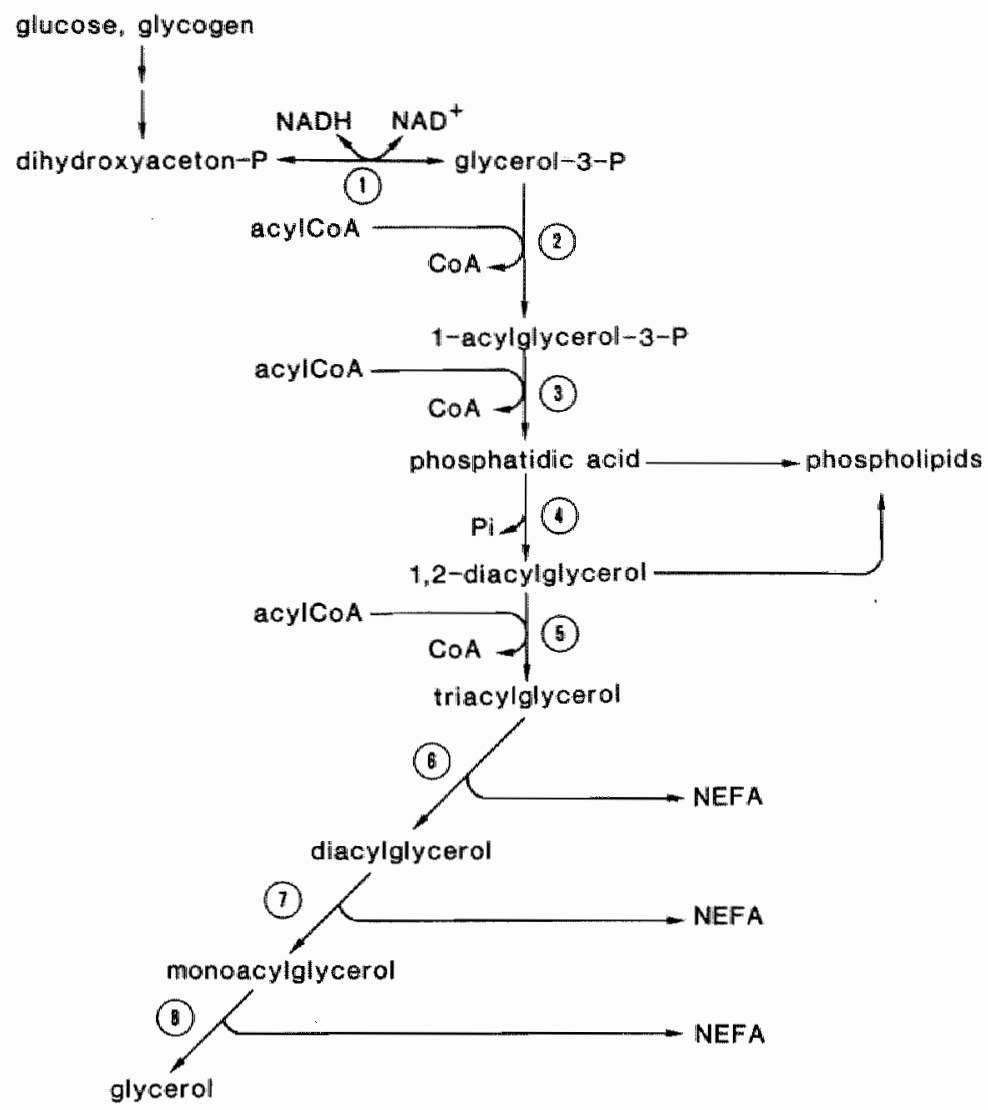

Fig 2.4 Synthesis and degradation of triacylglycerols in the myocardium. Numbers refer to the enzymes involved; (1) glycerol-3-phosphate dehydrogenase, (2) glycerol-3-phosphate acyltransferase, (3) 1-acylgiycerol-phosphate acyltransferase, (4) phosphatidic acid phosphatase, (5) diacylglycerol acyltransferase, (6) triacylglycerol lipase, (7) diacylglycerol lipase, (8) monoacylglycerol 11 pase. 
through the degradation of acetyl-COA in the citric acid cycle. Although all reactions involved in activation and transport of MEFA's into the mitochondrial matrix are essentially reversible, the rapid removal of the end-products of the activation reaction (i.e. AMP and pyrophosphate) and the high cytosolic ratio of carnitine/COA and the low ratio of carnitine/COA in the mitochondrial matrix will drive the entire process in the direction of oxidation.

Acyl-COA is also an essential intermediate. in the synthesis and turnover of triacylglycerols and phospholipids (fig 2.4). The formation of both triacylglycerols and glycerophospholipids starts with the acylation of the Sn-1 and $5 n-2$ positions of glycerol-3-phosphate, a reaction catalyzed by glycerol-phosphate-acyltransferase, resulting in the formation of phosphatidic acid. Then the phosphate is removed, yielding diacylglycerol. Triacylglycerols are formed by the subsequent coupling of a third acyl group to the $5 n-3$ C-atom. Degradation of triacylglycerols is achieved by the consecutive removal of acyl-moleties (fig 2.4). The hydrolysis of the first acyl-moiety is considered to be rate limiting. There is still no agreement regarding the role of the different endogenous 1 ipases in this process (reviewed by stam et all., 1987).

The formation of glycerophospholipids takes place through several pathways, depending on the species to be formed. Phosphatidylcholine (PC) and phosphatidylethanolamine (PE), quantitatively the most important phospholipid species, are mainly synthetized through reaction of diacylglycerol, on the one hand, with cytidinediphosphatidyl-choline (CDP-choline, an activated form of choline) or CDP-ethanolamine, on the other. Other glycerophospholipid species are synthetized through activation of phosphatidic acid with CTP under formation of CDP-diacylglycerol, and subsequent condensation of the phosphatidic acid moiety of this molecule with, for example, serine or inositol.

The acyl-moieties of the phospholipid pool are subject to continuous deacylation and reacylation (fig 2.5). Hydrolysis of the ester linkage of phospholipids is catalyzed by phospholipase $A_{1}$ and $A_{2}$. Several myocardial phospholipases have been described, differing in subcellular localization (membrane-bound, cytosolic, microsomal, lysosomal), pH-dependence and the requirement for divalent cations like calclum (Franson et al., 1972; Weglicki et a1., 1971, 1972; Nalbone and Hostetler, 1985). Before re-esterification NEFA's have to be activated. This reaction requires input of energy through pyrophosphate cleavage of ATP. Subsequentiy, the acyl-moiety is coupled to a 


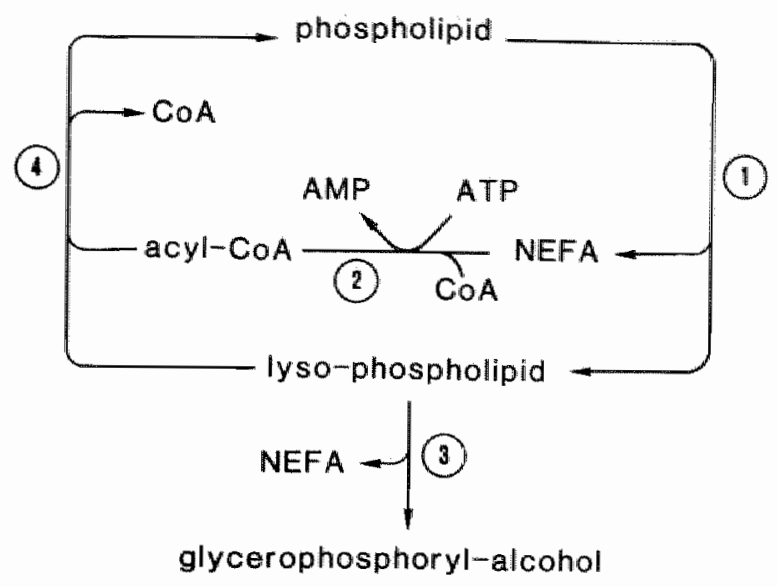

Fig 2.5 Deacylation and reacylation of phospholipids. Numbers refer to the enzymes involved; (1) phopholipase $A_{2}$, (2) acyl-COA synthetase, (3) lysophospholipase, (4) Tysophospholipid acyl transferase.

1ysophospholipid, a reaction catalyzed by lysophospholipid acyltransferase. The turnover process endows the tissue with the ability to remodel the fatty acyl composition of triacylglycerols and phospholipids in response to changing diet or environmental conditions. Recent investigations indicate that dietinduced changes in the membrane fatty acid composition have profound effects on myocardial function, especially in response to stress (for review see Lamers et al., 1987).

\subsubsection{Myocardial lipid metabolism during ischemia and reperfusion.}

Since most aspects of the changes in myocardial lipid metabolism will be thoroughly discussed in the chapters 5 through 7 , only a short survey of current ideas concerning the nature of and mechanism underlying these changes is given in this section.

Following the onset of ischemia fatty acid oxidation becomes inhibited, due to lack of molecular oxygen and an increase in the mitochondrial redox state (Moore, 1985). Nevertheless, some NEFA's are still extracted from the blood by 
the affected tissue in case of low-flow ischemia (Van der vusse et al., 1982). As a consequence, intermediates of fatty acid metabolism, like B-hydroxy fatty acids, long-chain acylcarnitine and long-chain acyl-CoA, accumulate in the tissue affected Moore et a1., 1980; Shug et al. 1978; Whitmer et a1., 1978). Due to the subcellilar distribution of free carnitine and free CoA, acylcarnitine predominantly accumulates in the cytosolic compartment, whereas the accumulation of acyl-COA is more or less confined to the mitochondrial matrix (Ide11-Wenger et a1. 1978). There are indications that during ischemia accumulation of these lipid intermediates is largely dependent on a continuous supply of exogenous NEFA"s (Van der Vusse et a1., 1987a). During complete flow cessation only insignificant changes in the myocardial content of acyl-CoA and acylcarnitine are observed (Paulson et al., 1984a). Similarly, in isolated glucose-perfused hearts only minor changes in these intermediates are observed during low-flow ischemia (Neely et a1., 1979). In contrast, in the presence of exogenous fatty acids marked increases in the myocardial contents of acylcarnitine and acyl-COA were found already within 15 minutes of ischemia (Whitmer et a1., 1978; Shug et a1., 1978; Suzuki et al., 1981).

Contrasting results have been reported concerning the changes in the myocardial content of endogenous triacylglycerols during ischemia. Several authors reported an increase in triacylglycerols during ischemia (Bruce and Meyers, 1973; Blltheimer et a1., 1978; Jesmok et al., 1978; Jodalen et a1., 1985; Burton et a1., 1986). Triacylglycerol synthesis might be favored due to the rise in glycerol-3-phosphate, a glycolytic intermediate forming the backbone of the triacylglycerol molecule, and the concomitant inhibition of fatty acid oxidation during ischemia. It should be noted, however, that in most studies the abserved rise in triacylglycerols is either confined to the lateral border zones of the jeopardized tissue (Bilheimer et al., 1978; Jodalen et al., 1985) or found only in necrotizing tissue (Bruce and Meyers, 1973; Jesmok et al., 1978). On the other hand, other investigators (Vik-Mo et a1., 1979) observed an enhanced release of glycerol from the ischemfc tissue, suggesting hydrolysis of triacylglycerols during ischemia. However, as demonstrated by Trach and coworkers (1986) enhanced release of glycerol is not necessarlly related to a net reduction of the trilacylglycerol content, but may al so reflect an increase in the turnover rate of triacylglycerols (fig 2.6 ). Augmented catecholamine release and, hence, the stimulation of hormone sensitive lipase activity is thought to be responsible for the ischemia induced 
enhanced hydrolysis of triacylglycerols (Hough and Gevers, 1975). The degradation of triacylglycerols could contribute to the accumulation of NEFA's and other lipid intermediates.

The rise in the myocardial content of NEFA's is a relatively late phenomenon and only starts after about 30 to 60 minutes of ischemia (Chien et al., 1984; Prinzen et a7., 1984). The relatively high contribution of arachidonic acid to the total rise in NEFA's suggests that the accumulating NEFA's originate from membrane phospholipids. The finding that the tissue content of lysophospholipids also increases during ischemia gives additional support to the idea that phospholipid homeostasis is disturbed during ischemia (Sobel et al., 1978; Corr et al., 1982). Based on the observed increase in the amount of arachidomic acid incorporated in triacylglycerols, Burton and coworkers (1986) suggested that NEFA's released from phospholipids will be incorporated into the triacylglycerol pool. Nevertheless, significant decreases in the myocardial content of phospholipids are generally only observed after prolonged ischemia of more than three hours (Chien et al., 1981; Man et a1., 1983; Steenbergen and Jennings, 1984; Chiariello et a1., 1987; Schwertz et a1., 1987). This finding does not favor the idea that the mere loss of phospholipids is a crucial factor in the development of irreversible tissue damage. It should be noted, however, that the absence of sizeable decreases of cardiac phospholipids does not exclude the possibility that significant degradation of phospholipids might have occurred either in a small population of severely damaged cells or in a certain cellular compartment. In this respect it is interesting to note that sarcolemmal phospholipids comprise only a small part of the cellular phospholipid content (Katz, 1982a).

The mechanisms responsible for the disturbances in phopholipid homeostasis during ischemia are unknown. The activity of phospholipases could be affected in various ways. First of all, changes in the ionic environment $\left(\mathrm{H}^{+}, \mathrm{Ca}^{++}\right)$may alter the physical characteristics of the phospholipid bilayer and render it more susceptible to phospholipase attack. The intercalation of amphipathic compounds and peroxidation of the fatty-acyl chains of the phospholipid bilayer may have similar effects. Secondly, the activity of phospholipases may be enhanced directly via changes in $\mathrm{pH}$ or calcium concentration. Furthermore, during ischemia release of hydrolytic enzymes, including acid phospholipases, from $1 y$ sosomes is feasible. Alternatively, it has been suggested that reacylation of phospholipids is impaired by partial inactivation of the enzymes 


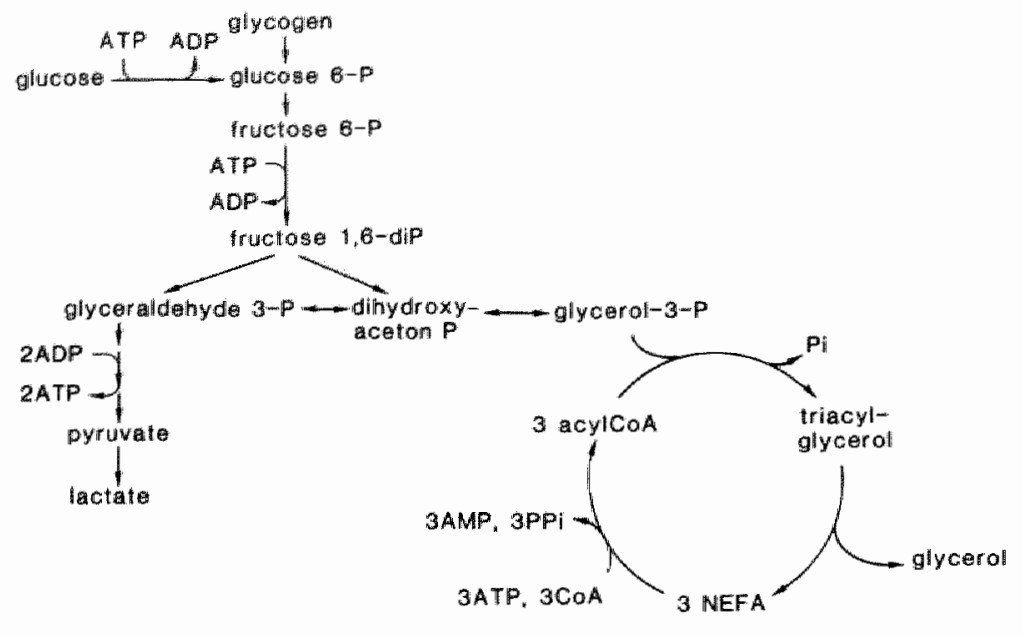

Fig 2.6 Relationship between glycolysis and triacylglycerol turnover. For information about the enzymes involved, the reader is referred to figures 2.1 and $2.4 . P_{i}$ refers to inorganic phosphate, $P P_{i}$ to pyrophosphate.

involved (Chien et a1., 1984; Das et al., 1986). Most studies directed to elucidate the role of phospholipases in the induction of tissue damage have focussed on phospholipase $A$. Other studies demonstrated that phospholipase $C$ is al so present in the heart (Hostetler and Ha11, 1980; Wolf and Gross, 1985) and stressed the point that this type of phospholipase, catalyzing the removal of the polar head group from the phospholipid molecule, might also play an important role (Yanagishita et a1., 1987; Gamache et a1., 1987).

Information about the effects of reperfusion on myocardial lipid metabolism is scarce. Experiments, using labelled fatty acids, indicate that the capacity of reperfused tissue to oxidize fatty acids seems to be impaired (Schwaiger et a1., 1985; Chatelain et al., 1987; Myears et a1., 1987). Nonetheless, several Investigators (Neely and McDonough, 1984b; Ichihara and Neely, 1985; Paulson et a1., 1986) reported that the tissue levels of acylcarnitine and acyl-CoA return to control values in reperfused tissue, suggesting nomalization of fatty acid oxidation and/or rapid reincorporation of these acyl-moieties into the phospholipid or triacylglycerol pool. Recently, Das et al (1986) and 
Burton et al (1986) reported a reduction in the tissue content of phospho1 ipids during reperfusion. The latter group al so observed that the myocardial content of WEFA's remains elevated in reperfused hearts. Studies from our laboratory indicate that accumulation of NEFA's may even proceed during reperfusion, despite adequate recovery of coronary perfusion (Van Bilsen et a1., 1987; Van der Vusse et al., 1987b). The mechamisms underlying these changes are still abscure.

\subsubsection{Metabolic and functional derangements due to lipid changes.}

Since the publication of 01 iver and coworkers (1968), who showed that during acute myocardial infarction arrhythmias were reiated to markedly increased serum fatty acid levels, it is assumed that elevated NEFA levels are harmful for the heart. Although not consistently confirmed (Kostis et al., 1973; Most et al., 1974), various experimental studies demonstrated that increased concentrations of extracellular NEFA's precipitate arrhythmias (Opie, 1970a; Kurien et a1., 1971; Willebrands et a1., 1973). Furthermore, it was demonstrated that augmented extracellular NEFA levels aggrevate the decline in function during restricted oxygen supply (Henderson et al., 1970; Most et al., 1972; Liedtke et a1., 1978) and increase myocardial damage during ischemia, as evidenced by an enhanced release of enzymes from the tissue affected (De Leiris and Opie, 1978; Bricknell and Opie, 1978).

Several mechanisms have been proposed to explain the adverse effects of elevated NEFA levels during ischemia. First, elevated NEFA levels result in an enhanced uptake of NEFA's from the blood and, hence, the use of NEFA's as a fuel will increase relative to that of glucose. The oxidation of NEFA's requilires a larger amount of oxygen per molecule of ATP produced ( $P / 0$ ratio of 2.85 as compared to 3.15 for glucose). Besides, it was observed that the oxidation of fatty acids required even more oxygen than expected on the basis of the P/O ratio (Mjos, 1971; Huetter et al., 1985a). It is obvious that this so-called axygen wasting effect of fatty acids might be detrimental to the heart during periods of oxygen shortage. Second, it has been shown that increased serum levels of NEFA's result in elevated tissue levels of acylcarnitine and acyl-CoA (Liedtke et al., 1978). Although questioned by some (LaNoue et a1., 1981), the latter intermediate is thought to be a potent 
inhlbutor of adenine nucleotide translocase and, hence, might impair ATP production by mitochondria (Shug et al., 1975; Shrago et a1., 1976a).

From in-vitro studies it became clear that elevated NEFA levels have deleterfous effects on several cellular processes. NEFA"s were faund to affect the activity of several glycolytic enzymes (Lea and Weber, 1968; Ramadoss et a1. 1976), to reduce the activity of the sarcolemmal bound $\mathrm{Na}^{+} / \mathrm{K}^{+}$ATPase (Lamers and Huelsmann, 1977), to disturb calcium homeostasis (Katz et al., 1982b; Philipson and Ward, 1985a), and to uncouple mitochondrial oxidative phosphorylation IPressman and Lardy, 1956; Huelsmann, 1958; Borst et al., 1962; Piper et a1. 1983). Comparative detrimental effects were observed for lipid intermediates, like acylcarnitine, acyl-CoA and 1ysophospholipids (reviewed by corr et a1., 1984). These lipid species have in common that they are amphipathic in nature and, therefore, preferentially intercalate into the phospholipid bilayer. Due to the detergent properties of amphipathic compounds. they will alter the physico-chemical characteristics of phospholipid bilayers (Fink and Gross, 1984).

Inevitably, the physico-chemical properties of membranes will also be affected by loss of membrane constituents from the bilayer, as a result of impailed phospholipid turnover. Consequently, the function of the membrane as a permeability barrier and as a suitable micro-environment for many membrane bound enzymes will be altered. 
EFFECTS OF PYRUVATE ON POST-ISCHEMIC MYOCARDIAL RECOVERY AT VARIOUS WORKLOADS.

\subsection{Introduction}

In recent years numerous measures have been developed and advocated to protect the heart against loss of function due to ischemic insults. Beside advantageous effects of drugs stabilizing calcium homeostasis, scavenging oxygen free radicals, inhibiting lipid degradation or preventing the depletion of intracellular ATP pools (Van der Vusse and Reneman, 1985b), beneficial effects of substrates like glucose (Hewitt et al., 1974) and glutamate (Pisarenko et al., 1986) have been reported.

Apparently contradictory results have been reported for pyruvate, a substrate for cardiac energy metabolism. When present as the only substrate, substantial adverse effects on post-ischemic cardiac tissue were observed (Bricknell and Opie, 1978). However, other studies indicated that pyruvate, when added as cosubstrate, afforded protection to the heart against hypoxia (Buenger et al., 1986a) and ischemia (Liedtke et al., 1976). Moreover, Mochizuki and Neely (1980) reported that pyruvate, added as cosubstrate during the reperfusion phase, improved functional recovery. In contrast, Gutterman and coworkers (1986) reported that intracoronary administration of pyruvate failed to limit infarct size following coronary occlusion and subsequent reperfusion.

To gain more insight into this controversy, the present study was conducted to investigate the metabolic and hemodynamic effects of pyruvate during both ischemia and reperfusion, using a standardized isolated, working, rat heart madel. Besides, it was explored whether pyruvate could reduce the adverse effects of an increased workload on post-ischemic recovery, because, contrary to glucose, the oxidation rate of pyruvate was found to increase proportionally to cardiac work (Kobayashi and Neely, 1979). Accordingly, it was hypothesized that the beneficial effects of pyruvate, if any, are more pronounced at higher workloads. Differences in workload were induced by 
changing the aortic Impedance. Since the functional stability of isolated, working rat hearts perfused with krebs-Henseleit buffer is often reduced (Duvelleroy et a1., 1976; Segel and Rendig, 1982; Hendriks et al., 1983), attention was also paid to the effects of pyruvate and aortic impedance on hemodynamic and metabolic perfomance during extended nomoxic perfusion.

Myocardial function was assessed from such parameters as the incidence and duration of ventricular fibrillation, left ventricular pressure and cardiac output. The energy status of normoxic, ischemic and reperfused hearts was assessed by measuring the tissue content of adenine nucleotides and nucleosides. The tissue contents of triacylglycerols, mon-esterified fatty acids, glycogen, NAD and lactate were monitored to assess the effects of pyruwate and workload on substrate demand of the heart. To this end release of lactate into the coronary effluent was also monitored. We also investigated whether there was a relation between functional recovery, on the one hand, and the tissue levels of adenine nucleotides and cellular damage, as estimated by the release of lactate dehydrogenase during reperfusion, on the other.

\subsection{Methods}

Preparation of the heart.

Male Lewis rats (body weight ranging from 250 to $320 \mathrm{~g}$ ) with free access to food (Standard Diet AM II, Hope Farms) and tap water were mildly anesthetized with diethylether. After thoracotomy the hearts were rapidly excised and placed in a petri-dish filled with ice-cold perfusion medium. After removal of 7 ung and fat tissue the heart was attached to the aortic cannula and retrograde perfustion, according to Langendorff, was started (perfusion pressure 8.0 kPa). Thereafter, the left atrium was cannulated through one of the lung veins to allow antegrade perfusion of the hearts. A catheter comnected to a pressure transiducer (CTC) was inserted into the left ventricle through the apex to measure left ventricular pressure.

Perfusion medilum.

The perfusion medium, a modified Krebs-Henseleit buffer, contained (in $\mathrm{mM}): \mathrm{NaCl}(130.0), \mathrm{KCl}(5.6), \mathrm{CaCl}_{2}(2.2), \mathrm{MgCl}_{2}(1.0), \mathrm{NaH}_{2} \mathrm{PO}_{4}(1.2), \mathrm{NaHCO}_{3}$ $(28.6)$. D (+)glucose $(11.1 \mathrm{mM})$ was added as substrate. Pyruvate $(5.0 \mathrm{mM}$, sodium 
salt) was added as cosubstrate where indicated. The solution was continuously gassed with a mixture of $95 \% \mathrm{O}_{2}-5 \% \mathrm{CO}_{2}\left(\mathrm{PO}_{2}>70 \mathrm{kPa}\right)$ and filtered (Millipore filter; $1.2 \mu \mathrm{m}$ pore sizel. Temperature was kept at $37^{\circ} \mathrm{C}$. pH varied between 7.38 and 7.45 .

Perfusion system.

The whole perfusion system (fig 3.1) was placed in a thermostated housing $\left(37^{\circ} \mathrm{C}\right)$. The hearts were perfused in a non-recirculating manner. Perfusion pressure (during retrograde perfusion) and diastolic aortic pressure (during antegrade perfusion) were controlled by air compression in the pressure chamber by means of a resistor placed between bubble trap and oxygenator. Preload was controlled by adjusting the overflow level in the oxygenator. Care was taken that perfusate supply via the atrial cannula was sufficient to maintain adequate stroke volume of the heart. Special attention was paid to the design of the aortic tract. A compliance chamber (air-volume $25 \mathrm{ml}$ ) was placed close to the heart. The hearts were allowed to work at two different workloads. This was achieved by means of two differently constructed aortic cannulas; one with a normal and one with an elevated impedance. The technical details are given in the appendix (section 3.6). Aortic pressure was measured via a catheter at the entrance of the aortic cannula.

Hemodynamics.

Hemodynamic variables were continuously registrated on a 6 channel recorder (Schwarzer). Left ventricular and aortic pressure were measured as indicated above. Left ventricular developed pressure (LVDP) was assessed from the difference between left ventricular systolic and end-diastolic pressure. Mean aortic flow (AF) was measured with an extracorporeal flow probe (Skalar) placed distal to the compliance chamber. The probe was connected to a sinewave electromagnetic flowmeter (Transflow 601). Coronary flow (CF) was measured by timed collection of the coronary effluent. Cardiac output (CO) was determined by adding $\mathrm{AF}$ and $\mathrm{CF}$.

\section{Experimental protocols}

Normoxia: After preparation was completed, the hearts were allowed to stabilize during $10 \mathrm{~min}$ retrograde perfusion at a pressure of $8.0 \mathrm{kPa}$. At the end of the stabilization period 4 hearts were freeze clamped. Eighteen other hearts were antegradely perfused for $120 \mathrm{~min}$ (left atrial filling pressure 1.0 $\mathrm{kPa}$; diastolic aortic pressure $8.0 \mathrm{kPa}$ ). These so-called "working" hearts were 


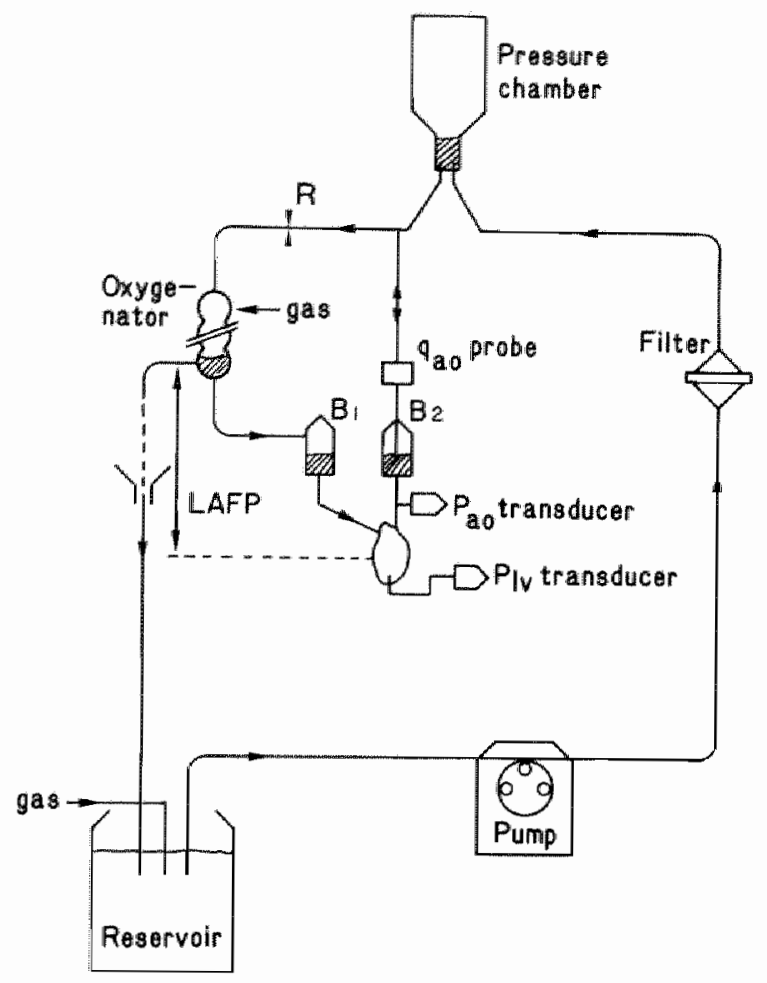

Fig 3.1 Schematic representation of the perfusion system for the assisted, isolated, working rat heart. Arrows indicate the direction of flow of perfusate. R refers to resistor for adjusting the perfusion pressure (in case of Langendorff perfusion) or diastolic aortic pressure (in case of antegrade perfustonl; BI, bubbie trap; 82 , compliance chamber: LAFP, left atrial filling pressure, $q_{a 0}$ : aortic flow, $p_{a 0}$ : aortic pressure, $P_{1 w}$ : left ventricular pressure.

alloted to four groups, depending on the type of substrate(s) supplied and the aortic impedance to which they were exposed. Eight hearts were supplied with glucose as substrate and exposed to a normal $(n=4)$ or high impedance $(n=4)$. Ten hearts were supplied with glucose and pyruvate as substrates and exposed to normal $(n=6)$ or high impedance $(n=4)$.

Ischemia: These experiments were performed on 12 hearts. Following 30 min 
of perfusion (at normal impedance) with either gilucose ( $n=6)$ or glucose and pyruvate $(n=6)$ hearts were subjected to $45 \mathrm{~min}$ of no-flow ischemia and subsequently freeze clamped.

Reperfusion: These experiments were performed on 18 hearts. Following ischemia the hearts were reperfused for $30 \mathrm{~min}$ (retrogradely during the first 5 min and antegradely, thereafter). Eight hearts were perfused with glucose as substrate and subjected to a normal $(n=4)$ or high impedance $(n=4)$. Ten hearts were supplied with glucose and pyruvate as substrates and subjected to a normal $(n=6)$ or high impedance $(n=4)$. Pyruvate was present during both the pre- and post-ischemic phase.

Biochemical analysis.

At the end of the experiments ventricular tissue was rapidly separated from atrial tissue and freeze clamped for biochemical analysis. Coronary effluent was sampled at regular time intervals for subsequent analysis.

Tissue: Small aliquots of tissue were freeze dried overnight at $-30^{\circ} \mathrm{C}$. Freeze dried tissue was weighed (range 5 - $10 \mathrm{mg}$ dry wt) and subsequently extracted at $-15^{\circ} \mathrm{C}$ in a mixture of perchloric acid $\left(3.0 \mathrm{~mol} .1^{-1}\right)$ and dithiothreitol ( $5 \mathrm{mmol} .1^{-1}$ ). The extraction vollume was adjusted to the welght of the tissue specimen and ranged between 150 and $200 \mu 1$. Extraction was performed by grinding the tissue with a glass rod, followed by rapid freezing (in liquid $\left.\mathrm{N}_{2}\right)$ and thawing of the mixture to a temperature of $4^{\circ} \mathrm{C}$. After centrifugation (at $4^{\circ} \mathrm{C}, 1200 \mathrm{~g}$ for $5 \mathrm{~min}$ ), a known amount of the supernatant was removed and neutralized with $\mathrm{KHCO}_{3}$, whereas the pelleted residue was stored at $-20^{\circ} \mathrm{C}$ for subsequent determination of glycogen. The salt-precipitate of the neutralized extract was pelleted by centrifugation (at $4^{\circ} \mathrm{C}, 1200 \mathrm{~g}$ for $60 \mathrm{~min}$ ) and the clear supernatant was stored at $-80^{\circ} \mathrm{C}$ until further analysis. Tissue contents of ATP, ADP, AMP, adenosine, inosine and NAD ${ }^{+}$were determined by high performance liquid chromatography (Varian 5500) according to the method of Wynants and Van Belle (1985). In short, a small sample of the neutralized extract (10 111) was injected on a reversed phase column (Lichrosorb RP-18, Merck) and eluted by gradient elution at a flow speed of $0.8 \mathrm{ml} . \mathrm{min}^{-1}$. Solvent A was an aqueous buffer of $\mathrm{NH}_{4}\left(\mathrm{H}_{2} \mathrm{PO}_{4}\right)(150 \mathrm{mM}, \mathrm{pH}=6.00)$, whereas solvent $\mathrm{B}$ consisted of a 1:1 mixture $(v / v)$ of acetonitrile and methanol. Peaks were detected at 254 $\mathrm{mm}$ (for detailed information see also chapter 4). Lactate was determined fluorometrically as descrübed by Passonneau (1974). Glycogen was determined as 
previously described (Van der Vusse et al., 1984b).

Another part of the deeply frozen tissue was powdered and extracted with chlorofom/methanol. After separation of the lipid classes by silicagel column chromatography and thin layer chromatography, non-esterified fatty acids (NEFA's) and triacylglycerols were detemined by gas-1iquid chromatography (Van der Vusse et al., 1982; Roemen and Van der Vusse, 1985; for detailed information see al so chapter 5 ).

Coronary Effluent: Lactate dehydrogenase (LDH) efflux was taken as an Index of the loss of cellular integrity. After addition of albumin (final cancentration $3 \% \mathrm{w} / \mathrm{v}$ to the effluent samples, the samples could be stored at $-80^{\circ} \mathrm{C}$ for several months without significant loss of LDH-activity (Snoeckx, 1987). LDH-activity was measured spectrophotometrically (Bergmeyer and Bernt, 1974). In the effluent samples lactate was determined spectrophotometrically with the use of a Technicon autoanalyzer (Apstein et al., 1970).

Normalization of biochemical data: As described above, values derived from measurements in samples of the neutralized perchloric acid extract are expressed in moles per gram dry weight. The way of expression of the tissue lipid data, i.e. per gram defatted dry residue weight, will be motivated in the method section of chapter 5. In the present and following chapters data regarding the release of various substances into the coronary effluent are expressed as units (moles or international enzyme units) per heart. These data were not normalized to gram wet or dry weight for reasons outlined below. The detemination of the weight after isolation and before canmulation, by 1 ifting the heart from the petri-dish will inevitably result in overestimation of the actual heart weight due to the presence of fluid in the ventricles. Moreover, at the end of the experiments heart weight is possibly affected by edema formation (see al so chapter 4). In theory, this problem could be avoided by detemination of the dry weight of the total heart through lyophilization, but this procedure might interfere with the subsequent determination of tissue Iiptds Isee Van der Vusse and Reneman, 1984, for the potential hazards in the determination of tissue 1 (pids). The body welght of the rats used ranged from 250 to $320 \mathrm{gram}$. As shown in figure 3.2 the heart weight of these rats averaged about 1 gram $(0.97 \pm 0.07 \mathrm{~g}$; mean $\pm S D, n=33)$. Therefore, whenever comparison of tissue data and coronary release data was required, it was assumed that the release per heart was equivalent to release per gram wet weight of heart tissue. For conversion of wet welght to dry weight a factor 5 was applied 


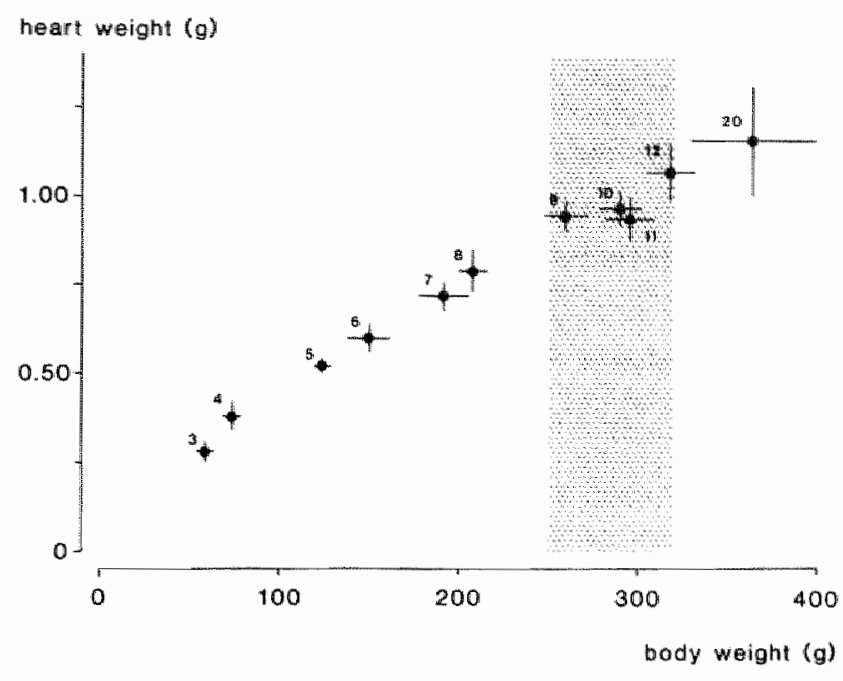

Fig 3.2 The relation between the heart weight and the body weight of male Lewis rats sacrificed at different ages. At each point the age of the rats is indicated (in weeks). The shaded area represents the range of body weilghts of the rats used for the present experiments. Data presented as means $\pm S D$.

(based on a percentage dry wt of approximately $20 \%$ of hearts freeze clamped immediately after removal from the body).

\section{Statistical analysis.}

Results are expressed as mean values \pm SD. The Student"s t test for paired and unpaired data was used for statistical analysis of differences within groups and between groups, respectively. The Pearson correlation coefficient ( $r$ ) was used to estimate the strength of the relation between two variables. P-values less than 0.05 were considered to be statistically significant. 


\subsection{Results}

Normoxic perfusions.

Variation of the aortic impedance ( see appendix for mathematical description of the impedance characteristics of the so-called normal and high impedance model) profoundly affected initial baseline hemodynamics (table 3.1). When the diastalic aortic pressure was adjusted to $8.0 \mathrm{kPa}$, the glucose-perfused hearts developed systolic aortic pressures averaging about 12.4 and 19.0

Table 3.1. Effect of prollonged normoxic perfusion on functional stability of isolated, working rat hearts, subjected to efther a normal or a high aortic impedance, and perfused in the absence or presence of pyruvate.

\begin{tabular}{|c|c|c|c|c|c|c|}
\hline \multirow[b]{2}{*}{ time $(m+n):$} & \multicolumn{2}{|c|}{$\begin{array}{c}H R \\
(\text { beats.min } \\
-1 \text { ) }\end{array}$} & \multicolumn{2}{|c|}{$\begin{array}{l}\text { LVDP" } \\
\text { (KPa })\end{array}$} & \multicolumn{2}{|c|}{$\left.\operatorname{lm} \min ^{-1}\right)$} \\
\hline & $\underline{15}$ & 120 & $\underline{15}$ & $\underline{120}$ & $\underline{15}$ & 120 \\
\hline \multicolumn{7}{|l|}{ perfusion conditions: } \\
\hline norma 1 impedance : & 247 & 239 & 12.6 & $12.0^{\mathrm{a}}$ & 76.8 & $67.8^{\mathrm{a}}$ \\
\hline glucose & \pm 24 & \pm 21 & \pm 0.5 & \pm 0.6 & \pm 8.0 & \pm 6.9 \\
\hline high impedance & 255 & 256 & 17.9 & $14.6^{\mathrm{a}}$ & 55.5 & $42.6^{a}$ \\
\hline glucose & \pm 24 & \pm 21 & \pm 0.8 & \pm 0.9 & \pm 0.8 & \pm 3.6 \\
\hline normali impedance: & 256 & 259 & 12.5 & 12.7 & 71.6 & $70.5^{a}$ \\
\hline glucose + pyruvate & +28 & \pm 30 & \pm 0.5 & \pm 0.6 & \pm 6.3 & \pm 6.4 \\
\hline high impedance & 253 & 258 & 19.4 & $18.9^{a}$ & 63.6 & $59.6^{\mathrm{a}}$ \\
\hline glucose + pyruvate & \pm 16 & \pm 17 & \pm 0.2 & \pm 0.4 & \pm 2.2 & \pm 2.1 \\
\hline
\end{tabular}

Data presented as means $\#$ SO. HR, LVDP and CO refer to heart rate, left ventricular developed pressure and cardiac output, respectively. Initial baseline values were meastred after $15 \mathrm{~min}$ to allow the hearts to adapt to the working mode. a Indicates significantly different $(p<0.05)$ from values measured at $t=15$. 

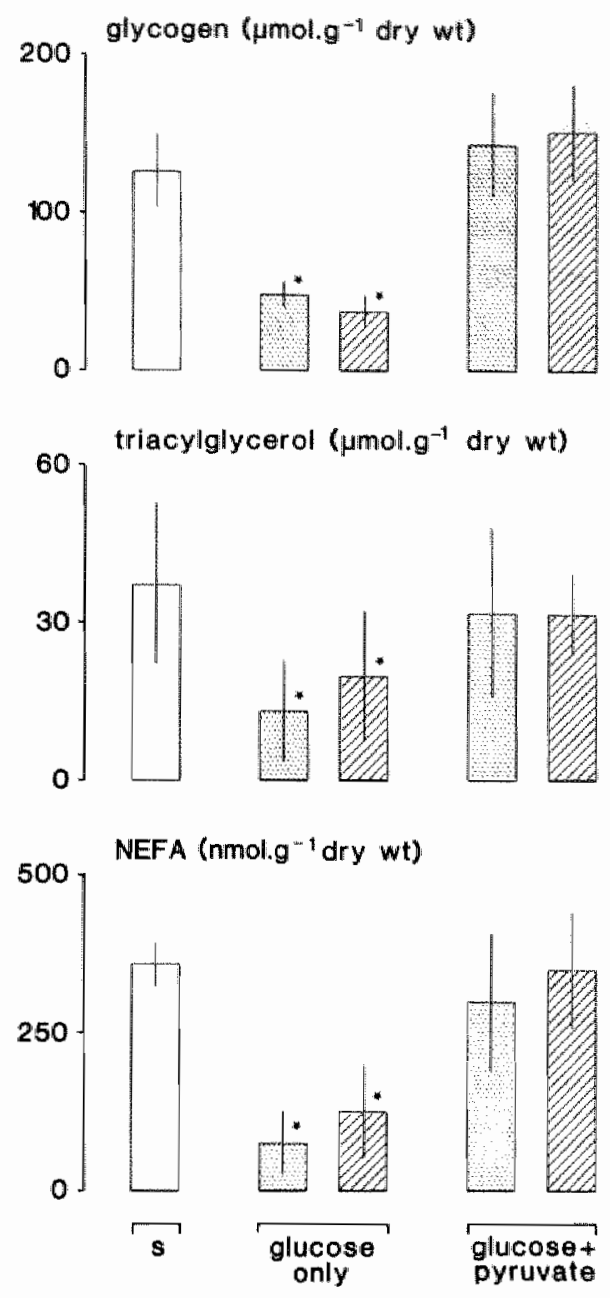

Fig 3.3 Tissue content of glycogen (expressed as glucase equivalents), triacylglycerols (expressed as fatty acyl equivalents) and non-esterifled fatty acids (NEFA's) of hearts freeze clamped immediately after $10 \mathrm{~min}$ of stabilization lopen bars, group 5 ) and hearts freeze clamped after $120 \mathrm{~min}$ of nomoxic perfusion at efther normal (shaded bars) or high aortic impedance (hatched bars), and perfused in the absence or presence of pyruvate as cosubstrate. Data presented as means \pm SD. Asterisk indicates significantly different $(p<0.05)$ from group $S$. 
K.Pa at nomal and high impedance, respectively. At high impedance the increase in aortic systolic pressure was associated with a comparable increase in left ventricular developed pressure (LVDP) and reduction of cardiac output (CO). Hemodynamic performance gradually declined when normoxic perfusion was extended. Despite insignificant changes in heart rate, both LVDP and CO were markedly reduced after 120 min (especially at high impedance). Pyruvate, when present as cosubstrate, did not affect initial baseline hemodynamics, but almost completely abolished functional decline during prolonged perfusion at nomal as well as high impedance (table 3.1 ).

With glucose as the sole exogenous substrate the myocardial content of glycogen and triacylglycerols was severely reduced after $120 \mathrm{~min}$ of nomoxic perfusion, at both low and migh impedance (fig 3.3 ). When pyruwate was supplied in addition to glucose, endogenous substrate levels were maintained. Moreover, the myocardial NEFA content was markedly increased under these circumstances ( $\mathrm{fig} 3.3$ ).

After 120 min of nomoxic perfusion the myocardial content of adenine mucleotides (AN) was significantly reduced (table 3.2). The decrease of AN was neither related to the impedance to which the hearts were subjected nor to the type of substrate(s) provided and averaged about $8 \mu$ mol. $g^{-1}$ dry weight for each group. anly for the hearts exposed to normal impedance and supplied with pyruvate as cosubstrate, the decline of AN was not associated with a significant decrease in the energy charge (i.e. [ATP + 0.5 ADP ]/[ATP + ADP + AMP ]).

Basal lactate release was affected by both aortic impedance and substrate supply. G1 ucose-perfused hearts released $0.5 \pm 0.2$ and $0.8 \pm 0.1 \mu \mathrm{mol} . \mathrm{min}^{-1}$. heart $^{-1}$ of lactate at normal and high impedance, respectively $(p<0.05)$. In the presence of pyruvate basal release of lactate was increased and amounted to $1.7 \pm 0.2$ and $2.2 \pm 0.1 \mu \mathrm{mol} . \mathrm{min}^{-1}$.heart ${ }^{-1}$ at normal and high impedance, respectively $(p<0.05)$. Onlly the glucose-perfused hearts, that falled to withstand the high impedance, showed a gradual increase in lactate production during the course of the experiments (from 0.8 to $1.4 \mu \mathrm{mol}$. $\mathrm{min}^{-1}$. heart ${ }^{-1}$ after 2 hours of normoxic perfusioni). In the other groups lactate production remained constant during 2 hours of nomoxic perfusion.

\section{Ischeni and reperfustion.}

In all glucose-perfused hearts restoration of flow following 45 min of ischemia was associated with ventricular fibrillation. In each group one out 
of four hearts fibrillated during the entire reperfusion period. For the remaining hearts the time required to resume spontaneous rhythm averaged about 10 minutes (table 3.3 , data in parentheses). In the electrically recovering hearts heart rate returned to control values, but the recovery of $L$ VDP and $C O$

Table 3.2 Myocardial content of adenime nucleotides and energy charge of hearts freeze clamped immediately after stabilization and hearts that were normoxically perfused for $120 \mathrm{~min}$ at various impedances, in the absence or presence of pyruvate.

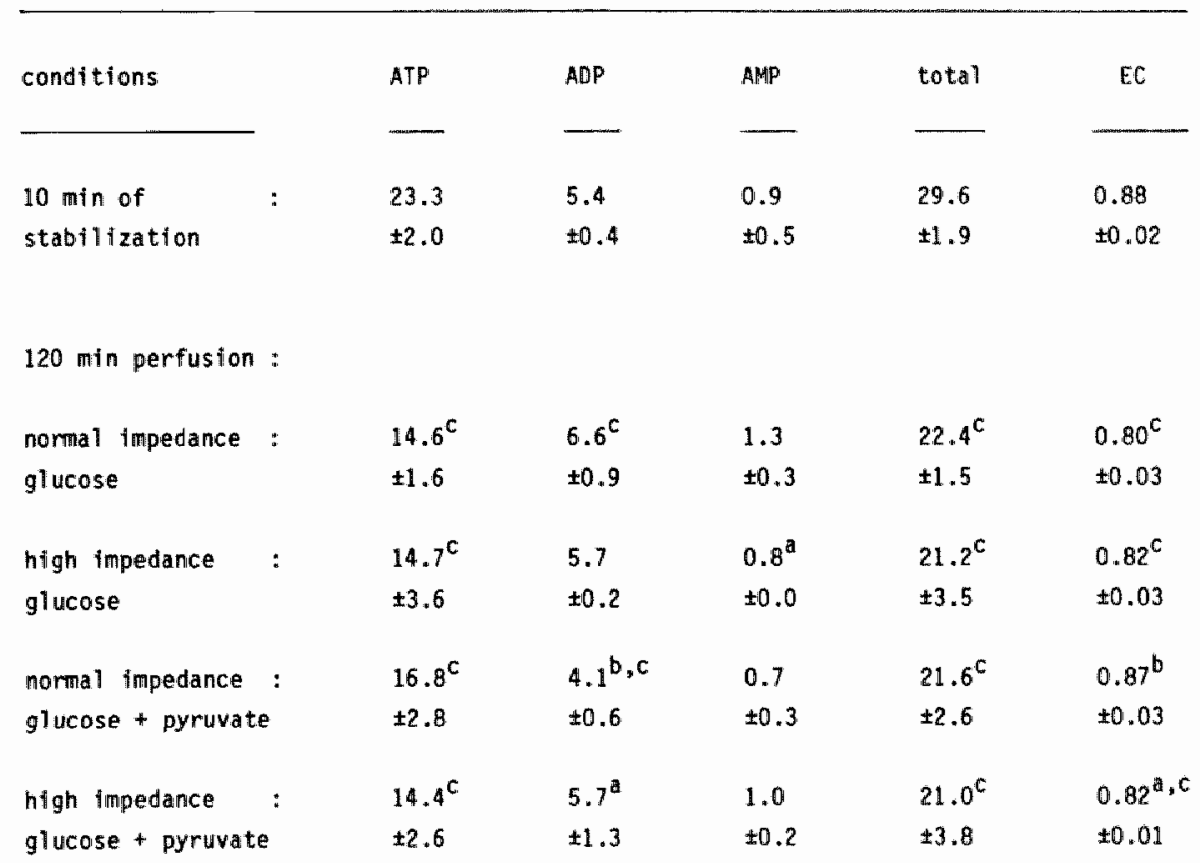

Data presented as means \pm SD. Tissue contents are expressed in $\mu$ mol $\mathrm{g}^{-1}$ dry wt. The energy charge (EC) is defined as ( (ATP +0.5 ADP)/(ATP + ADP + AMP)). Total refers to the sum of ATP, ADP and AMP. a indicates significantly different ( $p<0.05$ ) from hearts supplied with the same substrate(s) and exposed to the normal impedance. b indicates significantly different from hearts exposed to the same impedance and supplied with glucose as the sole substrate. C indicates significantly different from hearts freeze clamped at the end of the stabllization perfod. 


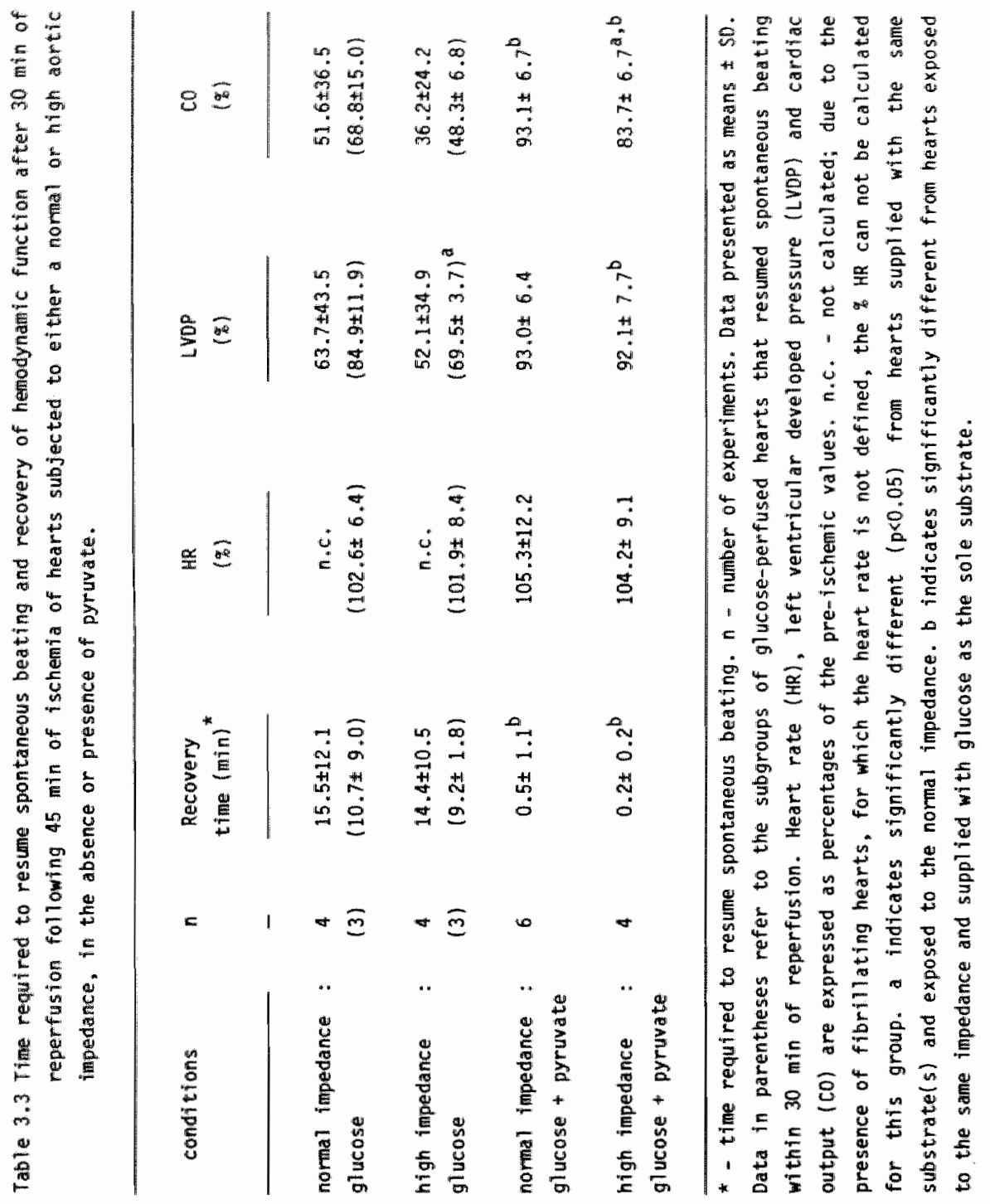


was 1 imited, especially at high impedance (fig 3.4, table 3.3 ).

In the presence of pyruvate only 3 out of 10 hearts (normal plus high impedance groupl fibrillated very shortiy upon reperfusion. The average time interval of fibrillation amounted to $0.4 \mathrm{~min}$. At the end of the reperfusion period heart rate was not different from its pre-ischemic value, and LVDP and Co were only slightly depressed (fig 3.4, table 3.3). At high impedance the recovery of $C O$ was significantly less as compared to hearts subjected to a normal impedance.

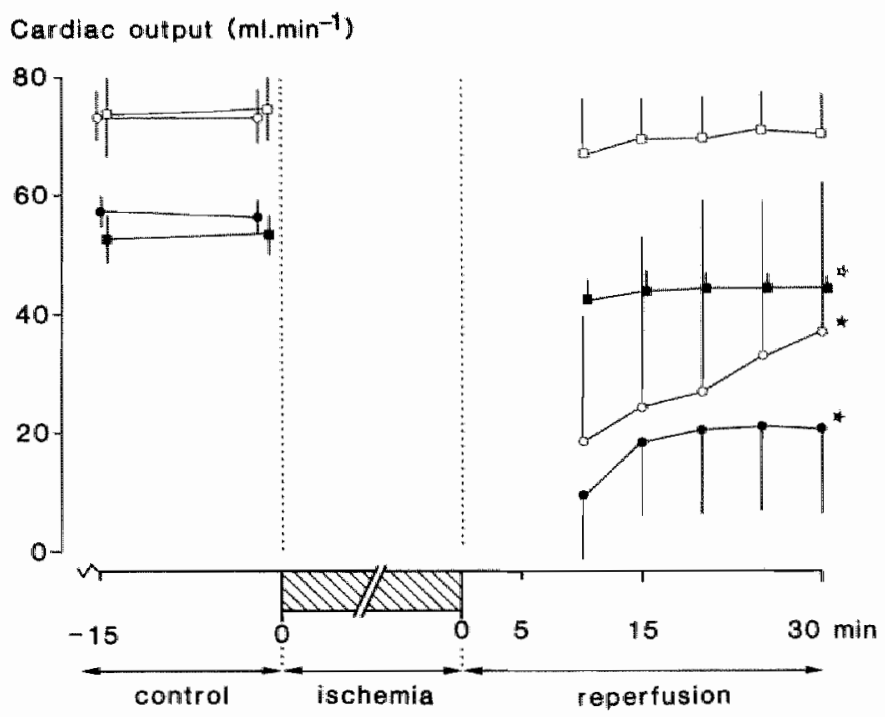

Fig 3.4 Effect of ischemia and reperfusion on recovery of cardiac output of hearts subjected to either a nomal (open symbols) or high (closed symbois) aortic impedance and perfused in the absence $(0$ and $\bullet)$ or presence of pyruvate $(\square$ and $\mathbf{\square})$ as cosubstrate. Data presented as means $\pm S D$. Open asterisk refers to significant difference ( $p<0.05)$ between hearts subjected to either normal or high impedance and perfused with the same substrate(s). Closed asterisk indicates significantly different from hearts subjected to the same impedance, but perfused in the presence of pyruvate. 


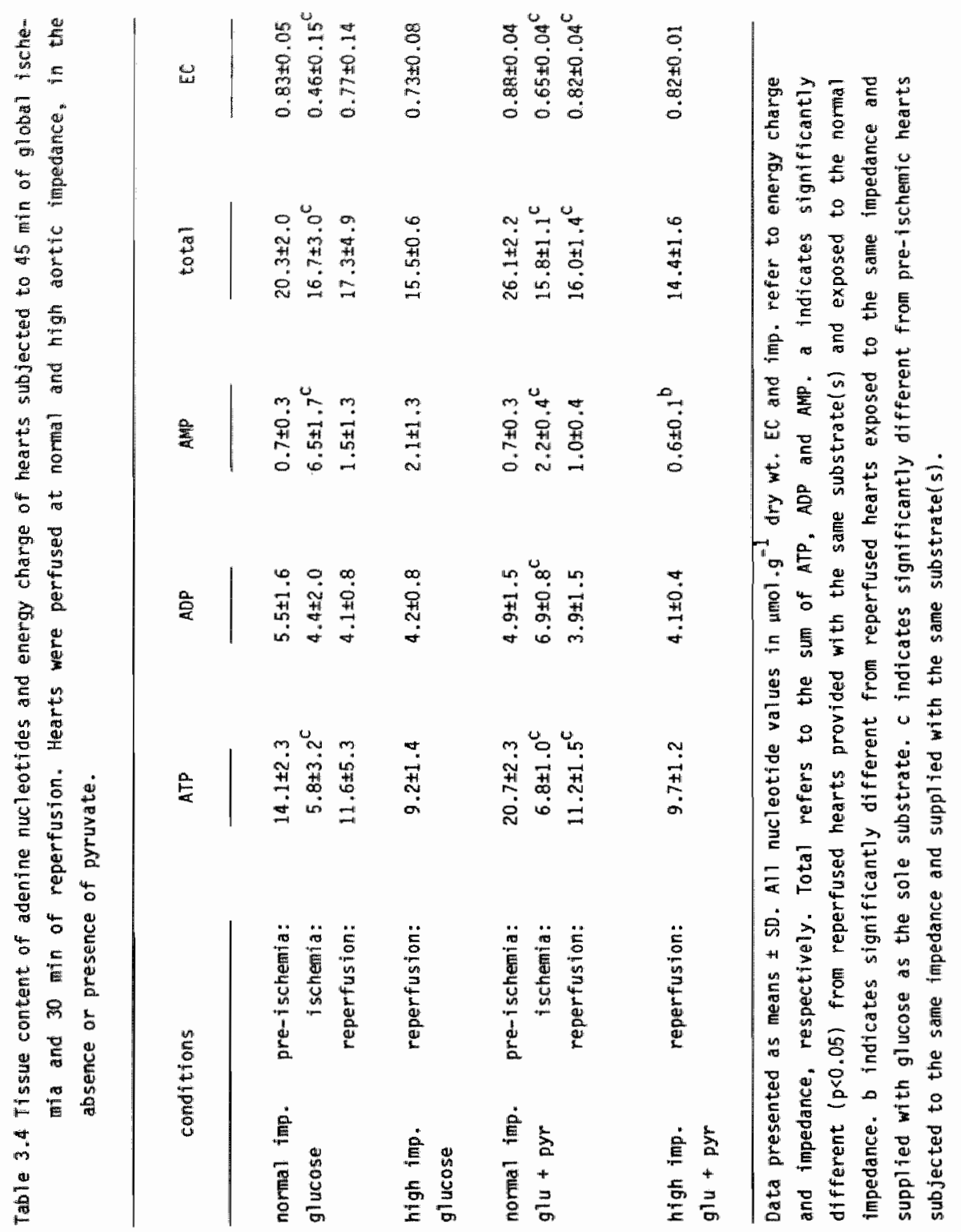


The presence of pyruwate during the pre-ischemic perfusion period did not affect the reduction of the myocardial total AN content during ischeinia (table 3.4). However, after $45 \mathrm{~min}$ of ischemia marked differences became apparent in the contribution of the indiwidual nucleotides to total AN. ANP accumulated to a much larger extent in ischemic hearts previously supplied with glucose alone. This was also reflected by a lower energy charge of these hearts. Pyruvate was found to reduce the decline in $\mathrm{NAD}^{+}$during ischemia (fig 3.5 ). Marked differences were also apparent in the accumulation of nucleosides during ischemia. In glucose-perfused hearts about equal amounts of adenosine and inosine accumulated in the ischemic tissue $13.4 \pm 0.9$ and $3.0 \pm 0.6 \mu \mathrm{mol} . \mathrm{g}^{-1}$ dry wt, respectively). In the presence of pyruvate, however, inosine was the most prominent degradation product $\left(2.2 \pm 1.0\right.$ and $5.8 \pm 1.0 \mu$ mol. $9^{-1} \mathrm{dry}$ wt for adenosine and inosine, respectively). During reperfusion the myocardial content of total AN was not restored. At the end of reperfusion no differences were observed in the total AN content between the various experimental groups $($ table 3.4$)$. The energy charge partially recovered during reperfusion.

Before the onset of ischemia the myocardial glycogen content of glucoseperfused hearts had al ready markedly declined (fig 3.5). The glycogen content further diminished in the globally ischemic hearts and remained depressed during reperfusion. In the presence of pyruvate glycogen levels were higher at the onset of ischemia. Although a substantial amount was consumed, glycogem stores were not exhausted during ischemia. At the end of the reperfusion period glycogen levels were in the same range of those in ischemic hearts.

During ischemia the accumulation of lactate was more pronounced in hearts supplied with pyruvate as cosubstrate during the pre-ischemic period lfig 3.5). Likewise, the release of lactate was augmented during reperfuston. However, these differences were less marked when these vallues were corrected for basal lactate release (table 3.5 ).

Despite an improved performance of hearts supplied with pyruvate, the cumulative release of $\mathrm{LDH}$ during reperfustion was not different from the values observed in glucose-perfused hearts (table 3.5). 

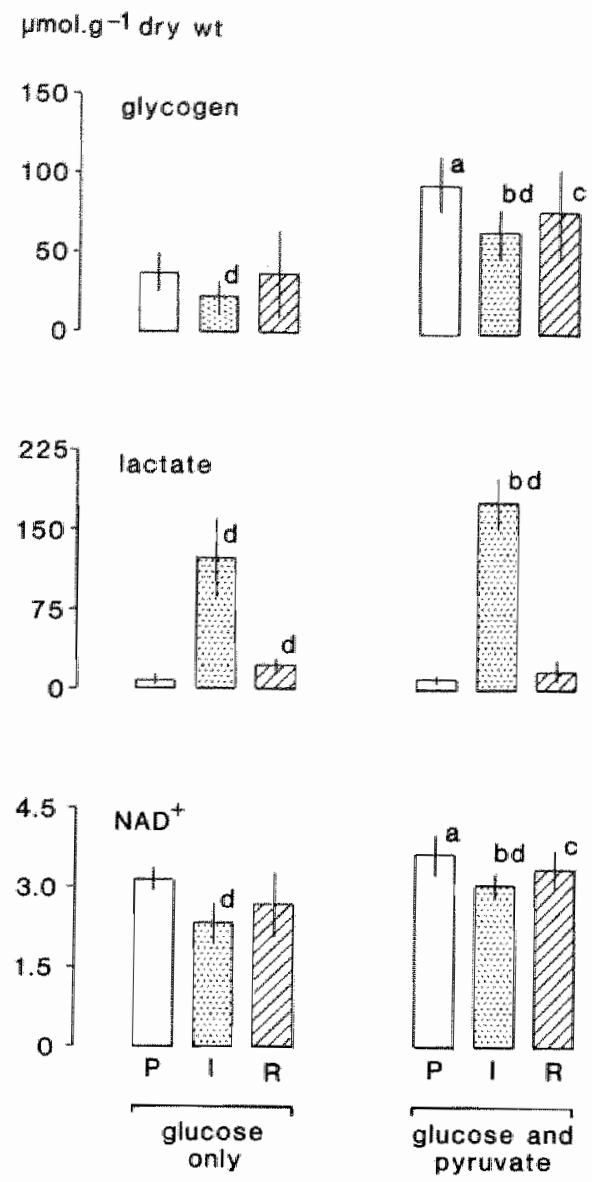

Fig 3.5 Myocardial content of glycogen (expressed as glucose equivalents), lactate and $\mathrm{NAD}^{+}$of pre-ischemic $(P)$, ischemic (I) and reperfused (R) hearts exposed to normal or high aortic impedance, and perfused in the absence or presence of pyruvate. a refers to significant difference $(p<0.05)$ between pre-ischemic hearts, perfused with or without pyruvate as cosubstrate. b refers to significant difference between ischemic hearts, perfused with or without pyruwate as cosubstrate. $c$ refers to significant difference between reperfused hearts, perfused with or without pyruvate as cosubstrate. d indicates significantly different from pre-ischemic walue. 
Table 3.5 Cumulative release of lactate and lactate dehydrogenase (LDH) during $30 \mathrm{~min}$ of reperfusion of hearts subjected to efther a nomal or high impedance in the absence or presence of pyruwate.

\begin{tabular}{|c|c|c|}
\hline Conditions & $\begin{array}{c}\text { Lactate } \\
(\text { fmol heart }\end{array}$ & $\begin{array}{c}\text { LDH } \\
(\text { unit ts.heart } \\
-1 \text { ) }\end{array}$ \\
\hline $\begin{array}{l}\text { nomial impedance } \\
\text { glucose }\end{array}$ & $\begin{array}{c}52.5 \pm 9.8 \\
(37.5)\end{array}$ & $\begin{array}{l}7.1 \pm 2.7 \\
(7.0)\end{array}$ \\
\hline $\begin{array}{l}\text { high impedance } \\
\text { glucose }\end{array}$ & $\begin{array}{l}51.6 \pm 6.0 \\
(27.6)\end{array}$ & $\begin{array}{c}8.6 \pm 2.3 \\
(8.4)\end{array}$ \\
\hline $\begin{array}{l}\text { normal impedance } \\
\text { glucose + pyruvate }\end{array}$ & $\begin{array}{l}94.9 \pm 9.2^{b} \\
(43.9)\end{array}$ & $\begin{array}{c}9.5 \pm 2.4 \\
(8.3)\end{array}$ \\
\hline $\begin{array}{l}\text { high impedance } \\
\text { glucose + pyruvate }\end{array}$ & $\begin{array}{c}98.5 \pm 10.9^{b} \\
(32.5)\end{array}$ & $\begin{array}{c}11.1 \pm 5.9 \\
(9.0)\end{array}$ \\
\hline \multicolumn{3}{|c|}{$\begin{array}{l}\text { Data presented as means } \pm S D \text {. Data in parentheses refer to cumula- } \\
\text { tive release of lactate and LDH corrected for basal release, as } \\
\text { measured during the pre-ischemic phase (mean values). a indicates } \\
\text { significantly different ( }<0.05 \text { ) from hearts provided with the } \\
\text { same substrate(s) and exposed to the normal inpedance. b indicates } \\
\text { significantly different from hearts exposed to the same impedance } \\
\text { and supplied with glucose as the sole substrate. }\end{array}$} \\
\hline
\end{tabular}

\subsection{Discussion}

Functional stabflity during prolonged normoxic perfusion.

The present findings demonstrate that pyruvate, supplied as cosubstrate to glucose-perfused hearts, preserves myocardial function during $120 \mathrm{~min}$ of normoxic perfusion. The gradual loss of function (especially at high workload) 
and the depletion of endogenous substrates, like glycogen and triacylglycerols, in glucose-perfused hearts indicates that exogenously supplied glucose is not able to meet the substrate requirements of the hearts. Since tissue levels of glycogen (see fig 3.5) and triacylglycerols (data not shown) are found to be reduced already within 30 minutes, the inadequacy of glucose as exogenous substrate can obviously already be demonstrated during the initial phase of ex-vivo perfusion. This can likely be explained by the limited transport rate of glucose across the sarcolemma, since glucose moieties, derived from glycogen, are readily consumed. The exogenous supply of pyruvate prevents the consumption of endogenous carbohydrate and lipid stores, both at normal and high workload. Obviously, uptake of this substrate, controlled by an active monocarboxylic acid transporter (Mann et al., 1985), is not rate limiting and able to meet the energy requirements of the isolated, working rat heart. The elevated intracellular level of NEFA's in pyruvate perfused hearts most likely reflects the competition between pyruvate and NEFA" $s$ for free COA. At the same time the elevated NEFA content prevents degradation of triacylglycerols by feedback inhibition of triglyceride lipase (Stam and Huelsmann, 1981).

Despite the marked reduction of tissue ATP content during prolonged normoxic perfusion, hemodynamic function of hearts perfused at both normal and high impedance was not compromised if pyruvate was present as cosubstrate. This observation is not in favor of a direct relationship between the tissue content of ATP and myocardial function. Reduction of myocardial ATP levels during normoxic perfusion, giving rise to a continuous release of uric acid from the heart (data not shown), has also been observed by others, in both Langendorff perfused hearts (De Kock et al., 1978) and working heart preparations (Segel et al., 1977). The significance of this phenomenon, reflecting an imbalance between degradation and formation of ATP in bloodfree perfused rat hearts, is not completely understood.

The present findings show that lactate production is enhanced (a) at increased aortic impedance and (b) in the presence of pyruwate. Lactate production in ex-vivo perfused hearts is a well-known phenomenon (Opie et al., 1971; Taegtmeyer et a1., 1980; Segel and Rendig, 1982). Basal lactate production is not necessarily a sign of inadequate supply of oxygen resulting in anaerobiosis, but might also provide a means to reduce cytosolic NADH levels, which are elevated due to high rates of aerobic glycolysis (Kobayashi and 
Neely, 1979, 1983b; Morgan et al., 1984). In case of pyruvate present as cosubstrate, mass action of increased levels of pyruwate, extracted by the cells from the extracellular space, has to be considered as well. Only in gl ucose-perfused hearts subjected to a high aortic impedance, lactate release rises during the course of the experiment. Segel and Rendig (1982) also observed a relation between augmented lactate release and functional deteriaration of nomoxic perfused hearts. However, it remains to be established if this is a reflection of the development of oxygen shortage.

\section{Ischemia and reperfusion.}

The present findings show that pyruvate reduces the incidence and duration of ventricular arrhythmias and improves hemodynamic recovery during reperfusion. Increased afterload and, hence, increased oxygen demand negatively influenced post-ischemic recovery, but this effect was less pronounced when pyruvate was present as cosubstrate, emphasizing the protective properties of pyruvate.

In the present experimental set-up pyruvate was present both before and after the period of ischemia. Consequently, potential beneficial effects af pyruvate during the ischemic as well as reperfusion phase have to be considered. The present findings demonstrate that in glucose-perfused hearts the glycogen content is markedly depressed prior to the onset of no-flow ischemia. So, the capacity to convert glucose moieties into lactate, with a concomitant anaerobic production of ATP, is depressed. It is note worthy that Neely and Grotyohann (1984a) have recently reported that pre-ischemic depletion of glycogen stores in hearts subsequently subdued to transient ischemia is beneficial. Obviously, the present findings are not in favor with this notion.

In case of low-flow ischemia conversion of extracted pyruvate to lactate will diminish the cytosolic $\mathrm{NADH} / \mathrm{NAD}^{+}$ratio. Hence, the inhibition of glycoTytic enzymes, like glyceraldehyde-3-phosphate dehydrogenase, might be relieved and glycolytic ATP production will be promoted (Liedtke et al., 1976). Indeed, Liedtke and coworkers (1976) demonstrated that pyruvate attenuated the depletion of ATP during ischemia. However, it is doubtful whether the glycolytic rate is actually enhanced under these circumstances, since it has been shown that the pyruvate induced rise in citrate will hamper glycolysis by inhibition of phosphofructokinase (Garland et a1., 1963; Wi11iamson, 1979). In this respect, Mochizuki and Neely (1980) convincingly showed that glycolytic 
flux was reduced during low-flow ischemila, when pyruvate was provided in addition to glucose.

It should be noted that, in contrast with low-flow ischemia, no pyruvate is supplied to the heart during the period of no-flow ischemia, as is the case In the present study. only a limfted amount of pyruvate is trapped in the extra- and intracellular tissue space, 1.e. about $10 \mu \mathrm{mol} . \mathrm{g}^{-1} \mathrm{dry}$ wt at the onset of ischemia (data not shown). Within 10 min of ischemia this pyruvate pool was found to be virtually depleted, most likely by conversion into lactate. Nevertheless, the higher energy charge, the elevated tissue content of $\mathrm{NAD}^{+}$(indicating a lower $\mathrm{NADH} / \mathrm{NAD}^{+}$ratio), the low AMP content and more elevated levels of inosine at the end of the ischemic period, indicate that pyruwate exerts a marked influence on ischemic myocardial metabolism. The improved energy status can be taken as evidence that pyruvate is able to Improve the tolerance to ischemia. In view of the small amount and rapid conversion of the pyruvate, trapped in the cardiac tissue at the onset of ischemia, it seems umlikely that this limited pool per se is responsible for the metabolic differences between ischemic hearts, previously perfused in the absence or presence of pyruvate. It is feasible that pre-ischemic perfusion with pyruvate has substantial influence on the metabolic status of the hearts prior to the ischemic insult. Beside effects on the myocardial glycogen content (see fig 3.5), other metabolic effects, like for instance on acetylCoA and citric acid levels (Kobayashi and Neely, 1983b), have to be considered.

No satisfying explanation can be given for the marked effects of pymuate on the accumulation of AMP (reduction) and inosine (increase) during ischemia. Apparently, in some way pyruvate stimulates the dephosphorylation of AMP. However, the reguition of AMP degradation is very complex. First, AMP can be degraded along two pathways (AMP -.. adenosine -.- inosine and AMP -.. IMP -.. inosine; see also fig 4.51 , both of which might be operative during ischemia (Achterberg et a1., 1985). Second, there is still no concensus as to the sites (parenchyma1, interstitial or endothelial) of adenosine and inosine formation. Interestingly, Ravid and associates (1984) demonstrated that pyruvate stimulated the activity of hypoxanthine-phosphoribosyl transferase and, hence, hypoxanthine salvage. However, it is not likely that the pyruvate-induced difference in salvage rate is sufficient to explain the marked differences in the purine content of ischemic hearts. 
The significantly elevated lactate levels at the end of the ischemic period are in favor of the idea of increased glycolytic activity during ischemia in hearts previously supplied with pyruvate. According to opie (1970b) the latter process will render the heart more resistant against ischemic damage. Recent findings of Huel smann and coworkers (unpublished observations) indicate that pyruvate reduces the accumulation of glycerol-3-phosphate during ischemia. The conversion of glucose(-moieties) to glycerol-3-P does not yield ATP, but instead requires input of ATP. Obviously, a reduction of glycerol-3-P formation would enhance lactate formation and, therefore, anaerobic ATP production. However, the findings of Rovetto and coworkers (1975) indicate that even in glucose-perfused hearts the amount of glycerol-3-P accumulating is by far outnumbered by the amount of lactate accumulating. So, it is questionable whether the pyruvate-induced reduction of glycerol-3-P formation and, hence, enhancement of anaerabic ATP production is of sufficient quantitative importance to render the heart more resistant to ischemia.

During complete flow cessation no oxidation of pyruvate can take place. After restoration of oxygen supply, however, pyruvate could serve as a readily extractable and oxidizable substrate (Evans et a1., 1963, Goldstein et a1., 1980). At that time glycolysis and fatty acid oxidation have not retained full activity and delivery of substrates to the citric acid cycle might be limited (Mochizuki and Neely, 1980; Kobayashi and Neely, 1983a). In Iine with the findings of Mochizuki and Neely (1980) pyruvate is able to enhance functional recovery during reperfusion without salvaging adenine nucleatides. Figure 3.6 clearly indicates complete dissociation between the content of ATP in postischemic hearts and the ability to recover. This finding supports the idea that the benefical effect of pyruvate results from higher turnower rates of ATP during the initial reperfusion phase, rather than preservation of ATP levels. The higher energy charge of hearts perfused with pyruvate as cosubstrate are in concert with this notion.

From a physiological point of view, the tissue content of ATP might be of 1 imited value as a determinant of post-ischemic functional recovery and irreversible tissue damage. Nevertheless, a multitude of studies provided evidence to support the hypotheses that a reduction of the tissue ATP content below a critical value (in the order of $5-10 \mu \mathrm{mol} . \mathrm{g}^{-1}$ dry $w \mathrm{t}$ ) is related to the occurrence of irreversible damage (Reimer et al., 1981a; Refmer and Jennings, $1981 \mathrm{c})$, and that the extent of post-ischemic funtional recovery is 1 inearly 

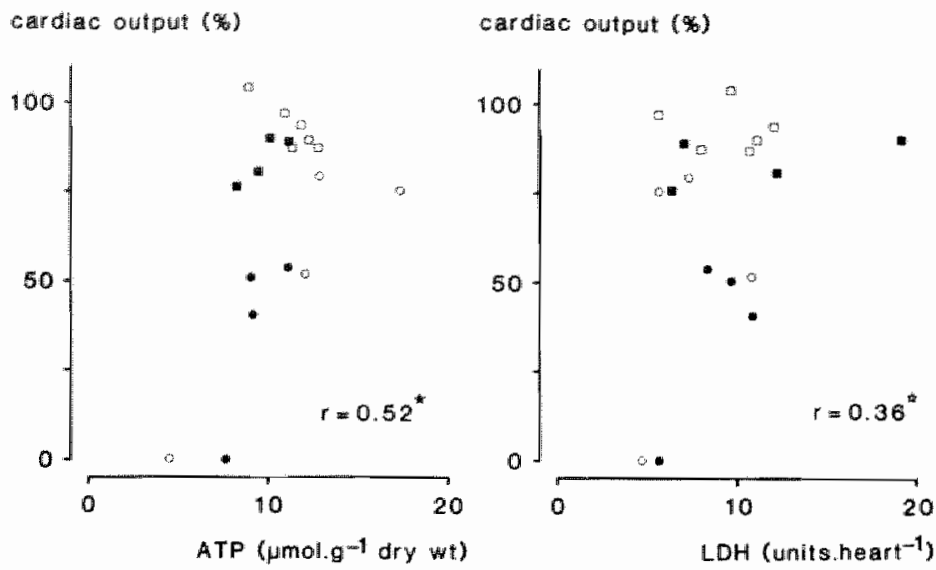

FHg 3.6 Relationships between the percentage recovery of cardiac output (expressed as percentage of the pre-ischemic value) and the tissue content of ATP at the end of reperfusion and cumulative release of LDH during $30 \mathrm{~min}$ of reperfusion, respectively. $O$ and refer to hearts perfused with glucose only, at mormal and high aortic impedance, respectively. $\square$ and $\square$ refer to hearts perfused in the presence of pyruvate, at normal or high aortic impedance, respectively. - not significant; $*-0<0.05$.

related to the tissue ATP content of reperfused hearts (Reibel and Rovetto, 1978; Watts et a1., 1980; Meno et a1., 1984). It should be kept in mind that the measured tissue value is an average of the ATP levels of all cells present in the tissue sample. It does not take into account possible inhomogeneities in the ATP content of the tissue sample. It does neither give information about the subcellular distribution of ATP. At least three, more or less separated, adenine nucleotide pools are likely to be present (Geisbuhler et a1., 1984), i.e, the mitochondrial (about 20\% of the cellular adenine nucleotide content), cytosolic and myofibrillar pool (together about 80\%). According to the phosphocreatine shuttle concept only a limited anount of ATP is required to sustain mechanical performance (Bessman and Geiger, 1981). In theory the cytosolic ATP content, and thus the cellular ATP content, can seriously 
decline without affecting cardiac mechanics. Recently this notion was confirmed by Kupriyanov and colleagues (1987). In an elegant study these investigators demonstrated that selective depletion of the cytosolic ATP pool during normoxia was not associated with severe mechanical failure. Furthermore, at the myofibrillar site the free energy change of hydrolysis of ATP must be sufficient in order to use the liberated energy for mechanical work. The free energy change of hydrolysis of ATP is mainly influenced by the cytosolic phosphorylation potential [ATP]/[ADP].[P $]$, in which [ATP], [ADP] and $\left[P_{i}\right]$ refer to the free cytosolic concentrations. A variety of studies has been performed to delineate whether the changes in free energy (c.q. phosphorylation potentiall are causally related to early ischemic/anoxic contractile failure (Kammermeier et al., 1982; for review see Gibbs, 1985). It is of interest to investigate the role of the cytoplasmic phosphorylation potential as a determinant of mechanical performance of reperfused hearts. Unfortunate$1 \mathrm{y}$, in this study the biochemical measurements do not allow such an approach.

The present findings also demonstrate that differences in post-ischemic functional recovery are not related to the amount of $L D H$ released during reperfusion (fig 3.6). Aithough questioned by some investigators (Piper et a)., 1984), in general, enzyme release from cardiac tissue is considered a sign of loss of cell membrane integrity and, hence, cell death (see Hermens et al., 1982). Therefore, it is unlikely that pyruvate diminishes the number of lethally damaged cells. This implicates that the condition of surviving cells must have been improved by pyruvate.

\subsection{Summary.}

In the present study the hemodynamic and metabolic effects of pyruvate, added as cosubstrate to glucose-perfused, transiently ischemic hearts, were evaluated. During two hours of normoxic perfusion at different workloads pyruvate improved functional stability and prevented depletion of glycogen and triacylglycerol stores. After 45 minutes of no-flow ischemia pyruvate was found to (a) attenuate the decline in energy charge at a comparable total adenine nucleotide content and (b) to enhance the net degradation of glycogen and the accumulation of lactate. After restoration of flow pyruvate reduced 
the incidence of fibrillation and markedly inproved recovery of cardiac output at both normal and high workload. Pyruwate did nelther attenuate release of lactate dehydrogenase, a marker for lethal cellular injury, nor improve the conservation of the total adenine nucleotide and ATP content of hearts reperfused for 30 minutes. The latter findings indicate that, in the present experimental set-up, in which transient ischemia of relatively short duration was studied, post-ischemic functional recovery is nefther related to the tissue content of ATP, nor to the number of irreversibly damaged cells.

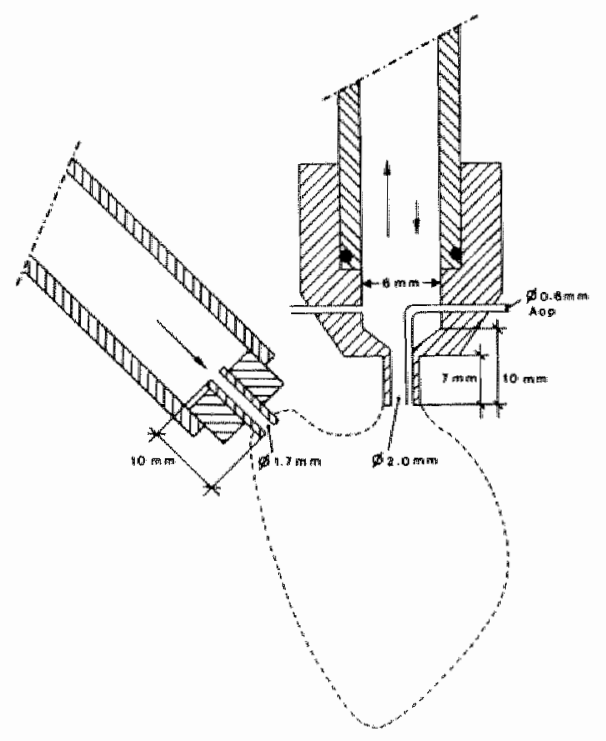

Fig 3.7 Detalled schene of the aortic and atrial cannulas. The dimensions of the aortic cannula, with relatively physilological impedance characteristics, and atrial cannula are indicated. The position of the aortic pressure (Aop) catheter is also shown. 


\subsection{Appendix}

Influence of aortic impedance on workload.

The workload to which the left ventricle of the isolated, working heart is subjected is a function of left atrial filling pressure, afterload (in many studies a water column of fixed height) and impedance of the artificial aortic outflow tract. The contribution of the latter component to the workload is often neglected in isolated rat heart preparations. Commonly, the fluid volume ejected by the isolated heart enters a rigid and narrow cannula, having a relatively high inertia and resistance as compared to the natural aortic impedance. In this study, the disadvantageous effects of the cannula were minimized by a more optimal design of the cannula (fig 3.7). Inertia and resistance to pulsatile flow were reduced by minimizing the length $(7 \mathrm{~mm})$ and maximizing the internal diameter of the proximal part of the cannula $(2 \mathrm{~mm}$ for hearts of about 1 gram). Distal to this part the cannula wi dened gradually to $6.0 \mathrm{~mm}$ to reduce effects of turbulence.

In the present study the aortic impedance and, hence, the workload, was varied by changing the internal diameter $(2.0$ and $1.2 \mathrm{~mm}$, respectively) of the proximal part of the aortic cannula. The effects of the construction of this device on aortic impedance and, hence, on workload will be discussed below.

According to the general, but difficult to solve Navier-Stokes equation, pressure along a cylindrical tube depends on the velocity as well as on acceleration of fluid within the tube. In a simpler approach pressure drop ( $P_{\text {tot }}$ ) along a tube can be approximated by the sum of three terms being the inertance term ( $P_{\text {inert }}$ ), the Bernouilli term $\left(P_{\text {bern }}\right)$ and the Poiseuille term $\left(P_{\text {pois }}\right)$. It holds approximately:

$$
\begin{aligned}
& \Delta P_{\text {inert }}=(d q / d t) \cdot p \cdot 1 /\left(\pi \cdot r^{2}\right) \\
& \Delta P_{\text {bern }}=\rho \cdot q^{2} /\left(2 \cdot \pi^{2} \cdot r^{4}\right) \\
& \Delta P_{\text {pois }}=q \cdot\left(8 \cdot \eta \cdot 1 /\left(\pi \cdot r^{4}\right)\right) \\
& \Delta P_{\text {tot }}=\Delta P_{\text {inert }}+\Delta P_{\text {bern }}+\Delta P_{\text {pois }}
\end{aligned}
$$

where $1=$ tube length $(7 \mathrm{~mm}$ for both cannulas $), r=$ tube radius, $q=$ volume 
flow $\left.(m) \cdot \mathrm{s}^{-1}\right), p=$ flufd density $\left(1050 \mathrm{~kg} \cdot \mathrm{m}^{-3}\right.$ for Krebs-Henseleit buffer $)$. $\eta=$ fluid viscosity $\left(10^{-3} \mathrm{~Pa} \cdot \mathrm{s}\right)$.

Peak inertial pressure is calculated from peak time derivative of flow. In this calculation ejection time is taken to be $25 \%$ of the cardiac cycle, and the shape of the aortic flow pulse is taken to be parabolic. Peak Bernoull1it and Poisseullie pressure components are based on peak flow vallues, which are approximately sixfold the time average of flow.

The maximum values of the three pressure components for hearts forced to eject through the wide and narrow cannula, respectively, are shown in table 3.6. The total pressure drop $\left(\Delta P_{\text {tot }}\right)$ is less then the sum of the maximum values of the components, because the individual maxima do not coincide in time. In the compliance chamber distal to the cannula the amplitude of the

Table 3.6 Calculated components of pressure drop and measured pressure drop across aortic cannulas with an internal diameter of 2.0 and $1.2 \mathrm{~mm}$, respectively.

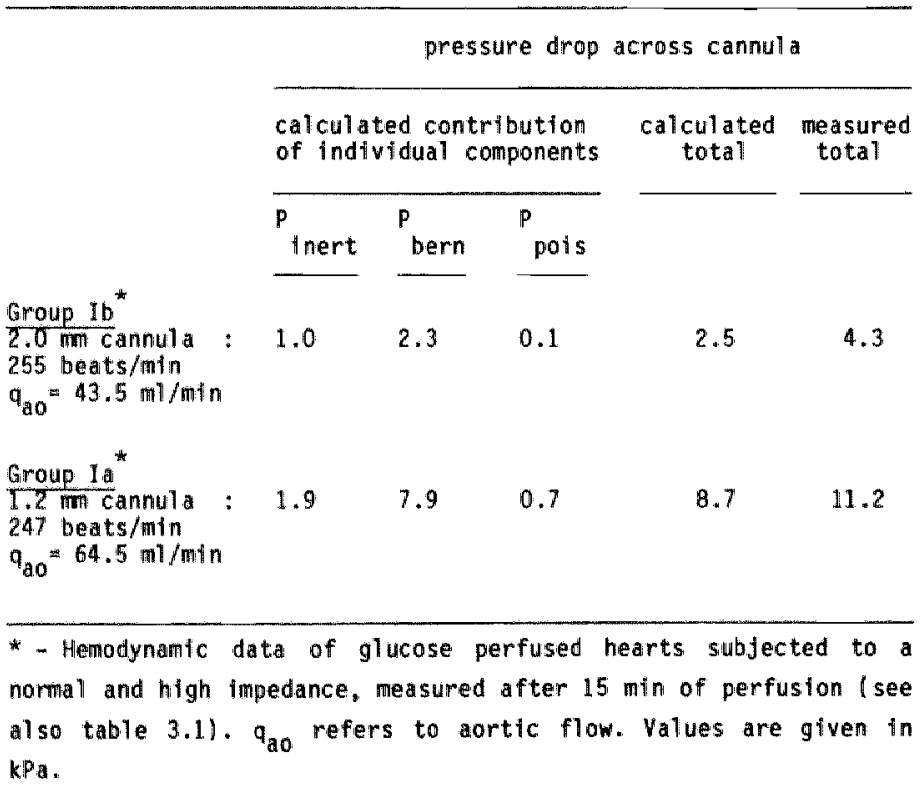


pressure pulses is attemuated to less than $1 \mathrm{kPa}$. Therefore, the systolic-diastolic difference in aortic pressure clasely reflects the pressure drop across the cannula. The calculated pressure drop across the camula agrees quite well with experimental results (table 3.6$)$. Since the area reduction due to the presence of the aortic pressure catheter in the aortic cannula was not taken into account the calculated pressure drop is slightly underestimated. In the above mentioned calculations the Bernouilli term, which is closely related to energy losses by turbulence, appears to be the major term. As a result of this, the $2 \mathrm{~mm}$ cannula behaves like a fluid resistance with little inertance. The beneficial effect of applying this cannula might be due to the resemblance with the natural aortic impedance. After all, at frequencies above heart rate the latter impedance is also mainly resistive (Westerhof et al., 1971; Fisher et a1., 1984) and is associated with systolic-diastolic pressure differences similar to what is found in the present isolated heart preparation.

since myocardial oxygen consumption is mainly determined by pressure development (Neely et al., 1967; Kobayashi and Neely, 1983b), high impedances will significantly enhance the oxygen demand of the heart. Huetter and coworkers (1985b) have demonstrated that the following equation:

$$
v_{2}=c_{0}+c_{1} \cdot H R \cdot P_{1 v, s y s t} \cdot s V+c_{2} \cdot P_{1 v, s y s t} \cdot H R
$$

where $c_{0}=0.3951, c_{1}=1.7025^{*} 10^{-3} \mathrm{kPa}^{-1} \cdot \mathrm{ml}^{-1} \cdot \mathrm{min}, c_{2}=1.3755^{* 10^{-3}} \mathrm{kPa}^{-1} \cdot \mathrm{min}$, $\mathrm{VO}_{2}=$ oxygen consumption (in $\mu \mathrm{mol} \mathrm{O}_{2} \cdot \mathrm{min}^{-1} \cdot \mathrm{g}^{-1}$ wet weight), $P_{1 \mathrm{v} \text {, syst }}=1$ left ventricular systolic pressure (in $\mathrm{kPa}$ ) and $S V=$ stroke volume (in $\mathrm{m}$. $\mathrm{min}^{-1}$ ),

is quite accurate in order to predict the actual oxygen consumption of isolated, working rat heart preparations. Using hemodynamic data, presented in table 3.1, the $\mathrm{VO}_{2}$ of hearts perfused with glucose as sole substrate was calculated to be 6.6 and 9.1 umol $0_{2} \cdot \mathrm{min}^{-1} \cdot \mathrm{g}^{-1}$ wet welght at normal and high impedance, respectively, i.e. an increase in oxygen demand of about $40 \%$ in the high impedance group.

The calculations given above clearly demonstrate that differences in the design of the aortic outflow tract may result in substantial changes in aortic impedance and, hence, workload of the heart. As shown in the results section differences in workload will significantly influence the experimental results. 
PURINE NUCLEOTIDE METABOLISM DURING ISCHEMIA AND REPERFUSION: ITS RELATION TO MYOCARDIAL DAMAGE.

\subsection{Introduction}

During ischemia myocardial metabolism becomes seriously disturbed (see for instance Liedtke, 1981). Residual ATP production by anaerobic glycolysis is insufficient to meet the energy demands of the oxygen-deprived tissue. As a consequence the tissue content of high-energy phosphates declines. Depletion of ATP below a critical value of $5 \mu \mathrm{mol}, \mathrm{g}^{-1}$ dry weight has been reported to be associated with the onset of irreversible damage of the tissue (Reimer et al., $1981 \mathrm{a}$; Reimer and Jennings, 1981c).

Prolonged myocardial ischemia will inevitably result in lethal tissue injury. Therefore, restoration of blood supply is essential for survival of the jeopardized myocardium. Nevertheless, even after timely reperfusion the tissue content of ATP remains depressed for a substantial period of time (Swain et al., 1982; Reimer et al., 1981b). This could result from the washout of degradation products, accumulated during the preceding ischemic period (Jennings et a1., 1981; De Jong et al., 1983) and/or impairment of mitochondrial function (Weishaar et a1., 1979; Edoute et a1., 1983).

The exact consequences of a depressed ATP content for myocardial integrity and function remain controversial. Many interventions, resulting in an attenuation of the depletion of ATP, have been shown to provide protection to the heart (Weishaar and Bing, 1980; Nayler et al., 1980). Nevertheless, the rellation between ATP and functional recovery during reperfusion is not unambiguous. Whereas several investigators reported a linear correlation between the tissue content of ATP of reperfused hearts and functional recovery (Reibel and Rovetto, 1978; Watts et al., 1980; Edoute et a1., 1983; Meno et a1., 1984), others reported a complete dissociation between these varfables (Neely and Grotyohann, 1984a; Taegtmeyer et al., 1985; Rosenkranz et al., 1986).

Relatively little is known about the changes in the myocardial guanine and 
pyridine nucieotide content during ischemia and reperfusion. Since both constituents play an important role in the energy production of the cell, changes in the tissue contents of these nucleotides might have serious implications (K1ein et a1., 1981; Swatn et al., 1982).

The present study was designed to evaluate the effects of ischemia and reperfusion on the depletion of purine and pyridine nucleotides, the accumulation and release of nucleosides and oxypurines, and the possible consequences of these events for post-ischemic myocardial performance and integrity. To this end isolated, working rat hearts were exposed to varying periods of normothermic global ischemia and subsequently reperfused. Beside ATP, GTP, NAD and related compounds, other intermediates of high-energy phosphate metabolism, like creatine phosphate and inorganic phosphate were measured. Gilycogen and lactate were monitored to assess the capacity of the heart to produce ATP anaerobically. The development of tissue edema and the release of lactate dehydrogenase during reperfusion were used as indexes of irreversible cellular damage.

Since preliminary results (Van Bilsen et al., 1985) indicate that ventricular fibrillation during reperfusion is associated with a lower myocardial ATP content, additional attention was paid to metabolic derangements that might cause this type of arrhythmias.

\subsection{Methods}

Heart perfusion.

Hearts were 1 solated and perfused as left ventricular ejecting hearts as descrlbed in detall elsewhere (chapter 3). The left atrial filling pressure was set at $1.0 \mathrm{kPa}$ and the diastolic aortic pressure was adjusted to $8.0 \mathrm{kPa}$. In the control situation the aortic input impedance imposed was associated with an aortic pressure pulse of about $4.5 \mathrm{kPa}$. Glucose $(11 \mathrm{mM})$ and pyruvate ( $5 \mathrm{mM}$ ) were added as substrates to the perfusion medium.

\section{Experimental protocols.}

Normoxia: To assess the effect of prolonged normoxic perfusion on myocardial function and metabolism, hearts were perfused as working hearts for 120 
minutes and subsequentiy freeze clamped.

Ischemia: After 30 min of normoxic perfusion hearts were either directly freeze clamped ( $n=11$, pre-ischemic controls) or subjected to $10,30,45,60$ or 90 min of no-flow ischemia ( $n=6-8$ per group) and freeze clamped at the end of the ischemic period.

Reperfusion: Following 30, 45 and $60 \mathrm{~min}$ of ischemia hearts were reperfused for an additional 30 min ( $n=6-16$ per group) and subsequently freeze clamped. To avoid a sudden increase in coronary pressure upon reperfusion, perfusion pressure was gradually increased from 0 to $8 \mathrm{kPa}$ (usually within 10 $\mathrm{sec})$. During the first $5 \mathrm{~min}$ of reperfusion the hearts were perfused retrogradely. Thereafter, the left atrial cannula was opened and hearts were allowed to eject during the remainder of the reperfusion period. Since the hearts were perfused in the assisted mode (see chapter 3) coronary perfusion pressure was maintained even when reperfused hearts were unable to provide their own coronary flow. Additional experiments were performed on hearts that were freeze clamped after 5 min of reperfusion following $60 \mathrm{~min}$ of no-flow ischemia $(n=8)$.

\section{Biochemical analysis}

Throughout the experimental protocol the coronary effluent was collected and sampled. At the end of the experiments ventricular tissue was separated from the heart and immediately frozen between aluminum $\mathrm{clamps}$ that were cooled in liquid nitrogen. Tissue and effluent samples were stored at $-80^{\circ} \mathrm{C}$ until analysis.

Tissue: Small aliquots of the deeply frozen tissue were freeze dried and extracted with perchloric acid as described previously (chapter 3). Tissue contents of adenine and guanine nucleotides, IMP, nucleosides, oxypurines, NAD (oxidized form) were determined by high performance liquid chromatography (Varian Vista 5500 HPLC) according to a modification of the method of Wynants and Van Belle (1985). A $10 \mu 1$ sample of the neutralized extract was applied to the pre-column (LiChroCART 4-4, Merck) and reversed phase LiChrosorb RP-18 column (stainless stee1, narrow-bore, $250 \times 4 \mathrm{~mm} 1 . \mathrm{d}$., Merck) by means of a loop valve injector (Valco). The column was thermostabilized at $25{ }^{\circ} \mathrm{C}$ using a water jacket. Stepwise gradient elution ( flow speed $0.8 \mathrm{ml}^{\mathrm{min}}{ }^{-1}$ ) using two solvents was applied to separate the compounds of interest. Solvent $A$ consisted of an aqueous buffer of $\mathrm{NH}_{4}\left(\mathrm{H}_{2} \mathrm{PO}_{4}\right)(150 \mathrm{mM}, \mathrm{pH}=6.0)$ prepared by mixing appropriate 
volumes of $\mathrm{H}_{3} \mathrm{PO}_{4}$ and $\mathrm{NH}_{4} \mathrm{OH}$ solutions. Solvent $\mathrm{A}$ was prepared daily and filtered through a cellulose acetate filter $(0.2 \mu \mathrm{m})$ before use. Solvent $B$ consisted of a 1:1 mixture (by volume) of acetonitrile and methanol. Each run started with a 6 min elution period of $100 \%$ A. From 6 to 11 min A was reduced to $95 \%$ and $B$ increased to $5 \%$. From 11 to 27 min $A$ was further reduced to $85 \%$ and, hence, $B$ was increased to $15 \%$. At $t=27$ min $A$ was brought back to $100 \%$ within $2 \mathrm{~min}$. Thereafter, the column was re-equilibrated with $100 \%$ a for 15 min. Peaks were detected at $254 \mathrm{~nm}$ using a UV detector (Varian UV-200, flow ce11 4.5 w1, path length $4 \mathrm{~mm}$, spectral band width $5 \mathrm{~nm}$ ). Sensitivity used was 0.005 AUFS at a time constant of $0.5 \mathrm{~s}$. Analogue signals were transposed and stored on a Varian DS 604 Data System. Peaks were identified by comparing retention times with known standards, by co-elution with known standards and using the enzymatic peak-shift method. Separation of GMP and uric acid was often incomplete. The 111-separated peaks were treated as one peak representing uric acid. As a consequence the tissue content of uric acid will slightiy be overestimated. Creatine phosphate, lactate and glycogen were determined as described by Van der Vusse and coworkers (1984b). Inorganic phosphate was determined with the use of an automated colorimetric assay according to Vam Belle (1970). The tissue water content was measured by lyophilization (overnight, $-30^{\circ} \mathrm{C}$ ) of an aliquot of the deeply frozen tissue.

Coronary effluent: Lactate dehydrogenase activity was measured spectrophotometrically according to Bergmeyer and Bernt (1974). Lactate concentration in the effluent samples was determined with the use of a Technicon autoanalyzer (Apstein et a1., 1970). Since it is generally accepted that the release of nucleotides into the effluent is negligible following ischemia, a faster and less cumbersome isocratic HPLC procedure, a modification of the method of Harmsen and colleagues (1981), was applied to monitor the content of nucleosides and oxypurines in the effluent. The elution buffer consisted of a mixture of 10 volumes of $\mathrm{NH}_{4}\left(\mathrm{H}_{2} \mathrm{PO}_{4}\right)(10 \mathrm{mM})$ and 1 volume of methanol. The $\mathrm{pH}$ was adjusted to 5.5 with a $2.5 \% \mathrm{NH}_{4} \mathrm{OH}$ solution $(w / v)$. Samples (50 $\mu 1$ ) were eluted at a flow speed of $1.5 \mathrm{ml} . \mathrm{min}^{-1}$ using a uBondapak/ $\mathrm{C}_{18}$ column ( $300 \times 4 \mathrm{~mm}$ 1.d., Waters Assoc.). Total run time was 15 min. Operating sensitivity was 0.01 AUFS at a time constant of $0.5 \mathrm{~s}$. During the first 3.5 min absorbance was measured at 293 nm (absorbance maximum of uric acid). Thereafter, the UVdetector swltched automatically to $254 \mathrm{~mm}$ for detection of the other peaks. 


\section{Statistical analysis}

Results are expressed as mean values and standard deviations. Differences between groups and within groups were tested for significance using student's $t$ test for unpaired and paired data, respectively. The Pearson correlation coefficient $(r)$ was used to estimate the strength of the relation between two variables. Linear regression was performed with the least-squares method. $p$ values less than 0.05 were considered to be statistically significant.

\subsection{Results}

Cardiac Hemodynamics.

During extended normoxic perfusion hearts were able to maintain hemodynamic function almost at the initial baseline level. After 120 min of perfusion left ventricular systolic pressure (LVSP) had not changed and the reduction of cardiac output ( $C O)$ was negligible.

Restoration of flaw following 30 and 45 min of no-flow ischemia was associated with a marked hyperemic response. During the first 5 minutes coronary

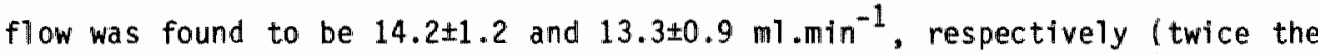
flow of normoxic perfused Langendorff hearts, i.e. about $7 \mathrm{ml} . \mathrm{min}^{-1}$ ). At the end of reperfusion coronary flow was comparable to the pre-ischemic values (fig 4.1, middle panel). Recowery of hemodynamic function was rapid and nearly complete. Heart rate (fig 4.1 , upper panel) and LVSP returned to control values. Cardiac output returned to $96 \%$ and $92 \%$ of its pre-ischemic value, following 30 and $45 \mathrm{~min}$ of ischemia, respectively (fig 4.1 , lower panel). Reperfusion following $60 \mathrm{~min}$ of ischemia was associated with considerable impairment of myocardial function. Only a moderate hyperemic response was observed $\left(9.2 \pm 2.3 \mathrm{ml} . \mathrm{min}^{-1}\right.$ during the first $\left.5 \mathrm{~min}\right)$. As compared to the preischemic value coronary flow tended to be reduced at the end of reperfusion, but this difference did not reach the level of significance. All hearts fibrillated during the initial reperfusion phase. After 30 min of reperfusion 9 out of 16 (56\%) hearts had been able to restore normal electrical activity. Recovery of hemodynamic function was slow and incomplete in this subgroup. The end-diastolic pressure remained elevated $(+76 \%)$ and LVSP and CO were found to be reduced to $93 \%$ and $68 \%$ of their pre-ischemic values, respectively. Heart 


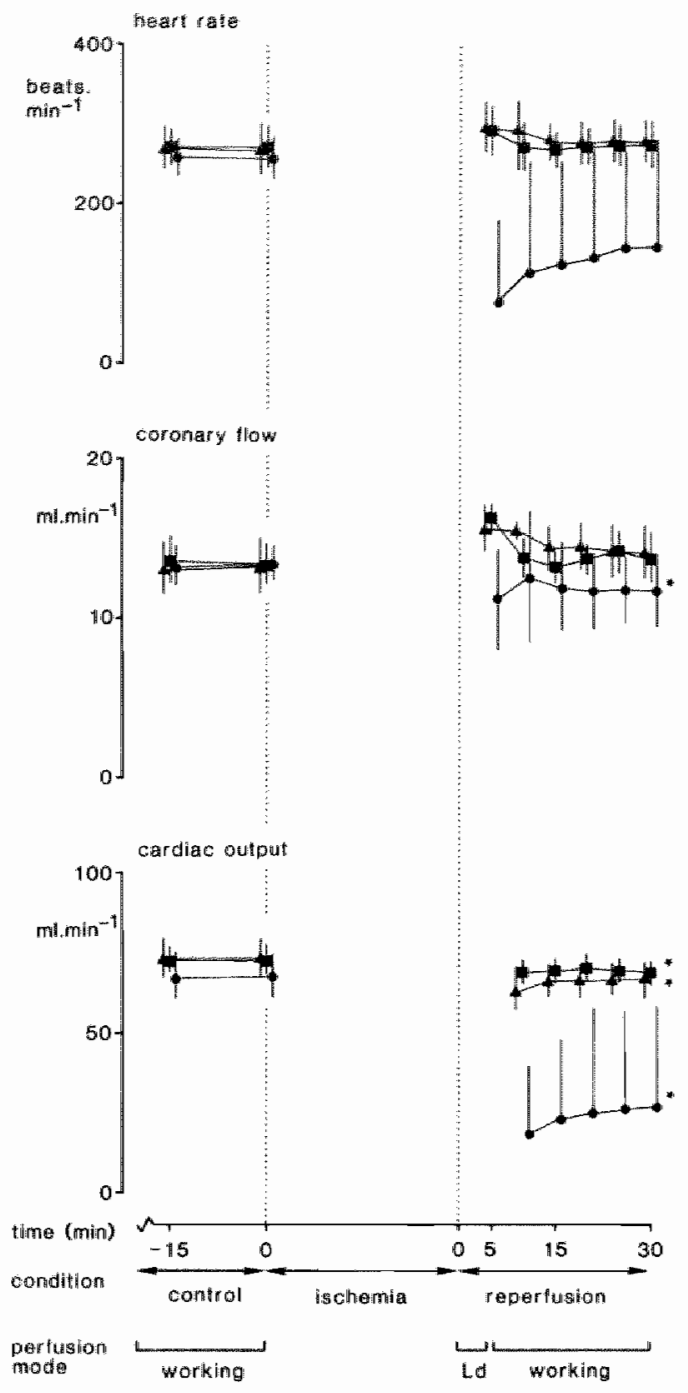

Fig 4.1 Recovery of heart rate (upper panel), coronary flow (middle panell), and cardiac output (lower panel) follawing 30 ( $\mathbf{E}), 45$ ( $\Delta$ ) and 60 ( ) min of no-flow ischemia of isolated rat hearts. Ld refers to perfusion according to Langendorff. Data expressed as means \pm SD. Asterisk indicates significantly different $(p<0.05)$ from pre-ischemic value. 
rate returned to pre-ischemic values.

\section{Tissue water content.}

During the first $45 \mathrm{~min}$ of no-flow ischemia the tissue water content gradually decreased (table 4.1). At larger duration of ischemia the tissue water content remained constant. The tissue water content returned to pre-ischemic values in hearts reperfused after 30 and $45 \mathrm{~min}$ of ischemia. In contrast, reperfusion after 60 min of ischemia was associated with a markediy elevated tissue water content.

Table 4.1 The effect of no-flow ischemia and reperfusion on the percentage wet weight and the tissue contents of lactate, glycogen, inorganic phosphate and creatine phosphate. Reperfusion, if applied, lasted for $30 \mathrm{~min}$.

\begin{tabular}{|c|c|c|c|c|c|}
\hline & $\begin{array}{l}\text { \& wet } \\
\text { weight }\end{array}$ & lactate & glycogen & $\begin{array}{l}\text { inorganic } \\
\text { phosphate }\end{array}$ & $\begin{array}{l}\text { creatine } \\
\text { phosphate }\end{array}$ \\
\hline Pre-ischemia & $83.70 \pm 1.75$ & $10.5 \pm 6.9$ & $100.4 \pm 21.9$ & $33.8 \pm 8.0$ & $30.5 \pm 10.8$ \\
\hline $10 \mathrm{~min}$ ischerita & $82.34 \pm 1.50$ & $75.4 \pm 5.9^{\mathrm{a}}$ & $76.1 \pm 12.4^{\mathrm{a}}$ & $64.4 \pm 5.1^{a}$ & $7.5 \pm 3.2^{\mathrm{a}}$ \\
\hline 30 min ischemia & $80.96 \pm 0.68^{a}$ & $154.2 \pm 21.4^{a}$ & $72.2 \pm 24.3^{a}$ & $77.3 \pm 6.5^{\mathrm{a}}$ & $9.5 \pm 5.3^{\mathrm{a}}$ \\
\hline+ reperfusion & $84.17 \pm 0.99^{b}$ & $18.5 \pm 6.5^{\mathrm{ab}}$ & $96.8 \pm 13.7^{b}$ & $39.5 \pm 7.7^{b}$ & $32.0 \pm 13.1^{\mathrm{b}}$ \\
\hline 45 min ischemia & $79.01 \pm 1.03^{a}$ & $180.6 \pm 24.2^{a}$ & $65.7 \pm 15.6^{a}$ & $97.9 \pm 16.2^{2}$ & $5.2 \pm 1.0^{a}$ \\
\hline + reperfusion & $84.88 \pm 0.85^{b}$ & $16.7 \pm 12.1^{b}$ & $73.2 \pm 27.4^{a}$ & $38.8 \pm 5.2^{b}$ & $33.5 \pm 7.7^{\mathrm{b}}$ \\
\hline $60 \mathrm{~min}$ ischemia & $79.08 \pm 1.59^{\mathrm{a}}$ & $213.7 \pm 26.3^{\mathrm{a}}$ & $50.1 \pm 20.0^{\mathrm{a}}$ & $90.3 \pm 12.2^{\mathrm{a}}$ & $5.1 \pm 2.4^{\mathrm{a}}$ \\
\hline+ reperfusion & $86.26 \pm 0.73^{\mathrm{abb}}$ & $17.2 \pm 11.4^{\mathrm{b}}$ & $55.3 \pm 19.5^{a}$ & $53.0 \pm 18.7^{\mathrm{ab}}$ & $28.6 \pm 2.7^{b}$ \\
\hline 90 min ischemia & $78.52 \pm 1.28^{\mathrm{a}}$ & $175.2 \pm 52.2^{a}$ & $23.1 \pm 9.9^{\mathrm{a}}$ & $98.8 \pm 7.2^{a}$ & $4.2 \pm 2.6^{\circ}$ \\
\hline $\begin{array}{l}\text { The content of } \\
\text { pressed as umol } \\
\text { significantly d } \\
\text { different from t } \\
\text { of the ischemic }\end{array}$ & $\begin{array}{l}\text { tabolltes is } \\
\text { jcose umits. } 9 \\
\text { cerent from } \\
\text { values meast } \\
\text { lod. }\end{array}$ & $\begin{array}{l}\text { pressed as } \\
\text { dry wt of } t \\
\text { - I schemitc }\end{array}$ & . $g^{-1}$ dry & $\begin{array}{l}\text { thssue. } \\
\text { means } \\
\text { indicates }\end{array}$ & $\begin{array}{l}\text { ogen is ex- } \\
\text { a indicates } \\
\text { inificantly }\end{array}$ \\
\hline
\end{tabular}


Table 4.2 The effect of no-flow ischemil and reperfuston on the tissue content of GTP, GOP, IMP and MAD*

\begin{tabular}{|c|c|c|c|c|}
\hline \multirow[b]{2}{*}{ pre-ischemia } & \multirow{2}{*}{$.3 \pm 0.1$} & \multirow{2}{*}{ GOP } & \multirow{2}{*}{ IAPP } & \multirow{2}{*}{$3.7 \pm 0.3$} \\
\hline & & & & \\
\hline $10 \mathrm{~min}$ ischemia & $0.9 \pm 0.2^{\mathrm{a}}$ & $0.5 \pm 0.1$ & $0.4 \pm 0.3^{\mathrm{a}}$ & $2.9 \pm 0.1^{a}$ \\
\hline 30 mitn is schemita & $0.7 \pm 0.4^{8}$ & $0.5 \pm 0.3$ & $0.6 \pm 0.4^{a}$ & $2.9 \pm 0.4^{a}$ \\
\hline + reperfusion & $1.1 \pm 0.1^{\mathrm{a}}$ & $0.4 \pm 0.1$ & $0.0 \pm 0.0^{b}$ & $3.7 \pm 0.2$ \\
\hline $45 \mathrm{~min}$ ischemia & $0.440 .1^{a}$ & $0.3 \pm 0.1^{a}$ & $0.6 \pm 0.3^{\mathrm{a}}$ & $3.1 \pm 0.2^{a}$ \\
\hline + reperfusion & $0.9 \pm 0.3^{\mathrm{ab}}$ & $0.3 \pm 0.1$ & $0.2 \pm 0.2^{b}$ & $3.4 \pm 0.4$ \\
\hline 60 miln Ischemia & $0.4 \pm 0.2^{2}$ & $0.3 \pm 0.1$ & $0.8 \pm 0.4^{a}$ & $3.1 \pm 0.4^{\mathrm{a}}$ \\
\hline+ reperfuston & $0.7 \pm 0.2^{\mathrm{ab}}$ & $0.4 \pm 0.1$ & $0.3 \pm 0.3^{b}$ & $3.4 \pm 0.4$ \\
\hline 90 min ischemfa & $0.2 \pm 0.1^{\mathrm{a}}$ & $0.4 \pm 0.1$ & $1.0 \pm 0.2^{\mathrm{a}}$ & $2.7 \pm 0.4^{\mathrm{a}}$ \\
\hline \multicolumn{5}{|c|}{$\begin{array}{l}\text { Data expressed as } \mu \text { mol. } \mathrm{g}^{-1} \text { dry wt of tissue (means } \pm \text { SO). } \\
\text { Reperfuston, if applied, lasted for } 30 \mathrm{~min} \text {. a indicates } \\
\text { slignificantly different from pre-ischemic values }(p<0.05) \text {. b } \\
\text { indicates significantly different from values measured at the } \\
\text { end of the ischemic period. }\end{array}$} \\
\hline
\end{tabular}

Enzym rellease.

Release of lactate dehydrogenase (LDH) was maximal between 5 and 10 min of reperfusion. Following 30 and $45 \mathrm{~min}$ of ischemia no significant release of LDH was observed during the last $10 \mathrm{~min}$ of reperfusion, indicating that release of LDH was completed within $20 \mathrm{~min}$ (data not shown). Following $60 \mathrm{~min}$ of ischemia, a small but significant release of LDH was still observed during this period. The cumulative release of LDH was related to the time duration of the preceding ischemic period (table 4.3). 
Table 4.3 Cumulatiwe release of purines, lactate and lactate dehyrdrogenase (LOH) during 30 min of reperfusion following a pertod of no-flow ischemia .

Cumulative release during $30 \mathrm{~min}$ of reperfustion

\begin{tabular}{|c|c|c|c|}
\hline & $\begin{array}{l}\text { purines } \\
\text { umol heart }\end{array}$ & $\begin{array}{l}\text { lactate } \\
\text { Hmot heart }\end{array}$ & $\begin{array}{c}\text { LDH } \\
\text { unfts heart }\end{array}$ \\
\hline \multicolumn{4}{|c|}{ preceding } \\
\hline \multicolumn{4}{|c|}{ is schemic } \\
\hline \multicolumn{4}{|l|}{ episode } \\
\hline \multirow[t]{2}{*}{$30 \mathrm{~min}$} & $1.29 \pm 0.49$ & $72.6 \pm 6.5$ & $3.5 \pm 1.0$ \\
\hline & $(0.94)$ & $(19.6)$ & $(2,5)$ \\
\hline \multirow[t]{2}{*}{$45 \mathrm{~min}$} & $1.95 \pm 0.34$ & $86.4 \pm 6.3$ & $9.7 \pm 2.5$ \\
\hline & $(1.34)$ & $(31.0)$ & $(8.5)$ \\
\hline \multirow[t]{2}{*}{$60 \mathrm{~min}$} & $2.65 \pm 0.46$ & $105.8 \pm 17.2$ & $22.0 \pm 7.5$ \\
\hline & $(2.24)$ & $(50.6)$ & $(20.6)$ \\
\hline \multicolumn{4}{|c|}{$\begin{array}{l}\text { Data are expressed as means } \pm S D \text {. Purine release is defined as the sum of } \\
\text { the release of adenosine, inosine, hypoxanthine, xanthine and uric acid. } \\
\text { Data in parentheses refer to the average cumulative release, when corrected } \\
\text { for basal release, as measured during the last } 15 \text { minutes of the pre-ische- } \\
\text { mic period. }\end{array}$} \\
\hline
\end{tabular}

\section{Lactate and glycogen.}

Ischemia resulted in a rapid increase in the tissue content of lactate (table 4.1). Extending the duration of the preceding ischemic period was associated with an increase in the cumulative release of lactate (table 4.3). Peak release was enhanced following longer periods of ischemia and was found to be $5.7 \pm 0.4,7.7 \pm 0.8$ and $9.0 \pm 1.1 \mu \mathrm{mol} . \mathrm{min}^{-1}$ during the first $5 \mathrm{~min}$ of reperfusion following 30,45 and $60 \mathrm{~min}$ of ischemia, respectively. Following 30 and $45 \mathrm{~min}$ of ischemia lactate release returned to pre-ischemic values within $10 \mathrm{~min}$ of reperfusiom. Following $60 \mathrm{~min}$ of ischemia lactate release was 
prolonged. At the end of reperfusion, following 30, 45 as well as 60 min of ischemia, the tissue content of lactate was not significantly different from the pre-ischemic value (table 4.1 ).

During ischemia the tissue glycogen content gradually declined. Reperfuston following $30 \mathrm{~min}$ of ischemia was associated with normalization of the myocardial content of glycogen. Following 45 and 60 min of ischemia hearts were unable to replenish their glycogen stores during reperfusion (table 4.1).

Creatine phosphate and inorganic phosphate.

Within 10 min of ischemia the myocardial creatine phosphate content was reduced to less than $25 \%$ of its pre-1schemic value and an $7 y$ slowly decreased thereafter (table 4.1). The inorganic phosphate content increased almost 3 fold during the first 45 min of 1 schemia and remained relatively constant thereafter (table 4.1).

At the end of reperfusion, following 30,45 and $60 \mathrm{~min}$ of ischemia, tissue

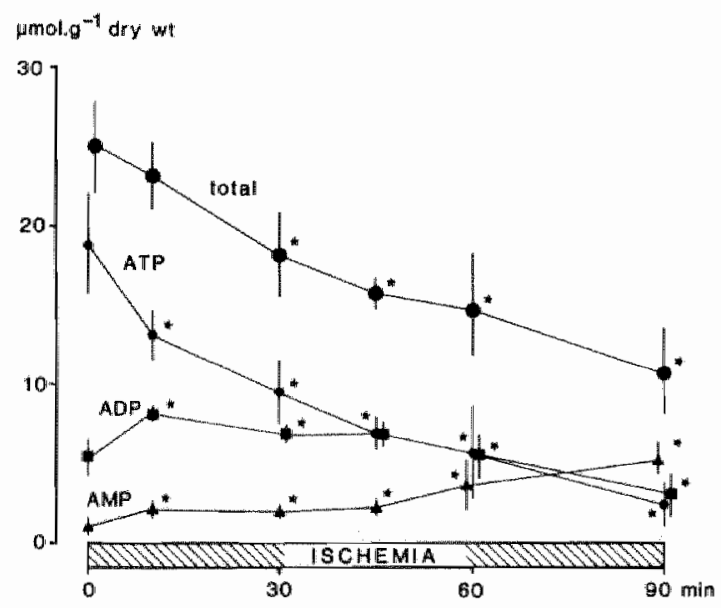

Fig 4.2 Time course of changes in the tissue content of ATP, ADP and AMP and the sum of adenine nucleotides during 90 minutes of no-flow ischemia. Data expressed as means \pm SO. Asterisk indicates significantiy different $(p<0.05)$ from pre-ischemic walue. 
levels of creatine phosphate were completely restored. At the end of reperfusion following 30 and 45 min of ischemia the myocardial content of inorganic phosphate had returned to pre-ischemic values. In contrast, in hearts subjected to 60 min of ischemia followed by reperfusion the control wal wes were not reached (table 4.1 ).

Purine nucleotide metabolism.

During early ischemia the decline in ATP was associated with a transient increase in ADP and doubling of the AMP level (fig 4.2). AMP further increased after 45 min of ischemia. After $90 \mathrm{~min}$ of ischemia the total adenine nucleotide content was reduced to $43 \%$ of its pre-ischemic value and AMP represented almost $50 \%$ of the adenine nucleotide poo1.

Like the adenine nucleotides, guanine nucleotides were degraded during ischemia (table 4.2). The rate of depletion of GTP paralleled that of ATP. Like ADP, the myocardial GDP content showed a transient increase. Due to

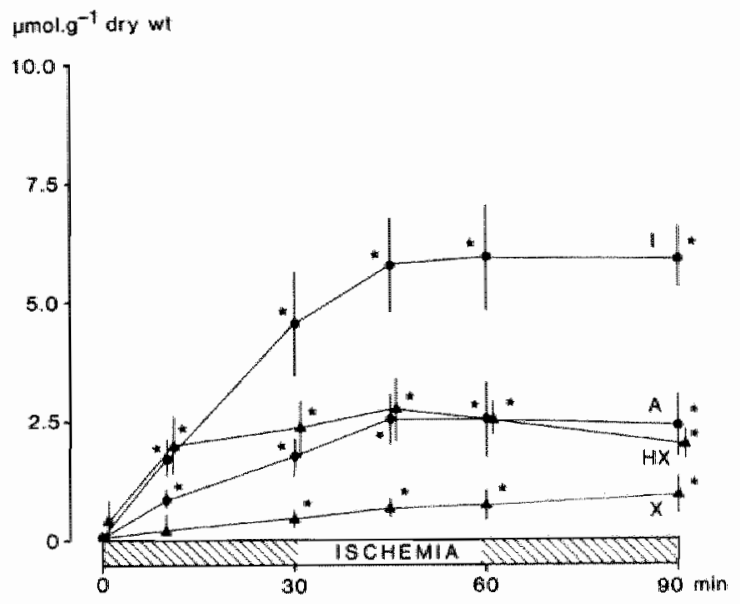

Fig 4.3 Time course of accumulation of nucleosides and purine bases during 90 min of no-flow ischemia. A refers to adenosine, I to inosine, $H X$ to hypoxanthine and $X$ to xanthine. Data expressed as means \pm SD. Asterisk indicates significantly different $(p<0.05)$ from pre-ischemic value. 
analytical imperfections (see methods) the time course of changes in the GMP content could not be evaluated properly. Only small amounts of IMP were found to accumulate in the ischemic tilssue. A significant decrease in NAD $^{+}$was observed during the first $10 \mathrm{~min}$ of ischemia. Thereafter $N A D^{+}$remained relatively constant (table 4.2 ).

As shown in fig 4.3 the reduction of purine nucleotides was associated with the accumulation of nucleosides and oxypurines. On a quantitative base inosine was by far the most prominent degradation product. Adenosine and hypoxanthine a1so accumulated in appreciable amounts, whereas xanthine was only present in minor amounts. The rise in the tissue content of uric acid was estimated to be $0.5 \mu \mathrm{mol} \cdot \mathrm{g}^{-1}$ dry wt during $90 \mathrm{~min}$ of ischemia. Taking into account that the estimated value is most likely overestimated (see method section), uric acid contributed only slightly to the total amount of degradation products accumulated. During the first $45 \mathrm{~min}$ of ischemia the myocardial content of nucleosides and oxypurines rapidly increased (fig 4.3). Thereafter, the tissue levels of the individual purines showed no significant changes.

The total amount of adenine nucleotides, measured at the end of reperfusion follawing 30,45 and $60 \mathrm{~min}$ of ischemia, was comparable to the sum of adenine nucleotides present at the end of the respective ischemic period (table 4.4). However, ATP partially restored at the expense of ADP and AMP. As a consequence, the adenylate energy charge significantly improved. Similariy, the level of GTP partially restored during reperfusion (table 4.2 ). Only small amounts of nucleosides and oxypurines were found to reside in the tissue after $30 \mathrm{~min}$ of reperfusion (not significantly different from pre-ischemic value; data not shown).

Appreciable amounts of purine nucleotide degradation products were released into the coronary effluent during reperfusion (table 4.3). Extending the duration of the preceding ischemic period resulted in an enhanced release of those substances. The qualitative and quantitative aspects of the release of individual nucleosides and oxypurines are illustrated in figure 4.4 , using hearts subjected to $60 \mathrm{~min}$ ischemia and $30 \mathrm{~min}$ reperfusion. Relatively small amounts of adenosine were released into the coronary effluent and the release was completed within $15 \mathrm{~min}$ of reperfusion. In contrast, release of inosine was very pronounced and lasted longer. The amounts of hypoxanthine and xanthine released during reperfusion were comparable. Release of uric acid was markediy enhanced during the initial reperfusion phase and returned to control 
Table 4.4 The tissue content of ATP, AOP and AMP and the energy charge of isolated rat hearts made ischemic for 30,45 and $60 \mathrm{~min}$ and in hearts reperfused for $30 \mathrm{~min}$ following 30,45 and $60 \mathrm{~min}$ of ischew mia, respectively.

\begin{tabular}{l} 
ATP \\
\cline { 2 - 4 }
\end{tabular}

values thereafter. Table 4.5 demonstrates that the cumulative release of adenosine and hypoxanthine was less than expected on the basis of the tissue content of adenosine and hypoxanthine at the end of ischemia. In contrast, the cumulative release of xanthine and uric acid was found to be larger than the amounts accumulating at the end of ischemia.

\section{Electrical behavior of reperfused hearts.}

As indicated above, 30 min of reperfusion following 60 min of ischemia was associated with severe electrical instability. Despite perfusion as assisted hearts, 7 out of 16 hearts failed to resume spontaneous beating. To investi- 
gate if this behavior was associated with some underlying metabolic disorder, this group was divided in a retrospective manner into three subgroups according to their electrical behavior. The first subgroup consisted of hearts that resumed regular rhythm within the first 5 min of reperfusion, the second subgroup of hearts that were able to do so between 5 and $30 \mathrm{~min}$ of reperfusion, and the third subgroup included hearts that failed to recover electrically within 30 min of reperfusion. The hearts that were subjected to 60 min of ischemia and freeze clamped after 5 minutes of reperfusion were divided into two subgroups: those that were able to regain normal rhythm within 5 min and those that were not.
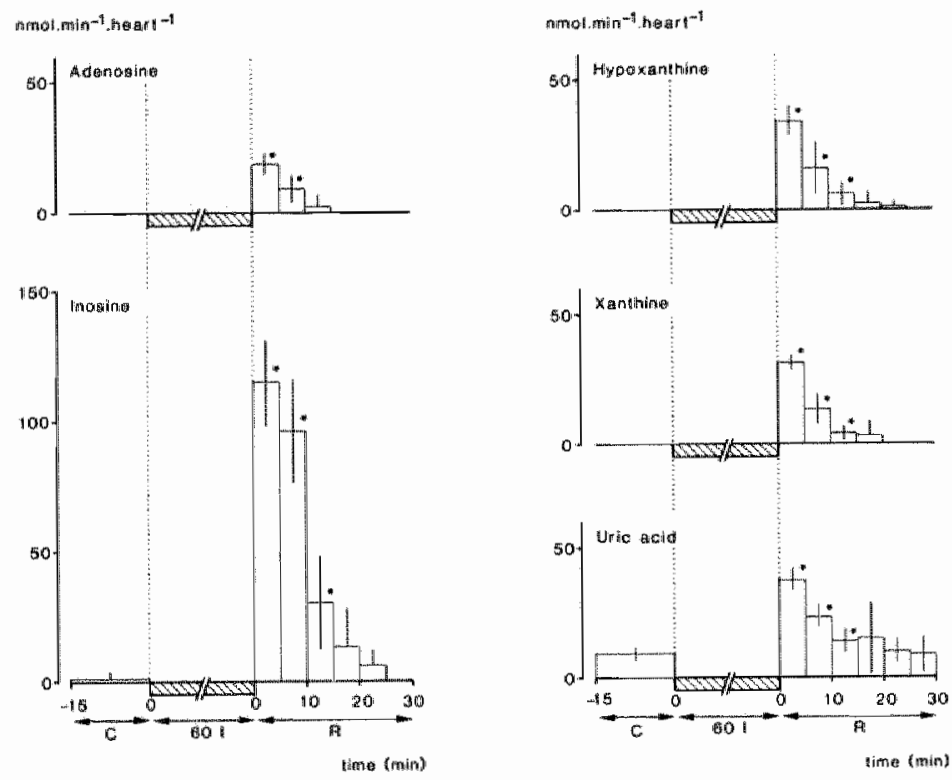

Fig 4.4 Release of nucleosides and axypurines from isolated rat hearts during control perfusion $(C)$ and during reperfuston (R) following $60 \mathrm{~min}$ of no-flow ischemia $(60 \mathrm{I})$. Bars refer to the release per min per heart as measured in the coronary effluent fractions collected over the indicated time periods. Data expressed as means \pm SD. Asterisk indicates signifficantly different $(p<0.05)$ from pre-ischemic value. 
Table 4.5 The tissue content of individual purines at the end of 60 min of no-flaw ischemia, and the cumulative release of these metabolites during subsequent $30 \mathrm{~min}$ of reperfusion.

\begin{tabular}{|c|c|c|}
\hline \multirow[b]{2}{*}{ Adenosine } & \multirow{2}{*}{$\begin{array}{l}\text { tissue content } \\
\text { (umol } .9^{-1} \text { wet } \\
0.50 \pm 0.16\end{array}$} & \multirow{2}{*}{$\begin{array}{l}\text { cumulative release } \\
\text { (umol. } \mathrm{g}^{-1} \text { wet } \\
0.14 \pm 0.05^{\mathrm{c}}\end{array}$} \\
\hline & & \\
\hline Inosine & $1.18 \pm 0.23$ & $1.29 \pm 0.18$ \\
\hline Hypoxanthine & $0.51 \pm 0.08$ & $0.29 \pm 0.10^{C}$ \\
\hline Xanthine & $0.15 \pm 0.07$ & $0.25 \pm 0.07^{\mathrm{C}}$ \\
\hline Uric Acid & $0.08 \pm 0.06$ & $0.26 \pm 0.14^{c}$ \\
\hline total & $2.34 \pm 0.46$ & $2.23 \pm 0.48$ \\
\hline \multicolumn{3}{|c|}{$\begin{array}{l}\text { Data refer to means } \pm 50 \text {. In order to express tissue content of purines as } \\
1 \text { mol. } g^{-1} \text { wet wt it was assumed that } 20 \% \text { of the heart consisted of dry } \\
\text { material. Cumul ative release of uric acid during the } 30 \text { min reperfusion } \\
\text { period was corrected for basal release of uric acid, as measured unden } \\
\text { pre-ischemic conditions. Nomoxic release of the other four purines was } \\
\text { negligible during the pre-ischemfc perlod. a indicates significantiy dif- } \\
\text { ferent }(p \times 0.05) \text { from the walue representing the content in the ischenic } \\
\text { tissue. }\end{array}$} \\
\hline
\end{tabular}

As shown in table 4.6 , the energy status of fibrillating hearts, freeze clamped after 5 min of reperfusion, resembled that of hearts freeze clamped at the end of the ischemic period. Only the creatine phosphate content was somewhat increased. The myocardial content of lactate was substantially lower due to partial wash-out of this metabolite. After 5 minutes of reperfusion the energy status of hearts, which were able to restore regular rhythm, was significantly improved, as evidenced by a high energy charge, markedly increased creatine phosphate content, and normalization of the inorganic phosphate content. 
The energy status of fibrlllating hearts, freeze clamped after 30 min of reperfusion was still seriously disturbed. Only a significant reduction ${ }^{\prime \prime}$ ADP and AMP and increase in creatine phosphate were observed, as compared to hearts freeze clamped at the end of ischemia. In contrast, hearts that had been able to resume reguliar rhythm within 5 minutes showed a marked increase in the tissue content of creatine phosphate and ATP and an almost complete restoration of the energy charge, as monitared after $30 \mathrm{~min}$ of reperfusion. The energy status of hearts, which restored regular rhythm after 5 min of reperfusion were comparable to that of rapidly recovering hearts. Glycogen levels in recovering hearts were higher in comparison with those of fibri1lating hearts. During the first $5 \mathrm{~min}$ of reperfusion (release of accumulated lactate) as well as at the end of reperfusion ("basal" lactate production) release of lactate from fibrillating hearts was enhanced. Cumulative release of lactate was found to be $86.5 \pm 7.7$ and $120.3 \pm 8.9$ umol theart $^{-1}$ per 30 min of reperfusion for rapldiy recovering and falling hearts, respectively $(0<0.05)$. In contrast, the cumulative release of LDH was comparable for both groups and amounted to $22.0 \pm 6.8$ and $21.9 \pm 8.8$ units.heart ${ }^{-1}$. Differences in the cumulative rellease of purines were not observed $\left(2.61 \pm 0.54\right.$ and $2.79 \pm 0.46 \mu$ mol.heart ${ }^{-1}$ per $30 \mathrm{~min}$ for rapidly recovering and fibrillating hearts, respectively).

The coronary flow of hearts unable to resume regular rhythm was found to be $7.9 \pm 2.3 \mathrm{ml} . \mathrm{min}^{-1}$ during the first $5 \mathrm{~min}$ of retrograde reperfusion. In contrast, a marked hyperemic response $\left(11.0 \pm 1.2 \mathrm{ml} . \mathrm{min}^{-1}\right)$ was observed in hearts which were able to restore normal electrical activity within the first 5 min of reperfusion.

\subsection{Discussion}

The findings in the present study demonstrate that in the presence of glucose and pyruvate as exogenous substrates, restoration of flow after 30 and 45 min of no-flow ischemia results in adequate hemodynamic recovery, despite the release of measurable amounts of $L D H$ and an appreciable diminution of the myocardial content of ATP. In contrast, reperfusion following 60 min of ischemia is associatied with ventricular fibrillation, marked functional impaiment, substantial release of LDH, and the development of tissue edema. 


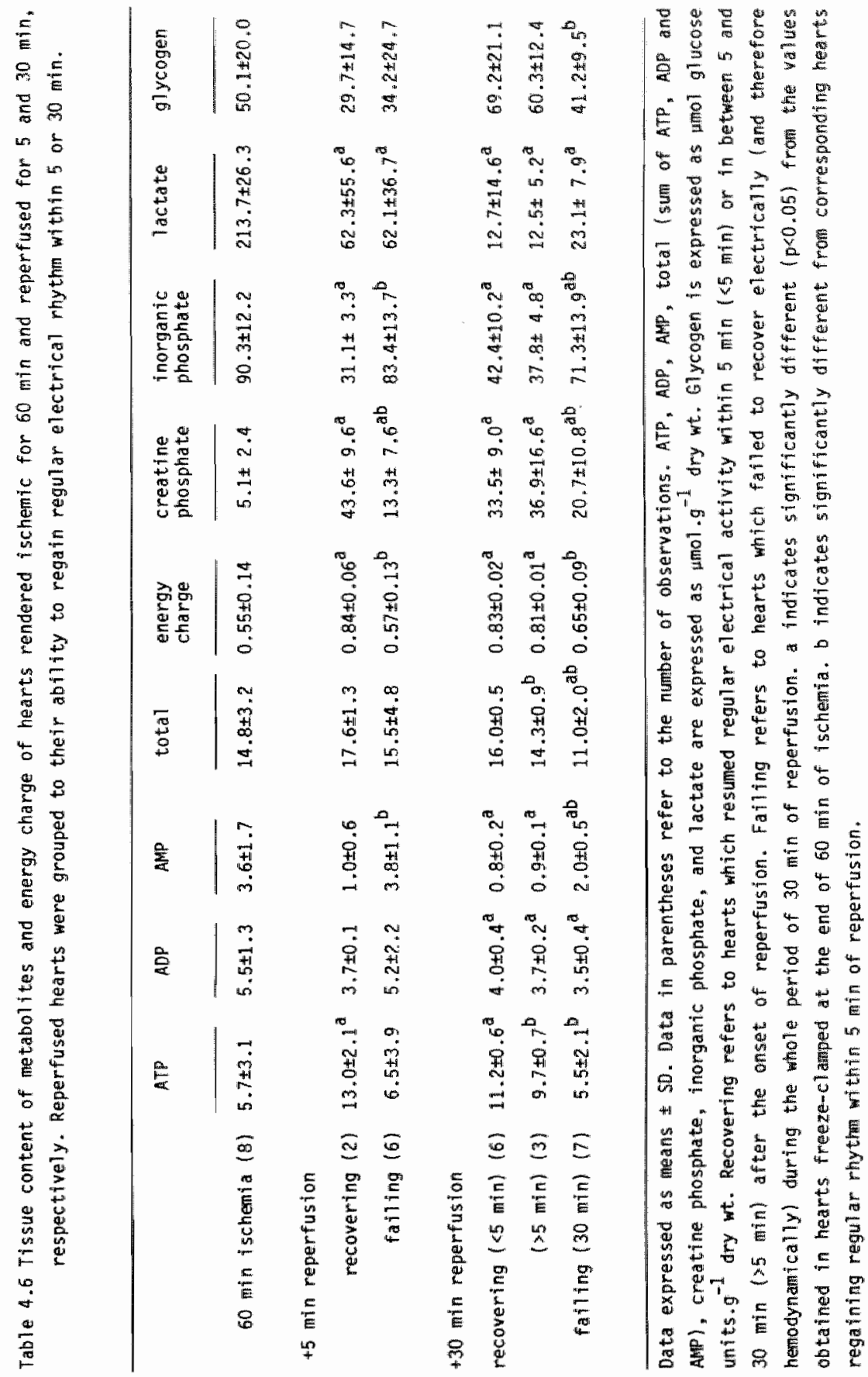


These findings will be discussed in relation to the metabolism of myocardial purines during ischemia and reperfusion.

Metabolic changes during ischemia.

The gradual decline in ATP indicates that anaerobic ATP production is insufficient to meet the energy demands of the non-contracting ischemic myocardium. The significant reduction in the myocardial content of $\operatorname{NAD}^{+}(-22 \%)$, observed after 10 min of ischemia, most likely reflects reduction of NAD $^{+}$to NADH (Klein et al., 1981; Swain et al., 1982), since previous reports have demonstrated that the total cardiac pyridine content only changes after prolonged ischemia (Jennings et a1., 1981; Klein et al., 1981).

During the first $45 \mathrm{~min}$ of ischemia the reduction of the total adenine nucleotide content is associated with a reciprocal increase in the tissue content of nucleosides and oxypurines. After 45 min of ischemia depletion of ATP and ADP is associated with a relatively fast increase in AMP, whereas the myocardial content of nucleosides and oxypurines hardly changes any further.

Based on the average increase of lactate during $45 \mathrm{~min}$ of ischemia (table 4.1) and on the assumption that the production of 1 mole of lactate corresponds to the phosphorylation of at least one mole of ADP, it is estimated that over $145 \mu \mathrm{mol} . \mathrm{g}^{-1}$ dry wt of ATP is produced anaerobically during this period. At the same time the myocardial content of adenine nucleotide degradation products is found to increase by about $11 \mu \mathrm{mol} . \mathrm{g}^{-1} \mathrm{dry}$ wt. So, from a kinetic point of view, during ischemia the degradation of adenine nucleotides is still minor as compared with the rate of de- and re-phosphorylation of ATP.

AMP formation during ischemia is considered to be mediated by the action of adenylate kinase (Reimer and Jennings, 1981c). However, AMP formation through activation of non-esterified fatty acids, has to be considered as well, since the turnover of endogenous lipid pools might be substantial (Chien et al., 1984; Trach et al., 1986). The absence of accumulation of appreciable amounts of IMP has been taken as evidence that not the deamination to IMP and subsequent dephosphorylation, but rather the direct dephosphorylation of AMP, yielling adenosine, is the main pathway involved in the degradation of adenine nucleotides (Jennings et al., 1981; Swain et al., 1982; see also fig 4.5). However, recently Achterberg and coworkers (1985) provided evidence that up to $40 \%$ of the purines formed during ischemia are not derived from the direct conversion of AMP to adenosine and suggested a significant contribution of IMP 
breakdown to purine formation.

During the first $45 \mathrm{~min}$ of ischemia, conversion of AMP into adenosine is apparently not hampered. Thereafter, AMP starts to accumulate in appreciable amounts, suggesting that endo-5'-nucleotidase, the enzyme most likely responsible for the dephosphorylation of AMP during ischemia (Schutz et a1. 1981). is inhibited. However, it has been shown that $5^{\prime}$-nucleotidase activity is increased at lower ATP concentrations (Naito and Lowenstein, 1981). It could be speculated that the AMP, accumulating during this phase, is confined to a compartment distinct from the localization of $5^{\prime \prime}$-nucleatidase. The possible consequences of the rise in the cellular AMP content for the turnover of phospholipids will be discussed in chapter 5. Following $45 \mathrm{~min}$ of ischemia the tissue contents of adenosine, inosine, hypoxanthine and xanthine remain virtually constant. The absence of flux through this pathway might be related to the specific localization of the enzymes involved (see fig 4.5), in combination with a limited diffusion rate during no-flow ischemia. For instance, the enzymes nucleoside posphorylase and xanthine oxidoreductase are localized in the endothelium exclusively. Alternatively, the inhibited flux might result from inhibition of (one of) the enzymes involved (product inhibition, depletion of co-factors). For instance, inhibition of xanthine oxidoreductase activity is feasible since this enzyme is likely to be converted to its oxidase form during ischemia (Chambers et all., 1985), and therefore becomes obligatory oxygen dependent.

Metabolic changes during reperfusion.

During reperfusion following 30,45 and $60 \mathrm{~min}$ of ischemia the tissue content of accumulated products (nucleosides, oxypurines, lactate) normalizes. Therefore, local areas of no-reflow and, hence, sustained ischemia, are not 1 ikely to be present at the end of reperfusion. The present findings indicate that restoration of flow not only results in the wash-out of the accumulated purines, but also relieves the inhibition of metabolic flux of purines, as evidenced by the quantitative differences in the tissue content of individual purines at the end of ischemia, on the one hand, and the cumulative amount of the individual purines released into the coronary effluent during subsequent reperfusion, on the other (see table 4.5). If the production of xanthine and uric acid during reperfusion is indeed catalyzed by the axidase form of xanthine oxidoreductase, then the production of substantial amounts of reactive 
oxygen species has to be anticlpated (fig 4.5). Using the data of table 4.4 it is estinctived that the total production amounts to $0.46 \mu$ mol. $g^{-1}$ wet wt during reperfuston following 60 min of ischemla. The pattern af release of the oxypurines indicates that the majority of these compounds is produced in the initial reperfusion phase (see fig 4.4). Hence, a burst in the formation of reactive oxygen species could well contribute to the development af reperfusion damage (Jolly et al., 1984; Chambers et al., 1985). The possible consequences of this process in the induction of lipidperoxidation and, hence,

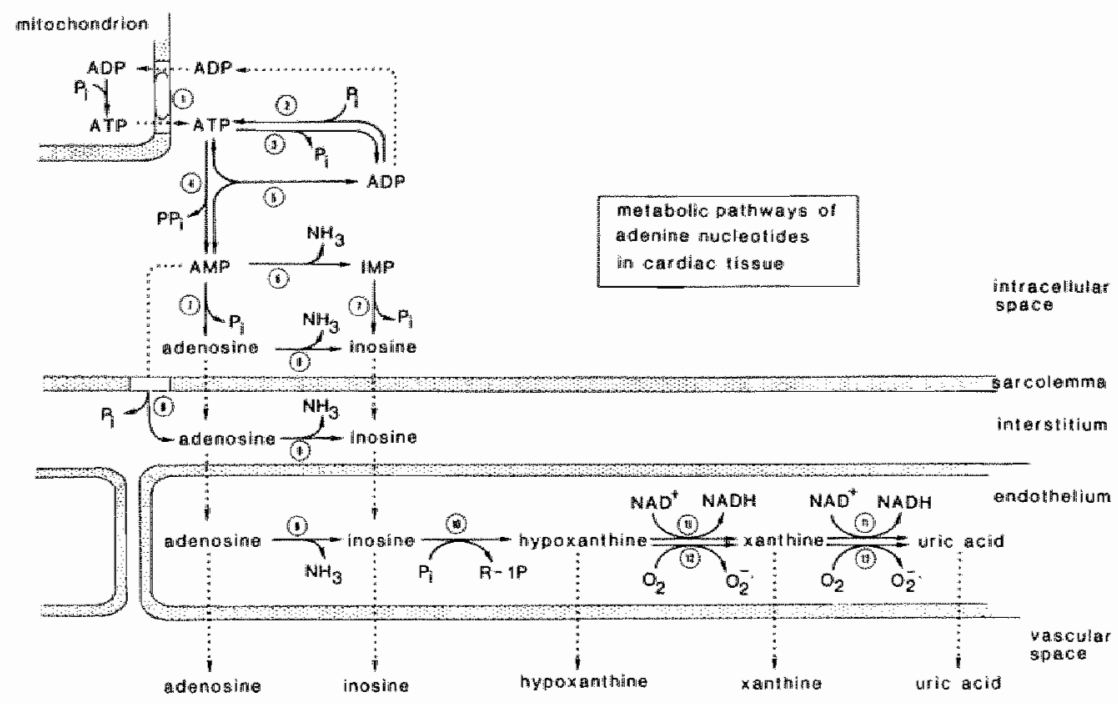

Fig 4.5 Major pathways involved in the degradation of adenine nucleatides. The enzymes involved and their localization are also shown. Dotted lines indicate transport of substances. $P_{i}$ refers to inorganic phosphate, $P P_{1}$ to pyrophosphate, $R-1 P$ to ribose-1-phosphate, and $0_{2}{ }^{-}$ to superoxide anton. (1) adenine nucleotide trainslocase, (2) glycolytic ATP production, (3) energy requiling processes, (4) pyrophosphate forming enzymes, (5) adenylate kinase, (6) AMP-deaminase, (7) endo-5'-nucleotidase, (8) ecto-5'-nucleotidase, (9) adenosine deaminase, (10) nucleoside phosphorylase, (11) xanthine dehydrogenase, and (12) xanthine oxidase. 
membrane damage remains to be established ffor review see Meerson et al." 1982). In this regard it is interesting to recall that the enzyme responsible, i.e. xanthine oxidoreductase, is located in the endothellum exclusively (Gerlach et al., 1985).

Referring only to non-fibrillating hearts (fibrillating hearts will be discussed in next section), the present findings indicate that reperfusion after both 30,45 and $60 \mathrm{~min}$ of ischemia results in nomalization of the myocardial creatine phosphate content. Reperfusion is not associated with further depletion of the adenine mucleotide pool and results in a partial restoration of the adenylate energy charge. In addition, functional recovery during reperfusion is still adequate (over $90 \%$ following 45 min ischemia) when the cardiac ATP content is reduced to $60 \%$ of its pre-ischemic value. Although it is well established that ischemia invariably results in depressed mitochondrial function (Edoute et al., 1983; Nayler et al., 1980), inconsistent results have been obtained regarding the persistance of these abnormalities during reperfusion (Kane et a1., 1975; Weishaar et a1., 1979; Kotaka et a1., 1982). The return of the myocardial creatine phosphate content and recovery of the energy charge in beating hearts, as observed in the present study and by others (Watts et a1., 1980; Takeo and Sakanashi, 1983; Meno et a1., 1984; Humphrey et a1., 1985), Indicate that mitochondrial ATP production is not seriously impaired. Thus, these findings support the view that the reduced content of ATP at the end of reperfusion is mainly due to wash-out of adenine nucleotide precursors, accumulating during ischemia, and is not due to the inability to rephosphorylate ADP as a result of mitochondrial damage. This observation indicates that under the present conditions mitochondrial function is not hampered by WEFA's and/or other 1 ipid-intermediates accumulated (see chapter 5).

Like ATP, the tissue content of GTP partially restores during reperfusion. Incomplete recovery of the guanine nucleotide pool might affect the recovery of the jeopardized myocardium. Guanine nucleotides are required as cofactors for the oxidation of a-ketoglutarate to succinate, an important step in the Krebs-cycle. It is conceivable that a reduced mitochondrial guanine nucleotide content and/or a reduced GTP/GDP ratio influences Krebs-cycle activity. However, to be able to delineate such an effect insight into at least the contents of the Krebs-cycle intermediates involved (a-ketoglutarate, succinylCOA, succinate) is required. In addition, guamine nucleotides serve important 
roles in protein synthesis, as substrate for guanylate cyclase, in the regulation of phosphatidylinositol-cycle activity and adenylate cyclase activity (Lefkowitz, 1974).

Since ATP is an essential reactant of all kinase reactions, which are known to function at near equilibrium, comparable percentage decreases in ATP and GTP are anticipated. Indeed, the ATP over GTP ratios are found to be relatively constant, when comparing pre-ischemic, ischemilc and reperfused hearts. As a consequence similar reductions in the myocardial content of uridine triphosphate might also be expected. Since uridine triphosphate is an essential co-factor in glycogen synthesis, it is tempting to suggest that the inability to replenish the glycogen stores during reperfusion following longer periods of ischemia is related to the depletion of uridine triphosphate.

Reperfusion arrhythmias.

During reperfusion following $60 \mathrm{~min}$ of ischemia some hearts resume normal electrical behavior within due time, whereas others keep fibrillating. Prolonged fibrillation is associated with a reduced coronary flow during the initial reperfusion phase and, among others, a reduced myocardial content of creatine phosphate, ATP and adenine nucleotides at the end of reperfusion (see table 4.6). Reperfusion-induced fibrillation could result from enhanced automaticity of the reperfused tissue or from re-entry, which in itself is caused by the heterogeneity in cellular injury and recovery (reviewed by Manning and Hearse, 1984). It has been suggested that reperfusion arrhythmias are characteristic for reversibly injured and potentially retrievable tissue (Corr and Witkowski, 1983). Preliminary results of experiments, performed in our laboratory, indicate that depolarization of the heart by infusion of a bolus of $\mathrm{KCl}$ enriched perfusion buffer $(20 \mathrm{mM})$ during reperfusion is followed by resumption of regular electrical activation and concomitant recovery of contractile activity. However, this response is often merely temporal and hearts restart to fibrillate after a short period. Anyhow, these findings indicate that the fibrillating hearts have still the capacity to restore their mechanical function.

The question rises as to the mechanism underlying the relationship between the low content of high-energy phosphate compounds and prolonged ventricular fibrillation. First, the low content of high-energy phosphates at the end of reperfusion could result from adverse effects of fibrillation such as under- 
perfusion of the tissue due to continuously elevated left ventricular pressure (about $4 \mathrm{kPa}$, data not shown). Second, prolonged fibrillation during reperfusion might be a consequence of enhanced tissue damage induced by the preceding ischemic insult. To be able to discern between these alternatives intra-individual comparison of the metabolic status at the end of ischemia and the electrical behavior during subsequent reperfusion is required. Unfortunately, the present experimental set-up does not allow such an approach.

Several lines of evidence, however, support the second idea. Dennis and coworkers (1983) abserved a relation between a more seriously disturbed glucose metabolism during low-flaw ischemia, and the occurrence of reperfusion induced fibrillation in guinea pig hearts. In addition, using dog hearts, Hale and coworkers (1985) observed a relation between lower CP and ATP levels at the end of ischemia and reperfusion-induced fibrillation. In line with these observations, we observed an enhanced release of lactate during the initial reperfusion phase from hearts unab?e to resume spontaneous beating during 30 min of reperfusion. However, no difference is observed in the cumulative release of LDH between both subgroups, as one might expect if prolonged fibrillation is related to reduced tolerance to ischemia. The finding of a comparable cumulative release of purines, in combination with a marked difference in the adenine nucleotide content at the end of reperfusion, seems paradoxical and is incompletely understood. The comparable release of purines is not in favor of the idea of a reduced tolerance to ischemia of hearts fibrillating during reperfusion, nor to the idea that fibrillation per se results in the degradation of nucleotides. According to both ideas enhanced release of purines from continuously fibrillating hearts would be anticipated. So, at present no satisfying explanation for the relationship between the observed electrophysiological and metabolic phenomena can be given.

\section{Functional recovery and myocardial damage.}

The findings in the present study indicate that important changes take place in the affected myocardium, when the ischemic period lasts $45 \mathrm{~min}$ or more. Several investigators have shown that the transition from reversible to irreversible damage takes place around this time interval of ischemia (Schaper et a1., 1979; Jennings et a1., 1978). Reimer and colleagues (1981) suggested a relation between the lass of cell volume regulation and irreversible cell damage. Indeed, the tissue water content of hearts reperfused folowing $60 \mathrm{~min}$ 


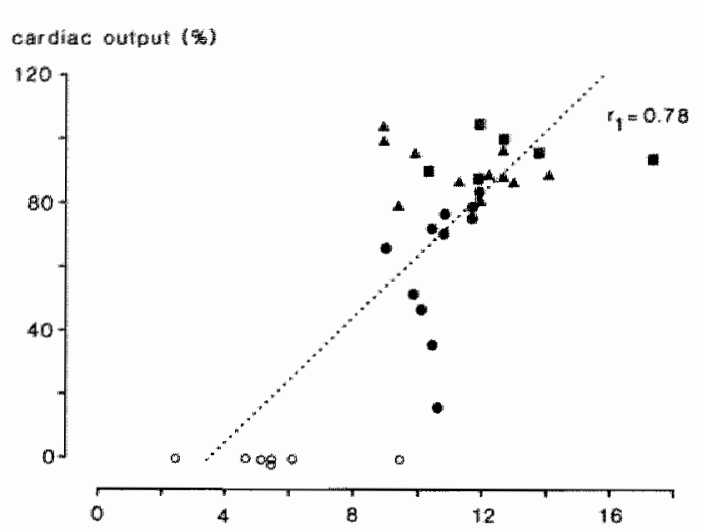

(a)

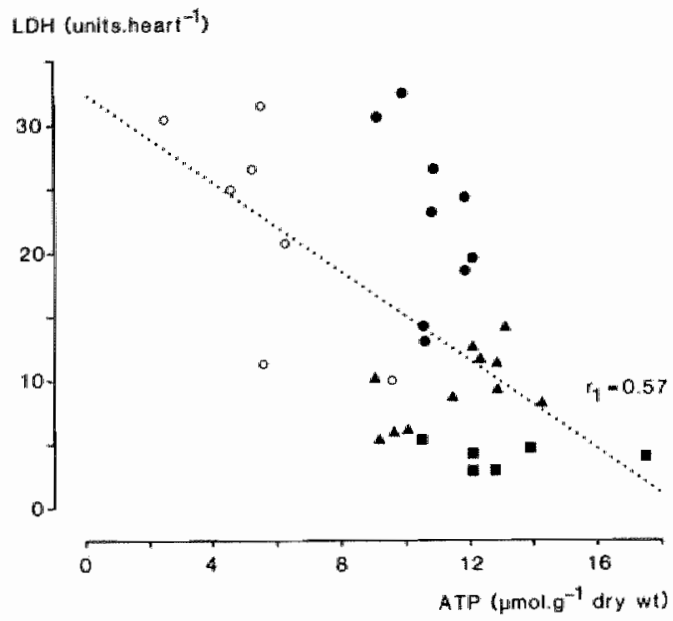

(b)

Fig 4.6 Relationships between (a) tissue content of ATP of reperfused hearts and the percentage recovery of cardiac output, and (b) the tissue content of ATP of reperfused hearts and the cumulative release of LDH during $30 \mathrm{~min}$ of reperfusion. Points refer to the paired data of individual hearts rendered ischemic for $30(\mathbf{D}), 45(\Delta)$ or $60 \mathrm{~min}$ of ischemia 1 and $O$ for electrically recovering and fibrillating hearts, respectively). $r_{1}$ refers to the correlation coefficient calculated on the basis of the paired data of all hearts examined. 
of ischemia is markedly increased. The development of contracture during ischemia has al so been associated with irreversible tissue damage. Humphrey and coworkers (1984) observed a relation between the late rise in AMP and contracture development. They suggested that AMP accumulation is likely to represent metabolic changes taking place at the myofibrils. Interestingly, the present findings show that the late rise of AMP during ischemia correlates in time with the loss of cell vollume regulation and notable impairment of function during subsequent reperfusion.

Several authors (Reibel and Rovetto, 1978; Watts et al., 1980; Edoute et a1., 1983; Meno et al., 1984 / reported a correlation between tissue levels of ATP at the end of reperfusion and post-ischemic functional recovery. In contrast, others failed to observe such a relation (Neely and Grotyohann, 1984a; Taegtmeyer et a1., 1985; Rosenkranz et al., 1986). As shown in fig 4.6a on first sight a strong linear correlation $(r=0.78)$ exists between the ATP content of reperfused hearts and the percentage recovery of cardiac output. However, this correlation is mainly determined by the cluster of data formed by the subpopulation of continuousiy fibrillating hearts (zero function, low ATP). When only hearts able to restore regular rhythm are considered no correlation was observed $(r=0.33)$. These findings suggest that the depletion of ATP concerns a pool not critically related to the contractile process. Taegtmeyer and associates (1985) argued that no relation between the tissue content of ATP and myocardial performance could be expected on the basis of the low $\mathrm{Km}$ for ATP of the ATP-ases of the contractile elements and, that the turnover rate of ATP/ADP might be more relevant in this respect. The 1 imited value of the tissue ATP content as a determinant of post-ischemic mechanical performance was already discussed in chapter 3.

The release of intracellular enzymes is generally accepted as an index of irreversible cell damage. Interestingly, no clear correlation is abserved between the myocardial content of ATP at the end of reperfusion and enzyme release $(r=0.57$, fig $4.6 \mathrm{~b})$. Again this $r$-value is 1 argely determined by the presence of continuously fibrillating hearts. An r-value as low as 0.13 is found when this subpopulation is excluded from the analysis. Due to cellular inhomogeneity, it is feasible that in some cel1s the ATP content reaches a critical level, as a result of which the cells become irreversibly damaged (about $5 \mu \mathrm{mol} . \mathrm{g}^{-1}$ dry wt according to Reimer et al., 1981a). Mevertheless, even then one would expect that at a lower tissue content of ATP a larger 
number of cells would reach this critical state and, hence, becone irreversibly damaged and lose their LDH content.

\subsection{Summary}

The effects of ischemia and reperfusion on myocardial adenine nucleotide metabolism and its relation to post-ischemic injury were assessed using isolated, working rat hearts, subjected to various periods of ischemia with or without an additional 30 min of reperfusion. During early ischemia the decline in ATP content was associated with a rapid accumulation of nucleosides and oxypurines. Thereafter, the increase of these substances ceased and AMP accumulated in substantial amounts. After restoration of flow the accumulated degradation products were released and, concomitantiy, further degraded. This might lead to the production of substantial amounts of reactive oxygen species through conversion of (hypo)xanthine to uric acid by xanthine oxidase and, hence, to free radical-induced cellular damage.

Prolonged fibrillation during reperfusion was associated with marked derangements in high-energy phosphate metabolism and enhanced release of lactate during reperfusion. However, enzyme release was not enhanced, suggesting that fibrillation was not associated with an exacerbation of irreversible cell damage.

At the end of reperfusion the total adenine nucleotide content was severe1y depressed, but similar to that as measured at the end of the corresponding ischemfc perfod. Nevertheless, the adenylate energy charge almost completely restored, as did the creatine phosphate content. Therefore, the 1ack of restoration of ATP levels in the post-ischemic heart results from the release of adenine nucleotide precursors (1.e. degradation products) and is not rellated to seriously impafred mitochondrial function. Finally, it is shown that the tissue content of ATP of reperfused hearts is a poor determinant of post-ischemic function as well as irreversible ce11 damage. 
LIPID ALTERATIONS IN ISOLATED, WORKING RAT HEARTS DURING ISCHEMIA AND REPERFUSION: ITS RELATION TO MYOCARDIAL DAMAGE.

\subsection{Introduction}

Disturbances in membrane function most likely play an important role in the transition from reversible to irreversible damage in ischemic myocardial tissue (Reimer et al., 1981a). There are indications that changes in myocardial lipid metabolism contribute to this process (Van der Vusse and Reneman, 1985b; Sen et a1., 1987). Both the degradation of phospholipids, important constituents of myocardial membranes, and the accumulation of amphipathic compounds, such as lysophospholipids and non-esterified fatty acids (NEFA's), are considered to be detrimental to myocardial cell function (reviewed by Katz and Messineo, 1981; Corr et al., 1984).

The accumulation of NEFA's may result from impaired oxidation of fatty acids extracted from the blood, release of fatty acids from endogenous triacylglycerol stores or the breakdown of phospholipids (Van der Vusse et al., 1982; Chien et al., 1984). Release of glycerol from the ischemic tissue (Vik-Mo et a1., 1979, Trach et al., 1986) suggests impairment of triacylglycerol homeostasis. The finding that substantial amounts of non-esterified arachidonic acid, a fatty acid that is predominantly esterified into phospholipids, accumulates within one hour of ischemia indicates disturbances in phospholipid homeostasis (Chien et al., 1984; Prinzen et a1., 1984). Both an increased rate of deacylation, due to enhanced phospholipase activity, and a reduced rate of reacylation might contribute to the observed changes in phospho1ipid homeostasis (Chien et a1., 1984; Das et al., 1986). The activity of acyl-COA synthetase, an enzyme involved in the latter process, requires ATP as a cofactor and is inhibited by AMP and adenosine (De Jong and Huelsmann, 1970). Therefore, the changes in adenine nucleotides and their degradation products would favor inhibition of acyl-COA synthetase during ischemia.

Limited information is available about the effect of reperfusion on 
myocardial lipid homeostasis. Recent findings of Das and coworkers (1986) indicate that reperfusion results in a massive degradation of phospholipids. Besides, oxidation of fatty acids was shown to be impaired during reperfusion (Schwaiger et al., 1985; Chatelain et a1., 1987). As a consequence, an addtional increase of myocardial NEFA's and/or lysophospholipids may be anticipated during reperfusion, which in itself could result in an exacerbation of myocardial damage.

It was the aim of the present study to investigate the effects of ischemia and reperfuston on myocardial lipid homeostasis. To this end the contents of individual phospholipid species, including the plasmalagen forms and lysoforms of phosphatidylcholine and phosphatidylethanolamine, were measured in isolated, working rat hearts after various periods of global no-flow ischemia and reperfuston. Triacylglycerol homeostasis was assessed by measuring the tissue content of triacylglycerols as well as that of glycerol-3-phosphate and glycerol. The relationship between NEFA accumulation and changes in the myocardial content of ATP, AMP and adenosine was assessed to delineate the role of the latter substances in the impaiment of lipid homeostasis. Finally, the relation between changes in myocardial lipid content and (a) functional recovery during reperfusion and (b) cellullar integrity, as measured by the release of myocardial emzymes, were investigated.

\subsection{Methods}

\section{Heart perfuston.}

The hearts of male Lewis rats were isolated and perfused as previously described (chapter 3). The perfusion medium consisted of a modified KrebsHenseleft bicarbonate buffer containing glucose (11 mM) and pyruvate (5 mM) as substrates. The hearts were perfused as isolated, assisted, working hearts at a left atrial filling pressure of $1.0 \mathrm{kPa}$ and a diastolic aortic pressure of 8.0 $\mathrm{kPa}$. Under control conditions the impedance of the aortic cannula resulted in an aortic pressure pulse of about $4.5 \mathrm{kPa}$.

Aortic flow was measured with an electromagnetic flow probe in the aortic outflow tract. Coronary flow was measured by timed collection of the coronary perfusate dripping from the heart. Left ventricular developed pressure (LVDP) 
was defined as the difference between left ventricular systolic and end diastolic pressure. Cardiac output was assessed by adding aortic flow and coronary f7ow.

\section{Experimental protocols.}

Normoxic experiments: In one series the working hearts were freeze clamped after 30 min of perfusion (pre-ischemic values, $n=9$ ). To assess the effect of long term normoxic perfusion on myocardial function, high-energy phosphate content and 1 ipid homeostasis, working hearts were perfused for 120 min and subsequently freeze clamped $(n=8)$.

Effect of ischemia: Following $30 \mathrm{~min}$ of control perfusion the hearts were subjected to various periods of no-flow ischemia at $37^{\circ} \mathrm{C}$, ranging from 10 to $90 \mathrm{~min}(\mathrm{n}=6-8$ for each series). The experiments were terminated by freeze cllamping the tissue after $10,30,45,60$ or $90 \mathrm{~min}$.

Effect of reperfusion: In these experiments the hearts were reperfused for 30 min following $30(n=4), 45(n=8)$ or $60 \quad(n=16)$ min of ischemia. During the first $5 \mathrm{~min}$ of reperfusion the hearts were perfused retrogradely (perfusion pressure $8.0 \mathrm{kPal}$ and antegradely thereafter during the rest of the observation period. The hearts were freeze clamped at the end of the reperfusion period. In a subset of experiments hearts were freeze clamped after 60 min of ischemia followed by 5 min of reperfusion $(n=8)$.

\section{Biochemical analysis.}

At the end of the experiments ventricular tissue was dissected free and immediately frozen between aluminum clamps cooled in liquid nitragen. During the experiments the coronary perfusate was collected and sampled. Tissue and effluent samples were stored at $-80^{\circ} \mathrm{C}$ unt 11 analysis.

Myocardial lipids. Part of the deeply frozen tissue (100-200 mg) was pulverized with a stainless steel pestle and a aluminum mortar, both cooled to the temperature of liquid nitrogen. Myocardial lipids were extracted as previously described (Van der Vusse et al., 1980, 1982). Basically, the tissue powder was extracted twice with chloroform/methanol according to folch and colleagues (1957). Heptadecanoic acid and triheptadecanoylglycerol were used as recovery standards for NEFA"s and triacylglycerols, respectively. A mixture of fatty acids, triacylglycerols and phospholipids was used as external standard. All solvents used for extraction and separation of lipid (sub)clas- 
ses contained $0.01 \%(w / v)$ of butylated hydroxytoluene. After extraction the lipid extract was applied to a silicagel column and stepwise eluted to separate non-polar from polar lipids (Roemen and Van der Vusse, 1985). Each lipid fraction was further separated by thin layer chromatography (TLC) using plates coated with silicagel (Kieselgel 60 , Merck).

After application of the non-polar lipid fraction, the plates were predeveloped with chloroform/methanol/acetic acid/water $(10: 10: 1: 1$, by vol) until the solvent front had moved $1 \mathrm{~cm}$ from its origin. After drying the plates were further developed with a mixture of petroleumether/diethylether/acetic acid $(120: 25: 1.5$, by vol). The lipid spats were visualized with uV light after spraying with Rhodamine $G$, scraped from the plates and directly methylated with Borontrifluoride $\left(\mathrm{BF}_{3}\right)$. NEFA's were methylated with $7 \% \mathrm{BF}_{3}$ in methanol at $20^{\circ} \mathrm{C}$ for $15 \mathrm{~min}$. Triacylglycerols (TG's) were methylated with $3.5 \% \mathrm{BF}_{3}$ in methanol/toluol $\left(4: 1\right.$, by voll) at $100^{\circ} \mathrm{C}$ for $30 \mathrm{~min}$. Methylation was stopped by addition of water and the fatty acid methyl esters (FAME's) were extracted with pentane. After evaporation of the solvent mixture under a stream of nitrogen the FAME's were redissolved in iso-octane containing $\mathrm{C15:0-methy1-}$ ester as internal standard and quantified by gas-1 lquid chromatography (Van der Vusse et a1., 19821.

The polar lipid fraction was separated into the various phospholipid subclasses by one dimensional TLC modified after Shaikh and Downar (1981). To this end the plates were developed with chloroform/methanol/acetic acid/water (75:60:10:6, by vol). This resulted in adequate separation of phosphatidylchol ine (PC), phosphatidylethanolamine (PE), sphingomyel in (SPH), diphosphatidylglycerol (or cardiolipin, DPG), lysophosphatidylcholine (LPC) and lysophosphatidylethanolamine (LPE). In most cases phosphatidylserine (PS) and phosphatidylinositol (PI) were poorly resolved and therefore treated as one spot.

After spraying with fluoresceine the lipid spots were visualized with UV light and scraped from the plate. The various phospholipid fractions were eluted from the silicagel with chloroform/methanol/water $(5: 5: 1$, by vol) and the solvents were subsequently evaporated to dryness $\left(\right.$ at $45^{\circ} \mathrm{C}$ under a stream of nitrogen). The phospholipids were redissolved in $1.0 \mathrm{ml}$ of chloroform/methanol/water $(16: 8: 1$, by vol; water contained $0.05 \mathrm{M} \mathrm{NaC1)}$. Of this solution $250 \mu 1$ was withdrawn and used for the determination of lipid phosphorus (modiffed according to Bartlett, 1959). The remaining 750 w were again evapo- 
rated to dryness and redissolwed in $1.0 \mathrm{ml}$ of $14 \mathrm{BF}_{3}$ in methanol. DPG, PI+PS, LPC and LPE were methylated for $15 \mathrm{~min}, P C$ and PE for $30 \mathrm{~min}$, and $S P H$ for 90 min at $100^{\circ} \mathrm{C}$. Methylation was stopped by addition of $1.0 \mathrm{ml}$ of water. The FAME's were further treated as described above. To determine the plasmalogen content of $P C$ and $P E$ additional precautions are required. After methylation the test tubes were placed on ice and, after cooling, $1.0 \mathrm{ml}$ of $\mathrm{NaOH}$ (5 M) was gently added. Subsequently the FAME's and dimethylacetals (DMA"s) were extracted with pentane (Morrison and Smith, 1964). FAME's and DMA's were separated by TLC, using toluol as developing solvent. The corresponding spots were eluted with chloroform, evaporated and redissolved in iso-octane. The FAME's and DMA's were analyzed by gas-liquid chromatography as previously described (Van der Vusse et al., 1982; Roemen and Van der Vusse, 1985).

Expression of lipid data. Due to possible edema formation during experiments (see chapter 4) and/or gain of the water content (through condensation) during handling of the deeply frozen tissue lipid data were not normalized to grams of wet weight of cardiac tissue. Instead, after extraction of the tissue powder with chloroform/methanol the remaining tissue residue was evaporated to dryness at room temperature overnight and subsequently at $80^{\circ} \mathrm{C}$ for 1 hour and finally weighed. Consequently, the myocardial content of the various lipids was expressed in moles/gram dry residue weight. Due to the extraction of the tissue lipids and loss of various substances during the washing procedures the percentage dry residue weight is appoximately 20-30\% lower as compared to the percentage dry weight, as measured after lyophilization of cardiac tissue. To 11lustrate, in hearts freeze $\mathrm{clamped}$ after $30 \mathrm{~min}$ of normoxic perfusion the percentage dry residue weight and and percentage lyophilized dry weight amounted to $13.7 \pm 0.9$ and $16.7 \pm 0.8$, respectively. For convenience the 1 ipid (phospholipid, triacylglycerol, NEFA) values presented are denoted as moles. $g^{-1}$ dry weight. It should be noted, however, that these values actually refer to moles. $\mathrm{g}^{-1}$ dry residue weight. In order to estimate the lipid content per gram lyophilized dry weight the lipid data presented should be divided by a factor 1.25 .

High-energy phosphates, glycerol-3-phosphate and glycerol. Analysis of adenine nucleotides, adenosine and creatine phosphate was performed in the neutralized perchloric acid extract of small aliquots of freeze dried tissue (5-10 mg). ATP, ADP, AMP and adenasine were determined by reversed phase HPLC (Lichrosorb RP-18 column) by gradient elution and UV detection as described by 
Wynants and Van Belle (1985). Creatine phosphate was measured fluorometrically as described elsewhere (Van der Vusse et al., 1984b). Glycerol-3-phosphate and glycerol were measured fluorometrically according to a procedure modified after Laurell and Tibbling (1966).

Lactate dehydrogenase. LDH activity in the coronary effusate was measured according to Bergmeyer and Bernt (1974).

Statistical analysis.

Results are expressed as mean values and standard deviations. Differences within and between groups were analyzed for significance using the Student's $t$ test for paired and unpaired data, respectively. The Pearson correlation coefficient $(r)$ was used to estimate the strength of the relation between two variables. Linear regression was performed with the least-squares method. $P$ values less than 0.05 were considered to be statistically significant.

\subsection{Results}

Functional and metabolic stability of normoxic hearts.

Hemodynamic function remained virtually unaffected during 2 hours of normoxic perfusion as working hearts. Left ventricular developed pressure (LVDP) was maintained, whereas stroke volume decreased only slightly (-3\%) during this period. As compared to hearts perfused for $30 \mathrm{~min}$ (pre-ischemic controls), the myocardial content of total adenine nucleotides had signifi-

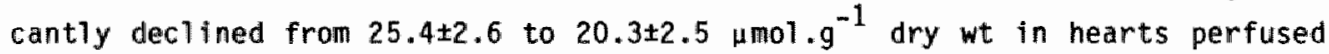
for two hours. Creatine phosphate levels remained constant during this period (about $30 \mu m o 1 . g^{-1}$ dry wt). The myocardial content of glycogen, triacylglycerols and of total NEFA's did not change either and averaged about 120, 30 and $0.3 \mu \mathrm{mol} . \mathrm{g}^{-1} \mathrm{dry} w \mathrm{t}$, respectively.

\section{Lipid content of normoxic hearts.}

The tissue contents of NEFA, triacylglycerols and phospholipids, including their relative fatty acid compositions, are presented in table 5.1. Total NEFA content represented less then $0.1 \%$ of the total amount of fatty acids of the heart. The contribution of poly-unsaturated fatty acids (especially C22:6) to 


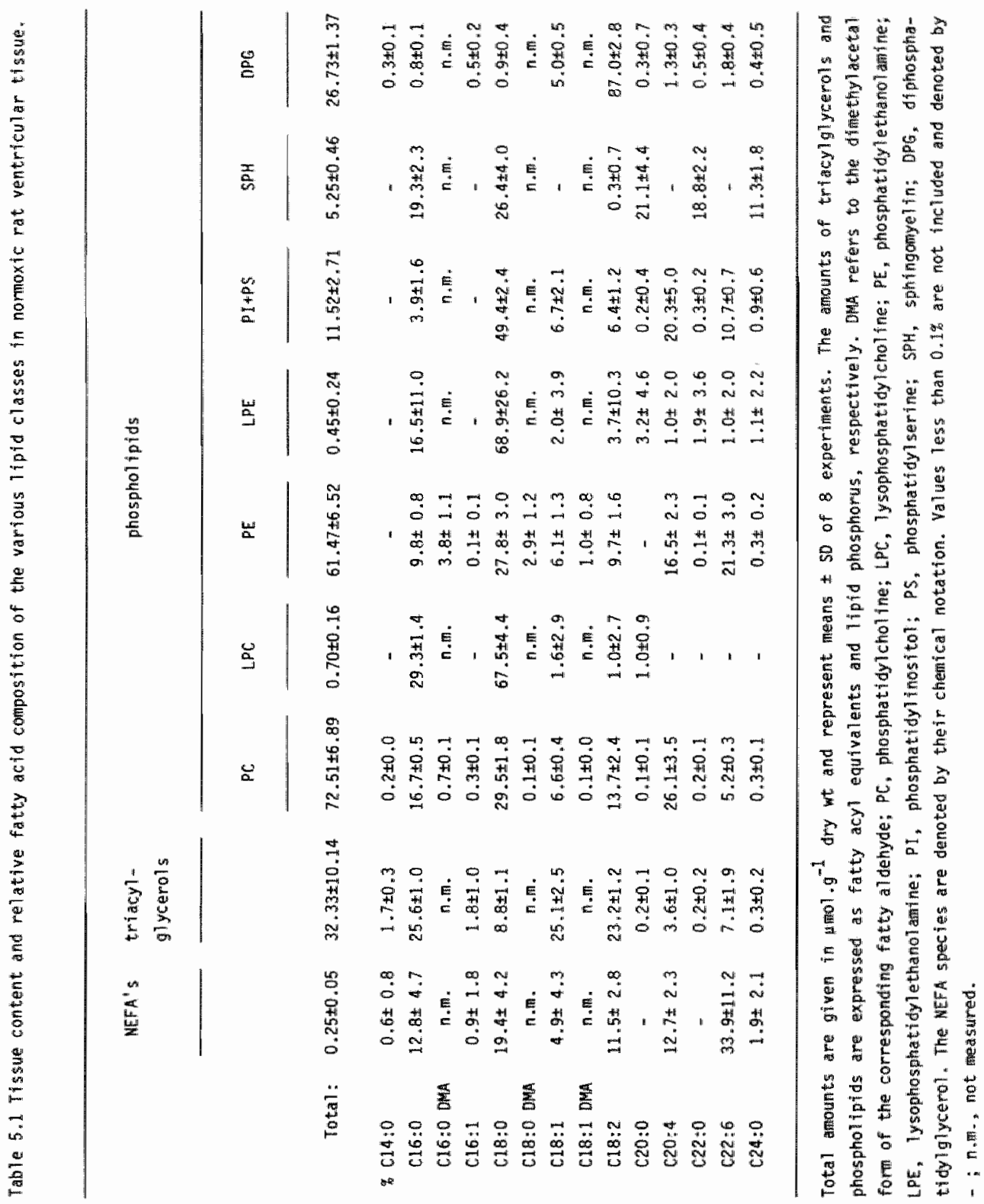


total NEFA"s was relatively high (the chemical notation of the fatty acid species is explatned in the legend of table 5.2). The tissue content of triacylglycerols was variable and averaged about 32 mol. $\mathrm{g}^{-1}$ dry wt lexpressed

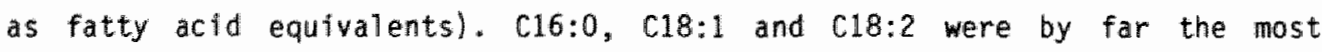
abundant fatty acids in this lipid class. The majority of acylmoieties was esterified to phospholipids. PC and PE were the major phospholipids. Together they comprised almost $75 \%$ of all phospholipids. The plasmalogen form of PC was present in small amounts and constituted $0.9 \%$ of total PC. In contrast, the plasmalogen form of PE constituted $7.8 \%$ of total PE. PC was relatively rich in $C 16: 0, C 18: 0, C 18: 2$ and $C 20: 4$, whereas $P E$ contained 1arge amounts of $C 18: 0$, C20:4 and $c 22: 6$. The tissue content of 1ysophospholipids was very low. LPC and LPE represented less than 1\% of their parent phospholipids. Lysophospholipids. were highly enriched in saturated fatty acids and contained only trace amounts of poly-unsaturated fatty acids. In contrast to the other phospholipid classes, sphingomyelin (SPH) contained large amounts of very long-chain saturated fatty acids (C20:0, C22:0 and c24:0). Nearly 90\% of the fatty acid moieties in diphosphatidylglycerol (DPG), on the other hand, consisted of $c 18: 2$ residues.

\section{I schemia .}

After $10 \mathrm{~min}$ of ischemia the myocardial creatine phosphate level was reduced to $7.5 \pm 3.2 \mu \mathrm{mo} . \mathrm{g}^{-1}$ dry wt, $1 . e$. about $25 \%$ of its nomoxic value. Thereafter, the creatine phosphate content decreased only slowly. The decrease in ATP content was more gradual (fig 5.1a). Initially, degradation of ATP resulted in a transient increase in ADP (not shown in figure). Maximum levels of ADP were measured after $10 \mathrm{~min}$ of ischemia $\left(8.1 \pm 0.5 \mu \mathrm{mol} . \mathrm{g}^{-1} \mathrm{dry}\right.$ wt, i.e. $150 \%$ of the normoxic value). Subsequently, ADP gradually declined reaching a value of $3.1 \pm 1.3 \mu \mathrm{mol} . \mathrm{g}^{-1}$ dry wt after $90 \mathrm{~min}$ of $i$ schemia. The AMP content doubled within the first 10 min of ischemia, remained relatively constant from 10 to 45 min of ischemia, and gradually increased again thereafter. During the first 45 min of ischemia the tissue content of adenosine gradually rose from $0.1 \pm 0.1$ to $2.5 \pm 0.6 \mu \mathrm{mol} \cdot \mathrm{g}^{-1} \mathrm{dry}$ wt remained constant thereafter.

NEFA's started to accumulate in the oxygen deprived tissue only after 45 min of ischemia, when ATP was already reduced to $36 \%$ of its pre-ischemic value (fig 5.1). The onset of NEFA accumulation coincided with the second-phase Increase in AMP and occurred when adenosine had reached its maximal tissue level. After $60 \mathrm{~min}$ of ischemia NEFA's had increased more than fourfold and 
fumal $g^{-1}$ dry wh.

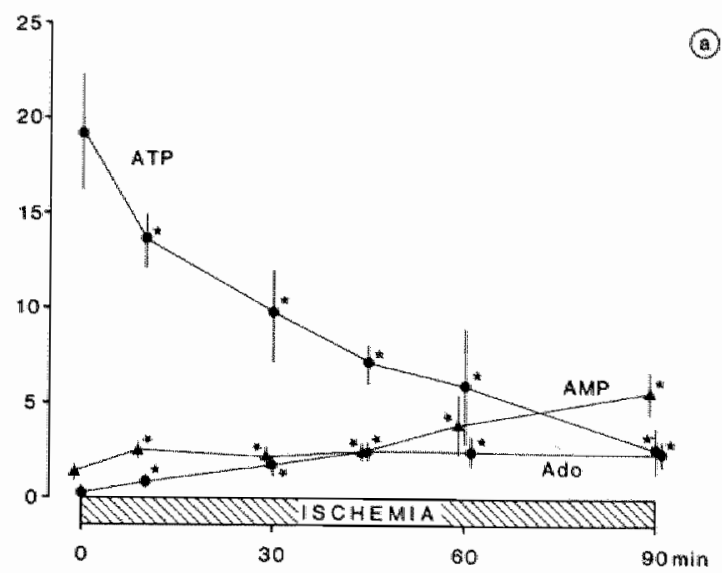

pmol.g-1 dry wh.

(b)

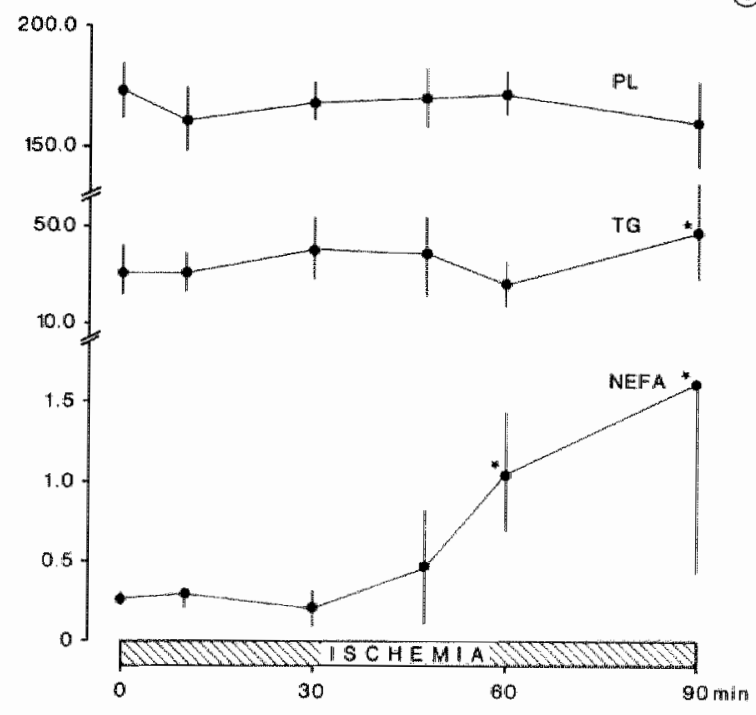

Fig 5.1 Time course of changes in the myocardial content of (a) ATP. AMP and adenosine (Ado) and (b) non-esterified fatty acids (NEFA), triacylglycerols (TG, expressed as fatty acid equivalents) and total phospholipids (PL, expressed as lipid phosphorus) during no-flow ischemia in isolated rat hearts. Data are expressed as means \pm SD. Asterisk indicates significantly different from pre-ischemic values $(p<0.05)$. 
continued to increase during the next half hour.

The contribution of each individual fatty acid to the rise in total MEFA"s during ischemia was found to be different (table 5.2, fig 5.2). During the first 30 in of 1 schemila $C 16: 0$ and $C 18: 1$ showed a transient rise. In contrast, the content of $c 20: 4$ and $c 22: 6$ gradually decreased during this period. From 30 to $90 \mathrm{~min}$ of ischemia the average tissue content of $\mathrm{C16:0,}, \mathrm{c18:0,C18:1}$ and C18:2 significantly increased. During this period $C 20: 4$ and $C 22: 6$ al so started to rise. After $90 \mathrm{~min}$ of ischemia not only the absolute amount of MEFA's had increased, but the percentage contribution of individual fatty acids to the total NEFA content had also changed (table 5.2 , data in parentheses). On a percentage base $c 16: 0, C 18: 1$ and $c 18: 2$ were markedly elevated, whereas $c 22: 6$ was reduced.

Accumulation of NEFA's in the oxygen deprived tissue was not associated with significant decreases in the myocardial content of total (fig 5.1b) or

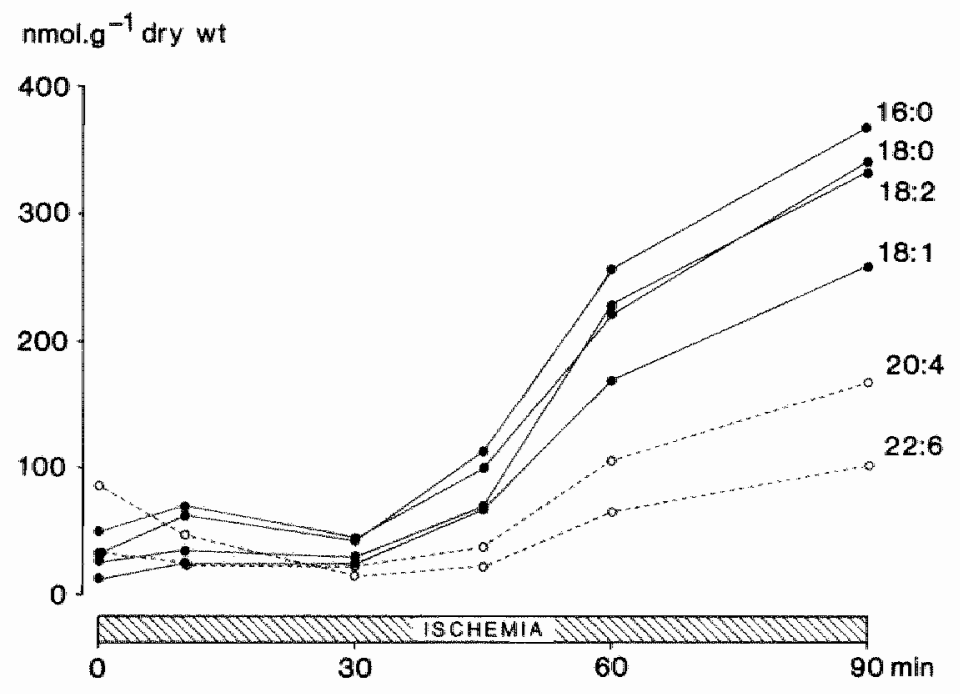

Fig 5.2 The accumulation of MEFA species during myocardiall ischemia (mean values). The NEFA's are denoted by their chemical notation. 


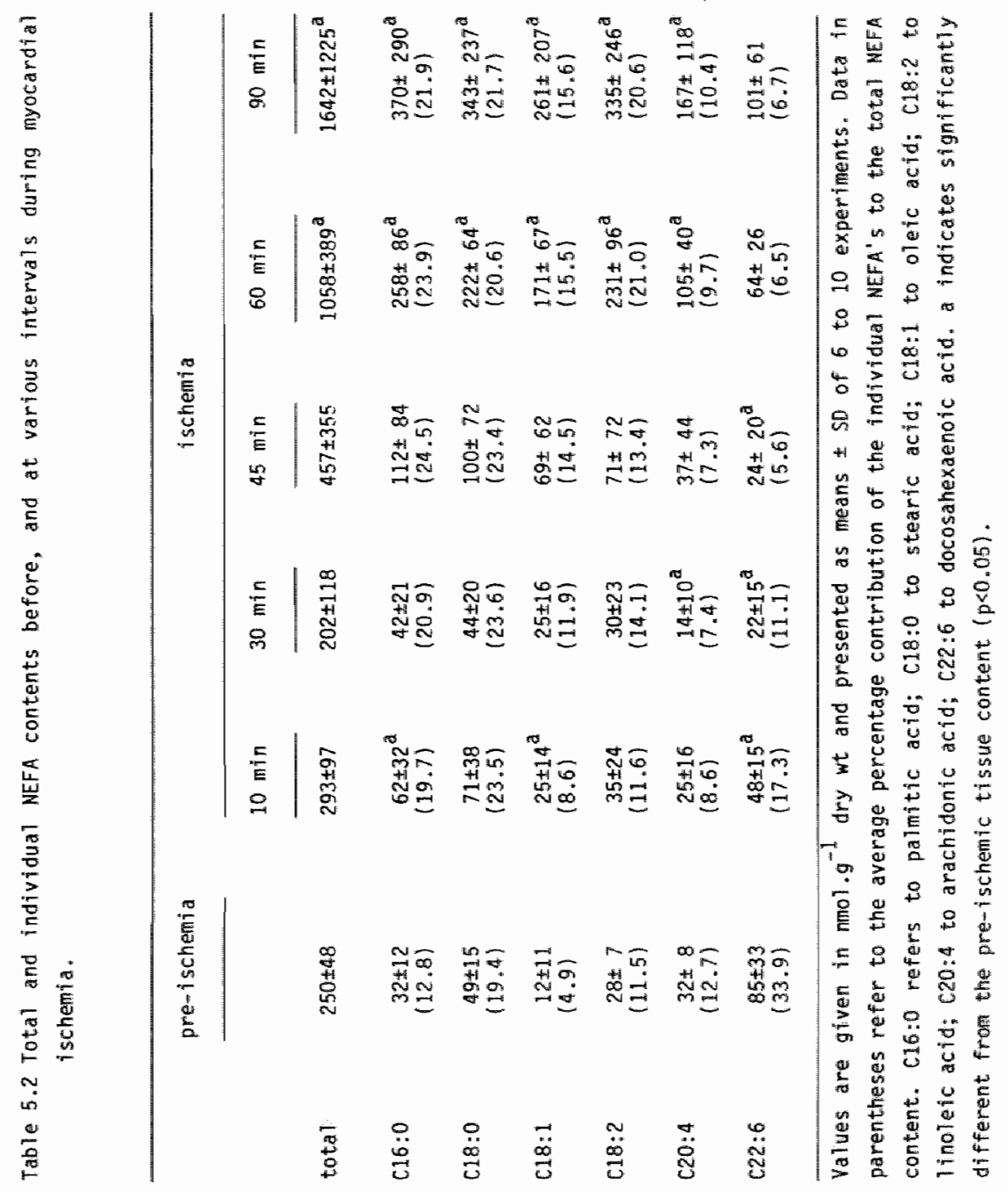




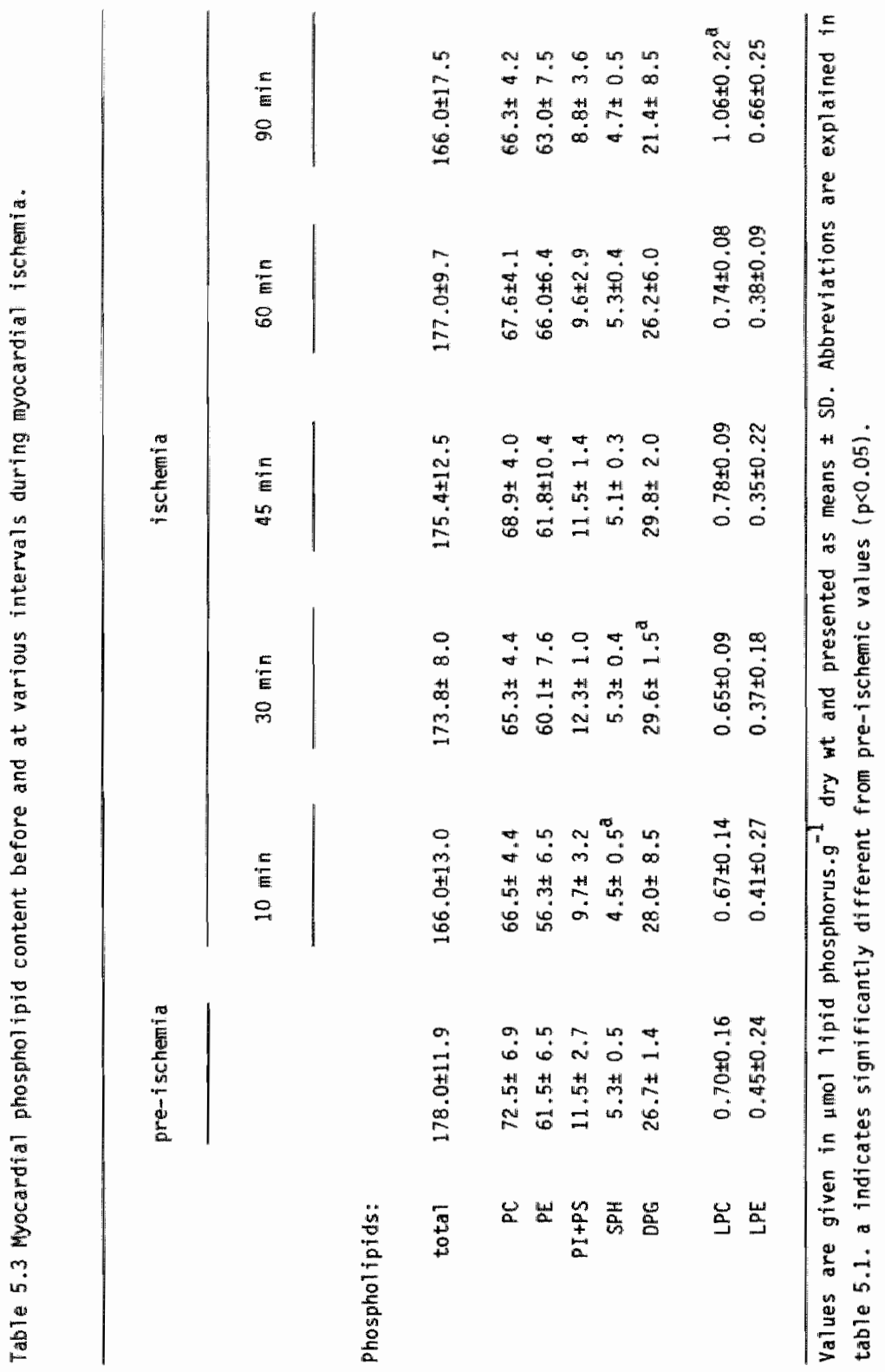


individual phospholipids (table 5.3). However, a minor, but significant increase in the myocardial content of LPC was observed from 60 to 90 min of ischemia. During $90 \mathrm{~min}$ of ischemia the average tissue content of LPC rose from 0.70 to 1.06 umol. $\mathrm{g}^{-1} \mathrm{dry}$ wt, i.e. a $51 \%$ increase. The myocardial content of LPE also tended to increase, but this change did not reach the level of significance.

The average tissue content of triacylglycerols of hearts freeze clamped after various periods of ischemia varied considerably. Only after 90 min of ischemia a significant increase was observed (fig 5.1b). After 30 min of ischemia the myocardial content of glycerol had increased almost 5 fold (fig 5.3). From 30 to $60 \mathrm{~min}$ of ischemia glycerol continued to increase to an average value of $5.1 \mu \mathrm{mol} . \mathrm{g}^{-1}$ dry wt. Concomitantly, an increase in the myocardial content of glycerol-3-phosphate, an essential substance for the synthesis of triacylglycerols, was observed.

\section{Reperfusion.}

The effects of the duration of ischemia on recovery of stroke volume during reperfusion are shown in figure 5.4. Restoration of flow following 30 min of no-flow ischemia resulted in almost immediate and complete recovery of hemodynamic function. Left ventricular developed pressure (LVDP) was completely restored and stroke volume recovered to $93.2 \%$ of its pre-ischemic value upon reperfusion. Reperfusion following 45 min of ischemia resulted in a slightly less adequate functional recovery. At the end of reperfusion LVDP and stroke volume had returned to $94.5 \%$ and $87.8 \%$ of their pre-fichemic vallue, respectively. Hemodynamic performance of reperfused hearts subjected to 60 min of ischemia was severely impaired. Average recovery of LVDP and stroke vollume amounted to $49.5 \%$ and $37.2 \%$, respectively. The degree of recovery varied substantially from one heart to another. Seven out of 16 hearts did not regain normal cardiac electrical activity at all and were subjected to alternating periods of tachycardia and fibrillation. Hearts with norinal electrical activity and stable rhythm recovered to a moderate extent $188.0 \%$ and $66.2 \%$ recovery of LVDP and stroke volume, respectively).

After 30 min of reperfusion following 30,45 or 60 min of ischemia the tissue content of creatine phosphate had returned to its pre-ischemic value (tabile 5.4). The total amount of adenine nucleotides remained depressed. However, in each group ATP content was partially restored at the expense of the 


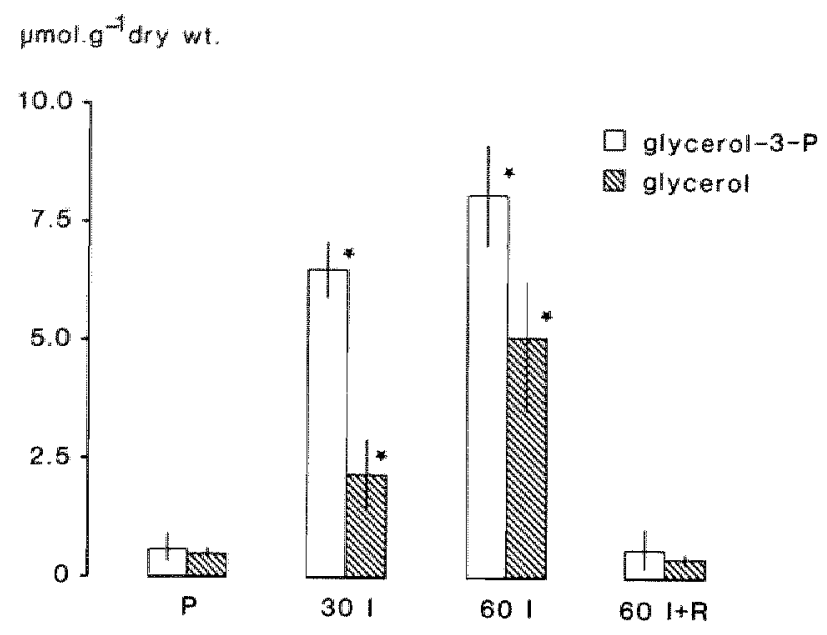

Fig 5.3 Changes in the myocardial content of glycerol-3-phosphate (open bars) and glycerol (hatched bars) after 30 and 60 min of no-flow ischemia, and $30 \mathrm{~min}$ of reperfusion follawing $60 \mathrm{~min}$ of ischemia. $P, I$ and $R$ refer to pre-ischemia, ischemia and reperfusion, respectively. Data are expressed as means \pm SD. Asterisk indicates significantly different from pre-ischemic values $(p<0.05)$.

contents of ADP and AMP. At the end of reperfusion ADP, AMP and adenosine contents had returned to their pre-ischemic values.

Reperfusion was associated with a rise in myocardial NEFA content (fig 5.5). The NEFA content was significantly increased in reperfused hearts previously exposed to 30 or $45 \mathrm{~min}$ of ischemia. The rise of NEFA's during reperfusion was very pronounced in hearts subjected to 60 min of ischemia followed by reperfusion. As compared to pre-ischemic hearts the percentage contribution of individual NEFA's to total NEFA's had changed significantly after ischemia and reperfusion (table 5.5). On a percentage base C18:1 and C18:2 markedly increased, $\mathrm{C20:4}$ remained constant, and C22:6 sharply decreased. Only minor differences were observed in the percentage contribution of individual NEFA"s in hearts rendered ischemic for $90 \mathrm{~min}$ as compared to 
stroke volume $(\mu l)$
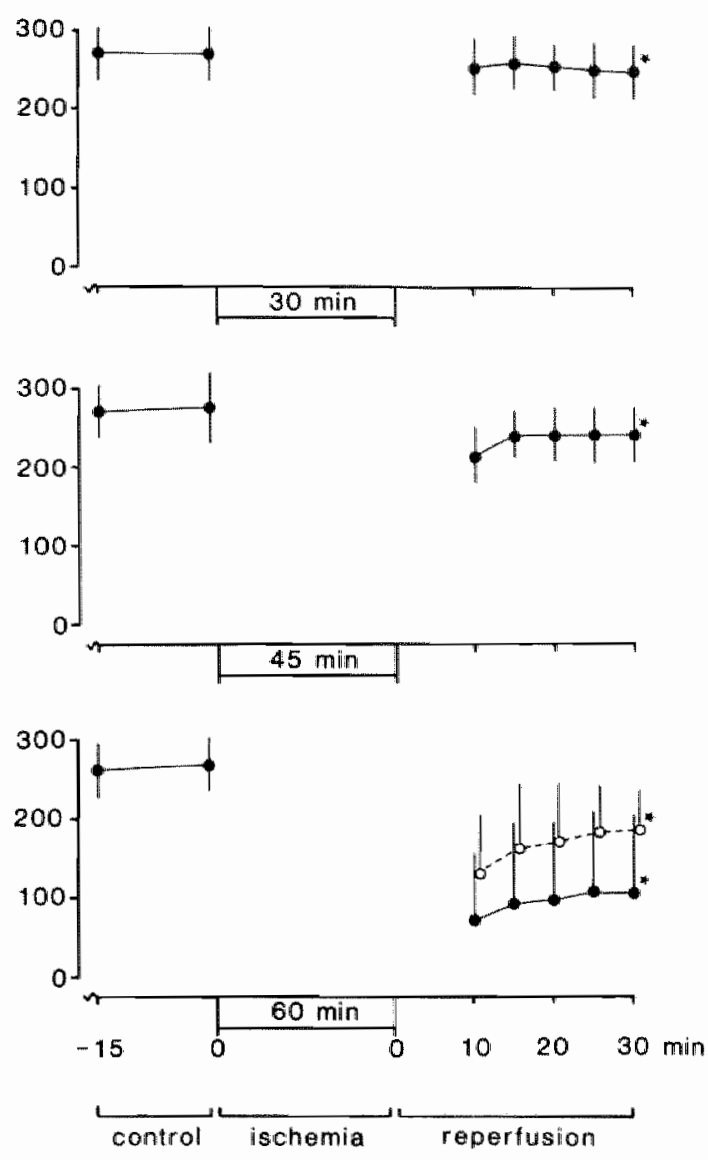

F1g 5.4 Recovery of stroke voiume during reperfusion following 30 (a), 45 (b) and $60 \mathrm{~min}(\mathrm{c})$ of no-flow ischemia. In the lower panel the solid line refers to the recovery of the entire group of hearts following $60 \mathrm{~min}$ of no-flow ischemila $(n=16)$. The dashed 1 ine refers to the recovery of the subgroup of hearts, that resumed regular rhythm during reperfusion $(n=9)$. Data are expressed as means \pm SD. Asterlsk designates significance between end-reperfusion value and pre-ischemic value $(p<0.05)$. 
Table 5.4 Myocardial content of creatine phosphate and ademine nucleotides before, and after ischemia of warlable duration with and without 30 ininutes of reperfusion.

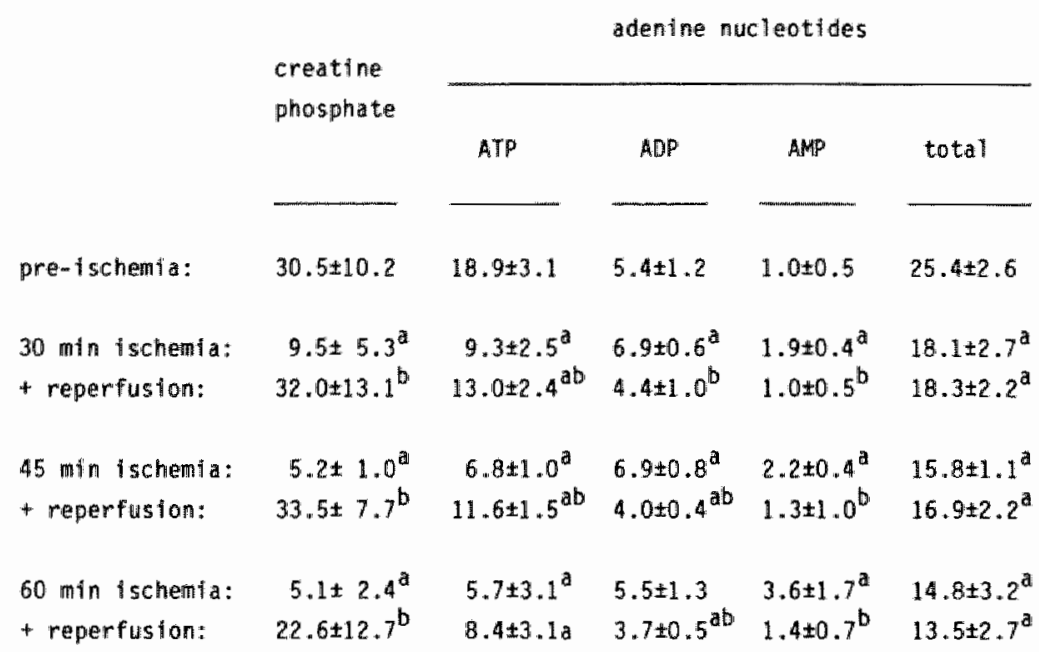

Data presented in $\mu$ mol. $g^{-1}$ dry wt and presented as means $\pm S O$. Total refers to sum of ATP, ADP and AMP. a - p<0.05 vs. pre-ischemic value. b - p<0.05 vs. ischemic value.

hearts subjected to $60 \mathrm{~min}$ of ischemia and $30 \mathrm{~min}$ of reperfusion. Only the contribution of C16:0 to total NEFA's was significantly less in reperfused hearts (table 5.5).

To investigate whether the reperfusion induced rise in NEFA's was instantaneous or more gradual, the tissue content of NEFA's was measured in hearts subjected to $60 \mathrm{~min}$ of $i$ schemia and $5 \mathrm{~min}$ of reperfusion. As compared to the hearts rendered ischemic for $60 \mathrm{~min}$, the content of NEFA's in the hearts reperfused during $5 \mathrm{~min}$ following $60 \mathrm{~min}$ of ischemia tended to increase

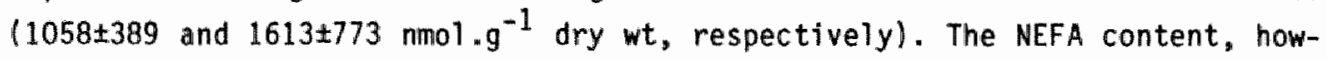
ever, was still substantially lower than the NEFA content of hearts reperfused for $30 \mathrm{~min}$ following this period of ischemia $\left(4130 \pm 2110 \mathrm{nmol} \cdot \mathrm{g}^{-1}\right.$ dry wt). This indicates that the rise of NEFA's during reperfusion is gradual, instead of 


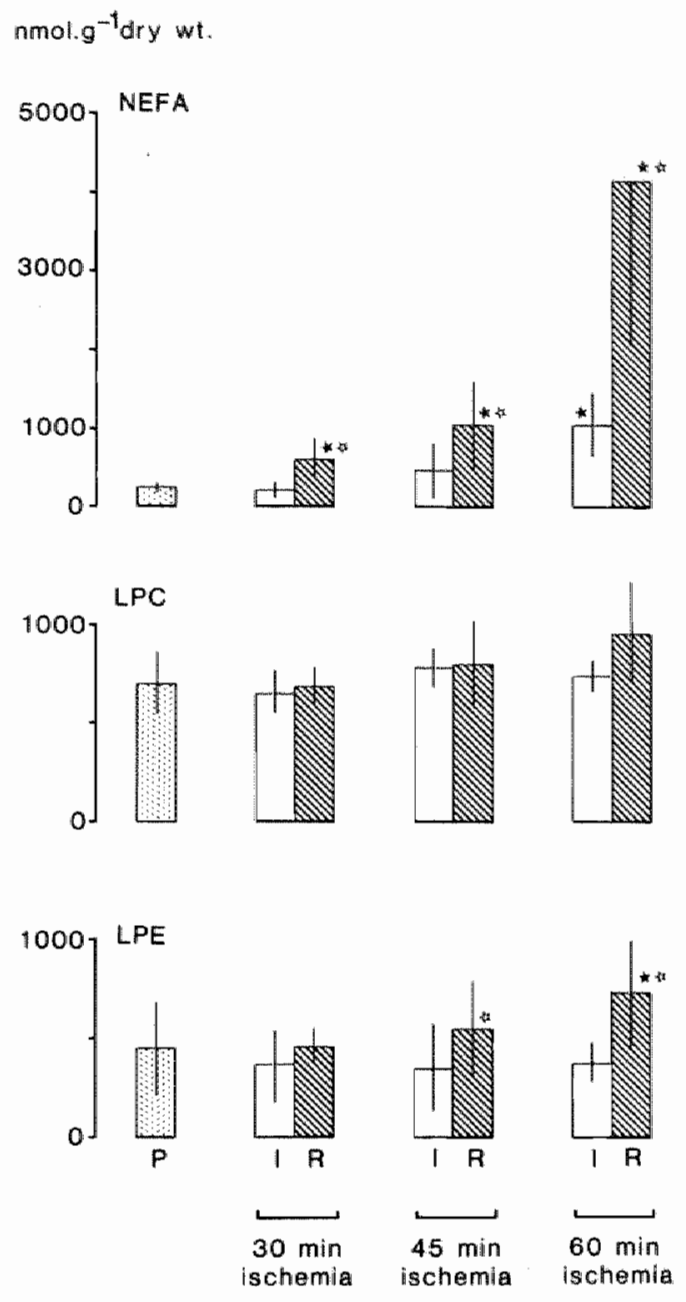

Fig 5.5 Effect of ischemia of varfable duration (I, open bars) and subsequent reperfuston ( $R$, hatched bars) on the myocardial content of NEFA's, lysophosphatidylicholine (LPC) and lysophosphatidylethanolamine (LPE) (the latter two expressed as lipid phosphorus). P' refers to preischemic control. The duration of the ischemic perfod is given at the bottom of the figure. Reperfusion 1 asted for $30 \mathrm{~min}$. Data are expressed as means $\pm S D$. Closed asterisk indicates significantly different from pre-ischemic value $(p<0.05)$. Open asterisk designates signiffcance between reperfusion value and ischemic value. 
Table 5.5 Total NEFA content and percentage contribution of individual NEFA's to total NEFA's before, and follawing 90 min of ischemial, and 60 win of ischemia plus 30 min of reperfusion.

\begin{tabular}{|c|c|c|c|c|}
\hline \multirow{9}{*}{$\begin{array}{l}\text { total NEFA's: } \\
\text { (umol. } g^{-1} \text { dry }\end{array}$} & & pre-1schemia & 90 min ischemi & $\begin{array}{l}60 \text { min ischemia } \\
30 \text { min reperfusion }\end{array}$ \\
\hline & $w t)$ & $0.25 \pm 0.05$ & $1.64 \pm 1.22^{a}$ & $4.13 \pm 2.1 \pm^{\mathrm{ab}}$ \\
\hline & & & & \\
\hline & $C 16: 0$ & $12.8 \pm 4.7$ & $21.9 \pm 1.8^{a}$ & $18.4 \pm 1.5^{\mathrm{ab}}$ \\
\hline & C18:0 & $19.4 \pm 4.2$ & $21.7 \pm 2.0$ & $21.3 \pm 3.7$ \\
\hline & $\mathrm{C} 18: 1$ & $4.9 \pm 4.3$ & $15.6 \pm 2.4^{a}$ & $15.6 \pm 1.3^{\mathrm{a}}$ \\
\hline & $\mathrm{C} 18: 2$ & $11.5 \pm 2.8$ & $20.6 \pm 1.4^{\mathrm{a}}$ & $22.5 \pm 3.4^{\mathrm{a}}$ \\
\hline & $C 20: 4$ & $12.7 \pm 2.3$ & $10.4 \pm 1.6$ & $11.4 \pm 2.1$ \\
\hline & $c 22: 6$ & $33.9 \pm 11.2$ & $6.7 \pm 2.1^{\mathrm{a}}$ & $7.3 \pm 2.3^{\mathrm{a}}$ \\
\hline $\begin{array}{l}\text { Data expresse } \\
\text { specles are } \\
\text { motation. a - } \\
\text { value. }\end{array}$ & $\begin{array}{l}\text { d as me } \\
\text { shown. } \\
\text { p<0.05 }\end{array}$ & $\begin{array}{l}\text { means } \pm \text { SD. On } \\
\text {. Individual } \\
5 \text { vs. pre-ische }\end{array}$ & $\begin{array}{l}\text { the quantitatively } \\
\text { FA's are denoted } \\
\text { ic value. } b-p<0.05\end{array}$ & $\begin{array}{l}\text { most importamt NEFA } \\
\text { by their chenical } \\
\text { vs. } 90 \text { min ischemic }\end{array}$ \\
\hline
\end{tabular}

being 1 imited to the first minutes of reperfusion.

Reperfusion following 30,45 and 60 min of ischemia was not associated with signifficant alterations in the tissue level of LPC (fig 5.5). In contrast, the myocardial LPE content was found to increase during reperfusion following 45 and $60 \mathrm{~min}$ of ischemia. In hearts reperfused for $30 \mathrm{~min}$ following $60 \mathrm{~min}$ of ischemia, tissue levels of LPE were almost twice the value measured after $60 \mathrm{~min}$ of ischemia. But even in these hearts the large increase of tissue NEFA's and the significant rise in LPE was not associated with a measurable decrease in the myocardial content of the major phospholipids (table 5.6). In reperfused hearts subdued to $60 \mathrm{~min}$ of ischemia only a small, but significant decrease in the content of the plasmalogen form of $P C$ was 
observed. No such change was observed in the pe plasmalogen content ltable 5.6). The triacylglycerol content of these hearts was comparable the of pre-ischemic hearts (table 5.6).

During reperfuston glycerol was released into the coronary effluent. Following 60 min of ischemia the cumulative release of glycerol during 30 math reperfusion amounted to $0.79 \pm 0.12$ unol heart ${ }^{-1}$. This value corresponds with a total release of glycerol of about 4 umol.g-1 dry wt of tissue. At the end of reperfusion the tissue contents of glycerol-3-phosphate and glycerol had

Table 5.6 hyocardial content of phospholipids and triacylglycerols before. and followitug 90 min of ischenta, and 60 min t schemia plus 30 min reperfuslon.

pre-ischemia 90 min ischemia $\quad 60$ iscota +
30 min reperfuston

phospholipids:

\begin{tabular}{|c|c|c|c|}
\hline total & $: \quad 178.0 \pm 11.9$ & $166.0 \pm 17.5$ & $172.3 \pm 26.4$ \\
\hline$P C_{d i}$ & $71.9 \pm 6.8$ & $65.8 \pm 4.1$ & $65.8 \pm 8.2$ \\
\hline$P C_{p 1}$ & $0.6 \pm 0.1$ & $0.5 \pm 0.2$ & $0.5 \pm 0.1^{a}$ \\
\hline$P E_{d i}^{H i}$ & $56.6 \pm 5.0$ & $58.1 \pm 6.5$ & $57.1 \pm 11.9$ \\
\hline$P E_{p l}$ & $4.9 \pm 1.8$ & $4.9 \pm 1.1$ & $4.6 \pm 1.2$ \\
\hline PItPS & $11.5 \pm 2.7$ & $8.8 \pm 3.6$ & $10.6 \pm 4.2$ \\
\hline SPH: & $5.3 \pm 0.5$ & $4.7 \pm 0.5$ & $5.4 \pm 0.5$ \\
\hline$D P G$ & $26.7 \pm 1.4$ & $21.4 \pm 8.5$ & $29.7 \pm 13.0$ \\
\hline $\begin{array}{l}\text { triacyl- } \\
\text { glycerols }\end{array}$ & $32.3 \pm 10.1$ & $52.0 \pm 11.9^{\mathrm{a}}$ & $33.5 \pm 13.5^{b}$ \\
\hline
\end{tabular}

Values are given in $\mu$ mol. $\mathrm{g}^{-1}$ dry wt and presented as mearls $\$$ SD. Trlacylglycerols and phospholipids (total and individual) are expressed as fatty acid equivalents and lipid phosphorus, respectively. $P C_{d i}$ and $P E_{d i}$ refer to the d-acyl forms of $P C$ and $P E$, respectively. $P C D A$ and $P E$ pl refer to the plasmalogen forms of $P C$ and $P E$, respectivelly, and are measured as the dimethylacetal forms of the fatty aldehydes. other abbreviations used are explained in table 5.1. a - p<0.05 vs. pre-ischentic value. b - p<0.05 vs. 90 min ischemic value. 
reached their pre-ischemic values (fig 5.3 ).

To assess the extent of myocardial cell damage the release of lactate dehydrogenase (LDH) into the coronary perfusate was measured during reperfustion. Cumulative release of $L D H$ was found to be related to the time duration of the preceding ischemic period and amounted to $3.5 \pm 1.0,9.7 \pm 2.5$ and $22.0 \pm 7.5$ units per heart per $30 \mathrm{~min}$ reperfusion after 30,45 and $60 \mathrm{~min}$ of ischemia, respectively.

As indicated above, restoration of flow following $60 \mathrm{~min}$ of ischemia resulted in a variable functional response. Some hearts fibrillated during almost the entire reperfusion phase, whereas others were able to resume spontaneous rhythm and to partially restore pump performance (see fig 5.4). This difference in electrical behavior was not associated with differences in the cumulative release of LDH during reperfusion (on the average 22.0 and 21.9 units per heart during 30 min of reperfusion for fibrillating and beating hearts, respectively). Moreover, no relation was found between the tissue content of NEFA's, LPC and LPE, on the one hand, and the electrical behavior of the reperfused hearts, on the other (table 5.7).

\subsection{Discussion}

Myocardial 1ipid homeostasis during normoxia.

The myocardial NEFA content of normoxic hearts is low and averages 0.25 $\mu \mathrm{mol} . \mathrm{g}^{-1}$ dry wt, i.e. about $0.04 \mu \mathrm{mol} . \mathrm{g}^{-1}$ wet wt (dry residue wt / wet wt ratio is 0.14$)$. Assuming that virtually all NEFA's are located in the cytosolic space, which comprises $50 \%$ of the tissue space of Krebs-Henseleit perfused hearts (Buenger and Soboll, 1986b), it can be estimated that the cytosolic NEFA concentration amounts to about $70 \mu \mathrm{mol} .1$ itre ${ }^{-1}$ of cytosolic fluid. This concentration would be incompatible with normal kinetics of fatty acill activation ( $\mathrm{Km}$ of acyl-COA synthetase is $8 \mu \mathrm{M})$. It is not known, however, how enzyme kinetics is affected by the fatty-acid binding protein (FABP), which is present in abundance in the sarcoplasm (Glatz et al., 1984). Moreover, pyruvate, present as exogenous substrate during perfusion of the hearts, has been shown to be a potent inhibitor of fatty acid oxidation (Evans et al., 1963). Indeed, in glucose-perfused nomoxic hearts the NEFA content was found 
Table 5.7 Tissue content of NEFA"s and lysophospholipids of fibrlllating and non-fibrillating hearts following 60 min ischemla and 30 min reperfusion.

\begin{tabular}{|c|c|c|c|}
\hline & NEFA"'s & LPC & LPE \\
\hline \multicolumn{4}{|l|}{ Fibrillating } \\
\hline hearts: & $4.55 \pm 0.97$ & $0.97 \pm 0.33$ & $0.75 \pm 0.36$ \\
\hline \multicolumn{4}{|l|}{ Recovering } \\
\hline hearts: & $3.80 \pm 0.94$ & $0.94 \pm 0.22$ & $0.71 \pm 0.21$ \\
\hline
\end{tabular}

to be substantially lower (about $0.10 \mu \mathrm{mol} . \mathrm{g}^{-1}$ dry residue wt or about 30

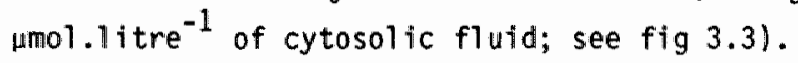

Glatz and coworkers (1984) reported a tissue content in the order of 100 nmol of FABP. $g^{-1}$ wet wt and a dissociation constant (Kd) of $1 \mu \mathrm{M}$ for rat heart FABP. FABP is considered to be a cytosolic protein and, hence, the FABP concentration in the cytosol will amount to about $200 \mu \mathrm{M}$. When these data are used to solve the equation

$K d=[N E F A] \cdot[F A B P] /[N E F A . F A B P$ complex $]$

it follows that the ratio of $[\mathrm{NEFA}] /[\mathrm{complex}]=1 / 200$. On the basis of this ratio and an estimated cytosolic (bound + unbound) NEFA concentration of 70 $\mu \mathrm{M}$ ( see above), an unbound NEFA concentration of $0.35 \mu \mathrm{M}$ can be calculated. Using isolated rat heart mitochondria, Piper and coworkers (1983) demonstrated that concentrations of 0.1-1.0 $\mu \mathrm{M}$ of unbound NEFA's completely abolish mitochondrial function. It should be noted that these investigators reported differences in the toxicity of individual NEFA"s. Nevertheless, the above described calculations indicate that elevated tissue NEFA levels will rapidiy interfere with mitochondrial function. 
Lipld changes during ischemia.

The findings in the present study lindicate that the total amount of NEFA's does not change during the first half hour of ischemia. The tilssue content of individual fatty acids, however, changed significantiy during this period. The content of poly-unsaturated fatty acids gradually decreases, whereas the content of saturated fatty acids increases. These findings suggest that already during early ischemia the turnover rates of lipid pools are likely to be affected. In line with these results, chien and coworkers (1984) provided evidence that remodelling of the fatty acyl composition of phosphatidylcholine took place before NEFA's started to accumulate.

The rise of the myocardial total NEFA content during ischemia is a rather late phenomenon, preceded by an extensive fall in creatine phosphate and a substantial decline in the tissue content of ATP. The mechanism underlying the accumulation of NEFA's is incompletely understood. In this model a potential role of circulating fatty acids can be excluded. Therefore, only net degradation of endogenous 1ipids, like triacylglycerols or phospholipids, has to be considered as a cause of the rise in NEFA"s during myocardial ischemia.

The present findings indicate that triacylglycerol homeostasis is affected during the initial phase of ischemia. Within 30 min after cessation of flow glycerol significantly accumulates in the oxygen deprived tissue labout 2 $\mu \mathrm{mol} . \mathrm{g}^{-1}$ dry wt; see fig 5.3). Since no measurable changes in the content of triacylglycerols and total NEFA's accur's during the same time interval, the rates of hydrolysis and synthesis of triacylglycerols must be in equilibrium. To illustrate the extent of cycling, this amount of glycerol corresponds with 20\% of the total amount of glycerol used as backbone in the cardiac triacylglycerol pool. Enhanced triacylglycerol cycling is most likely due to mass action of glycerol-3-phosphate, the content of which also significantly increases in ischemic tissue (see fig 5.3), due to degradation of glycogen and concomitantly impalired glyceraldehyde-3-phosphate dehydrogenase activity. The observed changes in the myocardial content of individual NEFA"s (see table 5.2) are in accord with cycling of triacylglycerols. The cycling of triacylglycerols is associated with the consumption of considerable amounts of ATP required for the activation of NEFA's to form acyl-COA and subsequent re-esterification. The consumption of ATP in this "futile" cycle will undoubtedly accelerate the depletion of ATP in the oxygen deprived tissue. On the other hand re-esterification of NEFA's into the triacylglycerol pool might protect 
the myocardium against the potential harmful effects of elewated levels of NEFA"s and other fatty acid derivatives.

The present findings are in agreement with those of Trach and cowonkers (1986), who observed enhanced triacylglycerol cycling in Langendorff perfused low-flow ischemic rat hearts. Conflicting results have been published by Burton and coworkers (1986). They demonstrated that the triacylglycerol level rapidiy increases during the initial phase of ischenia. Interestingly, Heathers and Brunt (1985) have reported a significantly increased activity of triacylglycerol lipase and impaired activity of glycerol-3-phosphate acyltransferase in homogenates of ischemic myocardial tissue. The latter findings would favor net hydrolysis of endogenous triacylglycerols in the affected tissue. The obvious discrepancy between the observations mentioned is incompletely understood.

During prolonged ischemia, i.e. more than 45 min, NEFA's significantly accumulate in the affected tissue. Incomplete cycling of triacylglycerols could result in a net production of NEFA's. Since the inter-individual variation in triacylglycerol content in the rat heart is very large and the observed increase in tissue NEFA"s corresponds to only a small percentage of the total amount of fatty acids incorporated in the triacylglycerol pool lless than $4 \%$ ), we can not expect to measure a stolichiometric relationship between accumulation of NEFA's and decrease, if any, of triacylglycerols in ischemic heart tissue. The observation that the triacylglycerol content at 90 min of ischemia was even significantiy increased in comparison with the pre-ischemic content makes it less likely that triacylglycerols are the main source of NEFA's during ischemia.

An alternative source for MEFA's, accumulating in the ischemic cells, are the phospholipids. Our results indicate that the rise of NEFA's is not associated with a measurable decrease in the myocardial phospholipid content. It should be noted, however, that a rise in NEFA's of 1.5 umol. $\mathrm{g}^{-1}$ dry wit after 90 min of ischemia still represents less than $1 \%$ of all fatty acids esterified in the total phospholipid pool. The chemical assay techniques available are not sensitive enough to measure such a small difference in tissue phospholiptd content. Measurement of the individual phospholipids, like PC, $P E$ and others (see table 5.3) indicates that the content of none of these phospholilpids was significantly altered. Other studies have shown that phospholipid depletion is only measurable after prolonged ischemia of more than three hours (Man et al., 
1983; Steenbergen and Jennings, 1984). Circumstantial evidence that phospholipids are responsible for the observed accumulation of NEFA's during oxygen deprivation is derived from the finding that arachidonic acid, which is. mainly esterified into phospholipids, contributes considerably to the total rise in NEFA's (Van der Vusse et a1. 1982; Chien et a1., 1984; Prinzen et al., 1984; Van Bilsen et al., 1987). Before that, Weglicki and coworkers (1973) already reported a relative increase in the tissue content of arachidonic acid as compared to saturated and mono-unsaturated fatty acids in dog heart tissue rendered globally ischemic. More direct evidence was obtained by Gunn and colleagues (1985), who demonstrated that arachidonic acid was specifically released from phospholipids in neonatal myocardial cell cultures during ATP depletion, using radiolabeled fatty acids.

In the present study small amounts of lysophospholipids are found to accumulate in prolonged ischemic tissue. This finding is consistent with other studies demonstrating that accumulation of lysophospholipids on a quantitative base, appears to be of minor importance or totally absent (Shaikh and Downar, 1981; Chien et al. 1984) and becomes only substantial in necrotizing tissue after prolonged ischemia (Steenbergen and Jennings, 1984). It should be noted that other investigators (Sobel et al., 1978) found evidence for a rapid accumulation of lysophospholipids during ischemia. The latter finding could not be corroborated by the present study. Assuming that NEFA accumulation is caused by phospholfipid breakdown, the lack of substantial accumulation of lysophospholipids could be explained by the presence of lysophospholipase activity. Indeed, Gross and Sobel (1983) and Nalbone and Hostetler (1985) observed a high intracellular activity of lysophospholipase in cardiac tissue. Further degradation of lysophospholipids could well explain the observed rise of saturated and mono-unsaturated fatty acids during ischemia, since these phospholipid species are highly enriched with these fatty acids (see relative fatty acid composition of LPC and LPE in table 5.1).

At this moment the mechanism invoived in the putative degradation of phospholipids during ischemfa is still a matter of debate. Deacylation of phospholipids could be increased by enhanced activity of phospholipase $A_{2}$. However, increased (Das et a1., 1986) as well as decreased (Bentham et al., 1987) phospholipase activity in ischemic cardiac tissue has been reported. In addition, the activity of acyl-COA synthetase and 1ysophospholipid acyltransferase has been found to diminish during ischemia (Das et al.. 1986), indica- 

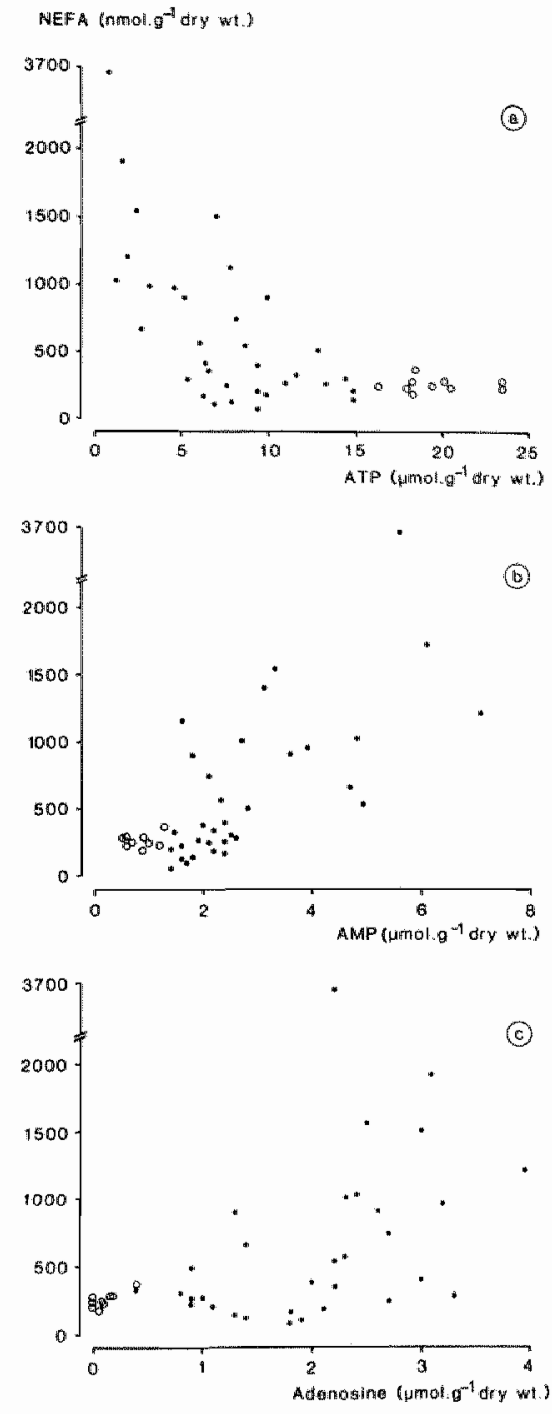

Fig 5.6 Relation between tissue content of (a) ATP and NEFA's and (b) AMP and NEFA's (c) adenosine and NEFA's of pre-ischemic hearts $(O)$ and hearts subjected to $10,30,45,60$ or 90 min of ischemia (•). 
ting that resynthesis of phospholipids might also be impaired.

Beside the aforementioned changes in the maximal activity or $V_{\text {max }}$ as measured under in-vitro conditions, of enzymes inwolved in the deacylationreacylation cycle, unfavarable changes in the intracellular environment of the enzymes may also negatively affect the turnover of phospholipids. Gunn and coworkers (1985), exploring the possible relationship between tissue ATP levels and release of arachidonic acid from the phospholipid pool, demonstrated that release of arachidonic acid already took place before ATP was reduced to levels approaching the $\mathrm{Km}$ of acyl-CoA synthetase, using a $\mathrm{Km}$ value of $0.8 \mathrm{mM}$. However, these authors did not take into account the potentially inhibitory effect of ischemic products like AMP and adenosine (De Jong and Huelsmann, 1970). An apparent $k i$ of $0.1 \mathrm{mM}$ for adenosine of both rat heart (De Jong and Huelsmann, 1970) and rat liver acyl-COA synthetase (Van Tol and Huelsmann, 1970) has been reported. An apparent $K i$ value of $0.2 \mathrm{mM}$ for AMP was estimated on the basis of experiments with rat liver mitochondria (Van Tol and Huelsmann, 1970). To explare in more detail the possible relationship between the tissue contents of ATP, AMP and adenosine on the one hand, and NEFA content on the other hand, the ATP, AMP and adenosine contents of individual hearts rendered ischemic for various periods, were plotted against their NEFA content. Figure 5.6 shows that, in general, NEFA accumulation only occurred when ATP levels in the ischemic tissue were less than $10 \mu \mathrm{mol} . \mathrm{g}^{-1}$ dry wt and AMP and adenosine levels exceeded $2 \mu$ mol. $\mathrm{g}^{-1}$ dry wt. Assuming an intracellular volume of about $60 \%$ of total volume and a dry to wet weight ratio of 0.2 , these tissue levels correspond to concentrations of about $3.3,0.7$ and 0.7 mmo1.1itre ${ }^{-1}$ of intracellular fluid for ATP. AMP and adenosine, respectively. Thus, in line with the findings of Gunn and coworkers (1985) NEFA levels rise when ATP levels are well above the $\mathrm{Km}$ value. However, the $\mathrm{Ki}$ values for AMP and adenosine are clearly surpassed, making the latter two substances good candidates to hamper acyl-COA synthetase activity in-situ and, hence, to promote accumulation of NEFA's during ischemia. However, due to the specific localization of this enzyme at the surface of the outer mitochondrial membrane and sarcoplasmic retficulum (Aas, 1971; Groot et al., 1976) and the well known compartmentalization and partial binding to cellular proteins of ATP and related compounds, extrapolation of tissue contents to intracellular concentrations for comparison with $\mathrm{Km}$ and $\mathrm{K} i$ values, measured under in-vitro conditions, should be done with care. Moreover, it should be recognized that such 
an extrapolation does neither take into account intercellular differences in the tolerance to ischemia and so-induced differences in the amounts of AMP and adenosine accumulating per cell.

\section{Lipid changes during reperfusion.}

The present results indicate that in the isolated rat heart madel reperfusilon per se results in a significant elevation of the myocardial NEFA content. This accurs already after relatively short periods of ischemia, i.e. 30 min of flow cessation. The final amount measured at the end of reperfusion is related to the time duration of the preceding ischemic period. Comparison of the NEFA. levelis of hearts subjected to $90 \mathrm{~min}$ of ischemia and hearts subjected to 60 min of ischemia and 30 min of reperfusion clearly indicates that restoration of flow after longer time periods of ischemia even enhamces the rate of lipid hydrolysis.

Circumstantial evidence indicates that it is very unlikely that triacylglycerols are the main source of the NEFA's accumulating during reperfusion. First of all, at the end of reperfusion following 60 min of ischenia the myocardial content of triacylglycerols is comparable to that in pre-ischemic hearts. Secondly, the amount of arachidonic acid $(\mathrm{C} 20: 4)$ incorporated in the triacylglycerol pool of normoxic hearts is $10 \mathrm{w}$ and amounts $1.16 \mu \mathrm{mol} . \mathrm{g}^{-1} \mathrm{dry}$ wt on the average. If al1 c20:4 accumulated after $60 \mathrm{~min}$ of ischemia and 30 min of reperfusion $\left(0.47 \mu \mathrm{mol} . \mathrm{g}^{-1}\right.$ dry $\left.w t\right)$ is derived from triacylglycerols, the amount of $020: 4$ in the triacylglycerol pool would have to be reduced by about $40 \%$. This is obviously not the case because the amount of c20:4 esterified to triacylglycerols at the end of reperfusion is found to be unchanged (1.24 umol. $\mathrm{g}^{-1}$ dry wt on the average).

It seems as if futile cycling of triacylglycerols, as observed during ischemia, ends immediately after restoration of flow. This conclusion is based on the finding that the amount of glycerol released during reperfusion matches the amount accumulated in the heart just prior to reinstallation of flow. In Iine with this notion is the observation that glycerol-3-phosphate, accumulated in the tissue at the end of the ischemic period, does obvilously not contribute to post-ischemic release of glycerol. Giycerol-3-phosphate accumulated is most likkely channeled into the glycolytic pathway, since normalization of the $\mathrm{NADH} / \mathrm{NAD}^{+}$ratio during reperfusion will relieve the inhibition of glyceraldehyde-3-phosphate dehydrogenase activity. 
Desplte the accumulation of large amounts of NEFA"s during reperfusion following $60 \mathrm{~min}$ of ischenta, the tissue content of the various phospholipids is not signiflcantly reduced and only a relatively small increase in the myocardial content of lysophospholipids is observed.

With respect to the possible cause of enhanced phospholipid degradation during the reperfusion period several mechanistic explanations have been offered recently. Calcium influx, resulting in the activation of phospho1 ipases has generally been suggested to be the cause of increased hydrolysis of phospholipids during reperfusion (Hsueh and Needleman, 1978, Das et al., 1986). Das and coworkers (1986) were able to demonstrate that the activity of phospholipase $A_{2}$, isolated from reperfused tissue, is enhanced. Moreover, these authors demonstrated that the $v_{\max }$ of acyl-CoA synthetase and lysophospholipid acyltransferase, measured under in-vitro conditions, remains depressed during reperfusion. Our results indicate that the reperfusion induced rise in NEFA's occurs despite normalization of the tissue levels of AMP and adenosine. This observation makes it less likely that NEFA accumulation during reperfusion is related to the putative inhibitory effect of these modulators of acyl-COA synthetase activity.

The question remains open as to why NEFA"s, the preferred substrates under normoxic conditions, continue to accumulate and are not used as metabolic fuel

Fig 5.7 Relationships between (a) tissue content of NEFA's at the end of the ischemic period (30, 45 or $60 \mathrm{~min}$ of ischemia) and percentage recovery of stroke volume as measured at the end of the subsequent $30 \mathrm{~min}$ of reperfusion (means $t S D$ ), (b) tissue content of NEFA's at the end of reperfuston following 30,45 and $60 \mathrm{~min}$ of 1 schemila and recovery of stroke wolume (paired data of individual hearts), and (c) tissue content of MEFA's of reperfused hearts and the cumulative release of LDH during $30 \mathrm{~min}$ of reperfusion. In panel b and $c$ the different symbols refer to individual hearts previously subjected to $30 \mathrm{~min}$ of ischenia ( $)$ ), 45 min of ischemia ( $\Delta)$, and 60 min of ischemia ( $)$ and $O$ for electrically recovering and fibrillating hearts, respective$1 y)$. $r_{1}$ refers to the $r$-value of all hearts examined, whereas $r_{2}$ refers the $r$-value of hearts that were able to restore regular rhythm during reperfustion. $* *-p<0.001$. 
strothe volume (w)

(a)

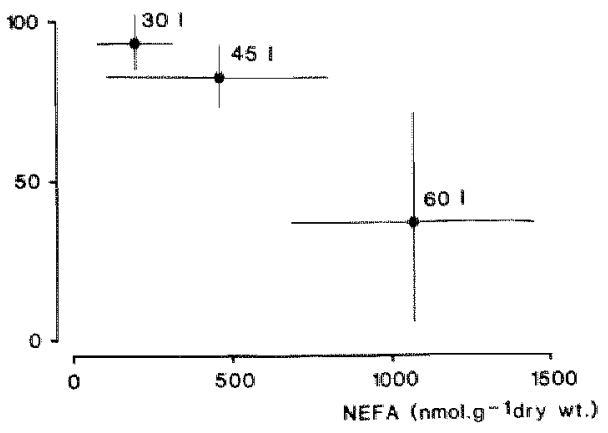

(b)

stroke volume: (w)

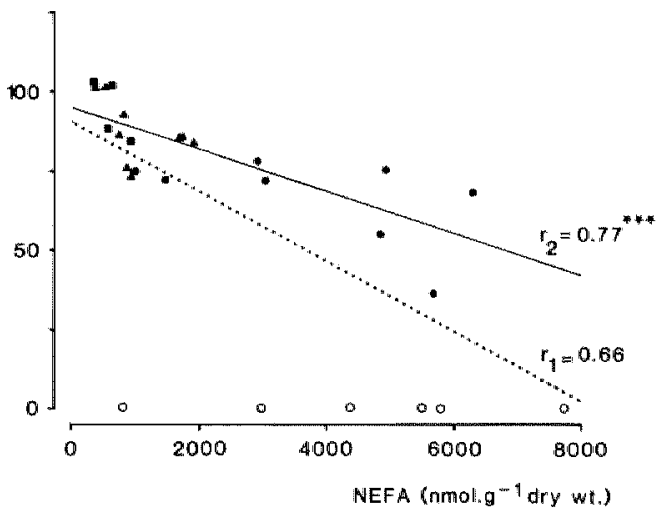

LOH (units heart ${ }^{-1}$ )

(c)

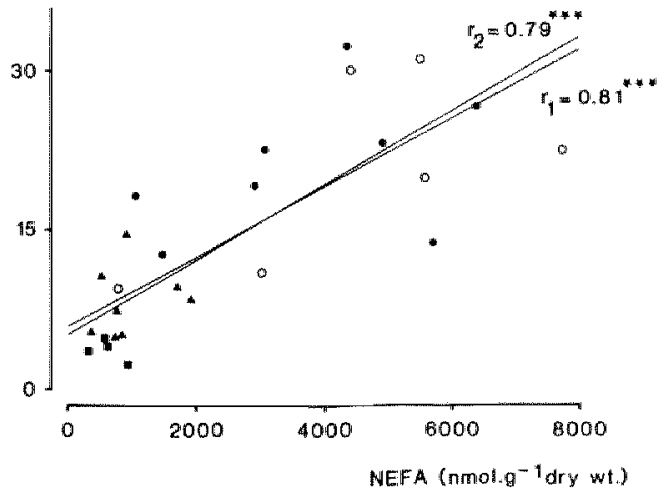


after restoration of oxygen supply to the affected tissue. Using radiolabeled fatty acids. Schwaiger and coworkers (1985) observed an impaired oxidation of fatty acids in reperfused dog cardiac tissue. In a Langendorff perfused rat heart model Burton and coworkers (1986) showed that reperfusion of previously ischemic tissue did not reverse the lipid changes taking place during ischemia. In addition, it is conceivable that pyruvate, present in the perfusion medium, competes with NEFA's for free COA, a cofactor required for both the oxidation of pyruvate and fatty acids, and hence, inhibits mitochondrial B-oxidation. Alternatively, accumulated NEFA"s could be confined to a compartment from where the NEFA's are inavailable for eventual oxidation.

\section{Lipid changes and myocardial damage.}

It seems plausible that changes in the lipid composition of myocardial membranes alter membrane function (Chien et a1., 1978; Smith et a1., 1980; Matthys et al., 1984). The present study shows that no gross alterations in the content of phospholipids, the major components of myocardial membranes, occur in transiently ischemic cardiac tissue. However, changes in the tissue content of NEFA's and lysophospholipids are observed. Both NEFA's and 1ysophospholipids have been shown to disturb membrane permeability and other vital cellular processes (reviewed by Katz and Messineo, 1981; Corr et al., 1984).

The present findings indicate that recovery of myocardial function is adequate when alterations in NEFA content in ischemic tissue are insignificant, i.e. after 30 and $45 \mathrm{~min}$ of ischemia. However, $60 \mathrm{~min}$ of ischemia

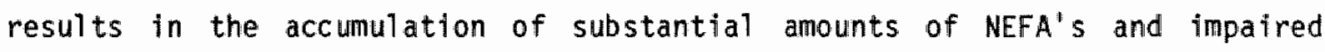
functional recovery during subsequent reperfusion (fig $5.7 \mathrm{a}$ ). Therefore, a relation between the NEFA content at the end of the ischemic period and the ability to restore myocardial function during subsequent reperfusion might be feasible. Also in previous studies from our laboratory (Prinzen et al, , 1984), using a regionally ischemic dog heart model, it was noticed that the time of onset of NEFA accumulation in the ischemic tissue paralleled the time course during which the transition from reversible to irreversible damage is likely to take place (Jennings et a1., 1978).

Plotting the paired data of individual hearts, reperfused following 30,45 and 60 min of ischemia, shows that the relation between the tissue NEFA content and the percentage recovery of stroke volume is rather poor $(r=0.66$, fig 5.7b). However, a correlation coefficient of 0.77 is found when fibril- 
lating hearts are not taken into account and only hearts that are able to resume spontaneous beating after the various periods of ischemia are considered.

It is worth mentioning, that the NEFA content of fibrillating hearts varies greatly (from 1 to $8 \mu \mathrm{mol} \cdot \mathrm{g}^{-1}$ dry wt) and is not significantly different from hearts that resume spontaneous beating during reperfusion following 60 min of ischemia (see also table 5.7). Therefore, it is unlikely that high intracellular levels of NEFA's are responsible for the induction and maintenance of ventricular fibrillation. Besides, the tissue content of lysophospholipids, also known to predispose the heart to arrhythmias (sobel et a1., 1978; Corr et al., 1982), is comparable for fibrillating and non-fibrillating hearts (table 5.7).

As discussed previously (section "myocardial lipid homeostasis during momoxia"), elevated tissue concentrations of NEFA's will interfere with normal mitochondrial function (Piper et a1., 1983). Accordingly, at these moxious tissue NEFA levels severe depression of mechanical performance of the heart might be anticipated. However, the present results show, that in the majority of reperfused hearts with a NEFA content of $1 \mu$ mol..$g^{-1}$ dry wt or more, recovery of mechanical activity is still acceptable. These findings suggest that the accumulated NEFA's are not dilstributed homogeneously over the affected tissue, but are compartmentalized at either the subcellular or the cellular level. The latter idea is supported by the good correlation between the tissue comtent of NEFA's at the end of reperfusion and the cumulative rellease of $L D H$ during reperfusion (fig $5.7 \mathrm{c}$ ). Comparable linear relations were obtained whether or not fibrillating hearts are taken into account. The amount of LOH released after $60 \mathrm{~min}$ of ischemia represents 6-7\% of total LDH activity of the heart (unpublished results), implicating that only a 1 imited number of myocytes is lethally injured. Since the release of intracellular enzymes is generally accepted as an index of loss of cellular integrity, it is feasible that NEFA accumulation is related to lethal cell injury. It could be speculated that NEFA accumulation during reperfusion, as a result of progressive degradation of phospholipids, is confined to a small number of irreversibly damaged cells. Conversely, NEFA levels remain low in reversibly damaged cells. The concept of cellular compartmentalization would pay tribute to the notion that high tissue levels of unbound NEFA"s are incompatible wilth normal mitochondrial function as well as to the present finding that post-ischemic 
function is adequate at noxious tissue levels of MEFA's. However, it still does not provide an answer to the question whether the lipid changes in this subpopulation of cells are either a cause or a result of irreversible damage.

\subsection{Summary.}

The effects of ischemia and reperfusion on myocardial lipid homeostasis were assessed using isolated, working rat hearts, subjected to various periods of ischemia (10 to $90 \mathrm{~min}$ ), with or without an additional $30 \mathrm{~min}$ of reperfusion. Ischemic periods shorter than $30 \mathrm{~min}$ were not associated with significant changes in the total NEFA and triacylglycerol content. The rise of the glycerol content during the same time interval indicates the existence of a energy consuming triacylglycerol-NEFA cycle. A significant rise in total NEFA's was only observed after $60 \mathrm{~min}$ of ischemia. The rise in NEFA's coincided with the reduction of the tissue level of ATP to values lower than 10 $\mu \mathrm{mol} \cdot \mathrm{g}^{-1}$ dry $w \mathrm{t}$, and a rise of AMP and adenosine to values exceeding 2 umol. $\mathrm{g}^{-1}$ ary wt. Since the latter substances are potent inhibitors of acyl-CoA synthetase activity, impaiment of the reacylation process might underly the rise of NEFA"s during ischemia.

Despite unchanged NEFA contents at the end of 30 and $45 \mathrm{~min}$ of ischemia and adequate functional recovery, reperfusion was associated with an increase in the tissue NEFA content. Reperfusion following $60 \mathrm{~min}$ of ischemia resulted in marked functional deterioration, a progressive increase of NEFA"s, and a rise of lysophospholipids. Reperfuston was not associated with a significant fall in the content of triacylglycerols and the various phospholipids. The occurrence of extended fibrillation during reperfusion was not associated with enhanced accumulation of NEFA's and lysophospholipids in the affected tissue.

No unambiguous relation was found between the NEFA content of reperfused hearts and post-ischemic function. In contrast, a strong correlation was found between the NEFA content and enzyme release during reperfusion. It is concluded that reperfusion results in additional changes in myocardial lipid metabo$1 \mathrm{fsm}$ and that the accumulation of NEFA's might be related to irreversible cell damage. 
EFFECTS OF MEPACRINE AND NICOTINIC ACID ON NEFA ACCUMULATION AND MYOCARDIAL DAMAGE IN TRANSIENTLY ISCHEMIC HEARTS.

\subsection{Introduction}

It is generally accepted that disturbances in myocardial lipid metabolism play an important role in the development of irreversible cell damage during ischemia and reperfusion (for review see Farber et al., 1981). Degradation of phospholipids not only leads to the loss of these essential membrane constituents, but also results in the accumulation of noxious metabolites, like lysophospholipids and non-esterified fatty acids (NEFA's) in oxygen deprived cells. Net hydrolysis of triacylglycerols also results in the accumulation of NEFA"s, while acceleration of the turnover of this lipid pool gives rise to an enhanced ATP consumption during ischemia. In theory, each of these events may contribute to the development of cell damage. As a consequence, inhibition of these derangements of lipid metabolism might protect the challenged myocardium.

Inhibitors of phospholipid degradation, like chlorpromazine and mepacrine, have been shown to retard or prevent the loss of membrane phospholipids during myocardial ischemia and/or reperfusion (Chien et a1., 1979; Das et a1., 1986). This was associated with salvage of the myocardium as evidenced by a reduction of enzyme release and/or a reduction in infarct size (see table 6.1 for an overview of published results obtained with mepacrinel. Likewise, nicotinic acid, a putative inhibitor of hormone stimulated triacylglycerol lipolysis, has been shown to reduce epicardial ST-segment elevation and to reduce infarct size (see table 6.2). The putative sites of action of both drugs are illustrated in figure 6.1 .

To delineate the relative importance of derangements in phospholipid and triacylglycerol homeostasis to myocardial damage, isolated, working, rat hearts, rendered transiently ischemic, were perfused in the presence of either mepacrine or nicotinic acid. Previous studies (Van der Vusse et al., 1982; 
Table 6.1 Effects of mepacrine on moctial metabolism and function: A surwey of the loterature.

\begin{tabular}{|c|c|c|}
\hline Study & experimental model & effects \\
\hline $\begin{array}{l}\text { Das et a1. } \\
\llbracket 1986 \rrbracket\end{array}$ & $\begin{array}{l}\text { open chest pig } \\
\text { - regtonial ischemia } \\
\text { followed by global } \\
\text { cardioplegic } \\
\text { arrest and reper- } \\
\text { fusion }\end{array}$ & $\begin{array}{l}\text { - reduction phospholipid } \\
\text { degradation } \\
\text { - preservation high-energy } \\
\text { phosphates } \\
\text { - reduction enzyme release }\end{array}$ \\
\hline $\begin{array}{l}\text { otani et al.* } \\
(1986)\end{array}$ & $\begin{array}{l}\text { - open chest plg } \\
\text { - reglonall ischemia } \\
\text { followed by global } \\
\text { cardioplegic } \\
\text { arrest and reper- } \\
\text { fuslion }\end{array}$ & $\begin{array}{l}\text { - reduction phospholipid } \\
\text { degradation } \\
\text { - preservation high-emergy } \\
\text { phosphates } \\
\text { - no improvement of cardiac } \\
\text { performance } \\
\text { - negatively inotropic }\end{array}$ \\
\hline $\begin{array}{l}\text { Chiariello et al. } \\
(1987)\end{array}$ & $\begin{array}{l}\text { - in situ rat heart } \\
\text { - coronary artery } \\
\text { ifgation }\end{array}$ & $\begin{array}{l}\text { - reduction phospholipid } \\
\text { degradation } \\
\text { - reduction infarct size }\end{array}$ \\
\hline
\end{tabular}

Chien et al., 1984; Van Bilsen et a1., 1987) have shown that the accumulation of NEFA's is a sensitive marker for derangements of lipid metabolism. Therefore, the effect of the drugs on lipid metabolism was assessed by monitoring the tissue content of NEFA's at the end of ischemia and reperfusion. Myocardial protection was assessed from (1) the incidence and duration of ventricular fibrillation after ischemia, (2) the recovery of left ventricular developed pressure and cardiac output, (3) the preservation of the myocardial hilgh-energy phosphate content and (4) enzyme release, a marker for loss of cell mebrane integrity. 
Table 6.2 Effects of aicotinic acid on myocardit metabolisw and function: A survey of the literature.

\begin{tabular}{|c|c|c|}
\hline $\begin{array}{l}\text { Kjekshus and Mibs. } \\
(1973)\end{array}$ & $\begin{array}{l}\text { - in situ rat heart } \\
\text { - isoproterenol } \\
\text { induced necrosis. }\end{array}$ & $\begin{array}{l}\text { - reduction arterial NEFA } \\
\text { level } \\
\text { - reduction cellular necrosis }\end{array}$ \\
\hline $\begin{array}{l}\text { Brownsey and Brunt } \\
(1977)\end{array}$ & $\begin{array}{l}\text { - Isola ted rat heart } \\
\text { - low-flow ischenia } \\
\text { plus adrenaline }\end{array}$ & $\begin{array}{l}\text { - reduction of functional } \\
\text { deterioration } \\
\text { - reduction of glycerol } \\
\text { release }\end{array}$ \\
\hline $\begin{array}{l}\text { Vik-Mo } \\
(1977)\end{array}$ & $\begin{array}{l}\text { - open chest dog } \\
\text { - regional ischemia }\end{array}$ & $\begin{array}{l}\text { - reduction arterial NEFA } \\
\text { level } \\
\text { - no effect on regional myo- } \\
\text { cardial blood flow } \\
\text { - reduction eplcardial ST- } \\
\text { segment elevation }\end{array}$ \\
\hline $\begin{array}{l}\text { Villk-Mo et al. } \\
\text { (1979) }\end{array}$ & $\begin{array}{l}\text { - open chest dog } \\
\text { - regional ischemia, } \\
\text { with or without } \\
\text { isoproterenol }\end{array}$ & $\begin{array}{l}\text { - reduction arterial MEFA } \\
\text { level } \\
\text { - reduction NEFA extraction } \\
\text { - effects on glycerol release } \\
\text { not unambiguous }\end{array}$ \\
\hline $\begin{array}{l}\text { KJek shus } \\
(1981)\end{array}$ & $\begin{array}{l}\text { - open chest dog } \\
\text { - regional ischemia } \\
\text { with or wi thout } \\
\text { previous reserpine } \\
\text { treatment. }\end{array}$ & $\begin{array}{l}\text { - reduction arterial MEFA } \\
\text { level } \\
\text { - reduction ST-segment el eva- } \\
\text { tions }\end{array}$ \\
\hline $\begin{array}{l}\text { Lamping et al. } \\
(1984)\end{array}$ & $\begin{array}{l}\text { - open chest dog } \\
\text { - reglonal ischemia } \\
\text { followed by reper- } \\
\text { fuston }\end{array}$ & $\begin{array}{l}\text { - improvement regional nyo- } \\
\text { cardial function } \\
\text { - reduction NEFA uptake } \\
\text { - enhanced subendocardial } \\
\text { blood fiow during reper- } \\
\text { fustion }\end{array}$ \\
\hline Trach (1984) & $\begin{array}{l}\text { - isolated rat heart } \\
\text { - low-flow ischemla }\end{array}$ & $\begin{array}{l}\text { - reduction glycerol release } \\
\text { - no effect an trfacylglyce- } \\
\text { rol content }\end{array}$ \\
\hline $\begin{array}{l}\text { Vilk-Mo et al. } \\
(19861)\end{array}$ & $\begin{array}{l}\text { - open chest dog } \\
\text { - coronary artery } \\
\text { occlusion }\end{array}$ & $\begin{array}{l}\text { - reduction arterial NEFA } \\
\text { level } \\
\text { - reduction of acylcarnitine } \\
\text { accumulation } \\
\text { - reduction of infarct size }\end{array}$ \\
\hline
\end{tabular}




\subsection{Methods}

Perfusion of the hearts.

Hearts from male Lewls rats were isolated and cannulated as described in detall previausly (chapter 3). The perfusion medium consisted of a modified Krebs-Henseleit blcarbonate buffer, supplemented with glucose (11 mM) and pyruvate ( $5 \mathrm{mM})$ as substrates.

Following $10 \mathrm{~min}$ of perfusion as Langendorff hearts (stabilization period), the hearts were perfused via the left atrium as assisted, working hearts. Left atrial filling pressure was set at $1.0 \mathrm{kPa}$ and the diastolic aortic pressure at $8.0 \mathrm{kPa}$. In the control situation the aortic input impedance used resulted in an aortic pressure pulse of about $4.5 \mathrm{kPa}$ (see chapter 3 for detalled information).

After $30 \mathrm{~min}$ of perfusion as working hearts, the hearts were rendered globally ischemic for 60 min (no-flow ischemia), followed by 30 min of reperfuston. During the first $5 \mathrm{~min}$ of reperfusion the hearts were retrogradely

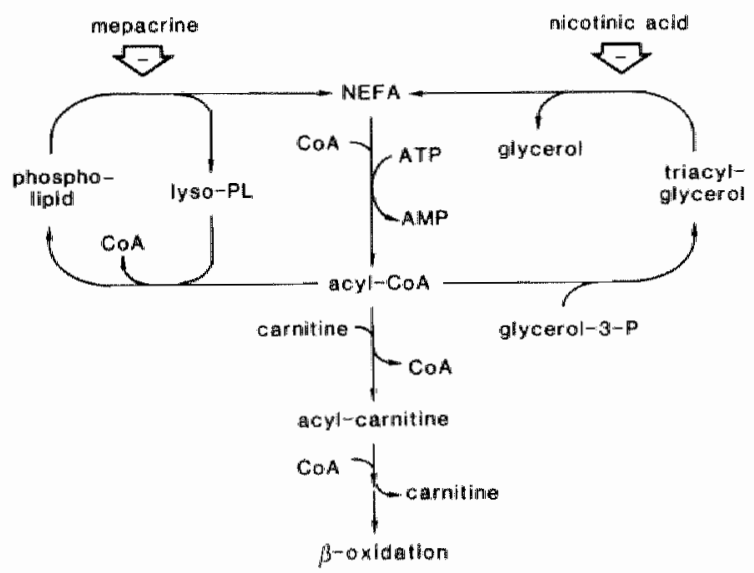

Flg 6.1 Schematic presentation (highly simplified) emphasizing the central role of NEFA's in phospholipid and triacylglycerol, homeostasis and the putative sites of action of mepacrine and nicotinic acid in myocardial lipid metabolism. 
perfused at a perfusion pressure of $8.0 \mathrm{kPa}$. Thereafter, the hearts were perfused antegradely. Hemodynamic variables. like aortic pressure, left ventricular pressure and aortic flow were measured as described elsewhere (chapter 3). Coronary flow was assessed by timed collection of coronary effluent in a graded cylinder. Cardiac output was calculated as the sum of aortic flow and coronary flow. Left ventricular developed pressure was calculated as the difference between systolic and end-diastolic left ventricular pressure.

Nicotinic acid (10 $\mu \mathrm{M}$ final concentration) or mepacrine (1 or $10 \mathrm{MM}$ final concentration) were added to the perfusate when indicated. Both drugs were dissolved in bi-distilled water. The drugs were administered during the pre-ischemic as well as post-ischemic phase. Hearts were freeze clamped at either the end of the pre-ischemic control period (non-treated, $n=9$ ), at the end of ischemia (mon-treated, $n=8$; nicotinic acid treated, $n=6$; mepacrine treated, $n=6$ and $n=3$ at $1 \mu M$ and $10 \mu M$ dose, respectively), or at the end of reperfusion (non-treated, $n=16$; nicotinic acid treated, $n=7$; mepacrine treated, $n=7$ and $n=4$ at $1 \mu \mathrm{M}$ and $10 \mu \mathrm{M}$ dose, respectively). Im addition, to assess the effects of the drugs on normoxic myocardial function, hearts were perfused antegradely for $120 \mathrm{~min}$ in the absence $(n=6)$ or in the presence of either nicotinic acid $(10 \mu M, n=3)$ or mepacrine $(1 \mu M, n=4)$ and subsequentily freeze c1 amped.

\section{Btochemical analysis.}

Perchloric acid extraction of freeze dried tissue samples was performed as described previously (chapter 3). Adenine nucleotides, nucleosides and oxypurines in the neutralized perchloric acid extract were determined by reversed phase HPLC according to the method of Wynants and Van Belle (1985). The neutralized extract was also used for the fluorometric determination of lactate (Van der Vusse et a1., 1984b) and glycerol-3-phosphate and glycérol (modified after Laurell and Tibbling, 1966). The tissue residue, remaining after extraction, was used to assess the myocardial glycogen content (Van der Vusse et a1., 1984b). Myocardial lipids were extracted using the Folch procedure as described in detafl elsewhere (Van der Vusse et al., 1982). Neutral and polar lipids were separated by silicagel column chromatography (Roemen and Van der Vusse, 1985). The neutral lipid fraction was further separated by thin layer chromatography. After elution from the silicagel powder NEFA's and 
triacylglycerols were (trans)methylated and determined by gas-liquid chromatography (Van der Vusse et a1., 1982).

Samples of the coronary effluent were used to determine lactate (Van der Vusse et al., 1982), nucleosides and oxypurines (Harmsen et al., 1981) and lactate dehydrogenase (Bergmeyer and Bernt, 1974).

Statistical analysis.

Results are expressed as mean values and standard deviations. Differences within and between groups were analyzed for sigmificance using Studient's $t$ test for paired and unpaired data, respectively. $P$ values less than 0.05 were considered to be statistically significant.

\subsection{Results}

Normoxic perfusion.

Nicotinic acid $(10 \mu \mathrm{M})$ did not affect hemodynamics of the normoxic working heart. In contrast, at a concentration of $10 \mu \mathrm{M}$ mepacrine had a depressant effect on myocardial performance. The hearts were barely able to generate pressure of any importance (left ventricular developed pressure did not exceed $5 \mathrm{kPa}$ ). At a concentration of $1 \mu \mathrm{M}$ the depressant effect was less. At this dose left ventricular developed pressure and cardiac ouput, as measured after $15 \mathrm{~min}$ of antegrade perfusion, amounted to $10.8 \pm 0.9 \mathrm{kPa}$ and $63 \pm 5 \mathrm{ml} \cdot \mathrm{min}^{-1}$, respectively, a small reduction as compared to the values $112.5 \pm 0.8 \mathrm{kPa}$ and $68 \pm 7 \mathrm{ml}^{\mathrm{min}} \mathrm{m}^{-1}$, in non-drug treated hearts. During the course of the experiments the decline in cardiac output averaged about $1.4 \%$ for non-treated hearts, and $3.4 \%$ and $3.8 \%$ for hearts treated with nicotinic acid and mepacrine $(1 \mu \mathrm{M})$, respectively. Following $120 \mathrm{~min}$ of antegrade perfusion no significant differences in the tissue levels of glycogen (about $80 \mu \mathrm{mol} . \mathrm{g}^{-1} \mathrm{dry} w \mathrm{t}$ ) and triacylglycerols (about $25 \mu \mathrm{mol} . \mathrm{g}^{-1}$ dry wt) were found. However, in the presence of nicotinic acid the myocardial NEFA content was significantly higher $\left(455 \pm 70 \mathrm{nmol} \cdot \mathrm{g}^{-1}\right.$ dry $\left.w t\right)$ than in non-treated and mepacrine $\left(\begin{array}{lll}1 & \mu \mathrm{M})\end{array}\right.$ treated hearts $\left(250 \pm 48\right.$ and $301 \pm 116 \mathrm{nmol} \cdot \mathrm{g}^{-1}$ dry wt, respectively). 
Ischemia and reperfusion.

Hemodynamic recovery.

As shown in fig 6.2, hemodynamic recovery of non-treated hearts following $60 \mathrm{~min}$ of no-flow ischemia was severely depressed. In fact, 7 out of 16 hearts fibrillated during the entire reperfusion phase. The ather 9 hearts fibrillated initially, but were able to resume spontaneous beating within $5.6 \pm 7.2 \mathrm{~min}$ after reinstallation of flow. In this subgroup cardiac output recovered to $68 \%$ of its pre-ischemic value (table 6.3 ). When nicotinic acid was provided, only 1 out of 7 hearts fibrillated during the reperfusion phase. The other hearts recovered contractile activity immediately upon reperfusion. In this subgroup

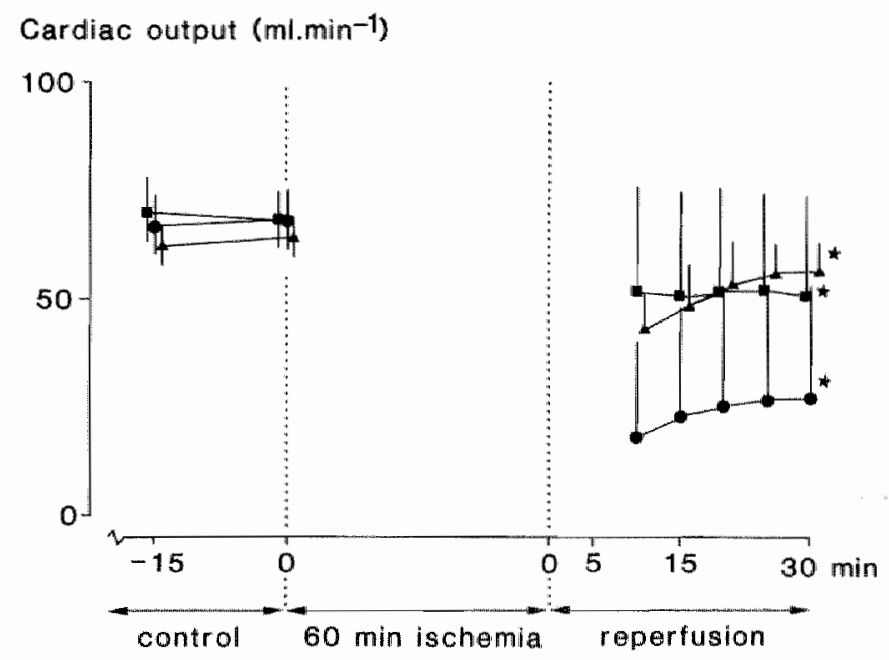

Fig 6.2 Effects of mepacrine $(1 \mu \mathrm{M})$ and nicotinic acid $(10 \mu \mathrm{M})$ on the recovery of cardiac output following $60 \mathrm{~min}$ of no-flow ischemia. Data are presented as means $\$ S D$. Non-treated hearts are indicated by $\bullet$, mepacrine treated hearts by $\boldsymbol{\Lambda}$, and nicotinic acid treated hearts by $\mathbf{m}$. During the first 5 minutes of reperfusion the hearts were retrograde$1 y$ perfused. Asterisk refers to significant difference $(p<0.05)$ between end-reperfusion value and preischemic value. 
hemodyramic function was less affected as compared to the subgroup of nonfibrillating control hearts. Hepacrine $(1$ uM) was found to completely prevent the occurrence of fibrillation during reperfusion. Hemodynamic recovery was ameliorated and comparable to that of the non-fibrillating nicotinic acid treated hearts (fig 6.2 , tabie 6.3).

Table 6.3 Recowery of hemodymanic function during reperfusion follawing 60 min of ischemia of non-treated hearts and hearts treated with nicotinic acid or mepacrine.

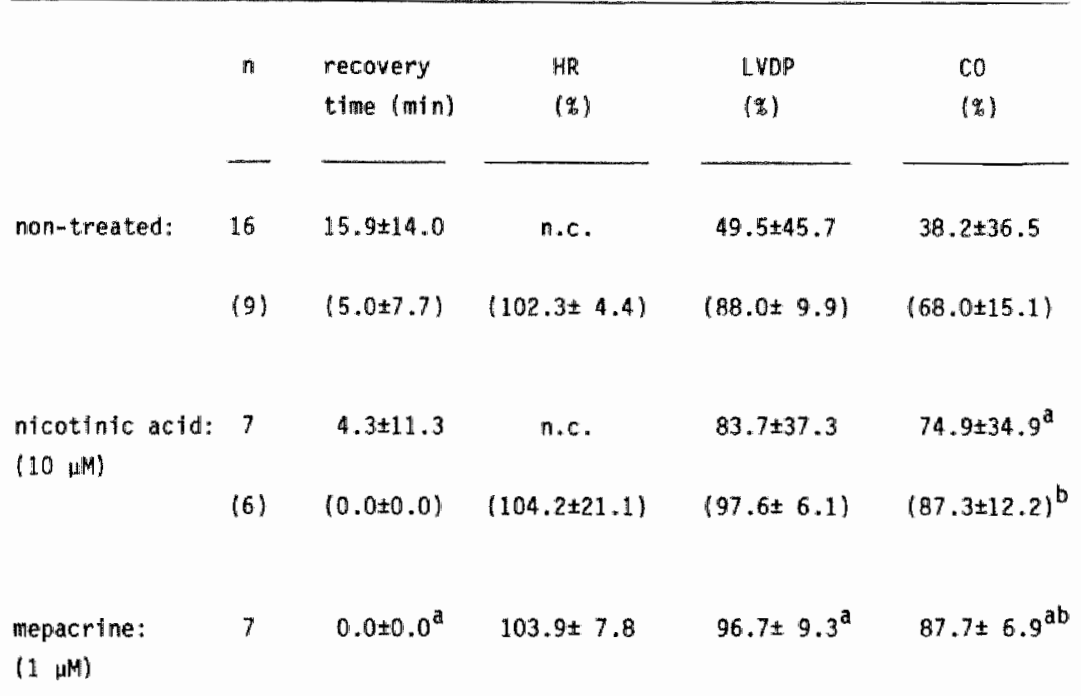

Data presented as means \pm 50 . Both drugs were present during the entire experimental protocol. $n$ refers to the number of hearts. Recovery time refers to the thie required to resume spontaneous beating. Heart rate (HR), left ventricular developed pressure (LVDP) and cardiac output (CO) are presented as percentages of the pre-ischemic values. n.c. - not calculated; due to the presence of fibrillating hearts, for which heart rate is not defined, the HR can not be calculated for this group. Data in parentheses refer to the sulbgroups of non-treated and nicotinic acid treated hearts that resumed spontaneous beating within 30 min of reperfusion. a indicates significantiy different $(p<0.05)$ from non-treated hearts. b indicates significantly different from the subgroup of non-treated hearts, which resumed spontaneous beating within 30 min of reperfusion. 
Table 6.4 Myocardial content of adenine nucleatides and thellegradation products. and energy charge of hearts rendered transiently ischemic and treated wh efther nicotinic acid or mepacrine.

\begin{tabular}{|c|c|c|c|c|c|c|}
\hline & ATP & ADP & AMP & $\begin{array}{c}\text { total } \\
\text { AN }\end{array}$ & $\begin{array}{l}\text { energy } \\
\text { charge }\end{array}$ & $\begin{array}{c}\text { total } \\
\text { purines }\end{array}$ \\
\hline \multicolumn{7}{|l|}{ non-treated: } \\
\hline pre-ischemia: & $18.9 \pm 3.1$ & $5.4 \pm 1.2$ & $1.0 \pm 0.5$ & $25.4 \pm 2.6$ & $0.85 \pm 0.05$ & $0.8 \pm 0.7$ \\
\hline Ischemia: & $5.7 \pm 3.1$ & $5.5 \pm 1.3$ & $3.6 \pm 1.7$ & $14.8 \pm 3.2$ & $0.55 \pm 0.14$ & $11.7 \pm 2.3$ \\
\hline reperfusion: & $8.4 \pm 3.1$ & $3.7 \pm 0.5$ & $1.4 \pm 0.7$ & $13.5 \pm 2.7$ & $0.75 \pm 0.11$ & $1.7 \pm 1.3$ \\
\hline
\end{tabular}

nicotinic acid (10 $\mu \mathrm{M})$ :
ischemia:
$5.6 \pm 1.2$
$6.1 \pm 0.5$
$1.7 \pm 0.3^{\mathrm{a}} \quad 13.3 \pm 1.1$
$0.64 \pm 0.04$
$8.8 \pm 1.4^{3}$
reperfusion:
$10.4 \pm 2.1$
$3.9 \pm 0.5$
$0.9 \pm 0.5 \quad 15.2 \pm 2.0$
$0.81 \pm 0.06$
$0.6 \pm 0.8$

mepacrine (1 $\mu M)$ :

ischemia:

$6.2 \pm 1.5 \quad 5.6 \pm 1.5$

reperfusion:

$10.2 \pm 1.9$

$3.2 \pm 0.4^{b}$

$2.0 \pm 1.4$

$13,8 \pm 1.8$

$0.60 \pm 0.13$

$9.1 \pm 2.4$

$13.8 \pm 2.4$

$0.86 \pm 0.02^{b}$

$0.0 \pm 0.1^{b}$

\begin{abstract}
Data presented as means \pm SO. Adenine nucleotides are expressed in 4 mol. $\mathrm{g}^{-1} \mathrm{dry}$ wt. Total refers to sum of ATP, ADP and AMP. Total purines refers to sum of adenosine, inosine, hypoxanthine and xanthine. Energy charge is defined as (IATP+0.5 $A D P) /(A T P+A D P+A M P))$. a indicates significantly different $(p<0,05)$ from non-treated ischemic hearts. b indicates significantly different from non-treated reperfused hearts.
\end{abstract}

Adenine nucleotides and related compounds.

Table 6.4 shows that the presence of neither nicotinic acid nor mepacrine (1 $\mu$ M) significantly preserved the total adenine nucleotide content during ischemia or reperfusion. However, the ischemic rise in the myocardial content of AMP was less pronounced when elther of the drugs was administered. During reperfusion ATP content was partially restored, whereas the contents of ADP and AMP declined. Nicotinic acid tended to improve the energy charge of reperfused hearts (NS). The energy charge restored to pre-ischemic levels when mepacrine $(1 \mu \mathrm{M})$ was present. At a concentration of $10 \mu \mathrm{M}$ mepacrine neither attenuated the depletion of adenine nucleotides. In this experimental group the total adenine nucleotide content amounted to $13.6 \pm 3.3 \quad(n=3)$ and $13.7 \pm 1.6$ $(n=4)$ at the end of ischemia and reperfusion, respectively. 
Table 6.5 Myocardal content of triacylglycurols, glycogen and lactate of hearts randered transiently ischemic and treated with ef ther ficotinic acid or mepacrine.

\begin{tabular}{|c|c|c|c|}
\hline & $\begin{array}{l}\text { triacyl- } \\
\text { glycerols }\end{array}$ & glycagen & lactate \\
\hline \multicolumn{4}{|l|}{ non-treated: } \\
\hline pre-ischemia: & $32.3 \pm 10.1$ & $100.4 \pm 21.9$ & $10.5 \pm 6.9$ \\
\hline ischemla: & $27.3 \pm 8.9$ & $50.1 \pm 20.0$ & $213.7 \pm 26.3$ \\
\hline reperfusion: & $33.5 \pm 13.5$ & $55.3 \pm 19.5$ & $17.2 \pm 11.4$ \\
\hline \multicolumn{4}{|c|}{ nicotinic acid $(10 \mu m)$ : } \\
\hline fichemia: & $23.9 \pm 4.4$ & $63.1 \pm 12.4$ & $149.0 \pm 1.7 .1^{\mathrm{a}}$ \\
\hline reperfusion: & $22.1 \pm 9.0$ & $79.4 \pm 28.6$ & $15.5 \pm 5.5$ \\
\hline \multicolumn{4}{|l|}{ mepacrine $(1, \mu)$ : } \\
\hline ischemia: & $24.0 \pm 7.9$ & $25.2 \pm 7.0^{\mathrm{a}}$ & $157.5 \pm 28.3^{\mathrm{a}}$ \\
\hline reperfusion: & $22.2 \pm 7.5$ & $71.5 \pm 24.0$ & $9.6 \pm 4.2$ \\
\hline \multicolumn{4}{|c|}{$\begin{array}{l}\text { Data presented as means } \pm S D \text { and in jmol } g^{-1} \text { dry wt. Triacylglycerols } \\
\text { and glycogen are expressed as fatty acid and glucose equivalents, } \\
\text { respectively. a indicates significantly different }(p<0.05) \text { from nom- } \\
\text { treated ischemic hearts. b indicates significantly different from } \\
\text { non-treated reperfused hearts. }\end{array}$} \\
\hline
\end{tabular}

As compared to the non-treated hearts the cumulative release of purines during reperfusion was significantly reduced in the presence of each of the drugs (table 6.6), which is in line with the lower tissue content of purines at the end of the preceding ischemic period (table 6.4).

Myocardial content of triacyiglycerols, glycogen and lactate.

The myocardial content of triacylglycerols of non-treated hearts was not significantly affected during ischemia or reperfusion. Administration of nicotinic acid $(10 \mu \mathrm{M})$ or mepacrine $(1 \mu \mathrm{M})$ did not influence the triacyiglycerol content either (table 6.5).

In non-treated hearts 60 min of ischemia resulted in a $50 \%$ reduction of the glycogen content and the accumulation of substantial amounts of lactate. 
In nicotinic acid treated hearts the glycogen content was comparable, but llactate accumulation was less pronounced at the end of ischemia. This corresponded with a reduced cumulative release of lactate during the reperfusion phase. In contrast, in mepacrine (1 $\mu M)$ treated ischemic hearts the giycogen content was significantly lower. This was not reflected by an increased accumulation of lactate in the ischenic tissue. During reperfusion the cumulative release of lactate from hearts, perfused in the presence of mepacrine $(1 \mu M)$, was comparable to that of non-treated hearts. However, when corrected for basal lactate release, the average cumulative release of lactate was about similar to that of hearts perfused in the presence of nicotinic acid (table 6.6).

In pre-ischemic non-treated hearts the tissue content of glycerol-3-phosphate and glycerol amounted to $0.6 \pm 0.3$ and $0.5 \pm 0.1 \mu \mathrm{mol} . \mathrm{g}^{-1}$ dry wt, respectively. As shown in figure 6.3 the accumulation of glycerol-3-phosphate was less pronounced in ischemic hearts treated with nicotinic acid as well as mepacrine $(1 \mu \mathrm{M})$. At the end of ischemia only in nicotinic acid treated hearts

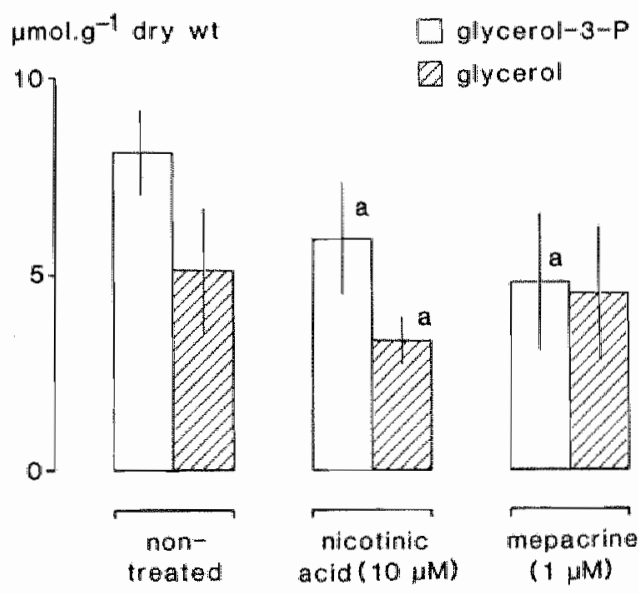

Fig 6.3 Tissue content of glycerol-3-phosphate (open bars) and glyceroll (hatched bars) of non-treated, nicotinic acid treated, and mepacrine treated hearts subjected to $60 \mathrm{~min}$ of 1 schemia. Data presented as means $\pm S D$. a indicates significantly different $(p<0.05)$ from nontreated hearts. 
the glycerol content was significantly reduced as compared to non-treated hearts.

After 30 min of reperfusion no differences in the glycogen content were observed between the groups. In each of the groups investigated the myocardial lactate content returned to pre-ischenic values.

Enzyme release.

The cumulative release of $L D H$ during reperfusion tended to reduce $(p<0.10)$

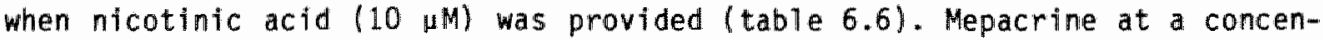
tration of $1 \mu \mathrm{M}$ did not affect $\angle D H$ release. However, at a concentration of 10 $\mu$ H of mepacrine LDH release was markedly reduced, i.e. $7.9 \pm 2.5$ units. heart ${ }^{-1}$ as compared to $22.0 \pm 7.5$ units.heart ${ }^{-1}$ per $30 \mathrm{~min}$ of reperfusion for the nontreated group.

Tab1e 6.6 Cumulative release of lactate dehydrogenase (LDH), lactate and purines during $30 \mathrm{~min}$ of reperfusion follawing $60 \mathrm{~min}$ of ischemia of non-treated hearts and hearts treated with nicotinic acid or mepacrine.

\begin{tabular}{|c|c|c|c|}
\hline & $\begin{array}{c}\text { LDH } \\
\text { (units.heart } \\
-1 \text { ) }\end{array}$ & $\begin{array}{c}\text { lactate } \\
\text { (umol. meart } \\
-1 \text { ) }\end{array}$ & $\begin{array}{c}\text { purines } \\
\text { (umol .heart } \\
\text { (u) }\end{array}$ \\
\hline non-treated & $\begin{array}{c}22.0 \pm 7.5 \\
(20.6)\end{array}$ & $\begin{array}{c}105.8 \pm 17.2 \\
(50.6)\end{array}$ & $\begin{array}{c}2.65 \pm 0.46 \\
(2.24)\end{array}$ \\
\hline $\begin{array}{l}\text { nicotinic acid } \\
(10 \text { iM) }\end{array}$ & $\begin{array}{c}16.7 \pm 5.1 \\
(14.7)\end{array}$ & $\begin{array}{c}80.2 \pm 12.3^{a} \\
(36.7)\end{array}$ & $\begin{array}{c}2.11 \pm 0.20^{\mathrm{a}} \\
(1.93)\end{array}$ \\
\hline $\begin{array}{l}\text { mepacrine } \\
(\mathbb{1} \| M)\end{array}$ & $\begin{array}{c}20.4 \pm 5.9 \\
(19.6)\end{array}$ & $\begin{array}{c}102.9414 .8 \\
(33.9)\end{array}$ & $\begin{array}{c}2.18 \pm 0.51 \\
(1.66)\end{array}$ \\
\hline \multicolumn{4}{|c|}{$\begin{array}{l}\text { Data presented as means } \# \text { S0. Purine release is defined as the sum of } \\
\text { the rellease of adenosine, inosine, hypoxanthine, xamthine and uric acid. } \\
\text { Data in parentheses refer to mean cumulative release, corrected for } \\
\text { basal LDH, lactate, and purime release, as measured during the pre- } \\
\text { ischemic phase, respectively. a indicates significantly different } \\
(\text { p } 0.05) \text { from mon-treated hearts. }\end{array}$} \\
\hline
\end{tabular}


Accumulation of NEFA's.

NEFA's were found to accumulate in non-treated hearts rendered ischemic for $60 \mathrm{~min}$ (fig 6.4 ). Nicotinic acid $(10 \mu \mathrm{M})$ reduced the extent of NEFA accumulation during ischemia by more than $50 \%$, whereas mepacrine $(1 \mu M)$ was found to be ineffective. However, at a concentration of $10 \mu \mathrm{M}$ of mepacrine the myocardial NEFA content of ischemic hearts $\left(235 \pm 106 \mathrm{nmol} \cdot \mathrm{g}^{-1}\right.$ dry wt, $n=3$ ) was not different from pre-ischemic control hearts.

Restoration of flow was associated with enhanced accumulation of NEFA's (fig 6.4). However, at the end of reperfusion the accumulation of NEFA's was attenuated when nicotinic acid $(10 \mu M)$ was administered. Mepacrine $(1 \mu M)$ tended to reduce the accumulation of NEFA's during reperfusion, but the difference did not reach the level of significance. The effect was more pronounced at the higher dose of mepacrine $(10 \mu \mathrm{M})$. At this dose the myocardial NEFA content of reperfused hearts amounted to $390 \pm 329 \mathrm{nmol}^{-1}$ dry wt $(n=4)$ only.

To assess whether the different modes of action of the drugs used were reflected by differences in the contribution of individual NEFA's to total NEFA accumulation, the percentage composition of this lipid pool was examined. As shown in table 6.7 , on $7 y$ the percentage contribution of docosahexaenoic acid (C22:6) to total NEFA's was found to differ between drug treated and non-treated hearts. No other significant differences were observed.

\subsection{Discussion}

In this study it was investigated whether nicotinic acid and mepacrine, putative inhibitors of harmone stimulated triacylglycerol lipase activity and phospholipase activity, respectively, protected the transiently ischemic heart. Experimental findings indicate that derangements in myocardial lifpid metabolism play an important, if not crucial, role in the sequence of events leading to irreversible damage during both ischemia and reperfusion (Farber et a1., 1981). Accordingly, specific interventions directed to reduce these derangements might prove to be beneficial to the jeopardized myocardium. Besides, any beneficial effect of such an intervention would give additional support to the notion that disturbed lipid homeostasis is involved in the 
Nicotinic acid.

It has been well established that catecholamines stimulate lipolysis in adipose tissue through a cAMP-protein kimase dependent mechamism. In addition, it is known that antilipolytic agents counteract the hormone dependent stimulation of lipolytic activity (Lech et al., 1977). Since these antilipolytic agents. like nicotinic acid, also act on cardiac tissue it is assumed that Mpolysis in the neart is regulated by harmone sensitive lipases in a similar

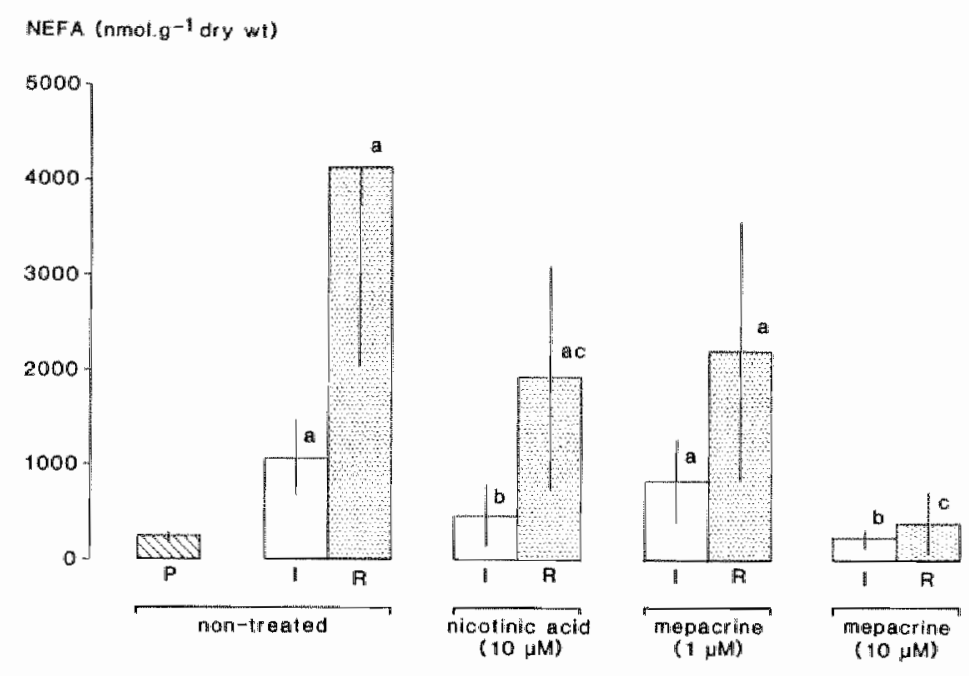

Fig 6.4 Myocardial content of NEFA"s of pre-ischemic hearts (P), hearts subjected to $60 \mathrm{~min}$ of ischemia ( $I$ ), and reperfused hearts $(R)$, perfused in the absence or presence of either nicatinic acid $(10 \mu \mathrm{M})$ or mepacrine $(1 \mu M$ and $10 \mu M$, respectively). Data presented as means $\pm S D$. a indicates significantily different $(p<0.05)$ from pre-ischemic nontreated hearts. $b$ refers to significant difference between ischemic drug treated hearts and ischemic mon-treated hearts. $c$ refers to significant difference between reperfused drug treated hearts and reperfused non-treated hearts. 
Table 6.7 Myocardial total NEFA content and percentage contribution of individual NEFA's to the total of non-treated, nicotintic acid treated and mepacrine treated hearts, reperfused for $30 \mathrm{~min}$ following 60 min of ischemia.

\begin{tabular}{|c|c|c|c|}
\hline & $\begin{array}{l}\text { non- } \\
\text { treated }\end{array}$ & $\begin{array}{l}\text { nicotinic } \\
\text { acid }(10 \mu \mathrm{M})\end{array}$ & $\begin{array}{c}\text { mepacmine } \\
(1 \mu \mathrm{M})\end{array}$ \\
\hline total MEFA's: & $4130 \pm 2111$ & $1916 \pm 1178^{a}$ & $2197+1370$ \\
\hline \multicolumn{4}{|l|}{ relative } \\
\hline \multicolumn{4}{|l|}{ compastition: } \\
\hline $016: 0$ & $18.4 \pm 1.5$ & $18.7 \pm 1.8$ & $18.9 \pm 0.7$ \\
\hline C18:0 & $21.3 \pm 3.7$ & $21.7 \pm 3.4$ & $20.1 \pm 1.1$ \\
\hline C18:1 & $15.6 \pm 1.3$ & $14.9 \pm 2.4$ & $15.6 \pm 1.5$ \\
\hline$C 18: 2$ & $22.5 \pm 3.4$ & $18.9 \pm 6.2$ & $22.5 \pm 1.8$ \\
\hline 0.20 .4 & $11.4 \pm 2.1$ & $10.7 \pm 1.0$ & $10.5 \pm 0.8$ \\
\hline 0.22 .6 & $7.3 \pm 2.3$ & $13.6 \pm 6.5^{\mathrm{a}}$ & $10.2 \pm 1.2^{\mathrm{a}}$ \\
\hline $\begin{array}{l}\text { Data presented } \\
\text { dry wt. The in } \\
\text { Only the quant } \\
\text { dicates slgnif }\end{array}$ & $\begin{array}{l}\text { ns } \pm \text { So. } \\
\text { NEFA's a } \\
\text { y most in } \\
\text { different }\end{array}$ & $\begin{array}{l}\text { FA's are exp } \\
\text { ed by theil } \\
\text { NEFA species } \\
\text { from non-tre }\end{array}$ & $\begin{array}{l}5 \text { nmol } \cdot g^{-1} \\
\text { natation. } \\
\text { awn. a in- } \\
\text { rts. }\end{array}$ \\
\hline
\end{tabular}

way (Christian et al., 1969; Lech et a1., 1977). Recently, Goldberg and Khoo (1985), Heathers and Brunt (1986) and Palmer and coworkers (1987) provided evidence to substantiate this nation.

Because of the stress associated with an ischemic attack, the leve1s of circulating catecholamines are elewated. As a result, in adipose tissue hormone dependent lipase activity will be stimulated and the arterial NEFA. level will rise. Myocardial ischemia also induces release of catecholamines from local cardiac stores (Schoemig et al., 1984) and, hence, stimulation of myocardial lipase activity and subsequent release of NEFA's from endogenous triacylglycerol pools can be anticipated (Brownsey and Brunt, 1977; Vik-Mo et al., 1979). So, under conditions of residual flow to the affected myocardium, the supply of both exagenous and endagenous NEFA's for mitochondrial oxidation is elevated. Since the oxidation of fatty acids requires a larger amount of 
oxygen per molecule of ATP produced, the, already impaired, oxygen supply to demand ratio will further deteriorate. In addition, an increased supply af NEFA's in combination with oxygen shortage, gives rise to an elevation of the tissue levels of other intermediates of fatty acid metabolism, like long-chain acyl-CoA and long-chain acylcarnitine (0pie, 1975; Vik-Mo et al., 1986), the concentrations of which may reach noxious levels.

In open-chest dog preparations nicotinic acid reduces the serum level of NEFA's by inhibiting the catecholamine stimulated release of NEFA's from adipose tissue, thereby reducing the supply of exogenous NEFA's to the affected myocardfum (Vik-Mo et a1., 1979, 1986; Kjekshus, 1981). In addition, nicotinic acid is thought to inhibit the catecholamine induced stimulation of myocardial lipolysis during ischemia. This notion is substantiated by Trach (1984), who demonstrated a diminished release of glycerol into the coronary effluent of glucose-perfused hearts subjected to low-flow ischemia, if nicotinic acid was supplied. However, Vik-Mo and coworkers (1979) were unable to detect a sigmificant effect of nicotinic acid on the release of glycerol in regionally ischemic dog hearts.

The findings of the present study, using a model of global no-flow ischemila, demonstrate that nicotinic acid reduces the accumulation of glycerol and NEFA's during ischemia. Thus, in line with the proposed mechanism of action, It seems likely that nicotinic acid inhibits hormome-stimulated triacylglycerol lipase activity. Conversely, this finding suggests that, at least, part of the NEFA's accumulating in non-treated ischemic hearts result from net hydrolysis of triacylglycerols. Because of the abundance of fatty acids esterified in the triacylglycerol pool relative to the NEFA content of ischemic hearts, the absence of a sizeable fall in the triacylglycerol content can not be taken as evidence that accumulating NEFA's are not produced by net hydrolysis of triacylglycerols during ischemia.

In a previous study (chapter 5) evidence was provided that triacylglycerol homeostasis is disturbed during no-flow ischemia. Since no rise in NEFA's was observed at a time that glycerol was already markedly increased, it was assumed that the turnover rate of the triacylglycerol pool was enhanced. As a consequence, a considerable part of the anaerobically produced ATP was consumed in this so-called "futile cycle". The present findings show that in the presence of nicotinic acid the content of glyceral in ischemic tissue is reduced as compared to ischemic non-treated hearts. This indicates that the 
activity of the triacylglycerol-NEFA cycle is partly inhibited. Consequently, nicotinic acid will lessen ATP usage of the ischemic tissue, and a positive effect on the energy status might be anticipated. The attenuation of the ischemic rise in AMP, a product of triacylglyceral-NEFA cycling (see fig 6.1), is in concert with this notion. However, significant preservation of the tissue ATP content is not observed.

Remarkably, nicotinic acid is also found to diminish the accumulation of glycerol-3-phosphate. Since during ischemia the extent of triacylglycerol cycling is reduced, a rise in the tissue content of this glycolytic intermediate would rather be expected. In this respect it is worth mentioning, that Schoonderwoerd and associates (1987) proposed an alternative mechanism for the catecholamine-induced stimulation of lipolytic activity. These investigators demonstrated that the CAMP-protein kinase dependent activation of lipolysis depends on an operative glycogenolysis. Therefore, the apparent hormone dependent stimulation of 1 ipase activity actually would result from an increased production of glycerol-3-phosphate by hormone dependent stimulation of glycogenolysis at the level of glycogen phosphorylase. Ample supply of glycerol-3phosphate would stimulate the re-esterification of the NEFA's released and prevent product inhibition of triacylglycerol lipase activity. It is tempting to speculate that nicotinic acid actually inhibits the hormone dependent stimulation of glycogenolysis and, hence, in this way reduces the accumulation glycerol-3-phosphate and, in turn, the activity of the triacylglycerol-NEFA cycle.

The present findings indicate that nicotinic acid (as well as mepacrine) reduces the accumulation of lactate in ischemic hearts. The possible consequences of this observation are not unambiguous. On the one hand, a reduction of lactate accumulation during ischemia was shown to correlate with improved mechanical recovery during the post-ischemic phase (Neely and Grotyohann, $1984 \mathrm{a})$. On the other hand, the amount of ATP produced by anaerobic glycolysis will be lowered, which might adversely affect recovery of transiently ischemic hearts (Opie, 1970b). It should be noted, however, that Vik-Mo and coworkers (1986) found that nicotinic acid did not influence the accumulation of lactate in the regionally ischemic dog heart.

During reperfusion NEFA accumulation is diminished, hemodynamic function is better preserved and enzyme release, a marker for cellular necrosis, tends to be reduced. The mechanism underlying the reduction of NEFA accumulation 
during reperfusion is incompletely understood. After restoration of flow catecholamines are rapidly washed out of the tissue and endogenous stores are depleted (Nayler and Sturrock, 1985). So, continued stimulation of hormone sensitive lipases is not very likely. An explanation could be that the attenuation of MEFA accumulation reflects the beneficial effect of nicotinic acid during the preceding ischemic period and is not related to the process of reperfusion itself.

\section{Mepacrine.}

Mepacrine belongs to the group of cationic amphiphilic drugs known to possess phospholipase inhibitory properties. It is known to accumulate in acidic compartments, like lysosomes (Kunze et al., 1982). The way in which mepacrine inhibits phospholipase activity is still unclear. Jain and coworkers $(1984,1985)$ found that mepacrine induced 50\% inhibition of pig pancreatic phospholipase activity at a concentration of about $60 \mu \mathrm{M}$. These authors provided evidence that mepacrine inhibits phospholipase $A_{2}$ non-competitively, probably through modification of the quality of the substrate interface (i.e. the phospholipid bilayer). In contrast, Vigo and colleagues (1980) proposed that the drug interacts directly with the enzyme.

In the present study the effect of mepacrine was tested, using concentrations (1 and $10 \mu \mathrm{M})$ far below the reported apparent $k i$ value of $60 \mu \mathrm{M}$. However, since mepacrine accumulates in cellular compartments (Kunze et al., 1982), the concentration of the drug in the coronary perfusate might be of less relevance. Mepacrine is found to reduce the accumulation of NEFA's during ischemia and reperfusion (especially at the higher dose level). At $10 \mu \mathrm{M}$, mepacrine significantly reduces enzyme release during reperfusion also. It should be noted that at this dose mepacrine exerts a marked negative inotropic effect. Phylipson and coworkers (1985b) demonstrated that the negative inotropic effect of cationic amphiphilic drugs is most likely related to their insertion into the phospholipid bilayer and subsequent interference with sarcolermal $\mathrm{Ca}^{2+}$ binding and $\mathrm{Na}^{+} / \mathrm{Ca}^{2+}$ exchange activity. During no-flow ischemia mechanical activity rapidly ceases and, hence, negative inotropic effects are likely to be less relevant under these circumstances. The observation that the depletion of adenine nucleotides during ischemia was not mitigated is in line with this notion. However, it can not be excluded that the observed reduction of enzyme release and NEFA accumulation are related to the 
negative inotropic effects of this agent during the reperfusion phase.

At a concentration of $1 \mu$ mepacrine exerts only a weak negative inotropic effect. As compared to non-treated ischenic hearts the accumulation of glyceroll was about similar (fig 6.3). However, a significant meduction of the myocardial content of glycerol-3-phosphate is observed. Besides, the glycogen content is found to be substantially lower at the end of ischemia. At present no satisfying explanation can be given for these phenomena. During reperfuston enzyme release is not affected, but arrhythmias are abolished: functional recovery is ameliorated, and the accumulation of NEFA's tends to be reduced, indicating that at this dose level mepacrine certainly provides protection.

Dtani and coworkers (1986) administered mepacrine at a final concentration of $50 \mu M$ (close to the $\mathrm{Ki}$ walue reported by Jain et a1., 1984) to pig hearts rendered transiently ischemic and also observed a marked negative inotropic effect. These investigators (Das et al., 1986; 0tani et a1., 1986) reported that mepacrine preserved the myocardial ATP levels during ischemia and reperfusion, reduced creatine kinase release, and prevented the loss of phospholipids during reperfusion. In addition, mepacrine was found to prevent the activation of microsomal phospholipase $A_{2}$, whereas it did not affect acyl-CoA synthetase and lysophospholipid acyltransferase activity. These findings suggest that mepacrine merely affects the rate of phospholipid hydrolysis. However, Chiariello and coworkers (1987), studying changes in the cardiac phospholipid content due to coronary artery ligation in rats, proposed that the reacylation of phospholipids is also positively affected by mepacrine. This notion is substantiated by the observation that mepacrine stimulates the incorporation of radio-labeled fatty acids into phospholipids in kidney slices (Erman et al., 1983). Kunze and coworkers (1982) clearly demonstrated that the activity of other enzymes involved in 1ysosomal lipid degradation, 1ike lysophospholipases and mono-acylglycerol lipase, are also inhiblted by mepacrime. Finally, it has been reported that mepacrine inhibits lipidperoxidation in both muscle homogenates and enzymefree test systems (Jackson et a7., 1984).* The latter finding indicates that this effect is not necessarily related to inhibition of phospholipase activity.

The findings mentioned above indicate that the effects of mepacrine may be mediated through other mechanisms than the inhibition of phospholipase $A_{2}$ activity. On the other hand it should be recognized, that the dose levels applied in some studies are far above the $K_{i}^{*}$ value of mepacrine for phospho- 
Iipase $A_{2}$ (60 according to Jain et al., 1984, 1985) and may therefore represent more aspecific effects of the drug, only relevant at those rellatively high concentrations.

Myocardial damage and lipid homeostasis.

Both nicotinic acid $(10 \mu \mathrm{M})$ and mepacrine $(1 \mu \mathrm{M})$ preserve myocardial function following $60 \mathrm{~min}$ of no-flow ischemia. As shown in figure 6.5 onty a weak correlation $(r=0.52)$ is found between the tissue content of NEFA's of reperfused hearts and the cumulative release of $\mathrm{LDH}$ during 30 minutes of reperfusion. In fact, the correlation coefficient is largely determined by hearts belanging to the non-treated group, characterized by a relatively high NEFA content and substantial release of LDH.

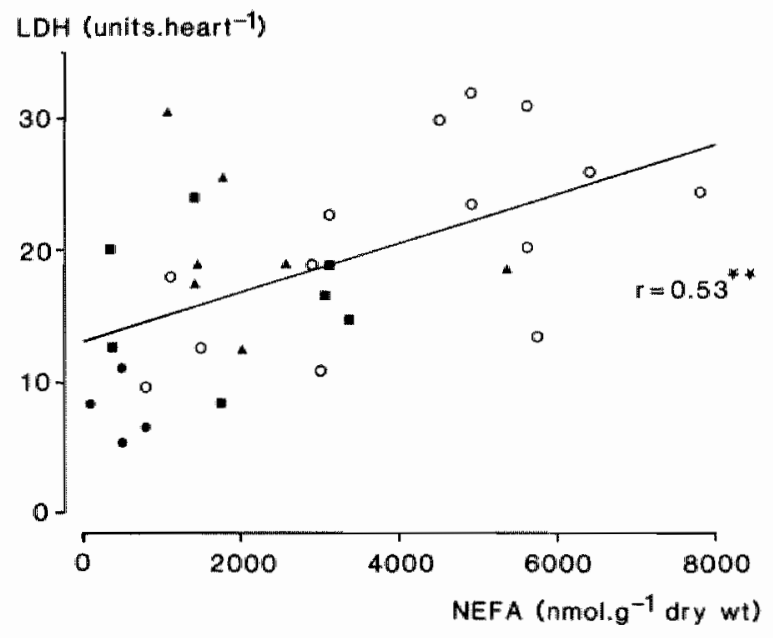

Fig 6.5 Relation between the NEFA content of mon-treated (O), nicotinic acid treated ( $\square$ ) and mepacrine treated ( $\Delta$ and - for $1 \mu \mathrm{M}$ and $10 \mu \mathrm{M}$, respectively) reperfused hearts and the cumulative release of $L D H$ during 30 minutes of reperfusion. $*-p<0.01$. 
In line with the proposed mechanism of action, nicotinic acid reduces the accumulation of NEFA's during ischemia. Since in the present experimental set-up effects on the oxygen supply/demand ratio during ischemf can be ignored, the effect must be mediated by either a reduction of the accumulation of noxious lipidic substances or a reduction of ATP consumption through inhibition of futile cycle activity.

The finding that mepacrine $(10 \mu \mathrm{M})$ reduces NEFA accumulation during reperfusion agrees with the observation of Das and coworkers (1986), who reported a preservation of the myocardial phospholipid content during reperfusion. In a previous study (chapter 5) we were unable to detect decreases in the myocardial phospholipid content of hearts subjected to 60 minutes of ischemia with or without an additional 30 minutes of reperfusion. The effects of nicotinic acid and mepacrine, if any, are likely to be positive and, hence, no changes in the myocardial phospholipid content are anticipated. However, we demonstrated that changes in the NEFA content provide a sensitive marker for disturbances in myocardial lipid metabolism. Therefore, in this study we only monitored the effects of these drugs on the cardiac NEFA content. It should be noted that there are large quantitative differences between the present findings and the observations of Das and coworkers (1986). In mon-treated pig hearts these investigators reported an $18 \%$ decline in total phospholipid content in reperfused hearts. This corresponds to about 30 umol. $\mathrm{g}^{-1} \mathrm{dry}$ wt of phospholipids or $60 \mu \mathrm{mol} . \mathrm{g}^{-1}$ dry wt of fatty acids. In the present study an increase in the myocardial NEFA content of (only) $4 \mu \mathrm{mol}^{-1} \mathrm{~g}$ dry wt in reperfused non-treated cardiac tissue is observed. The reason for this discrepancy is incompletely understood.

Based on the appreciable differences in the fatty acyl composition of the triacylglycerol and phospholipid pool (chapter 5, table 5.1) and the supposed different modes of action of the drugs used, it was reasoned that the composition of the NEFA pool will provide some insight into the nature of the derangements in lipid homeostasis. As shown in table 6.7, drug treatment does not appreciably influence the percentage contribution of individual NEFA's to the total NEFA content of reperfused hearts, which suggests that the origin of the NEFA's, accumulating during reperfusion mainly, Is similar. The relatively large amounts of arachidonic acid, a fatty acid almost exclusively present in the phospholipid pool, accumulating in both non-treated and drug treated reperfused hearts, support the idea that the majority of the NEFA's released 
orfginate from phospholipids. Howewer, further study is required to elucidate the role of the disturbances in triacylglycerol and phospholipid homeostasis in more deta11. At this moment, research conducted to investigate this problem is hampered by the lack of specificity of the drugs avallable.

\subsection{Summary}

To assess the nature of the lipid changes, as observed during ischemia and reperfusion, and their consequences for myocardial function and integrity, transiently ischemic hearts were perfused in the presence of nicatinic acid or mepacrine, putative inhibitors of triacylglycerol lipase and phospholipase activity, respectively. Nicotinic acid $(10 \mu M)$ reduced the accumulation of glycerol during $60 \mathrm{~min}$ of ischemia, indicating that the activity of the triacylglyceroll-NEFA cycle is lowered. The concomitant reduction of NEFA accumulation might be explained by a direct inhibitory effect of nicotinic acid on the net degradation of triacylglycerols and/or an indirect effect mediated by reduced ATP usage via the triacylglycerol-NEFA cycle. However, the latter idea is not substantiated by significant preserwation of the energy status of ischemic hearts. During reperfusion the rise of NEFA"s was also attenuated. This was associated with improved post-ischemic function, but not with preservation of the myocardial adenine nucleotide content or significant reduction of enzyme release.

At a concentration of 1 M mepacrine abolished reperfusion arrhythmias and improved post-ischemic function. However, in comparison with non-treated hearts the reduction of the NEFA content did not reach the level af significance. Enzyme release was not attenuated either. At 10 m mepacrine exerted marked negative inotropic effects, prevented the accumulation of NEFA's during ischemia and reperfustion, abolished reperfusion-arrhythmias and reduced enzyme release, but did not preserve the adenine nucleotide content.

In conclusion, pharmacological modification of lipid metabolism attenuates. myocardial damage of transiently ischemic hearts. Besides, the present findings strongly suggest that both the triacylglycerol and phospholfpid pool contribute to the observed derangements in myacardial lipid metabolism. 
THE EFFECTS OF PYRUNATE AND POCA, A CARNITINE ACYLTRANSFERASE I INHIBITOR, ON NEFA ACCUMULATION DURING ISCHEMIA AND REPEIRFUSION.

\subsection{Introduction}

It has been well established that myocardial ischemia is associated with disturbances in lipid metabolism, as evidenced by the accumulation of lipid intermediates like long-chain acylcarnitine and acyl-COA, non-esterified fatty acids (NEFA's) and lysophospholipids (reviewed by Katz and Messineo, 1981; corr et a1., 1984). Although knowledge about the mechanisms underlying these changes is still incomplete, the accumulation of the carnitine and COA derivatives appears to be a relatively fast process, related to the presence of exogenous fatty acids (Whitmer et a1., 1978; Shug, 1978), whereas accumulation of NEFA's takes place after longer periods of ischemia and appears to be related to the degradation of endogenous lipids (Prinzen et al., 1984; Chien et al., 1984; chapter 5).

The possible effects of reperfusion on myocardial lipid homeostasis are only beginning to be appreciated. Recently it was demonstrated, that in isolated rat hearts, suppllied with glucose and pyruvate as exogenous substrates, accumulation of NEFA's proceeds during reperfusion (chapter 5). Since no exogenous fatty acids were supplied the NEFA's, accumulating under these circumstances, have to be released from endogenous esterified fatty acid pools. Experiments with labeled fatty acids indicate that the oxidation of circulating fatty acids remains disturbed after restoration of flow (Schwalger et a1., 1985; Chatelain et a1., 1987; Myears et a1., 1987).

In the present study it was investigated whether interventions directed to modulate myocardial fatty acid oxidation affect the accumulation of NEFA's, released from endogenous 1 ipid pools as a result of ischemia and reperfusion. Secondly, assuming that accumulation of NEFA's might be detrimental to the myocardium, it was evaluated if such a modulation of the NEFA content, if any, 
is associated with differences in myocardial damage and functional recovery during reperfusion. To this end, isollated, glucose-perfused, working rat. hearts were subjected to $45 \mathrm{~min}$ of no-flow ischemia, with or without an additional $30 \mathrm{~min}$ of reperfusion. The hearts were perfused in the absence or presence of pyruvate, a substrate competing with fatty acids for mitochondrial free COA. Furthermore, the effect of sodium 2-(5-(4-chlorophenyl) penty 1))-oxirane-2-carboxylate (POCA), an inhibitor of carnitine acyltransferase $I$ and, hence, of fatty acid oxidation (Roesen and Reinauer, 1984; Wolf and Engel, 1985), on the accumulation of NEFA's during ischemia and reperfusion was evaluated (see fig 7.1 for the putative site of action of both interventions). In contrast to the experimental protocol used in the previous study (chapter 6), in the present investigation hearts were subjected to only 45 min of ischemia. This period was chosen, because of the supposed negative effects of POCA on the accumulation of NEFA's and, hence, on myocardial recovery.

Functional recovery was assessed from parameters, like the incidence and duration of ventricular fibrillation, heart rate, developed pressure and cardiac output. The effects of pyruvate and POCA on myocardial metabolism were assessed by measuring the tissue contents of adenine nucleotides and their

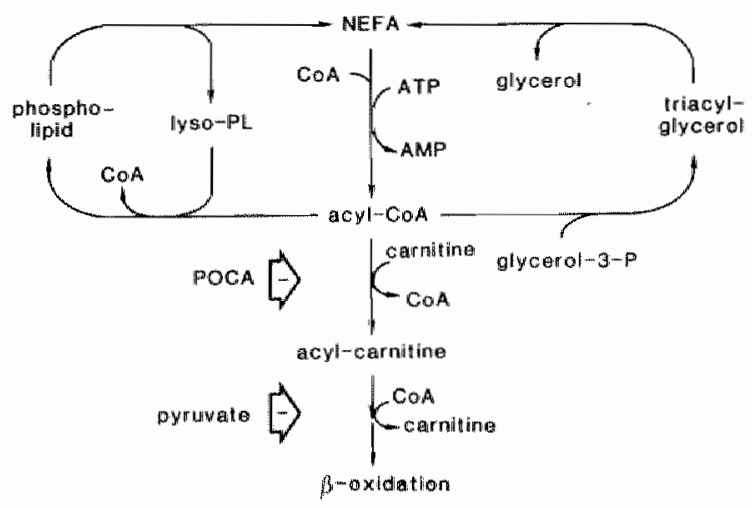

Fig 7.1 Schematic representation (highly simplified) emphasizing the central role of NEFA's in myocardial lipid homeostasis and the putative sites of action of pyruvate and POCA on the conversion of NEFA's. 
degradation products. The tissue content of triacylglycerols, glycogen and lactate were measured to monitor the effects of these interventions on substrate demand during ischemia and reperfusion. In addition, effluent concentrations of lactate and lactate dehydrogenase were measured. The latter was used as an index for the number of irreversibly damaged cells.

\subsection{Methods}

Perfusion of the hearts.

Hearts from male Lewis rats were isolated and perfused as assisted, working hearts. The experimental set-up has been described in detail prewiously (chapter 3). In short, hearts were perfused with an oxygenated, modified krebs-Henseleit buffer. Hearts were allowed to stabilize during 10 min of retrograde perfusion. Subsequently, the left atrial cannula was opened (left atrial filling pressure $1.0 \mathrm{kPa}$ ) and hearts were allowed to eject (applied diastolic aortic pressure $8.0 \mathrm{kPa}$ ). After $30 \mathrm{~min}$ of perfusion as working hearts, the hearts were rendered ischemic for $45 \mathrm{~min}$ (no-flow ischemia), followed by $30 \mathrm{~min}$ of reperfusion. During the first $5 \mathrm{~min}$ of reperfusion the hearts were retrogradely perfused (perfusion pressure $8.0 \mathrm{kPa}$ ). Thereafter, the hearts were perfused antegradely. Hemodynamic variables, like aortic pressure, left ventricular pressure and aortic flow (measured with an extracorporeal electromagnetic flow probe) were continuously recorded. Coronary flow was assessed by timed collection of coronary effluent in a graded cylinder.

The hearts were alotted to four groups. Hearts, supplied with glucose 011 mM) as the only exogenous substrate, were perfused in the absence or presence of POCA (sodium 2-(5-(4-chlorophenyl)pentyl))-oxirane-2-carboxylate, kindly prowided by Byk Gulden) at a final concentration of $10 \mu$ mol.1 itre ${ }^{-1}$. In two other groups hearts were supplied with glucose $(11 \mathrm{~mm})$ and pyruwate $(5 \mathrm{mM})$ as substrates, and perfused in the absence or presence of POCA.

Hearts were freeze clamped before the onset of ischemia ( $n=6-8$ per group), at the end of the ischemic period ( $n=5-8$ per group), or at the end of reperfusion ( $n=7$ per group). In addition, control hearts were normoxically perfused for 120 min in the absence or presence of pyruvate and subsequently freeze clamped ( $n=4$ per group). 
Biochemical analysis.

Freeze dried tissue samples were extracted with perchloric acid as described previously (chapter 3 ). Adenine nucleotides, nucleosides and oxypurines were determined by HPLC according to the method of Wynants and Van Belle (1985). Creatine phosphate, lactate and glycogen were determined as described by Van der Vusse and coworkers (1984b). Myocardial lipids were extracted using the Folch procedure. Neutral and polar lipids were separated by silicagel column chromatography (Roemen and Van der Vusse, 1985). The neutral 1ipid fraction was further separated using thin layer chromatography. The lipid spots, corresponding to the NEFA's and triacylglycerols, were scraped from the plates. After elution from the silicagel powder and (trans)methylation the lipids were detemined by gas-liquid chromatography (Van der Vusse et al." $1982)$.

Samples of the coronary effluent were used to assess the release of lactate (Van der Vusse et al., 1982) and lactate dehydrogenase (Bergmeyer and Bernt, 1974).

Statistical analysis.

Data are presented as means and standard deviations. Differences within groups or between groups were analyzed for significance using student"s $t$ test for paired and unpaired data, respectively. $P$ values less than 0.05 were considered to be statistically significant.

\subsection{Results}

Normoxia.

Hemodynamic stability, as estimated by the percentage reduction of cardiac output during 120 min of perfusion, was slightly impaired when glucose was the only substrate available $(11.9 \pm 1.9 \%$ decline), as compared to hearts perfused in the presence of pyruvate as cosubstrate $(1.6 \pm 0.8 \%$ decline). After $120 \mathrm{~min}$ of normoxic perfusion the tissue contents of glycogen and triacylgiycerols were markedly reduced in glucose-perfused hearts. Depletion of endogenous substrate stores was absent when pyruvate was added as cosubstrate (see 
chapter 3, fig 3.2). Under these conditions the myocardial NEFA content was. significantly higher $199 \pm 65$ and $298 \pm 108 \mathrm{nmol} \cdot \mathrm{g}^{-1}$ dry wt after $120 \mathrm{~min}$ of antegrade perfusion, in the absence and presence of pyruvate, respectively). In addition, the percentage contribution of individual NEFA" $s$ to the total NEFA content differed markedly (fig 7.2), the most marked difference being the very high tissue level of docosahexaenoic acid $(\mathrm{C} 22: 6)$ in the hearts perfused with pyruvate as cosubstrate. Comparison of hearts freeze clamped after $30 \mathrm{~min}$ (pre-ischemic controls, see belaw) or $120 \mathrm{~min}$ of normoxic perfusion showed, that prolonged perfusion did not alter the total NEFA content nor its relative composition.

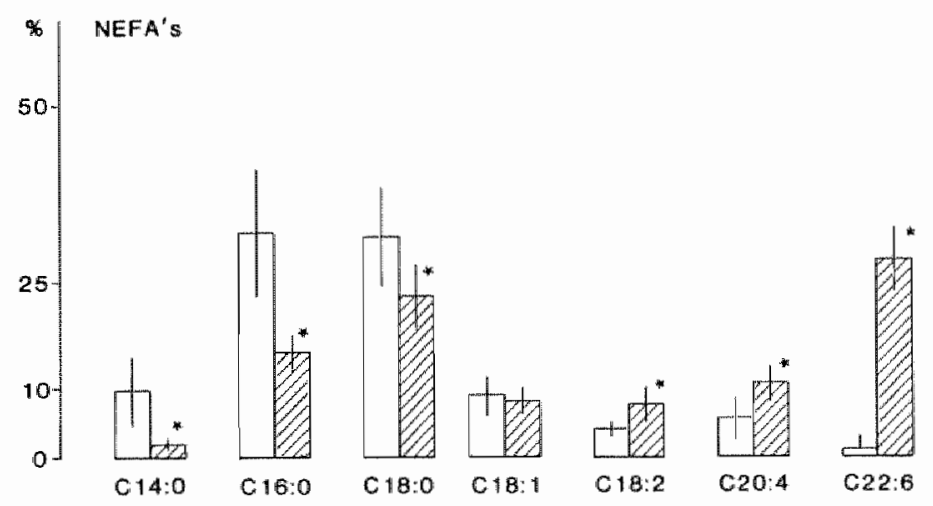

Fig 7.2 Percentage contribution of individual NEFA's to total NEFA content of working hearts perfused for $120 \mathrm{~min}$ and supplied with ef ther glucose (open bars, total NEFA content: $99 \pm 65 \mathrm{nmol}, \mathrm{g}^{-1}$ dry wt) or glucose and pyruvate as exogenous substratels) (hatched bars, total NEFA content: $298 \pm 108 \mathrm{nmol}^{-\mathrm{g}^{-1}}$ dry $\left.w \mathrm{t}\right)$. Data are presented as means \pm SD. NEFA's are denoted by their chemical notation. Asterisk indicates significantly different $(p<0.05)$ from glucose-perfused hearts. 
Table 7.1 Functional recavery following 45 win of ischemia of hearts supplied with glucose as substrate and perfused in the absence or presence of POCA 110 $\mu \mathrm{M})$, and hearts supplied with glucose and pyruvate as substrates, and perfused in the absence or presence of POCA.

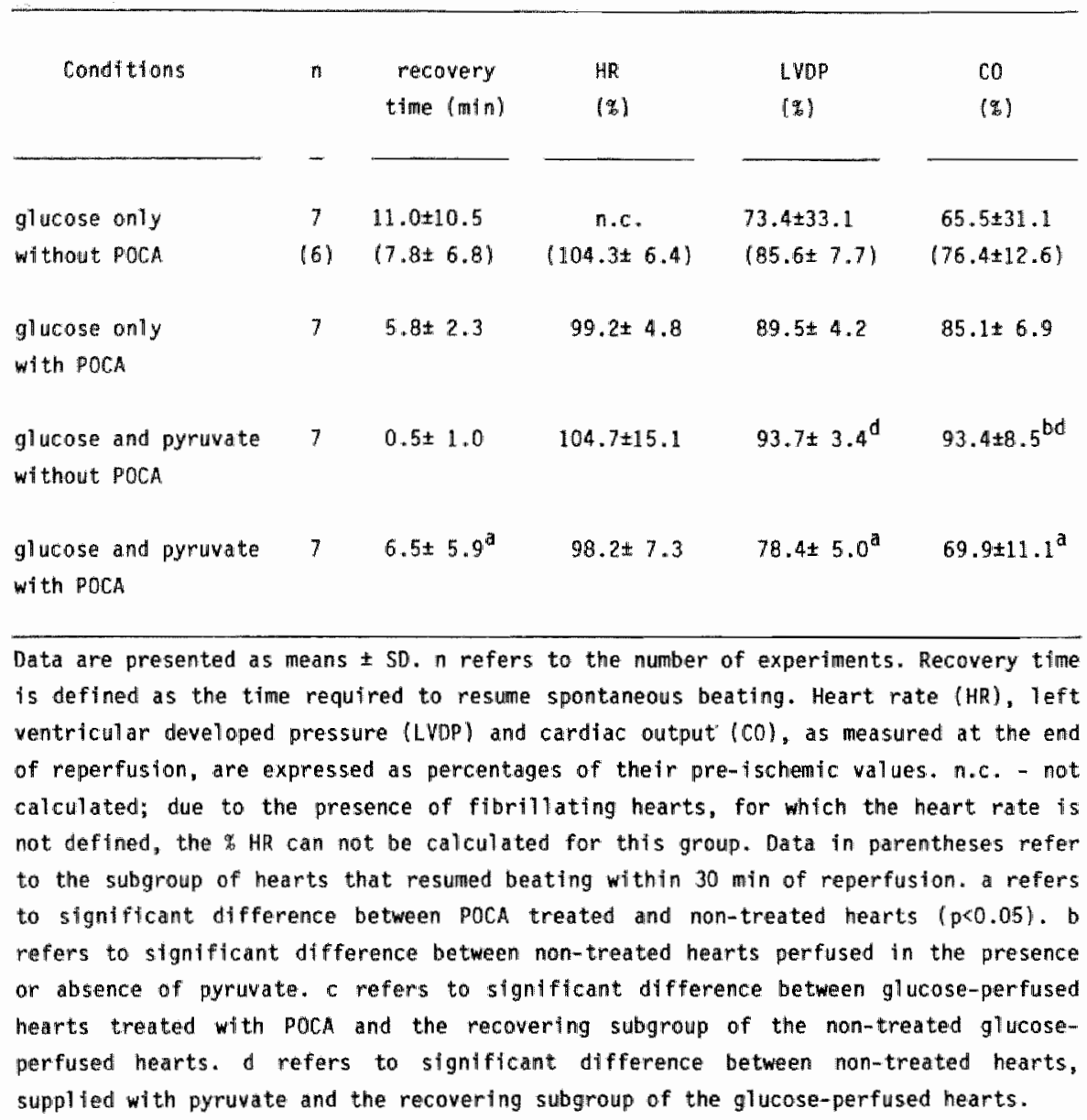




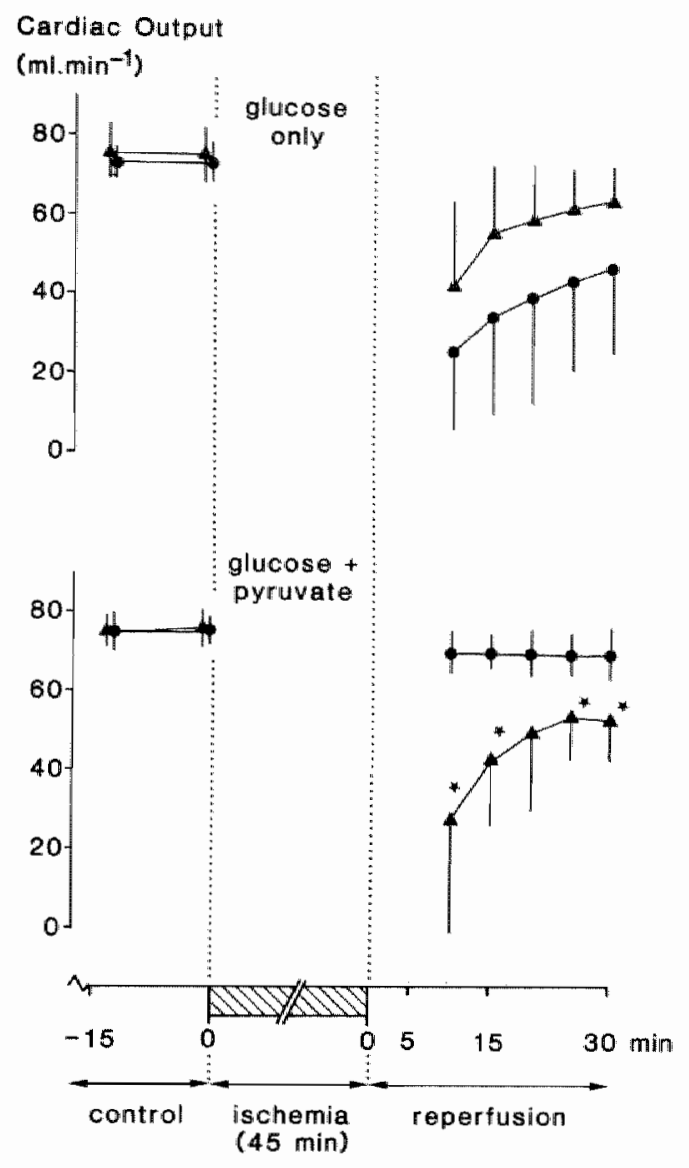

Fig 7.3 Recovery of cardiac output during reperfusion following $45 \mathrm{~min}$ of no-flow ischemia of hearts supplied with glucose as substrate and perfused in the absence ( $\bullet$ ) or presence $(\mathbf{\Lambda})$ of $10 \mu \mathrm{M}$ of POCA (upper panell, and hearts supplied with glucose and pyruvate as substrates and perfused in the absence $(\bullet)$ or presence $(\boldsymbol{\Delta})$ of POCA (1awer panel). Data are presented as means $\pm S D$. Asterisk refers to significant difference $(p<0.05)$ between hearts perfused with or without POCA. 
Ischemla and reperfusion.

Hemodynamic recovery.

When glucose was the only substrate avallable all hearts fibrillated after restoration of flow. The time required to resume normal electrical activity varied from heart to heart and averaged about 11 min (table 7.1). Likewise, the recovery of cardiac output was variable (fig 7.3, table 7.1). Hemodynamic recovery following ischemia was improved when pyruvate was present as cosubstrate. Pyruvate reduced the time required for hearts to resume spontaneous beating and increased the recovery of cardiac output. Even when glucose-perfused hearts that continued to fibrillate during reperfusion lonly 1 out of 7 in this group) were not taken into account the recovery of cardiac output was still less as compared to hearts supplied with pyruvate as cosubstrate.

The effect of POCA $(10 \mu \mathrm{M})$ on hemodynamic recovery was not unambiguous and appeared to be influenced by the substrate(s) used (fig 7.3, table 7.1). With glucose-perfused hearts POCA did not significantly affect hemodynamic recovery, although a tendency towards better recovery was observed. In contrast, when pyruvate was present as cosubstrate POCA increased the time required to resume spontaneous beating and reduced the recovery of cardiac output.

Enzyme release.

Cumulative release of LDH during reperfusion was not affected by the substrate(s) used and averaged 7 units.heart ${ }^{-1}$ per 30 min of reperfusion, in both the absence and presence of pyruvate (table 7.2). However, in the presence of POCA LDH release from glucose-perfused hearts tended to be reduced (3.6 units.heart ${ }^{-1}$ on the awerage), but this difference did not reach the level of significance. In contrast, addition of POCA to hearts, supplied with both glucose and pyruvate as exogenous substrates, tended to increase the release of $\mathrm{LDH}$ during reperfusion (NS).

Triacylglycerols, glycogen and lactate.

At the end of the pre-ischemic period the triacylglycerol content of glucose-perfused hearts was reduced by $50 \%$ as compared to hearts, supplied with pyruwate as cosubstrate (table 7.3). During ischemia the triacylglycerol content of glucose-perfused hearts did not change, whereas during reperfusion the content of this endogenous substrate further declined. POCA prevented the 
Table 7.2 Cumulative release of lactate dehydrogenase (LDH), Vactate and purimes during 30 min of reperfusion following 45 min of lischemita of hearts, supplied with glucose as substrate and perfused in the absence or presence of POCA $(10 \mu \mathrm{M})$, and hearts supplied with glucose and pyruvate as substrates, and perfused in the absence or presence of POCA.

\begin{tabular}{|c|c|c|c|}
\hline & Lunits. heart ${ }^{-1}$ ) & $\begin{array}{c}\text { lactate } \\
\text { (umol . heart }\end{array}$ & $\begin{array}{c}\text { purines } \\
\text { (umol theart }\end{array}$ \\
\hline glucase only & $6.7 \pm 3.9$ & $48.1 \pm 9.9$ & $1.90 \pm 0.19$ \\
\hline wi thout POCA. & $(6.5)$ & $(26.5)$ & $(1.59)$ \\
\hline glwcose only & $3.6 \pm 1.3$ & $28.6 \pm 5.2^{\mathrm{a}}$ & $1.91 \pm 0.17$ \\
\hline with POCA & $(2.4)$ & $(19.0)$ & $(1.75)$ \\
\hline gllucose and pyruvate & $7.4 \pm 2.2$ & $92.1 \pm 4.0^{b}$ & $1.81 \pm 0.21$ \\
\hline wit thout POCA & $(6.3)$ & $(33.9)$ & $(1.43)$ \\
\hline $\begin{array}{l}\text { glucose and pyruvate } \\
\text { wi th POCA }\end{array}$ & $\begin{array}{c}11.6 \pm 4.6 \\
(10.1)\end{array}$ & $\begin{array}{c}112.3 \pm 4.0^{\mathrm{a}} \\
(37.6)\end{array}$ & $\begin{array}{c}2.09 \pm 0.27 \\
(1.59)\end{array}$ \\
\hline \multicolumn{4}{|c|}{$\begin{array}{l}\text { Data expressed as means } \pm \text { SO. Purine release is defined as the sum of the release of } \\
\text { adenosine, inosine, hypoxanthine, xamthine and uric acid. Data in parentheses refer } \\
\text { to the average total amounts relleased, when corrected for basal release, as measured } \\
\text { during the pre- } 1 \text { schemic phase. a refers to significant difference between pocA } \\
\text { treated and non-treated hearts }(p<0.05) \text {. b refers to significant difference between } \\
\text { non-treated hearts, perfused in the absence or presence of pyruvate. }\end{array}$} \\
\hline
\end{tabular}

depletion of triacylglycerols in transiently ischemic glucose-perfused hearts. In the presence of pyruvate the triacylglycerol content al so remained constant during ischemia and reperfusion.

Pyruvate al so prevented the depletion of glycogen during the pre-ischemic phase (table 7.3). Although the glycogen content of ischemic hearts was also substantially higher in this group, ischemia was associated with a larger net reduction of this endogenous substrate. In glucose-perfused hearts POCA aggrevated the depletion of glycogen, as evidenced by the lower content in ischemic and reperfused hearts. 
Table 7.3 Myocardial content of triacyliglyterols, glycogen and lactate of preischemic, ischemic $(45$ min) and reperfused (30 min) hearts, supplied wh th glucose as substrate and perfused in the absence or presence of PDCA $(10 w M)$, and hearts supplied with glucose and pyruwate as substrates, and perfused in the absence or presence of POCA.

conditions

glucose onily

without POCA

glucose only

with POCA

glucose and pyruvate without POCA

glucose and pyruvate with POCA triacyl-

giycerols

pre- ischermita:

ischemla:

reperfusion:

$15.43 \pm 6.47$

$17.14 \pm 4.79$

$9.66 \pm 3.12^{c}$

glycogen

lactate

ischemia:

$23.03 \pm 0.15$

reperfusion:

$27.23+4.48^{\mathrm{D}}$

$4.4 \pm 1.9^{\mathrm{a}}$

$15.2 \pm 6.7^{b c}$

$63.4 \pm 20.7^{2}$

$4.6 \pm 2.4^{b c}$
pre-ischemia:
1 schewi a :

$31.38+7.16$

$35.45 \pm 10.82$

$95,3 \pm 18,5$

$9.4 \pm 3.9$

meperfustion:

$35.99 \div 9.74$

$65.7 \pm 15.6$

$180.6 \pm 24.2$

$57.2 \pm 12.3$

$8.4 \pm 3.9^{C}$

Ischerita:

$21.61 \pm 5.69^{\mathrm{a}}$

$21.5 \pm 23.6^{a}$

$144,6 \pm 27.1^{a}$

reperfusion:
$29.73 \pm 7.24$
$6.7 \pm 1.8^{c}$

Data are presented as means \pm 50 . All values in 4 mol. $g^{-1}$ dry wt. Triacylglycerolls are expressed as fatty acyl equivalents and glycogen as glucose equivalents. a refers to significant difference between ischemic hearts, treated or not treated with POCA $(p<0.05)$. D refers to stgnificant difference between reperfused hearts, treated or not treated with POCA. c indicates significantly different from ischemitc value.

During ischemia accumulation of lactate was most pronounced when pyruvate was present during the pre-ischemic phase (table 7.3). In contrast, relatively small amounts accumulated in glucose-perfused hearts treated with POCA. At the end of $30 \mathrm{~min}$ of reperfusion the myocardial lactate content had returned to pre-fschenic values. With the exception of hearts supplied with pyruvate as cosubstrate and perfused in the presence of POCA, the enhanced accumulation of lactate during ischemia was reflected by an enhanced release of lactate into the coronary effluent during reperfusion (table 7.2). However, it should be 
noted that pyruvate as we11 as POCA influenced basal lactate release. Addition of POCA to glucose-perfused hearts resulted in a reduced release of lactate during the pre-ischemic phase $(0.32 \pm 0.14$ as compared to $0.72 \pm 0.34$ $\mu \mathrm{mol} . \mathrm{min}^{-1}$. heart $\left.{ }^{-1}, p<0.05\right)$. Lactate release was elevated in the presence of pyruvate $\left(1.94 \pm 0.21 \mu \mathrm{mol} . \mathrm{min}^{-1}\right.$.heart $\left.{ }^{-1}\right)$ and POCA further increased basal

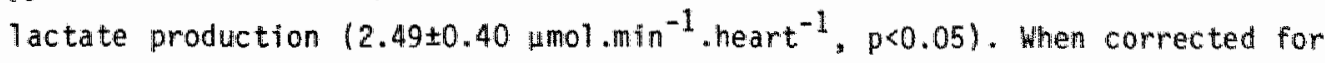
pre-ischemic (basal) lactate release (table 7.2 , data in parentheses), the differences in the average cumulative release of lactate during reperfusion were less outspoken.

High-energy phosphates and related compounds.

As shown in table 7.4 the tissue content of the individual adenine nucleotides of hearts subjected to 45 min of no-flow ischemia was markedly affected by the presence of pyruvate as cosubstrate during the pre-ischemic phase. As compared to glucose-perfused hearts the tissue content of ADP was reduced, whereas that of AMP was augmented. The tissue content of total adenine nucleotides was comparable. Moreover, differences were also apparent in the accumulation of degradation products during ischemia (table 7.5 ). In the presence of pyruvate the accumulation of adenosine was attenuated, whereas that of incsine was increased. This was also reflected by a diminished release of adenosine relative to inosine into the coronary effluent during the initial reperfusion phase (data not shown).

In glucose-perfused hearts POCA aggrevated the ischemia induced changes in the myocardial adenine nucleotide content, as evidenced by a very low energy charge. In this group appreciable amounts of IMP were found to accumulate. In ischemic hearts, supplied with pyruvate as cosubstrate during the pre-ischemic phase, the effects of POCA on adenine nucleotide metabolism were insignificant.

Reperfusion resulted in a sharp increase in the myocardial creatine phosphate content and a rise in ATP. Concomitantly, the levels of ADP and AMP tended to normalize. This was reflected by a recovery of the energy charge to values of about 0.8 in each group. At the end of reperfusion no significant differences in the total adenine nucleotide content were observed between the four groups investigated. This was reflected by the absence of significant differences in the cumulative release of purines during reperfusion (table 7.2). 


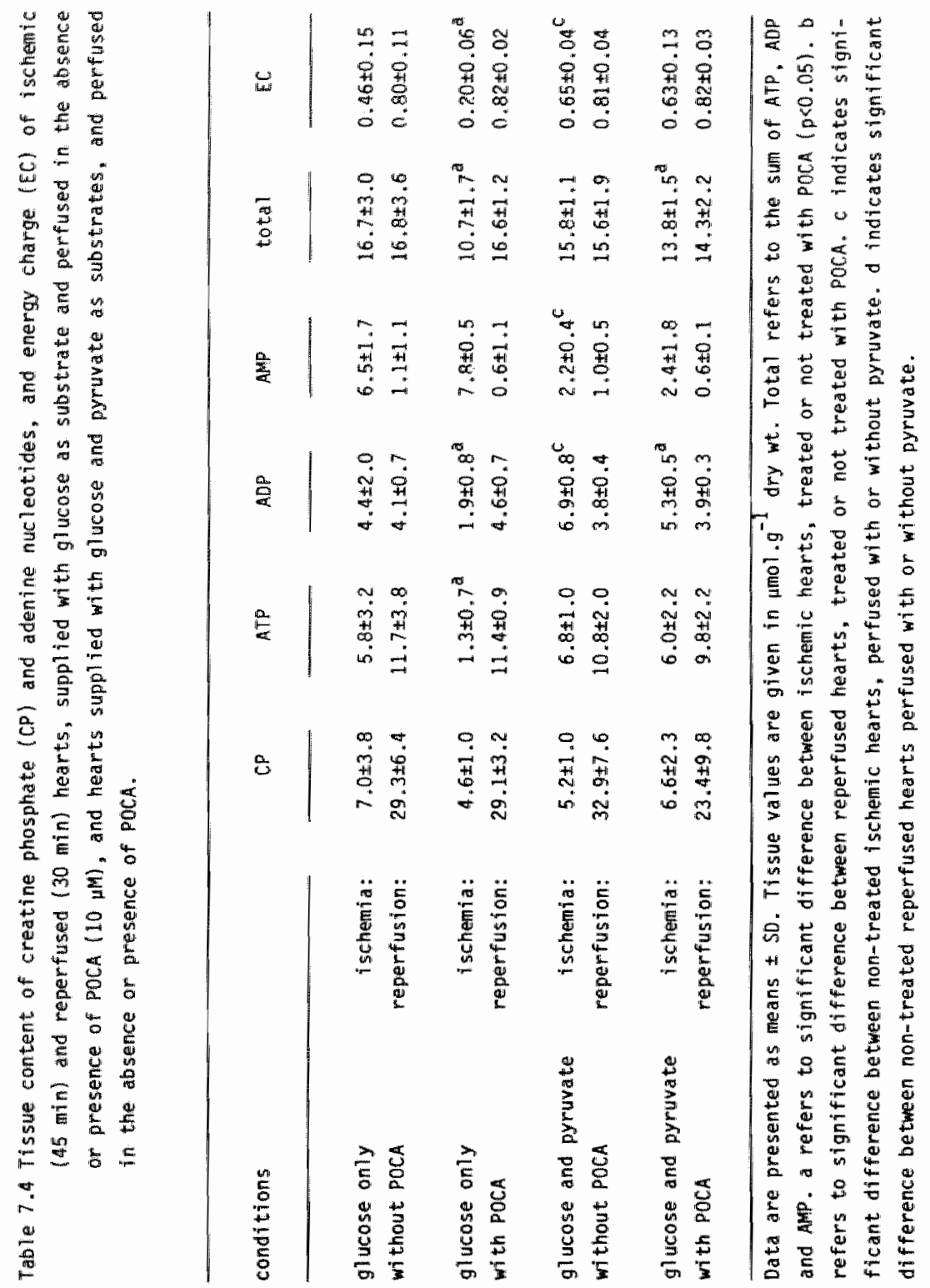


Table 7.5 Myocardial content of IMP, nucleosides and oxypurines of hearts subjected to 45 min of nom flow ischemia, supplied with glucose as substrate and perfused in the absence or presence of pocA $110 \mu \mathrm{M})$, and hearts supplied with glucose and pyruwate as substrates, and perfused in the absence or presence of POCA.

\begin{tabular}{|c|c|c|c|c|c|}
\hline conditions. & $\operatorname{IMP}$ & adenosine & inosine & $\begin{array}{l}\text { hypo- } \\
\text { xanthine }\end{array}$ & xanthine \\
\hline $\begin{array}{l}\text { glucose oniy } \\
\text { without POCA }\end{array}$ & $1.5 \pm 1.0$ & $3.4 \pm 0.9$ & $3.0 \pm 0.6$ & $1.2 \pm 0.9$ & $0.7 \pm 0.2$ \\
\hline $\begin{array}{l}\text { glucose only } \\
\text { with Poca }\end{array}$ & $2.8 \pm 0.4^{\mathrm{a}}$ & $4.2 \pm 0.5$ & $2.9 \pm 0.2$ & $2.4 \pm 0.3^{\mathrm{a}}$ & $0.5 \pm 0.1$ \\
\hline $\begin{array}{l}\text { Glucose and pyruvate } \\
\text { without POCA }\end{array}$ & $0.6 \pm 0.3$ & $2.2 \pm 1.0^{b}$ & $5.8 \pm 1.0^{b}$ & $2.7 \pm 0.7^{b}$ & $0.7 \pm 0.2$ \\
\hline $\begin{array}{l}\text { glucose and pyruwate } \\
\text { with POCA }\end{array}$ & $0.4 \pm 0.2$ & $2.1 \pm 0.9$ & $4.3 \pm 1.0^{7}$ & $1.7 \pm 0.3^{\mathrm{a}}$ & $0.6 \pm 0.1$ \\
\hline
\end{tabular}

\section{Non-esterified fatty acids.}

Forty-five min of ischemia resulted in a significant rise in the total NEFA content of glucose-perfused hearts (fig 7.4). Comparable levels were measured when POCA had been added to the perfusate. In contrast, when pyruvate was present as cosubstrate, no significant rise in NEFA's was observed during ischemia. Likewise, in POCA treated Ischenic hearts NEFA levels did not increase.

In hearts perfused with glucose as the only substrate the myocardial NEFA content tended to reduce during reperfusion (NS). When POCA was present no such tendency was observed. In fact, significantly larger amounts of NEFA's were found to accumulate in reperfused hearts, when POCA treated hearts were 
NEFA (nmol. $g^{-1}$ dry wi)
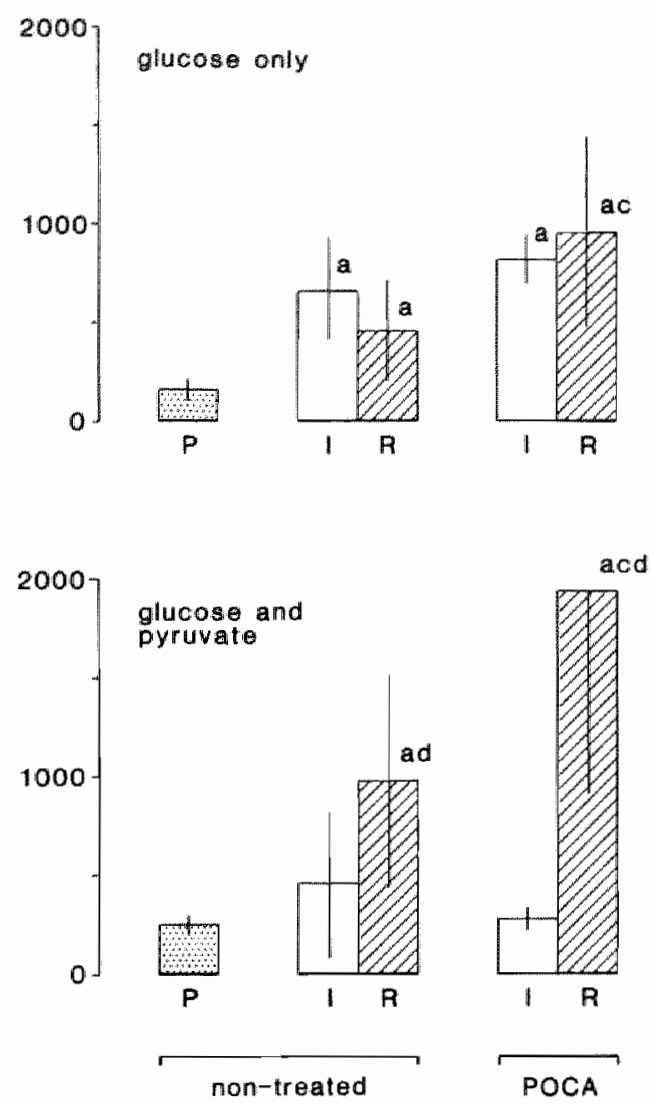

Fig 7.4 Myocardial NEFA content of pre-ischemic hearts ( $P$, shaded bars), hearts subjected to $45 \mathrm{~min}$ of ischemia (1, open bars), and hearts reperfused for 30 min ( $R$, hatched bars). The upper panel presents data of non-treated and POCA treated hearts supplied with glucose as exogenous substrate. The lower panel presents data of hearts supplied with glucose and pyruwate as substrates. Data are presented as meanis \pm SD. a indicates significantly different $(p<0.05)$ from pre-ischemic non-treated hearts. b refers to significant difference between ischemic POCA treated and non-treated hearts. c refers to significant difference between reperfused POCA treated and non-treated hearts. $d$ Indlcates significantiy different from the corresponding ischemic value. 


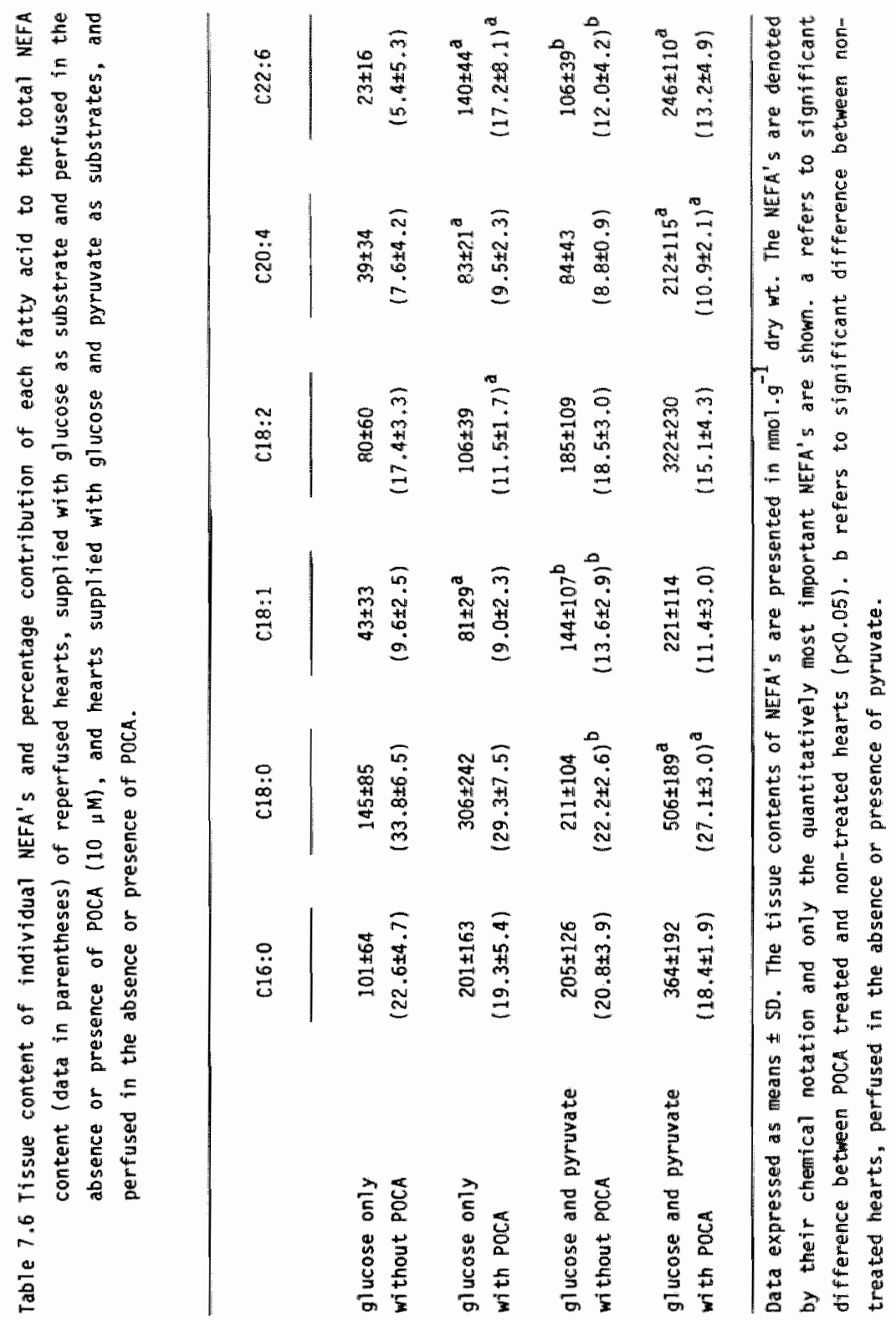


compared with non-treated hearts. With pyruvate as cosubstrate, reperfusion resulted in a significant increase in the myocardial NEFA content. The NEFA content of reperfused hearts was significantiy higher as compared to hearts perfused in the absence of pyruvate. Moreover, accumulation of NEFA's during reperfusion was substantially increased when the pyruvate-perfused hearts had been treated with POCA.

Beside differences in the total NEFA content of reperfused hearts, differences in the content of individual NEFA's and the percentage contribution of individual NEFA's to the total NEFA content were al so apparent (table 7.6$)$. In glucose-perfused hearts POCA not only induced a significant increase in the myocardial content of dacosahexaenoic acid $(C 22: 6)$, but al so an appreciable increase in the relative contribution of $c 22: 6$ to the total. Addition of pyruvate as cosubstrate was also associated with a relative enhancement of the contribution of $\mathrm{C} 22: 6$ to the total NEFA content. However, under these conditions administration of POCA only resulted in a rise in the content of $C 22: 6$, but did not affect the percentage contribution of $\mathrm{C} 22: 6$ to the total. Both pyruvate and POCA exacerbated the accumulation of arachidonic acid (C20:4) during reperfusion, but the percentage contribution of $620: 4$ to the total NEFA content remained relatively constant. Only in hearts with the highest total NEFA content (hearts supplied with pyruvate as cosubstrate and treated with POCA) a significant rise in the percentage contribution of arachidonic acid to total NEFA's was observed. Interestingly, despite comparable NEFA levels (close to $1 \mu \mathrm{mol} . \mathrm{g}^{-1} \mathrm{dry}$ wt) in POCA treated reperfused hearts, supplied with glucose, and in non-treated reperfused hearts, supplied with pyruvate as cosubstrate, differences in the relative composition of the NEFA pool were observed between these experimental groups (table 7.6). This was especially true for the percentage contributions of $C 18: 2$ and $C 22: 6$ to the total NEFA content.

\subsection{Discussion}

There is increasing evidence that augmented cellular NEFA levels adversely affect cellular function ( see for instance Lamers and Huel smann, 1977; Katz et al., 1982; Piper et al., 1983). The findings of the present study show that 
both the addition of pyruvate, a substrate competing with fatty acids for oxidation, and the administration of POCA, a carnitine acyltransferase I in hibitor, augment the tissue NEFA content of reperfused hearts.

A rise of the tissue NEFA content implies that the rate of uptake of exogenous fatty acids, or the rate of release of fatty acids from endogenous lipid pools, exceeds its rate of removal. In theory, removal of NEFA's is possible through (a) esterification with $C O A$ and carnitine without further conversion, (b) re-esterification into triacylglycerols or phospholipids, (c) subsequent degradation through $\beta$-oxidation, and/or (d) release into the venous effluent. In the present experimental set-up any role of circulating fatty acids can be excluded. Therefore, an increase in tissue levels of NEFA's implies that the rate of release from endogenous myocardial lipid pools exceeds $i$ ts removal. This is remarkable, considering the fact that NEFA's are a preferred substrate for the heart (Neely et a1., 1972b). This apparent discrepancy might be explained by assuming that either the process responsible for the activation, transport and degradation of NEFA's or the overall mitochondrial function is impaired during reperfusion. This notion is substantiated by the finding that the oxidation of exogenously applied radiolabeled fatty acids is hampered during reperfusion (Schwaiger et al., 1985; Chatelain et al., 1987; Myears et al., 1987). Alternatively, the accumulated NEFA's, originating from endogenous lipid pools, may be compartmentalized and, therefore, not directly avalaible for mitochondrial s-oxidation.

\section{Pyruvate as cosubstrate.}

It is shown that under nomoxic conditions glucose-perfused hearts deplete their glycogen and triacylglycerol stores. Addition of pyruvate as cosubstrate prevents the usage of endogenous substrate stores. Thus, pyruvate inhibits the oxidation of fatty acids derived from endogenous triacylglycerol pools. Concomitantly, the myocardial content of NEFA's is higher and the percentage contribution of individual NEFA's to total NEFA's is different (see fig 7.2). Elevated NEFA levels in nomoxic hearts, supplied with pyruvate as cosubstrate, most likely prevent degradation of triacylglycerols through product inhibition of triacylglycerol 1ipase activity (Stam and Huelsmann, 1981; Severson and Reinauer, 1982). The finding that the total NEFA content and its relative composition remain constant during prolonged normoxic perfusion indicates that the NEFA's are in equilibrium with the esterified fatty acid 
pools (1.e. phospholipids and triacylglycerols).

When glucose was used as the sole exogenous substrate the rise in NEFA's during 45 min of no-flow ischemia is found to be significant. No such change is found when pyruvate is added to the perfusate. The presence of pyruvate in addition to glucose during the pre-ischemic phase profoundly affects ischemic myocardial metabolism, as evidenced by the elevated tissue content of glycogen, lactate and inosine, the lower content of AMP, and the higher energy charge at the end of ischemia (see table 7.3, 7.4 and 7.5 ).

It is noteworthy that in glucose-perfused hearts the ischemic myocardial content of ATP is comparable, but AMP and adenosine levels are increased. The mechanism underlying these differences remains unclear, but might be related to differences in the capacity to produce ATP anaerobically (discussed in chapter 3). Elevated AMP and adenosine levels would favor inhibition of acylCoA synthetase activity (De Jong and Huelsmann, 1970) and, hence, impede re-esterification of NEFA's into either phospholipids or triacylglycerols (discussed in chapter 5). This might present a feasible explanation for the observed significant increase of NEFA's in glucose-perfused ischenic hearts.

The present findings indicate that reperfusion of glucose-perfused hearts, following 45 min of no-flow ischemia, does not evoke complete normalization of the myocardial NEFA content. Nevertheless, considerable amounts of fatty acids are oxidized, as evidenced by the substantial decline in the myocardial triacylglycerol content during reperfusion. Accordingly, it must be concluded that the transiently ischemic insult imposed does not seriously disturb the mitochondrial capacity to oxidize fatty acids. In the presence of pyruvate the myocardial triacylglycerol content remains unaltered and, concomitantly, the NEFA content rises significantly during reperfusion. Pyruvate is known to activate pyruvate dehydrogenase and, hence, to stimulate its conversion to acetyl-COA (Kobayashi and Neely, 1983b). As a consequence, the availability of mitochondrial free COA will be diminished (Kobayashi and Neely, 1983b) and Buoxidation becomes inhibited (Neely et al., 1972b). Since pyruvate is found to improve functional recovery, it is highly improbable that the observed enhanced rise in NEFA's during reperfusion is due to impairment of mitochondrial function. Thus the rise in NEFA's likely results from the inhibition of fatty acid oxidation, through competition of pyruvate and NEFA's for mitochondrial free CoA. 


\section{Effects of POCA.}

POCA only becomes effective as an inhibitor of carnitine acyltransferase I (CAT-I) after esterification with COA. The resulting POCA-COA ester strongly binds to the enzyme and inhibits its activity (Wolf and Engel, 1985). Several authors (Huetter et al., unpublished observations; Seftelberger et al., 1985) have demonstrated that POCA reduces fatty acid oxidation and myocardial oxygen consunption. In neonatal myocyte cultures POCA was found to prevent the accumulation of acylcarnitine and, concomitantly, to preclude the electrophysiological derangements associated with hypoxia (Knabb et a1., 1986). Likewise, Creer and coworkers (1986) demonstrated that POCA prevented both elevation of the acylcarnitine level and ventricular arrhythmias following coronary artery occlusion in the cat heart. Paulson and associates (1984c) reported that POCA prevented the accumulation of acyl-COA and acylcarnitine during low-flow ischemia, and improved post-ischemic functional recovery of isolated rat hearts, perfused with palmitate and glucose as exogenous substrates. In contrast, Seitelberger and coworkers (1985), using the regionally ischemic open-chest dog preparation, showed that infusion of POCA negatively affected regional mechanical function of the ischemic area, despite a shift from fatty acid towards glucose oxidation. It should be recognized that POCA is an amphiphilic drug that probably intercalates in the phospholipid bilayer. It can therefore not be excluded that POCA al so exerts some aspecific effects related to its amphiphilic nature.

Hypoglycemic agents, like oxfenicine, 2-tetradecylglycidic acid and POCA, are generally considered to afford protection to the ischemic myocardium (Pearce et al., 1979; Liedtke et al., 1984; Miller et al., 1986; Vik-Mo et a)., 1986). The beneficial effect is thought to be mediated through a reduction of oxygen consumption of the jeopardized myocardium by a shift from fatty acid to glucose oxidation during periods of oxygen shortage. It could be argued, however, that a reduction of fatty acid oxidation might also impair the elimination of fatty acids, released from endogenous 1 ipid pools during ischemia (Van der Vusse et a1., 1982; Chien et a1., 1984; Prinzen et a1., 1984; chapters 5 and 6), thereby contributing to the accumulation of NEFA's during ischemia and/or reperfusion.

In the present experimental set-up hearts were subdued to no-flow ischemia and, hence, oxygen supply is nil during this phase. Accordingly, positive effects of POCA, related to preferential oxidation of carbohydrate substrates, 
are not anticipated. Moreover, recent studies indicate that the accumulation of acyl-CoA and acylcarnitine is insignificamt in hearts perfused in the absence of exogenous fatty acids and subjected to no-flow ischemia (for rewiew see Van der Vusse et al., 1987a). Thus, under the present experimental condiltions, the reported attenuation of the accumulation of these fatty esters by POCA might not be that relevant. On the other hand POCA will prevent the post-1schemic oxidation of NEFA's accumulated and, hence might even be detrimental to the transiently ischemic heart.

Addition of POCA to the perfusate in the concentration as used in the present study $(10 \mu M)$ has been reported not to influence cardiac hemodynamics under nomoxic conditions (Roesen and Reinauer, 1984; Huetter et al., unpub1ished observations). However, at this dose fatty acid oxidation is seriously affected (Roesen and Reinauer, 1984; Wolf and Engel, 1985; Huetter et al., unpublished observations). The present study corroborates with earlier reports on the absence of effects of POCA on myocardial hemodynamics. Although we did not measure fatty acid oxidation directly, the finding that POCA is able to prevent the degradation of triacylglycerols in transiently ischemic glucoseperfused hearts, demonstrates that the concentration used is effective.

It is noteworthy that during the pre-ischemic phase POCA reduced lactate release from glucose-perfused hearts, whereas it increased lactate release from hearts supplied with pyruwate as cosubstrate. As yet, the underlying mechanism is unclear. It remains to be established whether this effect is related to the inhibition of CAT-I activity or the result of an aspecific effect of the drug. Interestingly, Roesen and Reinauer (1984) also reported that POCA reduced basal lactate release from glucose-perfused hearts. In the same study it was shown that POCA does not directly affect the activity of pyruvate dehydrogenase.

In the presence of POCA the NEFA content of glucose-perfused hearts substantially increases during reperfusion. All information available indicates that the effect of POCA is only mediated by the imhibition of CAT-I. ACcordingly, it must be concluded that POCA prevents the conversion of NEFA's into acylcarnitine and, hence, the oxidation of NEFA"s released from endogenous lipid pools. This notion is substantiated by the observations that (a) addition of pyruvate to the perfusate also results in an enhanced accumulation of NEFA" s in reperfused tissue and (b) that in the presence of both pyruvate and POCA the accumulation of NEFA's during reperfusion is further augmented, indi- 
cating that the effects of pyruvate and POCA are additive.

During ischemia, i.e. in the absence of oxygen, POCA has no effect on the myocardial NEFA content, indicating that POCA does not enhance the release of fatty acids from phospholipids or triacylglycerolls, but merely affects the rate of removal, i.e. oxidation, of NEFA's released. This notion also implies that, especially in glucose-perfused hearts, appreciable amounts of NEFA"s relleased from esterified fatty acid pools are oxidized during reperfusion. In other words, the amount of NEFA's accumulating during reperfusion does not necessarily reflect the amount of acyl-moleties released from myocardial lipids. Furthemore, since the rate of oxidation of the individual NEFA's might differ (Nomann et al., 1983), the relative contribution of individual NEFA's to the total NEFA content of reperfused hearts may not reflect the fatty acyl composition of its endogenous source.

\section{NEFA's and myocardial damage.}

Although the observed increments in tissue NEFA levels in reperfused hearts are in line with the proposed action of both pyruvate and POCA, no satisfying explanation can be given for the complex effects of pyruwate and POCA on hemodynamic recovery and cellular damage, as estimated by the release of $\mathbb{L D H}$.

Pyruvate is found to reduce the incidence and duration of ventricular fibrillation and to improve functional recowery. The addition of this substrate to the perfusion medium does not affect $\angle D H$ release, but enhances the accumulation of NEFA"s during reperfusion. In glucose-perfused hearts POCA tends to improve functional recovery and to reduce LDH release but, at the same time, augments the accumulation of NEFA's. In the presence of pyruvate POCA reduces functional recovery, aggrevates $L D H$ release, and enhances the accumulation of NEFA's. The absence of a clear relationship between the various experimental groups of reperfused hearts, regarding the tissue NEFA content of and cumulative release of $\mathrm{LDH}$, is 111 ustrated in figure $7.5 \mathrm{a}$. However, as shown in figure $7.5 \mathrm{~b}$, a weak but significant correlation $(r=0.62)$ is found when the paired data of individual hearts are plotted.

The present findings indicate that the differences in hemodynamic recowery between the various experimental groups are not related to either the myocardial content of ATP at the end of reperfusion (correlation coefficient $r=0.44$ ) or to the amount of $\mathrm{LDH}$ released during reperfusion $(r=0.17)$. Furthermore, no 


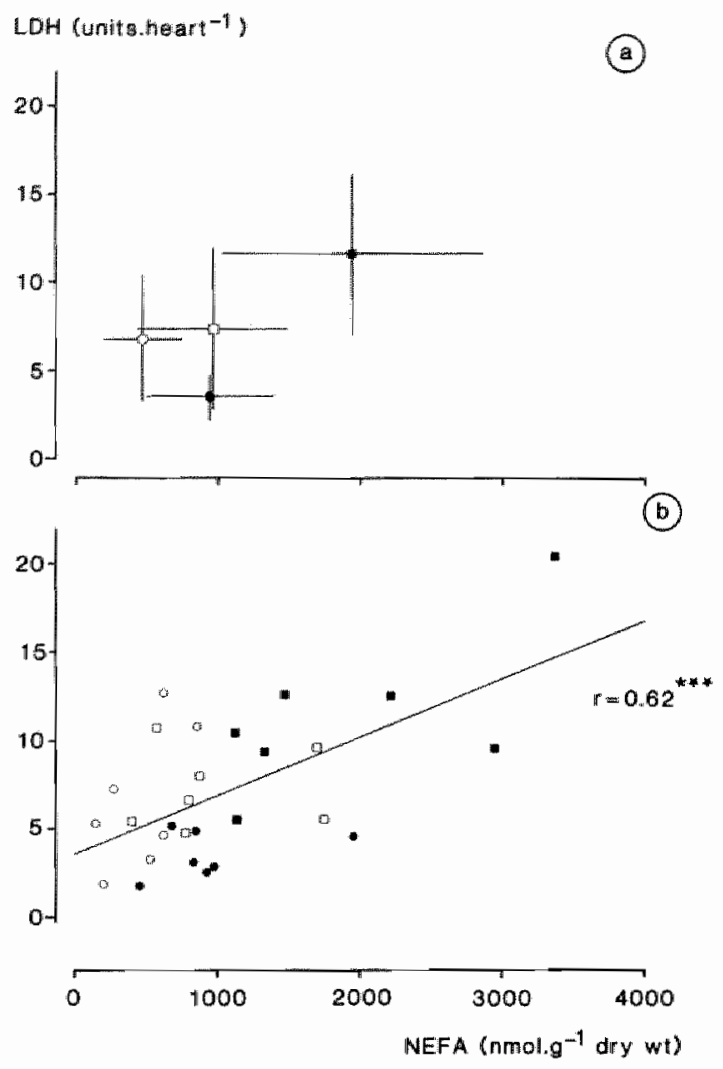

Fig 7.5 Relationship between the total NEFA content of reperfused hearts and the cumulative release of $L D H$ during $30 \mathrm{~min}$ of reperfusion following $45 \mathrm{~min}$ of ischemia. In the upper panel (a) data are presented as the means $\# S D$ of the four groups investigated. In the lower panel (b) the palred data of individual hearts are presented. $(0)$ and $(0)$ refer to non-treated and POCA treated hearts, supplied with glucose, respectively. (D) and (a) refer to non-treated and treated hearts, supplied with pyruvate as cosubstrate, respectively. $* \star$ - p<0.001. 
relation exists between the tissue content of NEFA's of reperfused hearts and functional recovery following $45 \mathrm{~min}$ of no-flow ischemia $(r=0.02)$.

Paulson and coworkers (1984c) demonstrated that POCA prevents the accumulation of acyl-COA and acylcarnitine during both low-flow ischemia and subsequent reperfusion of rat hearts supplied with glucose and fatty acids as exogenous substrates and, hence, a positive effect of POCA was anticipated. These authors indeed reported improved post-ischemic functional recovery. The present findings clearly demonstrate that this drug increases the accumulation of NEFA's during reperfusion. Despite that, a tendency towards better recovery and reduction of cellular damage is observed in glucose-perfused transiently ischemic hearts. In contrast, in the presence of pyruvate POCA aggrevates functional deterioration. Perhaps, the rise in NEFA's in reperfused hearts, perfused in the presence of pyruvate and treated with POCA, exceeds a level critical for normal cellular function, and thereby overrules the otherwise beneficial effects of POCA. However, interpretation of these results is hampered by the lack of information on the effects of pyruvate and POCA on the tissue levels of acyl-COA and acylcarnitine in ischemic and reperfused hearts. In addition, to gain more insight into the apparently contrasting effects of POCA on hemodynamic function and tissue damage of transiently ischemic hearts, supplied with different substrates, it is of interest to examine the dose dependency of these effects in relation to substrate supply.

\subsection{Summary}

In the present study we evaluated the effects of pyruvate, a substrate inhibiting fatty acid oxidative consumption, and POCA, a carnftine acyltransferase I inhibitor, on NEFA accumulation and myocardial damage of transiently ischemic hearts. In glucose-perfused hearts the NEFA content increased significantly during $45 \mathrm{~min}$ of no-flow ischemia. In the presence of pyruvate $(5 \mathrm{mM})$ the rise of NEFA's did not reach the level of significance. During ischemila POCA $(10 \mu \mathrm{M})$ is found not to alter NEFA accumulation of hearts perfused in both the absence and presence of pyruvate.

In glucose-perfused hearts the tissue NEFA content remained elevated during 30 min of reperfusion. Pyruvate as well as POCA caused an increase in 
the MEFA content of reperfused hearts. The effect of these substances on the accumulation of NEFA's appeared to be additive. However, the so-induced effects on the tissue NEFA content were not associated with unambiguous responses regarding post-ischemic function or enzyme release between the various experimental groups. Administration of pyruwate to glucose-perfused hearts improved post-1schemic function, but did not effect $L D H$ release during reperfusion. POCA tended to improve functional recovery (MS) and to attenuate LDH release (NS) of glucose-perfused hearts. In contrast, administration of POCA to hearts supplied with both glucose and pyruvate, deteriorated postischemic functional recovery and tended to enhance LDH release (NS).

The present findings indicate that the net release of fatty acyl moieties from myocardial lipids proceeds during reperfusion, but that the amount of accumulated NEFA's only partly reflects the amount released from myocardial lipids, because part of the NEFA's derived from these pools are likely to be oxidized. Secondly, no clear relation is found between the myocardial content of NEFA"s, hemodynamic recovery, and enzyme release during reperfusion, indicating a complex relation between tissue NEFA levels, their hamful effects as observed in-vitro, and consequences for myocardial function and integrity. 
ISCHEMIA, REPERFUSION AND MYOCARDIAL DAMAGE: CONCLUDING REMARKS.

\subsection{The nature of ischemia and reperfusion induced lipid changes.}

The present findings clearly demonstrate that deprivation of coronary flow as well as subsequent reinstallation of perfusate supply leads to disturbances in myocardiall lipid homeostasis.

During the first 30 minutes of ischemia the myocardial total NEFA content does not change. However, during the same period substantial amounts of glycerol, an end product of triacylglycerol breakdown, accumulate. These observations indicate that the triacylglycerol-NEFA cycle is operative. Hence, considerable amounts of ATP will be consumed as a result of this so-called "futile cycle". Afterwards the tissue NEFA content increases, implying that a disequilibrium arises between the rates of deacylation and reacylation of myocardial lipids. The further increase in myocardial content of glycerol and the accumulation of relatively large amounts of arachidonic acid, a fatty acid predominantly incorporated in phospholipids, among other fatty acids, indicate that disturbances in both triacylglycerol and phospholipid homeostasis are involved. This notion is substantiated by the finding that nicotinic acid and mepacrine, putative inhibitors of triacylglycerol and phospholipid hydrolysis, respectively, are able to reduce NEFA accumulation during ischemia. The relatively small, but significant increase in lysophospholipids provides additional evidence that phospholipid homeostasis is altered.

Reperfusion gives rise to an augmented rate of degradation of the myocardial esterified lipid pool. Because the amount of glycerol released during reperfusion matches the amount of glycerol accumulated at the end of the preceding ischemic period, it is reasonable to assume that triacylglycerol homeostasis is not seriously disturbed during reperfusion. As a consequence, the NEFA's accumulating during the reperfusion phase most likely originate from phospholipids.

The results presented in chapter 5 indicate that the rise in NEFA's during 
ischemia might be caused by impainment of the reacylation process. Inhibition of acyl-CoA synthetase activity is feasible through reduction of the tissue levels of ATP, an essential reactant, and augmentation of the tissue levels of AMP and adenosine, potent inhibitors of acyl-COA synthetase. Since after restoration of fllow the tissue level of ATP is partially restored and the levels of AMP and adenosine are normalized, this mechanism is certainly not operative during reperfusion. Accordingly, it is tempting to speculate that the mechanisms underlying the accumulation of NEFA's during ischemia and during reperfusion are not identical.

\subsection{Myocardial damage.}

In this section the results obtained regarding the effects of varying the duration of ischemia, substrate supply, and administration of nicotinic acid, mepacrine and POCA, putative inhibitors of triacylglycerol lipase, phospholipase $A_{2}$ and $B$-oxidation, respectively, will be discussed to delineate possible relationships between functional recovery, the tissue ATP content, lipid changes, and cell damage.

\subsubsection{Enzyme release and post-ischemic function.}

In the present studies the release of lactate dehydrogenase (LDH), a cytosolic enzyme, into the coronary effluent is considered to be a sign of serious cell injury. Figure 8.1 demonstrates that enzyme release and functional recovery during reperfusion are not related. In the present study the average release of $L D H$ never exceeds $10 \%$ of the myocardial LDH content. According to one extreme, this could indicate that each myocardial cell loses 10\% of its cytosolic LOH content at the most. It is not known if such a reduction of the cytosolic enzyme content will lead to disturbances in cell function. According to the other extreme, enzyme release is a result of lethal cell damage. When it is assumed that lethally damaged cells lose their complete content of cytosolic enzymes, it follows that $10 \%$ of the cells will be irreversibly injured at the most. Apparently such a diminution of viable 
tissue does not necessarily lead to severe disturbances in hemodymamic function of transiently ischemic hearts. This poses the question to which extent viable tissue can be missed before appreciable functional deterioration becomes inevitable. The data presented in figure 8.1 also show that fibrillation, with subsequent failure to produce cardiac output, occurs at both relatively low and high levels of enzyme release. This finding suggests that fibrillation is not related to the extent of cell damage.

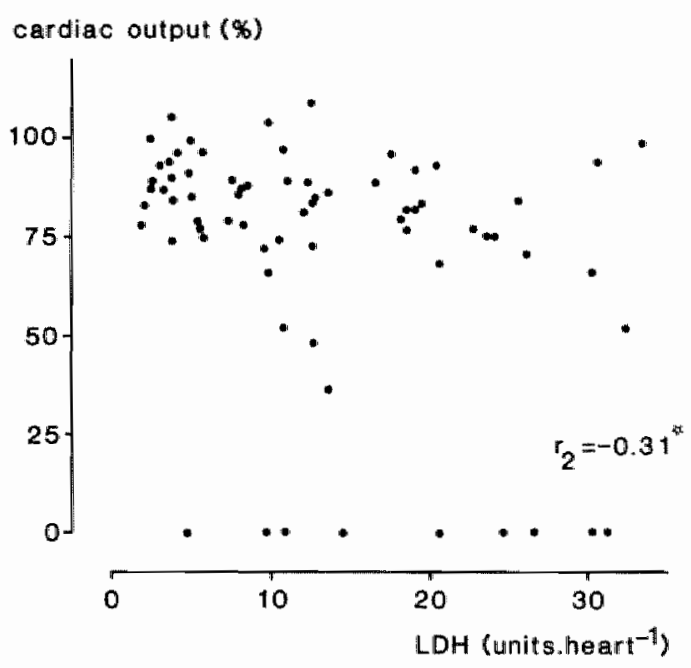

Fig 8.1 Relationship between the release of LDH during reperfusion and the percentage recovery of cardiac output of hearts reperfused for $30 \mathrm{~min}$ following 30 to $60 \mathrm{~min}$ of ischemia, and perfused in the absence or presence of pyruvate, nicotinic acid, mepacrine or POCA. Paired data of individual hearts are shown. The correlation coefficient $\left(r_{2}\right)$ was calculated on the basis of paired data from hearts that were able to resume spontaneous beating during reperfusion. not significant. 


\subsubsection{ATP, post-1 schemic function and cell damage.}

As shown in figure 8.2 in the present studies no relationship is found between the tissue content of ATP of reperfused hearts and the recovery of cardiac pump function. This implies that the tissue content of ATP is a poor determinant of hemodynamic function, as assessed in the early reperfusion phase. As dicussed in chapter 3 and 4 , the post-ischemic recovery of the rate of mitochondrial oxidative phosphorylation and/or the cytosolic phosphorylation potential are likely to be more important determinants of post-ischemic myocardial performance. So, it must be concluded that under the present experimental conditions the tissue ATP content provides information about. neither the rate of oxidative phosphorylation nor the phosphorylation potential. Nevertheless, several investigators (Reibel and Rovetto, 1978; Watts et al., 1980; Edoute et a1., 1983; Meno et a1., 1984) observed linear relationships between the tissue ATP content and functional recovery. In view of the well-known subcellullar compartmentalization of adenine nucleotides and the heterogeneity in the response of individual cells to ischemia and reperfusion the latter finding is rather unexpected.

Complete dissociation was al so observed between the tissue ATP content and the release of cellular enzymes (fig 8.2), indicating that overall ATP depletion, within the range of values measured, is not causally related to irreversible cell damage. It can not be excluded that, due to cellular heterogeneity, the ATP content reaches such low levels in a number of cells, as a result of which cellular integrity will be lost (Reimer at al., 1981a,c). However, if this is the case one would still expect that at a lower overall tissue ATP content a larger number of cells would reach this critical state and become irreversibly damaged. In this respect it is noteworthy that several investitgators (Bricknel1 and 0pfe, 1978; Higgins et al., 1982) proposed that glycolytically produced ATP serves an important role in the maintenance of cellular integrity, whereas ATP produced by mitochondrial oxidative phosphorylation is of more relevance in sustaining mechanical activity. This notion suggests that the source of the ATP produced might be of more importance than the tissue level of ATP per se. 

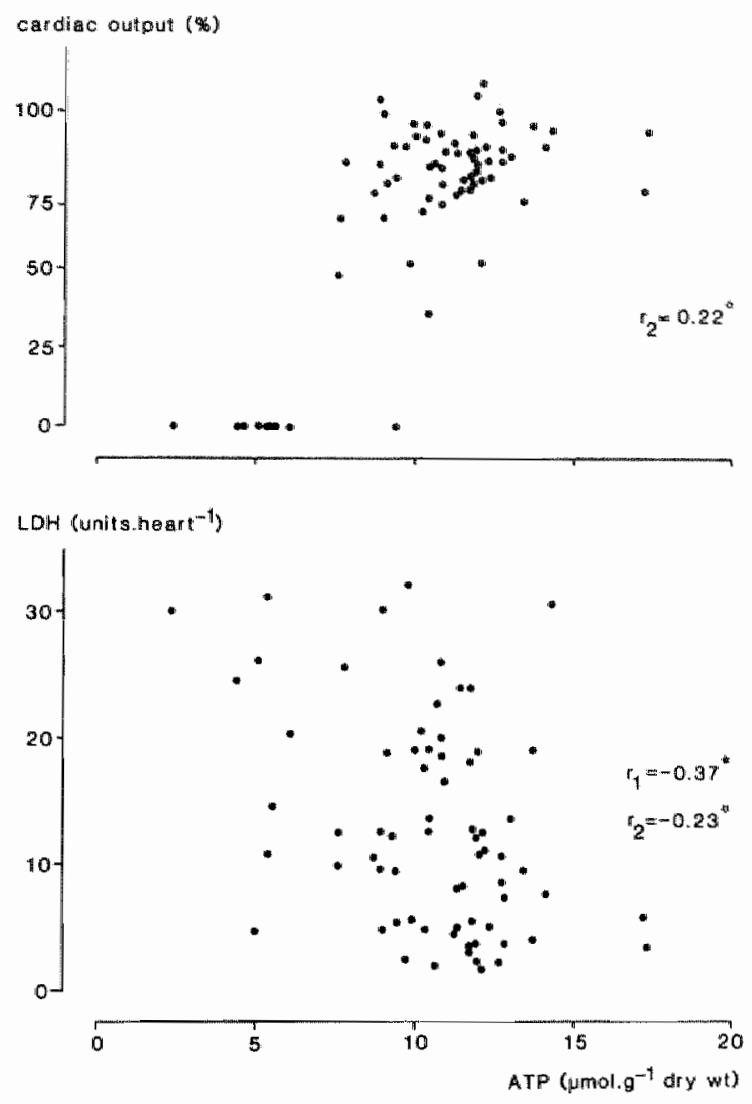

Fig 8.2 Relation between the tissue content of ATP at the end of reperfusion and the percentage recovery of cardiac output (upper panell and the release of $L D H$ during the reperfusion phase (lower panel) of hearts reperfused for $30 \mathrm{~min}$ following 30 to $60 \mathrm{~min}$ of ischemia, and perfused in the absence or presence of pyruwate, nicotinic acti, mepacrine or POCA. Paired data of individual hearts are shown. $r_{1}$ refers to the correlation coefficient of all hearts examined, whereas $r_{2}$ refers to only those hearts which were able to restore regular rhythm during the reperfusion phase. not sigmificant; $*$ - pe0.05. 


\subsubsection{Lipid changes and cell damage.}

In assessing the relation between the NEFA content of the various groups of ischemic hearts examined and the capacity to restore cardiac output during subsequent reperfusion ( $\mathrm{fig}$ 8.3a), no strong relationship between these two variables emerges $(r=-0.54$ when the group-averages are used to calculate the correlation coefficient). Weither could a significant relation be found when the NEFA content of non-fibrillating reperfused hearts was plotted against the post-ischemic recovery of cardiac output (fig 8.4a). Interestingly, substantial recovery of cardiac output is observed at NEFA levels, that have been shown to be incompatible with normal mitochondrial function (Piper et al., 1983; see al so chapter 5). This statement still holds when binding of NEFA's to cytosolic FABP is taken into account. Therefore, it must be concluded that the NEFA's accumulating during reperfusion have no access to the mitochondria and are somehow compartmentalized.

A correlation coefficient of 0.80 is obtained for the relation between the myocardial NEFA content, as measured at the end of ischemia, and the release of LDH during subsequent reperfusion (fig 8.3b). This finding suggests that the rise in NEFA's during ischemia reflects events determining the ultimate extent of cell damage, as measured by the amount of LDH released into the coronary effluent during the initial reperfusion phase. As shown in figure $8.4 \mathrm{~b}$ a relatively strong 1 inear relation is observed between the NEFA content of reperfused hearts and the release of $L D H$, whether or not fibrillating hearts are taken into account and irrespective of the intervention applied (varying the duration of ischemia, substrate supply, administration of pharmacological agents). However, as shown in the previous chapters the strength of the relationship is mainly determined by the experiments, in which the duration of the ischenic eplisode was varied. The other interventions applied do not strengthen the validity of this relation.

It should be noted that not only the toxicity of the NEFA's, accumulating as a result of hydrolysis of endogenous lipids, but also the degradation of membrane phospholipids per se has to be considered as a possible cause of disturbances of cellular integrity. In this respect the pharmacological agents are thought to act differently. Mepacrine should reduce the degradation of phospholipids as well as the accumulation of NEFA's. Nicotinic acid should only reduce the accumulation of NEFA's by inhibiting triacylglycerol break- 


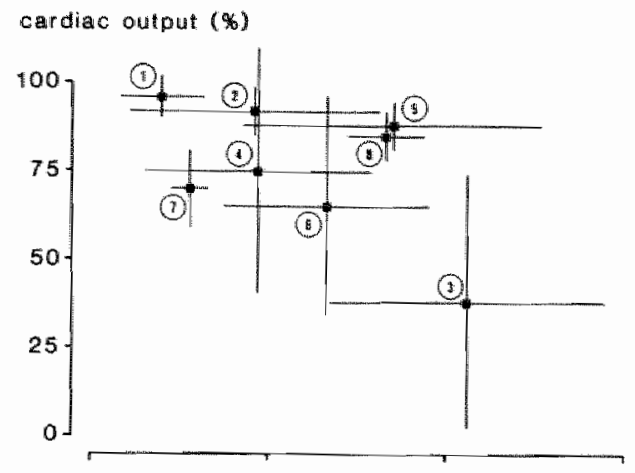

LDH (units.heart ${ }^{-1}$ )

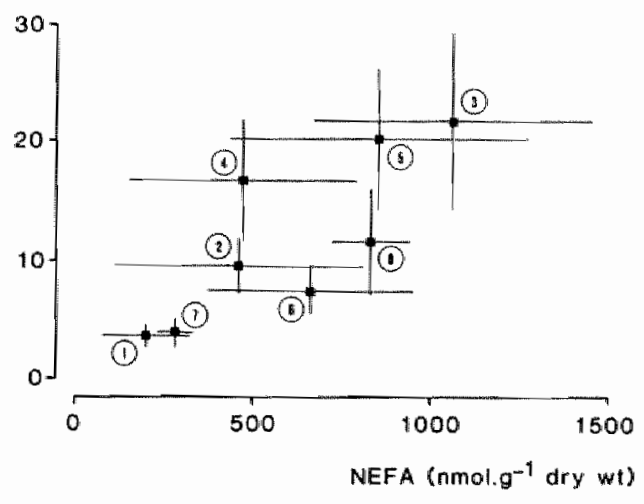

Fig 8.3 Relations between the tissue content of NEFA's at the end of the ischemic period and the percentage recovery of cardiac output (upper panel) and the cumulative release of $L O H$ during subsequent 30 min of reperfusion (Tower panel). Data presented as means $* 50$. The numbers refer to the various experimental groups. (1) glucose and pyruvate as substrates, $30 \mathrm{~min}$ ischemia. (2) glucase and pyruvate as substrates, 45 min ischemia. (3) glucose and pyruvate as substrates, $60 \mathrm{~min}$ ischemia. (4) glucose and pyruwate as substrates, 60 min ischemia, with nicotinic acid $(10 \mu \mathrm{M})$. (5) glucose and pyruvate as substrates, 60 min ischemia, with mepacrine $(1 \mu M)$. (6) glucose as substrate, 45 min ischemia. (7) glucose as substrate, 45 min ischemia, with POCA $(10 \mu M)$. (B) glucose and pyrurate as substrates, 45 min ischemia, with POCA $(10 \mu M)$. 

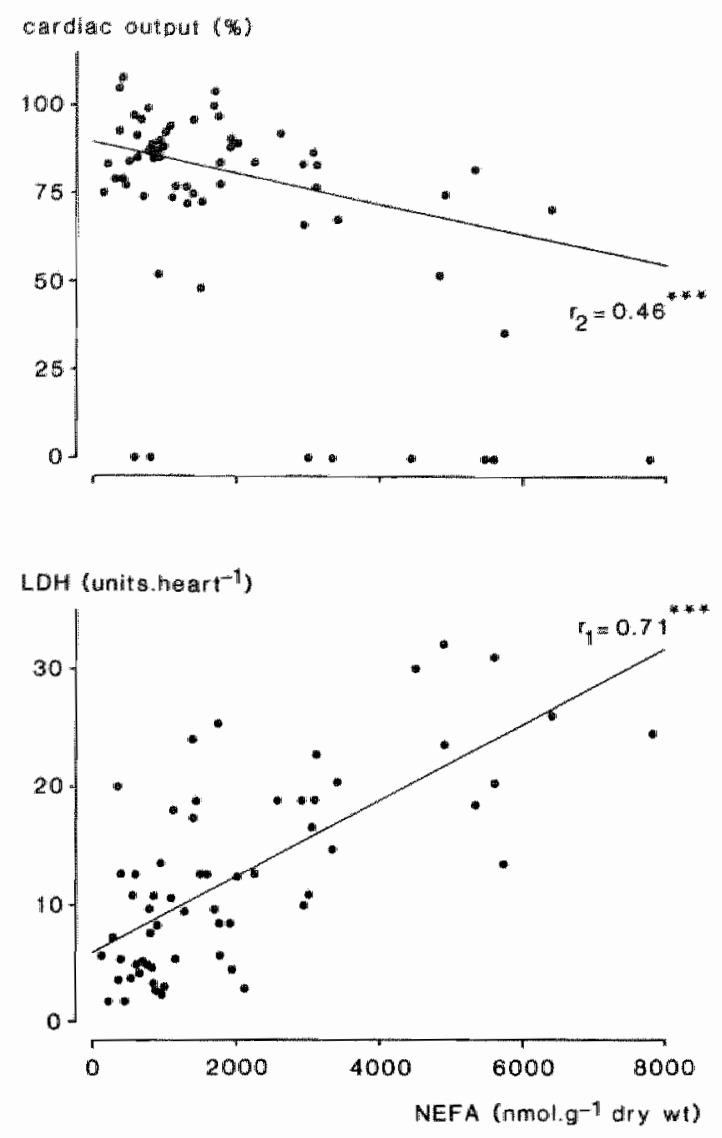

Fig 8.4 Relationships between the NEFA content of reperfused hearts, and the percentage recovery of cardiac output (upper panel) and the cumulative release of LDH during reperfuston (10wer panel) of hearts reperfused for $30 \mathrm{~min}$ following 30 to 60 min of ischemia, and perfused in the absence or presence of pyruvate, nicotinic acid, mepacrine or POCA. $r_{1}$ refers to the correlation coefficlent of all hearts examined, whereas $r_{2}$ refers to only those hearts which were able to restore regular rhythm during the reperfusion phase. ${ }_{*} \star_{-}<0.001$. 
down. However, the finding that nicotinic acid not only reduces the accumulation of MEFA's during ischemia, but also during reperfusion suggests that nicotinic acid has also an (indirect) effect on the degradation of phospholipids. In contrast, POCA should not affect hydrolysis of phospholipids duming reperfusion, but only interfere with the oxidation of the so-formed NEFA's and, therefore, stimulate NEFA accumulation.

Despite the relatively large increases of NEFA's in reperfused tissue, these amounts st 111 represent less than $2 \%$ of the fatty acids esterified into the cardiac phospholipid pool. It is hard to inagine that during reperfusion the loss of, at the most, $2{ }^{\circ}$ of the myocardial phospholipid content will seriously affect cardiac function and integrity. However, if the breakdown of phospholipids is confined to certain cellular membranes, e.g. the sarcolemma which comprises only a small percentage of the total cellular phospholipid content, cellular integrity might well be compromised. Alternatively, as a result of cellular heterogeneity, hydrolysis of phospholipids and, hence, accumulation of NEFA" s might occur in a limited number of cells only.

As discussed before, the fact that reperfused hearts show contractile activity at tissue NEFA levels incompatible with mitochondrial function, strongly suggests that the accumulating NEFA's are compartmentalized at the subcellular or cellular level. The following observations also support the notion that the accumulating NEFA's are not homogeneously distributed over the intracelluiar tissue space.

It is demonstrated that during reperfusion of hearts, supplied with glucose as the sole substrate, triacylgllycerols are degraded and obviously oxidized at a fast rate. Despite this, the myocardial NEFA content remains elevated. Moreover, the relative composition of the NEFA poot is entirely different from that of the triacylglycerol poo1, suggesting that the NEFA"s accumulated originate from another lipid pool. Conversely, it is also shown that the accumulation of NEFA's can be modulated through inhlbition of mitochondrial B-oxidation, suggesting that the accumulating NEFA's are, at least partly, located in cells with the capacity to activate, transport and oxidize fatty acids. These findings suggest that the NEFA's accumulated are compartmentalized at the subcellular level. It could be speculated that the NEFA"s released remain trapped at the sites of their origin, i.e. the various membrane systems and/or lipid droplets.

Assuming that enzyme release reflects irreversible cell damage, the ob- 
served relationship between $L D H$ release and the tissue NEFA content might be taken as evidence that the accumulation of NEFA's, representing degradation of phospholipids, is restricted to lethally damaged cells only. According to this view NEFA accumulation must be very pronounced in a small population of cells (less than 10\%). It remains to be established whether such a rapid rise of NEFA's during reperfusion is compatible with the kinetic properties of phospholipid hydrolyzing enzymes.

On first sight the rise in NEFA's during reperfusion might be taken as evidence for the existence of true reperfusion damage. However, it should be noted that there is also a relation between the myocardial NEFA content of ischemic hearts and the release of LDH during reperfusion (fig 8.3b). In addition, during reperfusion $L D H$ release and NEFA accumulation are out of phase. Shortly after restoration of flow LDH release is already maximal and rapidly declines thereafter, whereas the rise of NEFA's appears to continue. Hence, the rise of NEFA's during reperfusion might reflect post-mortem changes in cells, that already reached a state of irreversible damage.

In conclusion, it seems likely that the NEFA's released from endogenous lipids are somehow compartmentalized. The hypothesis that lipid changes are restricted to lethally damaged cells alone is challenging and requires further investigation. In addition, the question whether the rise in NEFA's is the cause or only the consequence of lethal cell damage remains also to be answered. 
Aas M (1971) Organ and subcellular distribution of fatty acid activating enzymes in the rat. Biochim Biophys Acta 231: 32-47

Achterberg $P W$, Harmsen $E$, De Jong JW (1985) Adenosine deaminase inhibition and myocardial purine release during nomoxia and ischemia. Cardiovasc Res 19: 593-598

Agress CM, Jacobs HJ, Glassner HF, Lederer MA, Clark WG, Wroblewski F, Karmen A, La Due JS (1955) Serum transaminase levels in experimental myocardial infarction. Circulation $11: 711-713$

Andrieu JL, Vial C, Fond B, Goldschmidt D, Lievre M, Faucon G (1979) Myocardial biochemical modifications induced by theophylline with reference to its value as antianginal drug. Arch Int Pharmacodyn 237: 330-342

Apstein CS, Puchner SE, Brachfeld $N$ (1970) Improved automated lactate determination. Anal Biachem 38: 20-34

Apstein CS, Mueller M, Hood WB jr (1977) Ventricular contracture and compliance changes with global ischemia and reperfusion and their effects on coronary resistance in the rat. Circ Res 41: 206-217

Apstein CS, Gravino FN, Haudenschild CC (1983) Determinants of a protective effect of glucose and insulin on the ischemic myocardium. Effects on contractille function, diastolic compliance, metabolism and ultrastructure during ischemia and reperfusion. Circ Res 52 : 515-527

Bartlett GR (1959) Phosphorous assay in column chromatography. J Biol Chem 23.4: $466-468$

Bentham JM, Higgins AJ, Woodward B (1987) Phospholipase A, activity during ischaemia in the isolated rat heart. Basic Res Cardiol 82 (suppl 1): $127-135$

Bergmeyer HU, Bernt E (1974) UV-assay for lactate dehydrogenase with pyruwate and NADH. In: Methods of enzymatic analysis. Vol 2, 574-579. Ed Bergmeyer HU, Weinheim: Verlag Chemie GmbH

Bessman SP, Geiger PJ (1981) Transport of energy in muscle: the phosphorylcreatine shuttle. Science 211: $448-452$

Bilheimer DW, Buja LM, Parkey RW, Bonte FJ, Willerson JT (1978) Fatty acid accumulation and abnomal 1 ipid deposition in peripheral and borderzones of experimental myocardial infarcts. J Nuc Med 19: 276-283

Borst $P$, Loos JA, Christ EJ, Slater EC (1962) Uncoupling activity of longchain fatty acids. Biochim Biophys Acta 62: 509-518

Braunwald $E$, Kloner $R$ (1982) The stunned myocardium: prolonged, post-ischemic dysfunction. Circulation $66: 1146-1149$

Bricknel 1 OL, Opie LH (1978) Effects of substrates on $t$ issue metabolic changes in the isolated rat heart during underperfusion and on release of lactate dehydrogenase and arrhythmias during reperfusion. Circ Res 43: 102-115

Brownsey RW, Brunt RV (1977) The effect of adrenaline-induced endogenous lipolysis upon the mechanical and metabolic performance of ischaemically perfused rat hearts. Clin Sci Mol Med 53: 513-521

Bruce TA, Meyers JT (1973) Myocardial lipid metabolism in ischemia and infarction. Rec Adv Stud Card Struc Metab 3: 773-780 
Buckberg $G D$ (1986) Studies of controlled reperfusion after ischenia. 1 . When is cardiac muscle damaged Irreversibly. J Thor Cardiovasc Surg 92: 483-487

Buenger $R$, Swindall B, Brodfe $D$, Zdunek $D$, Stiegler $H$, Walter $G$ (1986a) Pyruvate attenuation of hypoxia damage in isolated working guinea-pig heart. J Mol Cell Cardiol 18: 423-438

Buenger R. Soboll $S$ (1986b) Cytosolic adenylates and adenosine rellease in perfused working heart: Comparison of whole tissue with cytosolic nonaequeous fractionation analyses. Eur J Biochem 159: 203-213

Burton K. Buja LM, Sen A, W1lerson JT, Chien KR (1986) Accumulation of arachidonate in triacylglycerols and unesterified fatty acids during ischemila and reflow in the isolated rat heart. Am J Pathol 124:238-245

Chambers DE, Parks DA, Patterson G, Roy R, McCord JM, Yoshida 5, Parmley LF. Downey IM (1985) Xanthine oxidase as a source of free radical damage in myocardfial ischemia. J Mol Cell Cardiol 17: 145-152

Chatelain P, Papageorgiou I, Luthy P. Melchior JP, Rutishauser W, Lerch $R$ (1987) Free fatty acid accumulation in "stunned" myocardium. Bas Res Cardiol 82 (supp1 1): $169-176$

Chiariello M, Ambrosio G, Capella-Bigazzi M, Nevola $E$, Perrone-Filardi $P$, Marone G, Condorelli $M$ (1987) Inthibition of ischemia-induced phospholipase activation by quinacrine protects jeopardized myocardium in rats with coronary artery occlusion. J Pharmacol Exp Ther 241: 560-568

Chien KR, Abrams J, Serroni A, Martin JT, Farber JL (1978) Accelerated phospholipid degradation and associated membrane dysfunction in irreversible, ischemic liver cell injury. J Biol Chem 253: 4809-4817

Chien KR, Pfau RG, Farber JL (1979) Ischemic myocardial cell injury. Prevention by chlorpromazine of an accelerated phospholipid degradation and associlated membrane dysfunction. Am J Pathol 97: 505-530

Chien KR, Reeves JP, Buja LM, Bonte FJ, Parkey RW, Willerson JT (1981) Phospholipid alterations in ischemic myocardium. Temporal and topographical correlations with TC-99m-PPi accumulation and an in vitro sarcolemmal Ca permeability defect. Circ Res 48: $711-719$

Chien KR, Han A, Sen A, Buja LM, Willerson JT (1984) Accumulation of unesterified arachidonic acid in ischemic canine myocardium. Circ Res 54: 313-322

Christian DR, Kilsheimer GS, Pettett G, Paradise R, Ashmore J (1969) Regulation of lipolysis in cardiac muscle: A system similar to the hormonesensitive 1ipase of adipose tissue. Adv Enz Reg 7: 71-82

Corr PB, Snyder DW, Lee BI, Gross RW, Keim CR, Sobel BE (1982) Pathophysiological concentrations of lysophosphatides and the slow response. Am $J$ Physiol 243: H187-H195

Corr PB, Witkowski FX (1983) Potential electrophysiologic mechanisms responsible for dysrhythmias associated with reperfusion of ischemic myocardium. Circulation 68: $16-24$

Comr PB, Gross RW, Sobel BE (1984) Amphipathic metabolites and membrane dysfunction in ischemic myocardium. Circ Res 55: 135-154

Crass MF. McCask111 ES, Shipp JC (1970) Glucose-free fatty acid interactions In the working heart. J Appl Physial 29: 87-91

Creer MH, Knabb MT, Pogwizd SM, Saffitz JE, Sobe1 BE, Corr PB (1986) Antiarrhythmic effect of inhibition of accumulation of long chain acylcarnitines with ischemia (abstract). Circulation (suppl) 74: 67

Das DK, Engelman RM, Rousou JA, Breyer RH, Otani H, Lemeshow S (1986) Role of membrane phospholipids in myocardial injury induced by ischemia and reperfusion. Am I Physiol 251: H71-H79. 
DeBoer LWV, Ingwall JS, Kloner RA, Braunwald E (1980) Prolonged derangentents of canine myocandial purine metabolism after a brief coronary artery occlusion not associated with anatomic evidence of necrosis. Proc Nati Acad Sci USA $77: 5471-5475$

De Jong JW, Huelsmann WC (1970) Effects of Nagarse, adenosine and hexokinase on palmitate activation and oxidation. Biochim Biophys Acta 210: 499-501

De Jong JW, Harmsen E, De Tombe PP, Keyzer E (1983) Release of purine nucleosides and oxypurines from the isolated perfused rat heart. Adv Myocardiol 4: $339-345$

De Kock A, Lochner A, Kotze JCN, Gevers W (1978) Hypoxic, low-flow perfused rat heart - characterization as a model of global ischemia. Basic Res Cardiol 73: $506-523$

De Leiris J, Opie LH (1978) Effect of substrates and coronary artery ligation on mechanical performance and on release of lactate dehydrogenase and creatine phosphokinase in isolated working rat hearts. Cardiovasc Res 12: $585-596$

Dennis SC, Shattock MJ, Hearse DJ, Ball MR, Sochar M. McLean P (1983) Two different metabolic responses to ischaemia: inherent variability or artefact. Cardiovasc Res 17: 489-498

Duvelleroy MA, Duruble M, Martin JL, Teisseire B, Droulez J, Cain (1976) Blood-perfused working isolated rat heart. J Appl Physiol 41: 603-607

Edoute J, van der Merwe E, Sanan D, Kotze JCN, Steinmann C, Lochner A (1983) Normothermic ischemic cardiac arrest of the isolated working rat heart. Circ Res 53: 663-678

Engler RL, Schmid-Schoenbein GW, Pavelec RS (1983) Leukocyte caplllary plugging in myocardial ischemia and reperfusion in the dog. Am J Pathol 111: 98-111

Erman A, Azuri R, Raz A (1983) Phospholipase A inhibitors. Differential inhibition of fatty acid acylation into kidney lipids by mepacrine and p-bromophenacyl bromide. Biochem Pharmacol 32: 2083-2087

Evans JR, Opie LH, Renold AE (1963) Pyruvate metabolism in the perfused rat heart. Am J Physiol 205: 971-976

Farber JL, Chien KR, Mittnacht S (1981) The pathogenesis of irreversible cell injury in ischemia. Am J Pathol 102: 271-281

Fink KL, Gross RW (1984) Modulation of canine myocardial sarcolemmal membrane fluidity by amphiphilic compounds. Circ Res 55: 585-594

Fisher A, Challis RE, Swann P (1984) A controllable artificial afterload for isolated heart studies. J Biomed Eng 6: 305-310

Folch J, Lees $M$, Sloane-Stanley GH (1957) A simple method for the isolation and purification of total lipids from animal tissues. J Biol Chem 226: 497-509

Fox KAA, Bergmann SR, Sobel BE (1985) Pathophysiology of myocardial reperfusion. Amn Rev Med 36: 125-144

Franson $R$, Waite BM, Weglicki WB (1972) Phospholipase A activity of lysosomes of rat myocardial tissue. Biochem 11: $472-476$

Franson R, Weir DL. Thakkar J (1983) Solubilization and characterization of a neutral-active, calcium-dependent, phospholipase $A_{2}$ from rabbit heart and isolated chick embryo myocytes. J Mol Cell Cardiol 15: 189-196

Gamache DA, Hess ML, Franson RC (1987) Phospholipid alterations in canine sarcoplasmic reticulum induced by an acid active phospholipase $C$. Bas Res Cardiol 82 (suppl 1): 113-119

Garland $\mathrm{PB}$, Randle $\mathrm{PJ}$, Newsholme $\mathrm{EA}$ (1963) Citrate as an intermediary in the inhibition of phosphofructokinase in rat heart muscle by fatty acids, keton bodies, pyruwate, diabetes and starvation. Nature 200: 169-170 
Garland PQ, Randle PJ (1964) Regulation of glucose uptake by muscle. Biochem a 93: $678-687$

Gelsbuhler T, Altschuld RA, Trewyn RW, Anzel AZ, Lamka K, Brierley GP (1984) Adenine nucleotide metabolism and compartmentalization in isolated adult rat heart cells. Circ Res 54:536-546

Gerlach E, Nees 5, Becker BF (1985) The vascular endothellim: a survey of some newly evolving blochemical and physiological features. Bas Res Cardiol 80: $459-474(1985)$

Gibbs $C$ (1985) The cytoplasmic phosphorylation potential. Its possible role in the control of myocardial respiration and cardiac contractility. J Mol Cell Cardiol 17: 727-731

Glatz JFC, Baerwaldt CCF, Veerkamp JH, Kempen HJM (1984) Diurnal variation of cytosolic fatty acid-binding protein content and of palmitate oxidation in rat 1iver and heart. J B 101 Chem 259: 4295-4300

Glatz JFC, Veerkamp JH (1985) Intracellular fatty acid-binding proteins. Int J Biochem 17: 13-22

Goldberg DI, Khoo JC (1985) Activation of myocardial neutral triglyceride lipase and neutral cholesteryl esterase by CAMP-dependent protein kinase. 1 Biol Chem 260: 5879-5882

Goldstein RA, Klein MS, Sobel BE (1980) Detection of myocardial ischemia before infarction, based on accumulation of labeled pyruvate. I Nucl Med 21: $1101-1104$

Groot PHE, Scholte HR, Huelsmann WC (1976) Fatty acid activation: specificity, localization and function. Adv Lipid Res 14: 75-126

Gross RW, Sobel BE (1983) Rabbit myocardial cytosolic 1ysophospholipase. Purlfication, characterization, and competitive inhibition by L-palmitoyl carnitine. J Biol Chem 258: $5221-5226$

Gunn MD, Sen A, Chang A, Willerson JT, Buja LM, Chien KR (1985) Mechanisms of accumulation of arachidonic acid in cultured myocardial cells during ATP depletion. Am a Phyiol 249: H1188-H1194

Gutterman DD, Chilian WM, Eastham CL, Inou $T$, White CW, Marcus ML (1986) Fallure of pyruvate to salvage myocardium after prolanged ischemia. Am J Physiol 250: H114-H120

Haider B, Ahmed SS, Moschos CB, 0ldewurtel HA, Regan TR (1977) Myocardial function and coronary blood flow response to acute ischemia in chronic canine diabetes. Circ Res 40: 577-584

Hale SL, Alker KJ, Lo HM, Ingwall JS, K1oner RA (1985) Alterations in the distribution of high-energy phosphates during ischemia in a canine model of reperfusion-induced ventricular fibrillation. Am Heart J 110: 590-594

Harmsen E, de Jong JW, Serruys PW (1981) Hypoxanthine production by ischemic heart demonstrated by high pressure 1iquid chromatography of blood purine nucleosides and oxypurines. Clin Chim Acta 115: 73-84

Hearse DJ (1977a) Reperfuston of the ischemic myocardium. J Moll Cell Cardiol 9: $605-616$

Hearse DJ, Garlick PB, Humphrey SM (1977b) Ischemic contracture of the myocardilum: Mechanism and prevention. Am J Cardiol 39: 986-993

Heathers GP, Brunt RV (1985) The effect of coronary artery acclusion and reperfusion on the activities of triglyceride lipase and glycerol 3-phosphate acyl transferase in the isolated perfused rat heart. $\mathrm{J}$ Mol Cell Cardiol 17: $907-916$

Henderson AH, Most AS, Parmley WW, Garlin R, Sonnenblick EH (1970) Depression of myocardial contractility in rats by free fatty acids during hypoxia.

Circ Res 26: $439-449$ 
Hendriks FFA, Jonas DJ, Vam der Laarse A, Huysmans HA (1983) Cardiopleglc arrest in isolated blood-perfused working rat hearts. J Surg Res 35: 41-49

Hermens WT, Willems GM, Visser MP (1982) Quantification of circulating proteins. Martinus Nijhoff, The Hague/Boston/Londen

Hewitt RL, Lolley DM, Adrouny GA, Drapanas T 11974) Protective effect of glycogen and glucose on the anoxic arrested heart. Surgery $75: 1-10$

Higgins TuC, Bailey PJ, Allsopp D (1982) Interrelationship between cellular metabolic status and susceptibility of heart cells to attack by phospholipase. I Mol Cell Cardiol 14: 645-654

Hostetler KY, Hall LB (1980) Phospholipase C activity of rat tissues. Biochem Biophys Res Commun 96: 388-393

Hough FS, Gevers $W(1975)$ Catecholamine release as a mediator of intracellular enzyme activation in ischaenic perfused rat hearts. South Afr Med $\mathrm{J} 49$ : $538-543$

Houtsmuller UMT, Struyk CB, Wan der Beek A (1970) Decrease in rate of ATP synthesis of isolated rat heart mitochondria induced by dietary eruric acid. Biochim Biophys Acta 218: 564-566

Hsueh $W$, Needleman $P$ (1978) Cardiac and renal lipases and prostaglandin biosynthesis. Lipids 14:236-240

Huelsmann WC (1958) Over het mechanisme van de ademhalingsketen-phosphorylering. Ph.0. thesis, University of Amsterdam, The Netherlands, pp 45-61

Huetter JF, Piper HM, Spieckermann PG (1985a) Effect of fatty acid oxidation on efficiency of energy production in rat heart. Am J Physiol 249: $\mathrm{H} 723-\mathrm{H} 728$

Huetter JF, Piper HM, Spieckermann PG (1985b) An index for estimation of oxygen consumption in rat heart by hemodynamic parameters. Am $J$ Physiol 249: $H 729-H 734$

Humphrey SM, Holl is DG, Seelye RN (1984) Adenine pool catabolism in the ischemic, the calcium-depleted ischemic, and substrate free anoxic isolated rat heart: Relationship to contracture development. J Mol Cell Cardiol 16: $1127-1136$

Humphrey SM, Holliss DG, Seeley RN (1985) Myocardial adenine pool depletion and recovery of mechanical function following ischemia. Am J Physiol 248: H644-H651

Hunneman DH, Schweickhardt C (1982) Mass fragmentographic determination of myocardial free fatty acids. J Mol Cell Cardiol $14: 339-351$

Ichihara K, Neely JR (1985) Recovery of ventricular function in reperfused ischemic rat hearts exposed to fatty acids. An J Physiol 249: H492-H497

Idell-Wenger JA, Grotyohann LW. Neely JR (1978) Coenzyme A and carnitine distribution in normal and ischemic hearts. J Biol Chem 253: 4310-4318

Jackson MJ, Jones DA, Harris EJ (1984) Inhibition of lipid peroxidation in muscle homogenates by phosphollpase $A_{2}$ inhibitors. Bioscl Rep $4: 581-587$

Jain MK, Streb M, Rogers J, Dehaas GH (1984) Action of phospholipase $A_{2}$ on bilayers containing lysophosphatidyl choline analogs and the effect of inhibitors. Biochem Pharmacol 33: 2541-2551

Jain MK, Jahagirdar (1985) Action of phospholipase $A_{2}$ on bilayers. Effects of inhibitors. Biochim Biophys Acta 814: 319-326

Jenmings RB, Ganote CE (1974) Structural changes in myocardium during acute ischemia. Circ Res 35 (suppl 3): 156-172

Jennings RB, Hawk ins HK, Lowe JE, Hill ML, Klotman S, Reimer KA (1978) Relation between high energy phosphate and lethal injury in myocardial ischemia in the dog. Am J Pathol 92: 187-214 
Jemings RE, Reimer KA, HIII ML, Mayer SE (1981) Total ischemia in dog hearts in vitro. 1. Comparison of high energy phosphate production, utilization and depletion and of adenine nucleotide catabolism in total ischemia in vittro vs. severe ischemia in vivo. Circ Res 49: 892-900

Jennings: $R B$, Refmer $K A$ (1983) Factors involved in salvaging ischemic myocardium: effect of reperfusion of arterial blood. Circulation 68 (supp) 1): $25-36$

Jennings RB, Steenbergen C (1985) Nucleotide metabolism and cellular damage in myocardíal ischemia. Ann Rev Physiol 47: 727-749

Jennings RB, Reimer KA, Steenbergen C (1986) Myocardial ischemia revisited. The osmolar load, membrane damage, and reperfusion. J Mol Cell Cardiol 18: $769-780$

Jesmok GJ, Warltier DC, Gross GJ, Hardman HF (1978) Transmural triglycerides in acute myocardial ischemia. Cardiovasc Res 12: 659-666

Jodalen $H$, Stangeland L, Grong $K$, Vik-Mo $H$, Lekven J (1985) Lipld accumulation in the myocardium during acute regional ischaemia in cats. J Mol Cell cardiol 17: 973-980

Jo11y SR, Kane WJ, Bailie MB, Abrams G, Lucchesi BR (1984) Canine myocardial reperfusion injury: its reduction by the combined administration of superoxide dismutase and catalase. Circ Res 54: 277-285

Kammermejer $H$, Schmidt $P$, Juengling $E$ (1982) Free energy change of ATP-hydrolysis: a causal factor of early hypoxic failure of the myocardium. $J$ Mol Cel1 Cardiol 14: 267-277

Kane JJ, Murphy ML, Bisset JK, De Soysa N, Doherly JE, Straub KD (1975) Mitochondrial function, oxygen extraction, epicardial ST segment changes and tritiated digoxin distribution after reperfusion of ischemic myocardium. Am J Cardiol 36:218-224

Katz AM, Messineo FC (1981) Lipid-membrane interactions and the pathogenesis of ischemic damage in the myocardium. Circ Res $48: 1-16$

Katz AM (1982a) Membrane-derived lipids and the pathogenesis of ischemic myocardial damage. J Mol Cell Cardiol 14: 627-632

Katz AM, Nash-Adler P, Watras J, Messíneo FC, Takenaka $H$, Louis CF (1982b) Fatty acid effects on calcium influx and efflux in sarcoplasmic reticulum vesicles from rabbit skeletal muscle. Biochim Biophys Acta 687: 17-26

Kjekshus JK, Mjos OD (1973) Effect of inhibition of lipolysis on infarct size after experimental coronary artery occlusion. J Clin Invest 52: 1770-1778

Kjekshus JK (1981) Effect of inhibition of lipolysis on acute myocardial infury during coronary occlusion in normal and reserpinized dogs. Acta Med scand $645: 85-91$

Klein HH, Schaper J, Puschmann S, Nienaber C, Kreuzer H, Schaper W (1981) LosS of cantine myocardial nicotinamide adenine dinucleotides determines the transition from reversible to irreversible ischemic damage of myocardial cells. Basic Res Cardiol 76: 612-621

Kloner RA, DeBoer LWV, Darsee JR, Ingwall JS, Braunwald E (1981) Recovery from prolonged abnormalities of canine myocardium salvaged from ischemic necrosis by coronary reperfusion. Proc Nat1 Acad Sci USA 78: 7152-7156

Knabb MT, Saffitz JE, Corr PB, Sobel BE (1986) The dependence of electrophysiological derangements on accumulation of endogenous long-chain acyl carnitine in hypoxic neonatal rat myocytes. Circ Res 58: 230-240

Kobayashi K, Neely JR (1979) Control of maximum rates of glycolysis in rat cardiac muscle. Circ Res $44: 166-175$

Kobayashi K, Neely JR (1983a) Effects of ischemia and reperfusion on pyruvate dehydrogenase activity in isolated rat hearts, J Mol Cell Cardiol 15: $359-367$ 
Kobayashi $K$, Neely JR (1983b) Mechanism of pyruvate dehydrogenase activation by increased cardiac work. J Mol Cell Cardiol 15: $369-382$

Kostis JB, Mavrogeorgis EA, Horstmann E, Gotzoyannis 5 (1973) Effect of high concentrations of free fatty acids on the ventricular fibrillation threshold of nomal dogs and dogs with acute myocardial infarction. Cardiology $58: 89-98$

Kotaka K, Miyazaki Y, Ogawa K, Satake T, Sugiyama S, Ozawa Y (1982) Reversal of ischemia-induced mitochondrial dysfunction after caronary reperfusion. J Mol Cell Cardiol 14: 223-231

Kramer JKG, Hulan HW (1978) A comparison of procedures to determine free fatty acids in rat heart. J Lip Res 19: 103-106

Kuebler W, Spieckermann PG (1970) Regulation of glycolysis in the ischemic and anoxic myocardium. I Moll cell Cardiol 1: $351-377$

Kunze $H$, Hesse B, Bohn E (1982) Effects of antimalarial drugs on several ratliver lysosomal enzymes involved in phosphatidylethanolamine catabolism. Biochim Biophys Acta 713: 112-117

Kupriyanov VW, Lakomkin VL, Kapelko VI, Steinschneider AY, Ruuge EK, Saks VA (1987) Dissociation of adenosine triphosphate levels and contractile function in isovolumic hearts perfused with 2-deoxyglucose. J Mol cell Cardiol 19: 729-740

Kurien VA, oliver MF (1966) Serum free fatty acids after acute myocardial infarction and cerebral vascular occlusion. Lancet II: 122-127

Kurien VA. 01iver MF (1970) A metabolic cause for arrhythmias during acute myocardial hypoxia. Lancet I: 813-815

Kurien VA, Yates PA, 01iver MF (1971) The role of free fatty acids in the production of ventricular arrhythmias after acute coronary artery acclusion. Eur $\mathrm{J} \mathrm{Cl}$ in Invest 1: 225-241

Lamers. JMJ, Huelsmann WC (1977) Inhibition of ( $\left.\mathrm{Na}^{+}+\mathrm{K}^{+}\right)$-stimulated ATP-ase of heart by fatty acids. J Mol Cell Cardiol 9: 343-346

Lamers JMJ, Hartog JM, Verdouw PD, Huelsmann WC (1987) Dietary fatty acids and myocardial function. Bas Res Cardiol 82 (suppl 1): 209-221

Lamping KA, Menahan LA, Gross GJ (1984) Nicotinic acid, free fatty acids and myocardial function during coronary occlusion and reperfusion in the dog. J Pharmacol Exp Ther 231: 532-538

Langendorff 0 (1895) Untersuchungen am ueberlebendem Saugethierherzen. Arch Ges Physiol 61: $291-332$

LaNoue KF, Watts JA, Koch CD (1981) Adenine nucleotide transport during cardiac ischemia. Am J Physiol 241: H663-H671

Laurell $S$, Tibbling $G(1966)$ An enzymatic fluorometric micromethod for the determination of glycerol. Clin Chim Acta 13: $317-322$

Lavallee M, Cox D, Patrick TA, Vatner SF (1983) Salvage of myocardial function by coronary artery reperfusion 1,2 , and 3 hours after occlusion in conscilous dogs. Circ Res 53: 235-247

Lea MA, Heber G (1968) Role of enzymes in homeostasis. VIII. Inhibition of the activity of glycolytic enzymes by free fatty acids. J Blol Chem 243: $1096-1102$

Lech JJ, Jesmok GJ, Calwert DN (1977) Effects of drugs and hormones on Iipolysis in heart. Fed Proc 36: 2000-2008

Lefkowltz RJ (1974) Stimulation of catecholamine-sensitive adenylate cyclase by 5"-guanylyl-imidodiphosphate. J Biol Chem 249: 6119-6124

Liedtke $\mathrm{AJ}$, Nellis SH, Neely, JR, Hughes HC (1976) Effects of treatment with pyruvate and tromethamine in experimental myocardial ischemia. Circ Res 39: $378-387$ 
Lfedtke AJ, Mellis SH, Neely JR (1978) Effects of excess free fatty acids on mechantcal and metabolic function in normal and ischemic myocardium in swine. Circ Res 43: 652-661

Liedtke AJ (1981) Alterations of carbohydrate and lipid metabolism in the acutely ischemic heart. Progr Cardiovasc Dis 23: $321-336$

Liedtke Ad, Nellis SH, Mjos 00 (1984) Effects of reducing fatty acid metebolism on mechanical function in regionally ischemic hearts. Am $\mathrm{s}$ Physiol 247: $\mathrm{H} 387-\mathrm{H} 394$

Lochner A, Kotze JCN, Benade AJS, Gevers W (1978) Mitochondrial oxidative phosphorylation in low-flow hypoxia: role of free fatty acids. J Mol Cell Cardiol 10: $857-875$

Man RYk, Slater TL, Pelletier MP, Choy PC (1983) Alterations of phospholipids in ischemic canine myocardium during acute arrhythmia. Lipids 18: 677-681

Mann GE, Zlokovic BV, Yudillevich DL (1985) Evidence for a lactate transport system in the sarcolemal membrane of the perfused rabbit heart: kinetics. of unilirectional influx, carrier specificity and effects of glucagon. Biochim Blophys Acta 819: 241-248

Manning AS, Hearse DJ (1984) Reperfusion-induced arrhythmias: mechanisms and prevention. J Mol Cell Cardiol 16: 497-518

Maroko PR, Braunwald E (1976) Effects of metabolic and pharmacologic interventions on myocardial infarct size following coronary occlusion. Circulation 53: (suppl 1): 162-168

Matthys E, Patel Y, Kreisberg J, Stewart JH, Venkatachalam M (1984) Lipid alterations induced by renal ischemia: pathogenic factor in membrane damage. Kidney Int 26: 153-161

McCord JM (1985) axygen-derived free radicals in postischemic tissue injury. New Eng J Med 312: 159-163

Meerson FZ, Kagar VE, Kozlov JP, Belkina I, Arkkhipenko YV (1982) The role of 1 ipidperoxidation in pathogenesis of ischemic damage and the antioxidant protection of the heart. Bas Res Cardiol 77: 465-485

Meno $H$, Kanaide $H$, Okada M. Nakamura M (1984) Total adenine nucleotide stores. and sarcoplasmic reticular Ca transport in ischemic rat heart. Am J Physiol 247: H380-386

Miller WP, Liedtke AJ, Nellits SH (1986) Effects of 2-tetradecylglycidic acid on myocardial function in swine. Am J Physiol 251: H547-H553

Mishkin S, Steiln L, Gatmaitan L, Arias IM (1972) The binding of fatty acids to cytopiasmic proteins: Binding to $Z$ protein in liver and other tissues of the rat. Biochem Biophys Res Commun 47: 997-1003

Mjos oD (1971) Effect of free acids on myocardial function and oxygen consumption in intact dogs. J C1 in Invest 50: 1386-1389

Mochizuki S, Neely JR (1980) Energy metabolism during reperfusion following ischemia.J Physioll 76: 805-812

Moore KH, Radloff JF, Hull FE, Sweeley CC (1980) Incomplete fatty acid oxidation by ischenlic heart: B-hydroxy fatty acid production. Am J Physiol 239: H257-265

Moore KH (1985) Fatty acid oxidation in ischemic heart. Mol Physiol 8: 549-563 Morgan HE, Neely JR, Kira $Y(1984)$ Factors determining the utilization of glucose in isolated rat hearts. Basic Res Cardiol 79: 292-299

Morrison WR, Smith LM (1964) Preparation of fatty acid methyl esters and dimethylacetals from lipids with boron fluoride-methanol. J Lip Res 5 : $600-608$

Most AS, Szydlik PA, Sorem KR (1972) Effect of free fatty acid on myocardial function during hypoxia. Cariology 57: 322-332 
Most AS, Capone RJ, Szydlik PA, Bruno CA, Devona IS (1974) Fallure of free fatty acids to influence degree of myocardial injury following acute coronary acclusion in pigs. Cardiology 59: $201-214$

Murthy MSR, Pande SV (1987) Malonyl-COA binding site and the overt carnitine palmitoyltransferase activity reside on the opposite sides of the outer mitochondrial membrane. Proc Natl Acad SCi USA 84: 378-382

Myears DW, Sobel BE, Bergmann SR (1987) Substrate use in ischemic and reperfused canine myocardium: quantitative considerations. Am J physiol 253: H107-H114.

Naito $Y$, Lowenstein JM (1981) 5'-mucleotidase from rat heart. Biochemistry 20 : $5188-5194$

Nalbone G, Hostetler KY (1985) Subcellular localization of the phospholipases A of rat heart: evidence for a cytosolic phospholipase $A_{1}$. J Lipid Res 26: 104-114

Nayler $W G$, Ferrari $R$, Williams A (1980) Protective effect of pretreatment with verapamil, nifedipine and propanolol on mitochondrial function in the ischemic and reperfused myocardium. Am J Cardiol 46: 242-249

Nayler WG (1981) The role of calcium in the ischemic myocardium. Am I Pathol 102: $262-270$

Nayler WG, Sturrock WU (1985) Inhibitory effect of calcium antagonists on the depletion of cardiac norepinephrine during postischemic reperfusion. $J$ Cardiovasc Pharmacol 7: 581-587

Neely JR, Liebermeister $H$, Battersby EJ, Morgan HE (1967) Effect of pressure development on oxygen consumption by isolated rat heart. Am J Physiol 212: 804-814

Neely JR, Denton RM, England PJ, Randle PJ (1972a) The effects of increased heart work on the tricarboxylate cycle and its interactions with glycoTysis in perfused rat heart. Biochem $\mathrm{J}$ 128: 147-159

Neely JR, Rovetto MJ, Oram JF (1972b) Myocardial utilization of carbohydrate and Tipids. Progr Cardiovasc Dis 15: 289-329

Neely JR, Liedtke AJ, Whitmer JT, Rovetto MJ (1975) Relationship between coronary flow and adenosine triphosphate production from glycolysis and oxidative metabolism. Rec Adv Stud Card Struct Metab 8: 301-321

Neely JR, Garber D, McDonough K, Ide11-Wenger J (1979) Relationship between ventricular function and intermediates of fatty acid metabolism during myocardial ischemia: Effects of carnitine. In: Ischemic myocardium and antianginal drugs. Perspectives in cardiovascular research. Vol 3: 225-239. Eds Winbury MH, Akibo $Y$, New York: Raven Press

Neely JR, Grotyohann LW (1984a) Role of glycolytic products in damage to ischemic myocardium. Dissociation of adenosine triphosphate levels and recovery of function of reperfused ischemic hearts. Clrc Res 55: 816-824

Neely IR, MCDonough KH (1984b) Factors that influence myocardial levels of long-chain acyl CoA and acyl carnitine. In: Myocardial ischemia and lipld metabolism. 159-169. Eds Ferrari $\mathbb{R}$, Katz AM, Shug A, Visio1i 0, New York: Plenum Press

Normann PT, Norseth J, Flatmark T (1983) Acyl-CoA synthetase activity of rat heart mitochondria. Substrate specificity with special reference to very-long-chain and isomeric fatty acids. Biochim Biophys Acta 752: 474-481

Ockner RK, Manning JA, Poppenhausen RB, Ho WKL (1972) A Binding protein for fatty acids in cytosol of intestinal mucosa, liver, myocardium and other tissues. Science 177: 56-58 
0 Donnel1-Tomey $d$, Nathan $C F$ Lanks $K$, DeBoer $C J$, De La Harpe $J$ (1987) Secretion of pyruvate. An antioxidant defense of mammalian cells. J Exp Med 165: 500-514

07 iver MF, Kurien VA, Greenwood Th (1968) Relation between serum-free-fattyacids and arrhythmis and death after acute myocardial infarction. Lancet I: $710-715$

01sson RE, Hoeschen RJ (1967) Utilization of endogenous lipid by the isolated perfused rat heart. Biochem J 103: 796-801

Opie LH (1970a) Effect of fatty acids on contractility and rhythm of the heart. Nature 227: 1055-1056

Opie LH (1970b) The glucose hypothesis. Its relation to acute myocardial ischemia. J Mol Cell Cardiol 1: 107-115

Opie LH, Mansford KRL, Owen P (1971) Effects of increased heart work on glycolysis and adenine nucleotides in the perfused heart of normal and diabetic rats. Biachem $d$ 124: $475-490$

Opie LH, Owen P, Riemersma $R$ (1973) Relative rates of oxidation of glucose and free fatty acids by ischaemic and non-ischaemic myocardium after coronary artery 1 igation in the dog. Eur $J$ Clin Invest 3: 419-435

Ople $\mathbb{L H}$ (1975) Metabolism of free fatty acids, glucose and catecholamines in acute myocardial infarction. Am J Cardiol 36: $938-953$

opie LH (1984) Adequacy of oxygenation of isolated perfused rat heart. Bas Res Cardiol 79: 300-306

otani H, Engelman RM, Breyer RH, Rousou JA, Lemeshow S, Das DK (1986) Mepacrine, a phospholipase inhibitor. A potential tool for modifying myocardial reperfusion injury. J Thor Cardiovasc Surg 92: 247-254

Palmer WK, Caruso RA, Oscai LB (1987) Protell kinase inhibitor blocks the activation of a myocardial triacylglycerol lipase. J Mol Cell Cardiol 19: $653-659$

Passonneau $J$ (1974) Fluorometric method for the determination of lactate with LDH. In: Methods of enzymatic analysis. Vol 3: 1468-1472. Ed Bergmeyer HU, Weinheim: Verlag Chemie $\mathrm{GmbH}$

Paulson DJ, Schmidt MJ, Romens J, Shug AL (1984a) Metabolic and physiological differences between zero-flow and low-flow myocardial ischemia: effects of L-acetyl carnitine. Bas Res Cardiol 79: 551-561

Paulson DJ, Shug AL (1984b) Effects of myocardial ischemia and long-chain acyl-COA on mitochondrial adenine nucleotide translocator. In: Myocardial ischemia and lipid metabolism. 185-202. Eds Ferrari R, Katz AM, Shug A and Visioli 0 , New York: Plenum Press

Paulson DJ, Ward K, Sherratt HSA, Shug AL (1984C) Effects of 2-(5-(4-chlorophenyl)-pentyl)-oxirane-2-carboxylate on the metabolism and function of the ischentic myocardilum (abstr). Fed Proc 43: 902

Paulison DJ, Traxler J, Schmidt M, Noonan J, Shug AL (1986) Protection of the ischaenic myocardfum by L-propionylcarnitine: effects on the recovery of cardiac output after ischaemia and reperfusion, carnitine transport, and fatty acid oxidation. Cardiovasc Res 20: 536-541.

Pearce FJ, Forster J, Deleeuw G, Williamson JR, Tutwiler GF (1979) Inhibition of fatty acid oxidation in normal and hypoxic perfused rat hearts by 2-tetradecylglycidic acid. J Mol Cell Cardiol 11: 893-915

Peng CF, Kane JJ, Murphy ML, Staub KD (1977) Abnormal mitochondrial oxidative phosphorylation of ischemic myocardium reversed by $\mathrm{Ca}^{2+}$ - chelating agents. J Mol Cell Cardiol 9: 897-908

Philipgon $\mathrm{KD}$. Ward $\mathrm{R}$ (1985a) Effects of fatty acids on $\mathrm{Na}^{+}-\mathrm{Ca}^{2+}$ exchange and $\mathrm{Ca}^{2+}$ permeability of cardiac sarcolemmal vesicles. J Biol Chem 260 : 9666-9671 
Philipson KD, Langer GA, Rich TL 61985b) Charged amphiphiles regulate heart contractility and sarcolema-Ca interactions. Am J Physiol 248: $4147-150$

PIfper HM, Sezer 0, Schwartz P, Huetter JF, Spieckemann PG (1983) Fatty acidmembrane interactions in isolated cardiac mitochondria and erythrocytes. Biochim Biophys Acta 732: 193-203

Piper HM, Schwartz P. Spahr R. Huetter JF, Spieckermanm PG (1984) Early enzyme release from myocardial cells is not due to irreversible cell damage. I Mol Cell Cardiol 16: 385-388

Pilsarenko OI, Lepil in MG, Ivanov VE (1986) Cardiac metaboll ism and perfomance during $L$-glutamic acid infusion in postoperative cardiac fallure. Clin $5 c i$ $70: 7-12$

Pressman BC, Lardy HA (1956) Effect of surface active agents on the latent ATPase of mitochandria. Biochim Biophys Acta 21: 458-466

Prinzen FW, Van der Wusse GJ, Arts $T$, Roenen THM, Coumans WA, Reneman $R S$ (1984) Accumulation of nonesterified fatty acids in ischemic canine myocardium. Am J Physiol 247: H264-H272

Prinzen FW, Alewijnse R, Van der Vusse GJ, Kruger RTI, Van der Nagel T, Reneman RS (1987) Coronary artery stenosis controlled by perfusion pressure: Description of the servo-system and time-dependent changes in regiomal myocardial blood flow. Bas Res Cardiol 82: 375-387

Ramadoss CS, Uyeda K, Johnston JM (1976) Studies on the fatty acid inactivation of phosphofructokinase. J Bial Chem 251: 98-107

Ravid K, Diamant P, Avi-Dar Y (1984) Regulation of the salvage pathway of purine nucleotide synthesis by the oxidation state of NAD in rat heart cells. Arch Biochem Biophys 229: $632-639$

Reibel DK, Rovetto MF (1978) Myocardial ATP synthesis and mechanical function following oxygen deficiency. Am J Physiol 234: H620-H624

Reimer KA, Jennings RB, Hill ML (1981a) Total ischemia in dog hearts, in vitro. II. High-energy phosphate depletion and associated defects in energy metabolism, cell volume regulation, and sarcolemmal integrity. circ Res 49: $901-911$

Reimer KA, Hill ML, Jennings RB (1981b) Prolonged depletion of ATP and of the adenine nucleotide pool due to delayed resynthesis of adenine nucleotides following reversible myocardial ischemic injury in dogs. J Mol cell Cardiol 13: 229-240

Reimer KA, Jennings RB (1981c) Energy metabolism in the reversible and irreversible phases of severe myocardial ischemia. Acta Med Scand 651: 19-27

Roemen THM, Van der Vusse GJ (1985) Application of silicagel column chromatography in the assessment of non-esterified fatty acids and phosphoglycerides in myocardial tissue. J Chromatogr 344: $304-308$

Roesen P, Reinauer $H$ (1984) Inhibition of carnitine palmitoyltransferase 1 by phenylalkyl-oxiranecarboxylic acid and 1 ts influence on lipolysis and glucose metabolism in isolated, perfused hearts of streptozotocinudiabetic rats. Metabol ism 33: 177-185

Rosenkranz ER, Okamoto $F$, Buckberg GD, Vinten-Johansen J, A1len BS, Leaf $J$, Bugyi $H$, Young $H$, Barnard $R J$ (1986) Studies of controlled reperfusion after ischemia. Biochemical studies: fallure of adenosine triphosphate levels to predict recovery of contractile function after controlled reperfusion. J Thorac Cardiovasc Surg 92: 488-501

Rovetto MJ, Whitmer JT, Neely JR (1973) Comparison of the effects of anoxia and whole heart ischemia on carbohydrate utilization in isolated working rat heart. Circ Res 32: 699-711

Rovetto M], Lamberton WF, Neely JR (1975) Mechanisms of glycolytic inhibition in ischemic rat hearts. Circ Res $37: 742-751$ 
Schaper $J$. Wulch J, Winkler B, Schaper W (1979) U1trastructural, functional and blochemical criteria for estimation of reversibility of ischemic Injury: al study on the effects of global ischemia on the isolated dog heart. J Mol Cell Cardiol 11: 521-541

Schoemig A, Dart AM, Dietz R, Mayer E, Kuebler W (1984) Release of endogenous catecholamines in the ischemic myocardium of the rat. part A: Locally mediated release. Circ Res 55: 689-701

Schoonderwoerd $K$, Broekhoven-Schokker $S$, Huelsmann WC, Stam $H$ (1987) Stimulation of myocardial neutral triglyceride lipase activity by adenosine3':5"-monophosphate: involvement of glycogemolysïs. Bas Res Cardiol 82 (supp1 1): 29-35

Schutz W, Schrader J, Gerlach E (1981) Different sites of adenasine formation in the heart. Am J Physiol 240: H963-H970

Schwaiger $M$, Schelbert HR, Ellison D, Hansen $H$, Yeatman $L$, Vinten-Johansen $d$, Selin C, Barrio J, Phelps ME (1985) Sustafned regional abnomalities in cardiac metabolism after transient ischemia in the chronic dog model. I Am Coll Cardiol 6: 336-347

Schwertz DW, Halverson J, Isaacson T, Feinberg H, Palmer JW (1987) Alterations in phospholipid metabolism in the globally ischemic rat heart: emphasis on phosphoinositide specific phospholipase $C$ activity. J Mol Cell Cardiol 19: 685-697

Segel LD, Wollner M, Miller RR, Amsterdam EA, Chacko KJ, Drake C, Stoll PJ, Mason DT (1977) Contractility and energetics effects of ethanol and isoproterenol using an improved biologically stable isolated ejecting rat heart system. Res Commun Chem Pathol Phamacol 17: 555-573

Sege1 LD, Rendig SV (1982) I solated working heart perfusion with perfluorochemical emulsion Fluosol-43. Am J Physiol 242: H485-H489

Seitelberger $R$, Kraupp 0 , Winkler M, Brugger G, Raberger G (1985) Effects of the acylcarnitine-transferase blocking agent Sodium 2(5-(4-chloropheny1)pentyl)-oxilane-2-carboxylate (POCA) on metabolism and regional function in the uniderperfused canine myocardium. J Cardiovasc Pharmacal 7: 273-280

Sen A, Buja LM, Willerson JT, Chien KR (1987) Membrane phospholipid metabolism during myocardial ischemia: past, present and future. Bas Res Cardiol 82 (supp1 1): $121-125$

Severson DL, Hurley B (1982) Regulation of rat heart triacylglycerol ester hydrolases by free fatty acids, fatty acyl COA and fatty acyl carnitine. J Mol Cell Cardiol 14: 467-474

Shaikh NA, Downar E (1981) Time course of changes in porcine myocardial phospholipid levels during ischemia. Circ Res 49: 316-325

Shen AC, Jenntings RB (1972a) Myocardial calcium and magnesium in acute ischemic injury. Am J Pathol 67: 417-440

Shen $A C$, Jennings RB (1972b) Kinetics of calcium accumulation in acute myocardial ischemic injury. Am $\mathrm{J}$ Pathol 67 : $441-452$

Sherman SC, Chien KR, Mittnacht S, Farber JL (1980) Microsomal membrane structures and function subsequent to calcium activation of an endogenous phospholipase. Arch Bilochem Biophys 205: 614-622

Shipp JC, Thomas JM, Crevasse $L$ (1964) Oxidation of carbon-14-1abeled endogenous lipids by isolated perfused rat heart. Science 142: $371-373$

Shrago E, Shug AL, Sul H, Bittar N, Folts JD (1976a) Control of energy production in myocardial ischemia. Cilrc Res 38 (suppl 1): 75-79

Shrago E (1976b) Myocardial adenine nucleotide translocase. J Mol Cell Cardioll 8: $497-500$ 
Shug AL, Shrago E, Bittar N, Folts JD, Koke JR (1975) Long chain fatty acyl COA imhibition of adenine nucleotide transiocation in the ischemic myocardium. Am J Physiol 228: 689-692

Shug AL, Thomassen JH, Folts JD, Bittar $N$, Klein MI, Koke JR, Huth PJ (1978) Changes in tissue levels of carnitine and other metabolites during myocardial ischemia and anoxia. Arch Biochem Biophys 187: 25-33

Smith MW, Collan Y, Kahng MW, Trump BF (1980) Changes in mitochondrial lipids of rat kidney during ischemia. Biochim Biophys Acta 618: 192-201

Snoeckx LHEH (1987) Ischemia tolerance of the hypertrophied rat heart. Ph.D. thesis. University of Limburg, Maastricht. The Netherlands

Sobel BE, Corr PB, Robinson AK, Goldstein RA, Witkowski FX, Klein MS (1978) Accumulation of lysophosphoglycerides with armythmogenic properties in ischemic myocardium. I Clin Invest 62: 546-553

Spector AA (1971) Metabolism of free fatty acids. Progr Biochem Pharmacol 6: $130-176$

Stam $H$, Huelsmann WC (1981) Control of lipolysis in triglyceride-enriched rat hearts. Ann Nutr Metab 25: 11-19

Stam H, Schoonderwoerd K, Huelsmann WC (1987) Synthesis, storage and degradation of myocardial triglycerides. Bas Res Cardiol 82 (suppl 1): 19-28

Steenbergen C, Jennings RB (1984) Relationship between lysophospholipid accumulation and plasma membrane injury during total in vitro ischemia in dog heart. \Mol Cell Cardiol 16:605-623

Steenbergen $\mathrm{C}$, $\mathrm{H} i 11 \mathrm{ML}$, Jennings RB (1985) Volume regulation and plasma membrane injury in aerobic, anaerobic, and ischemic myocardium in witro. Effect of osmotic cell swelling on plasma membrane integrity. Circ Res 57: $864-875$

Stremmel W, Strohmeyer G, Borchard F, Kochwa S, Berk PD (1985) Isolation and partial characterization of a fatty acid binding protein in rat liver membranes. Proc Nat1 Acad Sci USA 82: 4-8

Suzuki $Y$, Kamikawa T, Kobayashi A, Masumara V, Yamazaki N (1981) Effects of L-carnitine on tissue levels of acyl carnitine, acyl coenzyme $A$ and high energy phosphate in ischemic dog hearts. Jap Circ J 45: 687-694

Swain JL, Sabina RL, MCHale PA, Greenfield JC, Holmes EW (1982) Prolonged myocardial nucleotide depletion after brief ischemia in the open-chest dog. Am J Physiol 242: H818-H826

Taegtmeyer $H$, Hems $R$, Krebs $H A(1980)$ Utilization of energy-providing substrates in the isolated working rat heart. Biochem J 186:701-711

Taegtmeyer $H$, Roberts AFC, Raine AEG (1985) Energy metabolism in reperfused heart muscle: metabolic correlates to return of function. I Am Coll Cardiol $6: 864-871$

Takahashi K, Kako KJ (1983) The effect of a calcium channel antagonist, Nisoldipine, on the ischemia-induced change of canine sarcoleminal membrane. Bas Res Cardial 78: 326-337

Takenaka F, Takeo 5 (1976) Effects of isoproterenol on myocardial lipid metabosi im in rat hearts perfused with and without exogenous substrates. Mol Cell Cardiol 8: 925-940

Takeo S, Sakanashi M (1983) Possible mechanisms for reoxygenation-1nduced recovery of myocardial high-energy phosphates after hypoxia. I Mol Cell Cardiol 15: $577-594$

Trach V (1984) Untersuchungen zum Zusammenhang von Lipolyse und Glykolyse bel Ischaenie an isolierten Rattenherzen. Ph.D. thesis. Justus-Liebig-Universitaet, Giessen, West Gemany 
Trach $V$, Buschmansmenkel $E$, Schaper $W$ (1986) Relation between lipolysis and glycolysis during ischemia in the isolated rat heart. Basic Res Cardiol 31: $454-464$

Tranum-Jensen $J$, Janse M, Fiolet JWT, Krieger WJG, D'Aloncourt CN, Durer D (1981) Tissue osmolarity, cell swelling and reperfusion in acute regional myocardial ischemid in the isolated porcine heart. Circ Res 49: $364-381$

Van Belle $H$ (1970) New and sensfive reaction for automatic determination of inorganic phosphate and its application to serum. Anal Biochem 33: 132-142

Van Bilsen M, Van der Vusse GJ, Coumans $M$, Willemsen $P$, Reneman RS (1985) Recovery of myocardial function after varying periods of ischemia of isolated working rat hearts (abstract). J Mol Cell Cardiol 17 (suppl 3): 82

Van Bilsen M, Engels $W$, Willemsen PHM, Coumans WA, Van der Vusse GJ, Reneman RS (1987) Arachidonic acid accumulation and eicosanoid synthesis during ischaemla and reperfusion in isolated rat hearts. In: Prog Appl Microcirc, vol 12. Microcirculation and inflammation, 236-243. Eds Messmer K, Hammersen $F$, Basel: Karger

Van der Vusse Gu, Roemen THM, Reneman RS (1980) Assessment of fatty acids in dog left ventricular myocardium. Biochim Biophys Acta 617: 347-352

Van der Vusse GJ, Roemen THM, Prinzen FW, Coumans WA, Reneman RS (1982) Uptake and tissue content of fatty acids in dog myocardium under normoxic and ischemic conditions. Circ Res 50: 538-546

Van der Vusse GJ, Roemen THM, Flameng W, Reneman RS (1983) Serum-myocardium gradients of non-esterified fatty acids in dog, rat and man. Biochim Biophys Acta 752: $361-370$

Van der Vusse GJ, Reneman RS (1984a) The myocardial non-esterified fatty acid controversy. J Mol Cell Cardiol 16: 677-682

Van der Vusse GJ, Coumans WA, Van der Veen FH, Drake A, Flameng W, Suy R (1984b) ATP, creatine phosphate and glycogen content in human myocardial biopsies: markers for the efficacy of cardioprotection during aortacoronary bypass surgery. Vasc Surg 18: 127-134

Van der Vusse GJ, Roemen THM, Reneman RS (1985a) The content of non-esterified fatty acids in rat myocardial tissue. A comparison between the Dole and Folch extraction procedures. J Mol Cell Cardiol 17: 527-531

Van der Vusse GJ, Reneman RS (1985b) Pharmacological intervention in acute myocardial ischemia and reperfusion. Trends Pharmacol Sci 6: 76-79

Van der Vusse GJ, Prinzen FW, Van Bilsen M, Engels W, Reneman RS (1987a)

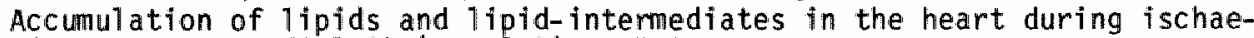
mfa. Bas Res Cardiol 82 (suppl 1): 157-167

Van der Vusse Gu, Prinzen FW, Reneman RS (1987b) Disturbances in myocardial lipid hameostasis during ischemia and reperfusion. In: Activation, metabo$1 \mathrm{ism}$ and perfusion of the heart. 665-681. Eds Sidemann $S$, Beyar $R$, Dordrecht: Martinus Nijhoff Publishers

Van Tol A, Huel smann WC (1970) Dual localization and properties of ATP-dependent long-chain fatty acid activation in rat liver mitochondria and the consequences for fatty acid activation. Blochim Biophys Acta 223: 416-428

Vigo C, Lewis GP, Piper PJ (1980) Mechanisms of inhibition of phospholipase A2. Biochem Pharmacol 29: 623-627

Vik-Mo H (1977) Distribution of coronary blood flow during acute coronary occiusion in dogs. Effect of nicotinic acild and sodium salicylate. Scand $\mathrm{J}$ Clin Lab Invest $37: 697-703$

Vik-Mo H, Riemersma RA, Mjós OD, 01 iver MF (1979) Effect of myocardial ischaemia and antilipolytic agents on lipolysis and fatty acid metabolism in the in situ dog heart. Scand $\mathrm{J} \mathrm{Cl}$ in Lab Invest 39: 559-568 
Wik-Mo H, MJos OD, Neely JR, Maroko PR, Ribeiro LGT (1986) Limitation of myocardial infarct size by metabolic interventions that reduce accumulation of fatty acid metabolites in ischemic myocardium. Am Heart $\mathrm{J}$ 111: 1048-1054

Vogel WM, Cerel AN, Apstein CS (1986) Post-ischemic cardiac chamber stiffness and coronary vasomotion: the role of edema and effects of dextran. $J$ Mol Cell Cardiol 18: $1207-1218$

Watts JA, Koch CD $2+$ LaNoue KF 11980$)$ Effects of Ca ${ }^{2+}$ antagonism on energy metabolism: $\mathrm{Ca}^{2+}$ and heart function after ischemia. Am J Physiol 238: H909-H916

Weglicki WB, Waite BM, Sisson P, Shohet SB (1971) Myocardial phospholipase A of microsomal and mitochondrial fractions. Biochim Biophys Acta 231: $512-519$

Weglicki WB, Waite BM, Stam AC (1972) Association of phospholjpase A with a myocardial membrane preparation containing the $\left(\mathrm{Na}^{+}+\mathrm{K}^{+}\right)-\mathrm{Mg}^{2}$-ATPase. $\mathrm{J} \mathrm{Mol}$ Cell Cardiol 4: 195-201

Weglicki WB, Owens $K$, Jrschel $\mathrm{CW}$, Serur JR, Sonnenblick EH (1973) Hydrolysis of myocardial lipids during acidosis and ischemia. Rec Adw Stud Cardiac Struct Metab 3: $781-793$

Weishaar RE, Sarma JSM, Maruyama $Y$, Fisher R, Bing RJ (1977) Regional blood. flow, contractility and metabolism in early myocardial infarction. Cardiology $62: 2-20$

Weishaar RE, Tschurtschenthaler GV, Ashikawa K, Bing RJ (1979) The relationship of regional coronary blood flow to mitochondrial function during reperfusion of the ischemic myocardium. Cardiology $64: 350-365$

Weishaar RE, Bing RJ (1980) The beneficial effect of a calcium channel blocker, diltiazem, on the ischemic reperfused heart. I Mol cell cardiol 12: $993-1011$

Westerhof, $N$, Elzinga G, Sipkema $P$ (1971) An artificial arterial system for pumping hearts. J Appl Physiol 31: 776-781

Whitmer JT, Idell-Wenger JA, Rovetto MJ, Neely JR (1978) Control of fatty acid metabolism in ischemic and hypoxic hearts. J Biol Chem 253: 4305-4309

Will lebrands AF. Ter Welle HF, Tasseron SJA (1973) The effect of a high molar FFA/albumin ratio in the perfusion medium on rhythm and contractility of the isolated rat heart. J Mol Cell Cardiol 5: 259-273

Williamson JR (1979) Mitochondrial function in the heart. Ann Rev Physiol 41: 485-506

Wolf WA, Gross RW (1985) Identification of neutral active phospholipase C which hydrolyzes choline glycerophospholipids and plasmalogen selective phospholipase $A_{2}$ in canine myocardium. I B 101 Chem 260: 7295-7303

Wolf HPO, Engel DW (1985) Decrease of fatty acid oxidation, ketogenesis and gluconeogenesis in isolated perfused rat liver by phenylalkyl oxirane: carboxylate (B807-27) due to inhibition of CPT I (EC 2.3.1.21). Eur J Biochem 146: $359-363$

Hynants $J$, Van Belle $H$ (1985) single-run high performance liquid chromatography of nucleotides, nucleosides and major purine bases and its application to different tissue extracts. Anal Biochem 14:4: $258-266$

ranagishita $T$, Konno N, Geshi E, Katagiri T (1987) Alterations in phosphoIipids in acute ischemic myocardium. Jap Circ J 51: 41-50 

SLMMMARY

Reduced supply of blood to cardiac muscle (ischemia) results in electrophysiological, mechamical and metabolic disturbances, and eventually in irreversible loss of function of the affected tissue. Timely restoration of blood supply is the only way to avoid irreversible injury. During the last decades several clinical methods have been developed to restore blood supply to the acutely ischemic tissue. However, experimental findings suggest that reperfusion per se also induces tissue damage. Knowledge of the biochemical mechanism, ultimately responsible for the development of irreversible cell damage during myocardial ischemia and/or reperfusion is far from complete. Recent research addressing this issue indicated that disturbances in myocardial lipid metabolism might play an essential role. Previous studies from our laboratory showed that non-esterified fatty acids (NEFA's) accumulate during ischemia. This process was found to be related to the extent of adenosine triphosphate (ATP) depletion and is likely to be caused by degradation of membrane phospholipids. Therefore the objective of this study was to obtain more insight into:

- the time course of accumulation of NEFA's and its relation to changes in the myocardial content of phospholipids and triacylglycerols.

- the relation between adenine nucleotide and carbohydrate metabolism, on the one hand, and NEFA accumulation during ischemia, on the other.

- the nature of the lipid changes, if any, taking place during reperfusion.

- the role of the lipid changes during ischemia and reperfusion in the development of myocardial damage.

- the ability to modify myocardial lipid metabolism through metabolic and pharmacological interventions and its consequences for myocardial damage.

To this end isolated, working rat hearts were subjected to periods of global ischemia of variable duration (10 to 90 minutes), with or without an additional 30 minutes of reperfusion. The hearts were perfused with a modified Krebs-Henseleit buffer containing glucose and pyruvate (unless otherwise indicated) as substrates. During the experiments hemodynamic behavior was monitored (heart rate, left ventricular pressure, cardiac output) to assess 
the extent of functional impaiment following transient ischemia. At the end of the experiments the hearts were freeze clamped for analysis of the tissue conterit of NEFA's (tatal and individual spectes), triacylglycerols, phospholipids (the various subclasses, including lyso-forms). The tissue contents of glycerol-3-phosphate and glycerol were determined in arder to detect possible disturbances in triacylglycerol metabolism. Creatine phosphate, adenine muclleotides, mucleosides and oxypurines were maesured to assess the role of these compounds in the occurrence of posit-ischemic damage, and to delineate possible relationships between derangements in high-energy phosphate metabollsm and lipid metabolism. The coronary efflluent was sampled for analysis of the release of lactate dehydrogenase (LDH), a marker of tissue injury. In addition, the release of nucleosides and oxypurines, lactate and glycerol was monltored.

In chapter 1 the relevance of the present study is discussed and the aims are formulated. In chapter 2 the features of the experimental model chosen and an overview of the biochemical derangements associated with ischemia and reperfusion, with special reference to myocardial lipid metabolism, are given.

The results regarding the hemodynamic and metabolic properties of the isolated heart under normoxic and transiently ischemic conditions are presented in chapter 3. It is shown that addition of pyruvate as cosubstrate to normoxically perfused hearts supplied with glucose as exogenous substrate improved hemodynamic stability and prevents consumption of endogenous substrate stores, like glycogen and triacylglycerols, at nomal and high workloads. In addition, pyruvate ameliorated post-ischemic hemodynamic recovery. However, this effect was associated with neither preservation of the tissue adenine nucleotide content nor attenuation of $L D H$ release during reperfusion.

The effects of ischemia and reperfusion on myocardial adenine nucleatide metabolism and its consequences for myocardial injury are presented in chapter 4. During early ischemia the decline in the ATP content was associated with rapid accumulation of nucleosides and oxypurines. Thereafter, the formation of these degradation products ceased and AMP accumulated in substantial amounts. on reperfusion the accumulated degradation products were further degraded and released from the heart. At the end of the reperfusion period the total adenine nucleotide content was comparable to that measured at the end of the previously ischemic period. However, during reperfusion the energy charge recovered substantially. Hence, it is concluded that incomplete recovery of 
ATP is not caused by serious impairment of mitochondrial function, but merely due to the release of adenine nucleotide precursors. Furthermore, the data obtained indicate that the tissue ATP content of reperfused hearts is a poor determinant of mechanical performance as well as cell injury.

In chapter 5 it is shown that the first measurable derangements in myocardial lipid metabolism during ischemia concern the triacylglycerol pool. The activity of the triacylglycerol-NEFA cycle is markedly enhanced during early ischemia, resulting in the accumulation of glycerol whout concomitant accumulation of NEFA's. The accumulation of NEFA's is a rather late phenomenon, preceded by a substantial decline in ATP, and coinciding with the accumulation of AMP, an inhibitor of acyl-COA synthetase. the latter enzyme controls (re)incorporation of fatty acids into the phospholipid molecule. The possibility that the ischemic accumulation of NEFA's is related to impairment of this reacylation process is discussed. Reperfusion results in an additional rise in the cardiac NEFA content. No measurable decreases in the contents of the various phospholipid subclasses are observed, but the increase of non-esterified arachidonic acid during reperfusion indicates that the phospholipid pool is evidentiy involved. The finding that mechanical performance of reperfused hearts is still acceptable at tissue NEFA levels, that should be incompatible with normal mitochondrial function (on the basis of in-vitro findings), suggests that the accumulating NEFA's are somehow compartmentalized. The strong relationship between the tissue NEFA content of reperfused hearts and the release of $L D H$ during the reperfusion period could indicate that the NEFA's are compartmentalized at the cellular level.

To assess the role of the various endagenous lipid pools in the accumulation of NEFA's during ischemia and reperfusion and the consequences of 1 ipid changes for myocardial function and integrity, transientiy ischemic hearts were perfused in the presence of nicotinic acid and mepacrine, putative inhibitors of triacylglycerol lipase and phospholipase $A_{2}$. respectively (chapter 6), in the absence or presence of pyruvate, a known inhibitor of fatty acid oxidation (chapter 7), and in the presence of POCA, a carnitine acyltransferase 1 inhibitor (chapter 7$)$.

Nicotinic acid $(10 \mu \mathrm{M})$ reduced the accumulation of glycerol during ischemia and diminished NEFA accumulation during both ischemia and reperfusion. At a concentration of 1 MM mepacrine did not attenuate accumulation of NEFA's. At higher doses $(10 \mu \mathrm{M})$ mepacrine markedly decreased NEFA accumulation in ische- 
mic as well as reperfused cardiac tissue and depressed post-ischemic release of LDH. These findings confirm previous results (chapter 5) that both the triacylglycerol and phospholipid pool contribute to the derangements in myocardial lipid metabolism.

Pyruvate (5 mM) as well as POCA (10 $\mu M)$ enhanced NEFA accumulation during reperfusion, when added separately or in combination. Thus, it is concluded that inhibition of fatty acid oxidation promotes the accumulation of NEFA's derived from endogenous lipid pools. Conversely, these findings indicate that net degradation of endogenous lipid pools proceeds during reperfusion, but that due to mitochondrial oxidation, the amount of accumulated NEFA's only partly represents the amount released from these pools.

In conclusion, the findings of the present studies provide evidence that disturbances in both triacylglycerol and phospholipid homeostasis take place in transientiy ischemic cardiac tissue. Reperfusion does not result in nomalization of lipid metabolism, but instead aggrevates degradation of endogenous lipid pools. Besides, the results obtained affirm recent views that the recovery of hemodynamic function and the tissue content of adenine nucleotides (or ATP, to be more precisely) are poor markers for cardiac cell damage. Madulation of the extent of derangement of the myocardial lipid metabolism, as measured as the accumulation of NEFA's, was not associated with unambiguous responses regarding post-ischemic function or enzyme release, indicating a complex relation between tissue NEFA levels, on the one hand, and myocardial function and integrity, on the other. Future research should be aimed to establish whether the observed 7 ipid changes are causally related to irreversible cell damage or only reflect post-mortem changes in already irreversibly damaged cells. 
Een verminderde doorbloeding (ischemie) van hartspierweefsel leidt tot veranderingen in de electrofysiologische en mechanische eigenschappen van het weefsel en tot ernstige verstoringen in de stofwisseling. Langdurige ischemie zal uiteindelijk leiden tot afsterven wan het weefsel. Tiljdig herstel van de doorbloeding (reperfusie) is de enige remedie tegen het optreden van weefselversterf. In de laatste decennia zijn er diverse methodieken ontwikkeld om de doorbloeding van acuut ischemisch weefsel te herstellen. Er zijn echter experimentele aanwijzingen, dat deze zgn. reperfusie op zich zelf ook weefselschade kan induceren.

$\mathrm{Er}$ is nog weinig bekend over het biochemische mechanisme, dat verantwoordelijk is voor het ontstaan van anherstelbare beschadiging van hartsplercellen tijdens ischemie en/of reperfusie. Er komen meer en meer aanwijzingen, dat verstoringen in de vetstofwissling hierbij een essentiële rol spelen. Met name de afbraak van fosfolipiden, belangrijke bouwstenen van membranen, en de stapeling van vrije (niet-veresterde) vetzuren en lyso-fosfolipiden in het weefsel, zouden de levensvatbaarheid van de hartspiercellen ongunstig beinvloeden. Inzicht in dit proces zou uiteindelijk kunnen leiden tot een meer gerichte therapeutische behandeling van - al dan niet tijdelijke - ischemie.

Doel van het huidige onderzoek was dan ook om na te gaan of ischemie en reperfusie leiden tot verstoringen in de vetstofwisseling, en $z 0 \mathrm{ja}$, wat de aard van deze verstoringen is, en of deze verstoringen gerelateerd zijn aan het optreden van celversterf. Om hierin meer inzicht te verkrijgen werden geisoleerde ratteharten, die geperfundeerd werden met een kunstmatig medium (aangepaste Krebs-Henseleit buffer), onderworpen aan een perlode van globale ischemie, al dan niet gevolgd door reperfusie.

Na een algemene inleiding (hoofdstukken 1 en 2) wordt in hoofdstuk 3 ingegaan op de metabole en hemodynamische eigenschappen van het normaal geperfundeerde en ischemisch/gereperfundeerde werkende rattehart. Gezien de centrale rol die energie-rijke fosfat verbindingen (creatline fosfaat, adenine nucleatiden) spelen bij het onderhouden van de mechanische activiteit en het in stand houden van de integriteit van het hartsplerweefse1, wordt in hoofdstuk 4 ingegaan op de mogelijke rol van deze verbindingen en hun omzettings 
produkten bij het ontstaan van ischemie en/of reperfusie-schade. In de daarop volgende hoofdstukken wordt ingegaan op de veranderingen in de cellulaire vetstofwisseling, die optreden tijdens ischemie en reperfusie. Hierbij is specialle aandacht besteed aan de weefselinhoud aan vrije vetzuren en de twee belangriflkste gebonden (veresterde) vetzuurvoorraden, de triacylglycerolen en fosfollpiden (hoofdstuk 5). Tevens is onderzocht of de veranderingen in de vetzuurstofwisseling te beinvloeden zijn (hoofdstukken 6 en 7 ). Ingegaan wordt op de magelijke gevolgen van de veranderingen in de vetzuurstofwissling voor het post-ischemisch functioneel herstel en het ontstaam wan onherstelbare weefselschade. Dilt latste werd gemeten aan de hand van het vrijkomen van weefsel-eiwitten (enzymen). De belangrijkste bevindingen van deze studie kunnen als volgt worden samengevat.

Reeds vroeg in de ischemische fase treden er aantoonbare verstoringen in de triacylglycerol stofwisseling op. Dit gat echter nog niet gepaard gaat met een toename van de inhoud aan vrije vetzuren. Pas later, als het gebrek aan zuurstof meer dan 45 minuten bedraagt, is er een stijging van vrije vetzuren in het weefsel waarneembaar. Het is mogelijk dat het sterk gedaalde gehal te aan adenosine trifosfaat (ATP) en de daarmee gepaard gaande stapeling van adenosine monofosfaat (AMP) en adenosine in ischemisch weefsel, de inbouw van vrije vetzuren in fosfolipiden en triacylglycerolen remt en daardoor - wellicht ten dele - verantwoordelijk is voor de waargenomen stijging van vrije vetzuren tijdens de ischemische periode.

Reperfusie resulteert, afhankelijk van de duur van de voorliggende ischemie en de gepleegde interventies, tot onvolledig functioneel herstel en het vrijkomen van enzymen uit de hartspiercellen. Doordat omzettings produkten van adenine nucleotiden tijdens de reperfusie vrijkomen, treedt er tijdens reperfusie geen volledig herstel op van de ATP inhoud in het hart. Reperfusie resulteert in een verdere afbraak van weefsellipiden. Ondanks een verveelvoudiging van de wrije vetzuur concentratie in het weefsel vertegenwoordigt deze stijging slechts enkele procenten van de hoeveelheid vetzuren, die is ingebouwd in fosfolipiden en triacylglycerolen. Er werd dan ook geen significante afname in de weefselinhoud van deze verbindingen waargenomen. Op basis van de toename aan lyso-fosfolipiden en vrij arachidonzuur, een vetzuur dat vrijwel uitsluitend in fosfolipiden wordt aangetroffen, is net echter aanneme$1 j j k$, dat een deel der vetzuren onstaat door afbraak van membraan fosfoli- 
piden. Stoffen, die de afbrak van triacylglycarolen en fosfolipiden remmen (respectievelijk nicotime zuur en mepacrine) blijken de vetzuur stapeling tijdens ischemie en reperfusle te reduceren, hetgeen suggereert dat verstoringen in zowel de fosfolipide en triacylglycerol huishouding een rol spelen. De stapeling van vetzuren tijdens reperfusie is verhoogd wanneer de vetzuur verbranding gerend wordt, hetgeen aantoont dat een deel van de vetzuren, die gevormd worden door afbraak van weefsellipiden, in de mitochondria verbrand wardt.

Het gehalte aan ATP in gereperfundeerde harten blijkt niet gerelateerd te zijn aan het post-ischemische herstel van pompfunctie. Tevens is er geen relatie aantoonbaar tussen ATP en de mate van celversterf (gemeten als het vrijkomen van enzymen). Ondanks aanwijzingen uit de literatuur (in-vitro experimenten), dat vrije vetzuren in de - in dit proefschrift - gevonden concentraties toxisch voor het hart zouden zijn, blijkt de pompfunctie van een groot deel der onderzochte gereperfundeerde harten nog respectabel. Dit wijst erop, dat de stapelende vetzuren niet homogeen over het weefsel verdeeld zijn, maar op subcellulair danwel cellulair niveau gecompartimenteerd zijn. In het algemeen kam men stellen dat er een relatie lijkt te bestaan tussen de vrije vetzuur inhoud van gereperfundeerde harten en het vrijkomen van enzymen tijdens reperfusie. Dit suggereert, dat de stapeling van vrije vetzuren mogelijk alleen gelocaliseerd is in die cellen, die onherstelbaar beschadigd zijn. Nauwkeurige analyse van de relatie tussen vetzuur stapeling en het vrjkomen van enzymen tijdens reperfusie toont echter aan, dat deze relatie niet onder alle omstandigheden geldig is. Toekomstig onderzoek zal moeten aantonen of de verstoringen in de vetstofwisseling oorzakelijk verband houden met het ontstaan van weefselschade, of slechts de weerspiegeling vormen van processen, die optreden in reeds onherstelbaar beschadigde hartsplercellen. 
De schrijver van dit proefschrift werd geboren op 30 september 1958 te Delft. Na het behalen van het wo diploma aan de Stedelijke Scholen Gemeenschap Hugo Grotius te Delft in 1976 werd in datzelfde jaar de studie biologie aangevangen aan de Rijksuniversiteit Leiden. Het kandidaatsexamen biologie werd afgelegd in januari 1980. Het doctoralexamen biologie met hoofdrak celbiologie en bijvakken elecronenmicroscopie en microbiologite werd afgelegd in november 1982. Sinds januari 1983 is de schrijver werkzaam als wetenschappelijk assistent bij de vakgroep fysiologie van de Rijksuniversiteit Limburg. Het in dit proefschrift beschreven onderzoek werd verricht in het kader van het deelproject "Myocard", onderdeel van het hoofdproject "Hart en Vaatziekten", onder begeleiding van Dr. G.J. van der Vusse en Prof. Dr. R.S. Reneman. 
Dat het voorliggende werk mijn naam draagt doet tekort aan al diegenen, die hebben bijgedragen aan de totstandkoming van dit proefschrift. Prof. Dr. R.S. Reneman en Dr. G.J. van der Vusse wil ik bedanken voor de toewijding en inzet waarmee zij het in dit proefschrift beschreven onderzoek hebben begeleid en voor de - niet alleen - wetenschappelijke ondersteuning bij het op schrift stellen van dit onderzoek. Peter Willemsen, Will Coumans en Theo Roemen hebben het leeuwendeel van de biochemische bepalingen voor hun rekening genomen en als zodanig de "grondstoffen" voor dit proefschrift aangeleverd. Luc Snoeckx heeft mij ingewijd in de beginselen van geì saleerde hart perfusies. De vele discussies met Erik van der Veen, Frits Prinzen en Jan Glatz zijn van wezenlijk belang geweest voor dit proefschrift. Lucienne de Boer en Theo van der Nagel ben ik erkentelijk voor hun hulp bij het camera-gereed maken van het manuscript. De omslag van dit boekje werd ontworpen door Sandra Beekveld.

Tot slot wil ik Prof. Dr. Allessie, Prof. Dr. Struyker Boudier, Prof. Dr Zwaal, en in het bijzonder Prof. Dr. Hül smann en Prof. Dr. Piper, bedanken voor de kritische wijze waarop zij - in de hoedanigheid van leden van de beoordelingscommissie - het proefschrift, toen nog manuscript, hebben doorgenomen. 